CONCEPTUAL DESIGN OF COAL-FUELED DIESEL SYSTEM FOR STATIONARY POWER APPLICATIONS

Toplcal Repprt

May 1989

Work Performed Under Contract No. AC21-88MC25124

For

U.S. Department of Energy

Morgantown Energy Technology Center

Morgantown, West Virg!nla

By

Arthur D. Liftle, inc.

Cambridge, Massachusetts 


\section{DISCLAIMER}

This report was prepared as an account of work sponsored by an agency of the United States Government. Neither the United States Government nor any agency thereof, nor any of their employees, makes any warranty, express or implied, or assumes any legal liability or responsibility for the accuracy, completeness, or usefulness of any information, apparatus, product, or process disclosed, or represents that its use would not infringe privately owned rights. Reference herein to any specific commercial product, process, or service by trade name, trademark, manufacturer, or otherwise does not necessarily constitute or imply its endorsement, recommendation, or favoring by the United States Government or any agency thereof. The views and opinions of authors ex. pressed herein do not necessarily state or reflect those of the United States Government or any agency thereof.

This report has been reproduced directly from the best available copy.

Available to DOE and DOE contractors from the Office of Scientific and Technical Information, P.O. Box 62, Oak Ridge, TN 37831; trices available from (615)576.8401, FTS 626.8401.

Available to the public from the National Technical Information Service, U.S. Department of Commerce, 5285 Port Royal Rd., Springfield, VA 22161. 


\title{
Conceptual Design of Coal-Fueled Diesel System for Stationary Power Applications
}

\author{
Topical Report
}

Work Performed Under Contract No.: DE-AC21-88MC25124

\author{
By \\ Arthur D. Little, Inc. \\ 20 Acorn Park \\ Cambridge, Massachusetts 02140-2390
}

May 1989 


\section{Table of Contents}

List of Tables

List of Figures viii

I. EXECUTIVE SUMMARY

A. Objectives of the Conceptual Design Study 1

B. Participants and Methodology 1

C. Summary of Results $\quad 2$

II. OVERALL FACILITY DESIGN AND COAL-FUELED ENGINE 5

A. Plant Configuration and Major Subsystems 5

B. Recent Stationary Power Installations by Cooper-Bessemer 10

C. Diesel Engine Components Modified for Coal 11

D. Engine Component Cost Estimates 16

$\begin{array}{ll}\text { E. Overhaul Cost Estimates } & 17\end{array}$

III. STATIONARY POWER MARKETS TO BE SERVED 20

A. Selection of Applications and Plant Configurations $\quad 20$

B. Cogeneration Prime Mover Requirements by Industry 22

C. Growth in Electric Power Capacity - Projected Need for Capacity Additions 22

D. Regions of Greatest Potential $\quad 25$

E. Market Share for Coal Diesel Systems - Other Competing Technologies 28

F. Capacity-Growth Scenarios for Modular Coal Diesel Plants 30

IV. COAL PROCESSING AND TRANSPORTATION 33

A. Coal Processing Analysis Methods $\quad 33$

B. CWS Specifications $\quad 34$

C. Plant and Process Description 36

D. Description of Process Areas 36

E. Capital Cost Estimates 44

F. Operating Cost Estimates $\quad 46$

G. Feedstock and Transportation $\quad 52$

H. CWS Cost Summary $\quad 52$

I. Cost Analysis Uncertainties aná R\&D Directions 58

J. Cost Modeling Runs $\quad 59$

K. Cost Look-Up Table and Impact of Variables 61 


\section{Table of Contents}

(Continued)

\section{EMISSION CONTROL SYSTEM DESIGN}

Page

A. Introduction and Emission Targets 67

B. Emission Control Technologies for Preliminary Conceptual Design 69

C. Selection of Integrated System Design Options $\quad 78$

D. Cost Analysis Methodology and Assumptions $\quad 81$

E. Discussion of Economic Analysis 96

F. Conclusions/Directions for Emissions R\&D Program 112

VI. ANALYSIS OF ECONOMICS 115

$\begin{array}{ll}\text { A. Summary } & 115\end{array}$

B. Engine Coniponent Cost Premiums Associated with Coal 115

C. Cost to Proluce Engine-Grade Coal Fuels 117

D. Cost of Emission Control Systems 118

E. Projected Cost of Coal-Fueled Diesel Power 119

F. Parametric Sensitivity Analysis 119

VII. TECHNOLOGY GAPS AND HIGH PRIORITY R\&D DIRECTIONS 125

VIII. COMMERCIALIZATION PLAN AND PROJECTED PENETRATION RATE 128 REFERENCES R-1

Appendix A: CWS Plant Equipment Lists A-1

Appendix B: CWS Process Cost Model B-1

Appendix C: Sample CWS Cost Model Runs $\quad$ C-1

Appendix D: Coal Feedstock Analyses $\quad$ D-1

Appendix E: Alternative Designs for Higher Efficiency E-1

Appendix F: Emission Control Technologies $\quad$ F-1

Appendix G: Emission Control System Options - Process Diagrams $\quad$ G-1

Appendix H: Cost Calculations for Emission Control System Options $\quad$ H-1

Appendix I: Computer Model of Coal-Fueled Diesel System Economics I-1 


\section{List of Tables}

Table No

II-1 Cooper-Bessemer Model LSVB-20 Diesel Engine

II-2 Coal Engine Fuel System Components 13

II-3 Coal Engine Combustion System Components $\quad 13$

II-4 Coal Engine Lube System Components 16

II-5 Coal Engine Intake/Exhaust System 16

II-6 Estimated Cost Premiums for Coal Diesel Engine Components 17

II-7 Engine Maintenance and Overhaul Costs 19

III-1 Coal Diesel Plant Configurations $\quad 22$

III-2 Number of Existing Manufacturing Plants with Diesel Cogeneration Poten- 23

III-3 Potential Demand for Diesel Engines for Cogeneration in Existing U.S. 23

III-4 Fossil Fueled Power Plant Additions, 1991-2010 Forecast 24

III-5 Regions with Capacity Additions and Their Potential for CWS Diesel 26 Plants

III-6 Actual vs. Forecast KWH Demand Growth (1983-1987)

III-7 Recent Trends in Stationary Engines (New Orders for North America) 29

III-8 Western Europe New Orders for Stationary Engines $\quad 30$

III-9 Significant Potential Growth in Reciprocating Engine Power Plant Capac- 31

III-10 Scenario for Coal Diesel Market Penetration $\quad 32$

IV-1 Engine-Grade CWS Specifications $\quad 35$

IV-2 Typical Characteristics of Two CWS Fuels Produced by AMAX 37

IV-3 Process Plant Areas for 1.5\% Ash CWS 40

IV-4 Process Plant Areas for 0.5\% Ash CWS 40

IV-5 Capital Costs for CWS Processing Plant $45^{\circ}$

IV-6 Processing and Operating Cost Factors for CWS Plant 46

IV-7 Labor Requirements $\quad 47$

$\begin{array}{lll}\text { IV-8 } & \text { Power Usage by Area } & 48\end{array}$

IV-9 Chemical Reagent/Addicive Costs $\quad 50$

IV-10 Operating Cost Summary for CWS Plant $\quad 51$

IV-11 Coal Properties by Source (As Received Basis) 53

IV-12 Coal Transportation Cost Estimates 54 


\section{List of Tables}

(Continued)

Table No

Page

IV-13 Costing Assumptions $\quad 55$

IV-14 CWS Plant Cost Summary - Physical Cleaning Plant 56

IV-15 CWS Plant Cost Summary - Chemical Cleaning Plant 57

IV-16 CWS Costing Uncertainties $\quad 60$

IV-17 Assumptions for CWS Specifications Used in Cost Modeling Runs 62

IV-18 CWS Cost Look-Up Table $\quad 63$

IV-19 Fuel Quality Scenarios $\quad 65$

IV-20 Comparison of Costs for Eastern vs. Western Coals in Western Coal Plant 66

V-1 New Source Performance Standards for Stationary Sources $\quad 68$

V-2 Assumed Engine Operating Conditions $\quad 70$

V-3 Systems for Coal-Fueled Diesel Operation $\quad 71$

$\begin{array}{lll}\text { V-4 Emission Control Subsystems } & 74\end{array}$

V-5 Probability of Technical Success for Emission Control Technologies 80

V-6 Emission Control System Options and Priorities for Research 82

V-7 Design and Cost Estimate Classifications $\quad 84$

V-8 Methods Used to Estimate Subsystem Equipment Costs 86

V-9 Summary of SCR Cost Data $\quad 87$

V-10 SCR Equipment and Catalyst Costs Used in Economic Analysis 90

V-11 Differential Costs of Coal-Fueled Engine Relative to Oil-Fueled Engine for 92 Production of 125 psig Steam

V-12 Equipment Costs for Subsysteriss 94

V-13 Commodity Prices for Operating Cost Calculation 95

V-14 Coal-Fueled Diesel Emission Control System Capital and Operating Cost 97

V-15 Coal-Fueled Diesel Emission Control System Capital and Operating Cost 98 Summary for 4 LSB6 Engines (7.2 MW)

V-16 Coal-Fueled Diesel Emission Control System Capital and Operating Cost 99 Summary for 2 LSVB20 Engires (12 MW)

V-17 Coal-Fueled Diesel Emission Control System Capital and Operating Cost 100 Summary for 2 LSVB20 Engines (12 MW - No Cogeneration) 
TableNo. Page

V-18 Coal-Fueled Diesel Emission Control System Capital and Operating Cost 101

Summary for 4 LSVB20 Engines (24 MW)

V-19 Effect of Manifold Air Temperature on Process History 111

VI-1 Key Modifications to Economic Model 116

VI-2 Impact of Coal Fuel on Maintenance and Overhaul Practices 117

VI-3 Emissions Control Subsystem Costs 118

VI-4 Projected Cost of Power for Coal-Fueled Diesel Plant 119

VI-5 Cost of Power Depends on Source Coal and CWS Process $\quad 120$

VI-6 Coal Transportation to Various Cities Affects Cost of Power by 5-10\% 121

VI-7 Choice of Emission Control System Affects Cost of Power 122

VI-8 Increased Load Factor Can Lower Power Costs by About 5-10\% 122

$\begin{array}{ll}\text { VI-9 Uncertainty Level } & 124\end{array}$

VIII-1 Cooper-Bessemer Commercialization Plan for Coal-Fueled Diesel 129 


\section{List of Figures}

Eigure No

II-1 Cooper-Bessemer LSVB Dual Fuel Engine Cross Section

Page

II-2 Typical LSVB Engine Heat Balance

II-3 Plant Layout

II-4 Plant Layout

II- $; \quad$ Button Nozzle 14

II-7 Combustion Chamber Design $\quad 15$

III-1 Regions for Potential Coal Diesel Applications 27

IV-1 Schematic of AMAX R\&D Engine-Grade Coal Cleaning Process - $1.5 \% \quad 38$

IV-2 Schematic of AMAX R\&D Engine-Grade Coal Cleaning Process - Ultra- 39 Low Ash Configuration

V-1 Integration of Emission Control Subsystems with Engine Sy'stems 72

V-1A Example of Emission Control Design Configuration $\quad 79$

V-2 Cost of SCR for Engine Emission Control $\quad 88$

V-3 Capital Cost for Cogeneration System $\quad 103$

V-4 Annual Operating Cost for Cogeneration System $\quad 104$

V-5 Annual Operating Cost vs. Probability of Technical Success for 1.8 MW $\quad 106$ Cogeneration System

V-6 Annual Operating Cost vs. Probability of Technical Success for 7.2 MW Cogeneration System

V-7 Annual Operating Cost vs. Probability of Technical Success for $12 \mathrm{MW}_{\mathrm{e}} \quad 108$ Cogeneration System

V-8 Annual Operating Cost vs. Probability of Technical Success for $12 \mathrm{MW}_{\mathrm{e}} \quad 109$

V-9 Annual Operating Cost vs. Probability of Technical Success for $24 \mathrm{MW}_{\mathrm{e}} \quad 110$

V-10 Coal-Diesel NO Target Compared to Gas Turbines 114

VI-1 Emission Control Costs Appear Acceptable Above About 7 MW Plart 123 Size

VII-1 Coal-Fueled Diesel R\&D Priorities $\quad 126$ 


\section{EXECUTIVE SUMMARY}

\section{A. OBJECTIVES OF THE CONCEPTUAL DESIGN STUDY}

The ADL/Cooper team prepared a preliminary conceptual design of a coal-fueled diesel system as part of a previous systems study, and this design concept was described in the 1986 Topical Report. ${ }^{(1)}$ Since then, our team has accumulated extensive results from testing coal-water slurry on the 13-inch bore JS engine ( $400 \mathrm{rpm})$ in 1987 and 1988. These results provided new insights into preferred design concepts for engine components. One objective, therefore, was to revise the priliminary design to incorporate these preferred design concepts. In addition, there were certain areas where additional, more detailed analysis was required as a result of the previous conceptual design. Another objective, therefore, was to perform additional detailed design effort, as follows:

- Market applications and engine sizes: ADL prepared a more detailed regional analysis of modular power new capacity needs in the U.S. The results are reported in Chapter III.

- Coal-water slurry cleaning and grinding processes were re-examined in light of recent developments (AMAX). The results of this re-examination can be found in Chapter IV.

- Emission controls and hot gas contaminant controls were characterized in sufficient detail to allow cost estimates (PSI). Nine emission control system options were compared and of these four were selected as most promising. The results appear in Chapter V.

- Component durability: ADL and Cooper estimated the cost of wear resistant parts for the coal-fueled engine, including injection nozzle inserts, rings, liner, valves, valve seats, turbocharger blades, crankcase bearings and the filtration system. The expected lifetime of components and the number of required replacements of these components during the total engine life were also estimated. Key results are reported in Chapter II.

- Costs and performance targets for each major subsystem component-by-component were analyzed. This provided more detail than the 1986 Systems Study which estimated only overall maintenance and capital cost premiums for the entire diesel system. See Chapter II, Sections $D$ and $E$, for results.

Combining all this design information, ADL performed a computer-based economic analysis, including a parametric sensitivity analysis, which is reported in Chapter VI. Also, CooperBessemer and ADL revised the commercialization plan (Chapter VII). Critical variables affecting market feasibility were flagged for attention. $R \& D$ priorities for the ongoing coal-fueled diesel program were reexamined (see Chapter VIII).

\section{B. PARTICIPANTS AND METHODOLOGY}

Cooper-Bessemer provided preliminary designs of coal diesel cogeneration and power plants, including parts lists, estimated costs, site drawings, and maintenance schedules. Cooper- 
Bessemer and $\mathrm{ADL}$ also specified durable components (e.g., valves, rings, liners, turbocharger) including costs and replacement schedule based on existing knowledge (see Section II). Cooper-Bessemer also updated the commercialization plan (see Section VIII).

AMAX provided designs for two alternative engine grade CWS processes (physical and chemical cleaning), estimated costs for processing typical U.S. coals to meet specifications, specified the additive package, and designed the on-site fuel storage subsystem (see Section IV).

ADL reviewed the electric power and cogeneration trends in the US. for the next twenty years, including a region-by-region analysis of new capacity. Particular attention was given to modular capacity requirements below $100 \mathrm{MW}$ plant size and below $15 \mathrm{MW}$ engine size (see Section II).

PSI identified appropriate emission control technologies and designed integrated emission control packages $\left(\mathrm{NO}_{\mathbf{x}}, \mathrm{SO}_{\mathbf{x}}\right.$, particulate) which will enable the coal diesel to meet future anticipated emission limits. Costs and development risks were included in their analysis (see Section V).

\section{SUMMARY OF RESULTS}

Five power plant design configurations were studied, ranging in size from the $1.8 \mathrm{MW}$ plant based on a single 6-cylinder Cooper-Bessemer LSB-6 engine to the $24 \mathrm{MW}$ plant which is based on four 20-cylinder LSVB-20 engines. Both cogeneration and power-only configurations were studied. Plant availability is known to be $90 \%$ for the LS series engine, and shaft efficiency is $40 \%$ on a higher heating value (HHV) basis. The engine has been designed so that these performance para.neters should be the same for operation on coal water slurry as foi standard operation on diesel fuel, and preliminary engine tests on CWS bear this out. Bottoming cycle options described in Appendix E can raise plant efficiency to approximately $46 \%$ (HHV), which is quite advantageous not only for lowering fuel consumption but also for reducing the greenhouse gas $\left(\mathrm{CO}_{2}\right)$ impact.

The engine is designed to burn physically cleaned "engine-grade" CWS with up to $1.5 \%$ ash on a dry coal basis; this is a major departure from earlier fuel specifications which called for relatively costly $0.5 \%$ ash chemically-cleaned CWS. The maximum particle size specification is in the 50 to 75 micron range. The slurry would be regionally produced in the same metropolitan area as the diesel plants and then delivered locally by tank truck, not unlike the practice for diesel oil today. The $180 \mathrm{ton} / \mathrm{hr}$ regional coal cleaning plant has been configured into a preliminary process design, and can be estimated to cost $\$ 135$ million installed. The processing cost for physical cleaning and slurry formulation is estimaied at $\$ 0.81 / \mathrm{MMBtu}$, to which must be added the amortized capital cost of approximately $\$ 0.55 / \mathrm{MMBtu}$. A number of suitable coal feedstocks have been identified such as Kentucky Blue Gem and Elkhorn (see Table IV-11), using these coals it appears that clean CWS can be delivered to coal diesel power plants at a total cost of $\$ 2.75$ to $\$ 3.50 / \mathrm{MMBtu}$. Both Eastern and Western coals (e.g., Utah Castlegate) are attractive.

Special durable engine components have been specified to minimize erosive wear by coal and ash. Cooper has budgeted an extra $\$ 1.7$ million (50\% additional) for the installed cost of a 6 MW engine to cover these modified and redesigned engine components, the most critical of which are: 
- Piston rings and liners ( $100 \%$ assumed cost increase; $12000 \mathrm{hr}$ life vs. $25000 \mathrm{hr}$ std)

- Injection system (200\% assumed cost increase; $500 \mathrm{hr}$ life vs. $2000 \mathrm{hr}$ std)

- Cylinder heads (50\% assumed cost increase)

- Turbocharger (200\% assumed cost increase; $25000 \mathrm{hr}$ life vs. $100000 \mathrm{hr}$ std)

The total overhaul and parts replacement for each $6 \mathrm{MW}$ coal diesel engine is estimated at $\$ 195,000$ per year (vs. $\$ 70,000$ per year for conventional engine). This tranclates to 5.2 mills $/ \mathrm{kWh}$ vs. $1.9 \mathrm{mills} / \mathrm{kWh}$ for the conventional diesel engine.

The coal diesel conceptual design is for a plant which has lower emissions than any state-of-theart coal steam plant ( 0.6 and $1.2 \mathrm{lb} / \mathrm{MMBtu}$ for $\mathrm{NO}_{\mathrm{x}}$ and $\mathrm{SO}_{\mathrm{x}}$, respectively). The emissions control subsystem is easy to distinguish from that of a conventional large stationary engine, in that it relies heavily on exhaust treatment modules, such as:

- Cyclone upstream of turbocharger to remove larger particles (over 5 micron size)

- Selective Catalytic Reduction (SCR) for $\mathrm{NO}_{x}$ controi

- Spray dryer for $\mathrm{SO}_{2}$ control

- Baghouse for particulate control and to capture sorbent

Preliminary cost estimates for this emissions subsystem indicate that for a $12 \mathrm{MW}$ coal diesel plant the total cost will be about $\$ 2.50 / \mathrm{MMBtu}(\$ .0219 / \mathrm{kWh})$, plus or minus $25 \%$ depending on the control options selected. This is significantly higher than our previous 1988 estimate, and reflects actual quotations for appropriate size components. It should be emphasized that the emission control cost estimates presented here are conservative and probably will be reduced in the course of developing actual components for the engine. Of the nine candidate emissions control systems analyzed in Chapter V, this system is the only one which relies on conventional technology for $\mathrm{SO}_{2}$ and $\mathrm{NO}_{\mathrm{x}}$ control. Three other systems based on "unconventional" technology also appear worthy of further R\&D for the coal diesel system (see Chapter V).

Another finding from the emissions analysis was that coal diesel plants below about $7 \mathrm{MW}$ appear to be prohibitively costly when fully equipped to control $\mathrm{NO}_{\mathrm{x}}$ and $\mathrm{SO}_{\mathrm{x}}$ emissions. This does not rule out all future sites for the 2-7 MW cogeneration market, however. This is proven by the recent active market in gas- and oil-fueled stationary reciprocating engines below $7 \mathrm{MW}$, most of which have $\mathrm{NO}_{\mathrm{x}}$ emissions levels far in excess of the $0.6 \mathrm{lb} / \mathrm{MMBtu}$ target of the coal diesel design (with SCR) described in this report.

The overall cost of electricity is forecast to be between 6 and $7 \not / \mathrm{kWh}$ for the typical coal-diesel plant (12 MW capacity). This estimate is essentially unchanged from one 1986 study; whereas, emissions subsystem costs have been set at higher levels, this is compensated by coal slurry cleaning costs which have been revised downward based on physical cleaning (1.5\% ash). The coal diesel technology would appear to become competitive as soon as the diesel fuel oil price 
reaches about $\$ 0.79 /$ gallon $(\$ 5.50 /$ million Btu). The highest $R \& D$ priorities are now assigned to specific options for achieving lower cost coal processing methods, lower cost $\mathrm{NO}_{\mathrm{x}}$ control, and durable injection nozzle tips and piston rings. 


\section{OVERALL FACILITY DESIGN AND COAL-FUELED ENGINE}

\section{A. PLANT CONFIGURATION AND MAJOR SUBSYSTEMS}

The stationary coal diesel facility has a design configuration based on today's staticnary diesel and dual-fuel engine power plants. The coal diesel power plant is intended for capacities from 1.8 MW output (one six-cylinder engine) up to $48 \mathrm{MW}$ output (eight 20-cylinder engines). The Cooper-Bessemer Models LSB/LSVB engines, suitably modified for coal, will be used for these power plants. This engine series is nominally rated at $300 \mathrm{~kW}$ per cylinder and can be built as an in-line engine $(6,8,10$ cyinuders; 1.8 to $3 \mathrm{MW})$ and as a vee-form $(12,16,20$ cylinders; 3.6 to 6 MW). Table II-1 shows the basic parameters of the LSVB engine, and Figure II-1 shows the basic components in cross section. The brake mean effective pressure (bmep) at $200 \mathrm{psi}$ is relatively conservative (about $2 / 3$ that of locomotive engines), and this gives the Cooper LSB and LSVB Series engines the advantages of large combustion space in the cylinder, low overhaul and maintenance costs, and relatively high efficiency (sce Figure II-2). Preliminary tests with the model JS engine indicate that the engine efficiercy on coal fuel will be essentiaily the same as with diesel oil (about $40 \%$ ). Also, bottoming cycle options exist which can raise the plant efficiency to about $46 \%$ (see Appendix E).

Table II-1

COOPER-BESSEMER MODEL LSVB-20 DIESEL ENGINE

\begin{tabular}{ll}
\hline No. of cylinders & 20 \\
Arrangement & Vee-form, turbocharged, intercooled \\
Output (nominal) & $8385 \mathrm{bhp}(6000 \mathrm{~kW}, 300 \mathrm{~kW}$ per cylinder) \\
Bore & $15.5^{\prime \prime}$ \\
Stroke & $22.0^{\prime \prime}$ \\
Speed (nominal) & $400 \mathrm{rpm}$ \\
Brake mean effective pressure (nominal) & $200 \mathrm{psi}$ \\
Specific fuel consumption & $0.345 \mathrm{lb} / \mathrm{bhp}-\mathrm{hr}(6300$ Btu/hp-h) \\
Fuel spec & $\# 2$ diesel fuel/heavy diesel fuel \\
Lube oil consumption & $15,000 \mathrm{bhp}-\mathrm{h} / \mathrm{gal}$ \\
\hline
\end{tabular}

The engine will be designed to burn "engine-grade" coal water slurry $(0.5$ to $1.5 \%$ ash is the current range of ash specifications, on a dry coal basis) of 10 to 15 micron mean particle size, with 50 to 75 micron maximum size. This slurry would be regionally produced (see Section IV) and delivered by tank truck to the power plant, not unlike the practice for diesel oil today.

The overall plant configuration is shown in Figures II-3 and II-4 for a typical cogeneration configuration of two 20-cylinder engines (12 MW total output). The emissions control system is different than for a conventional stationary engine plant, and includes the following modules in the sequence seen by the exhaust gas: 


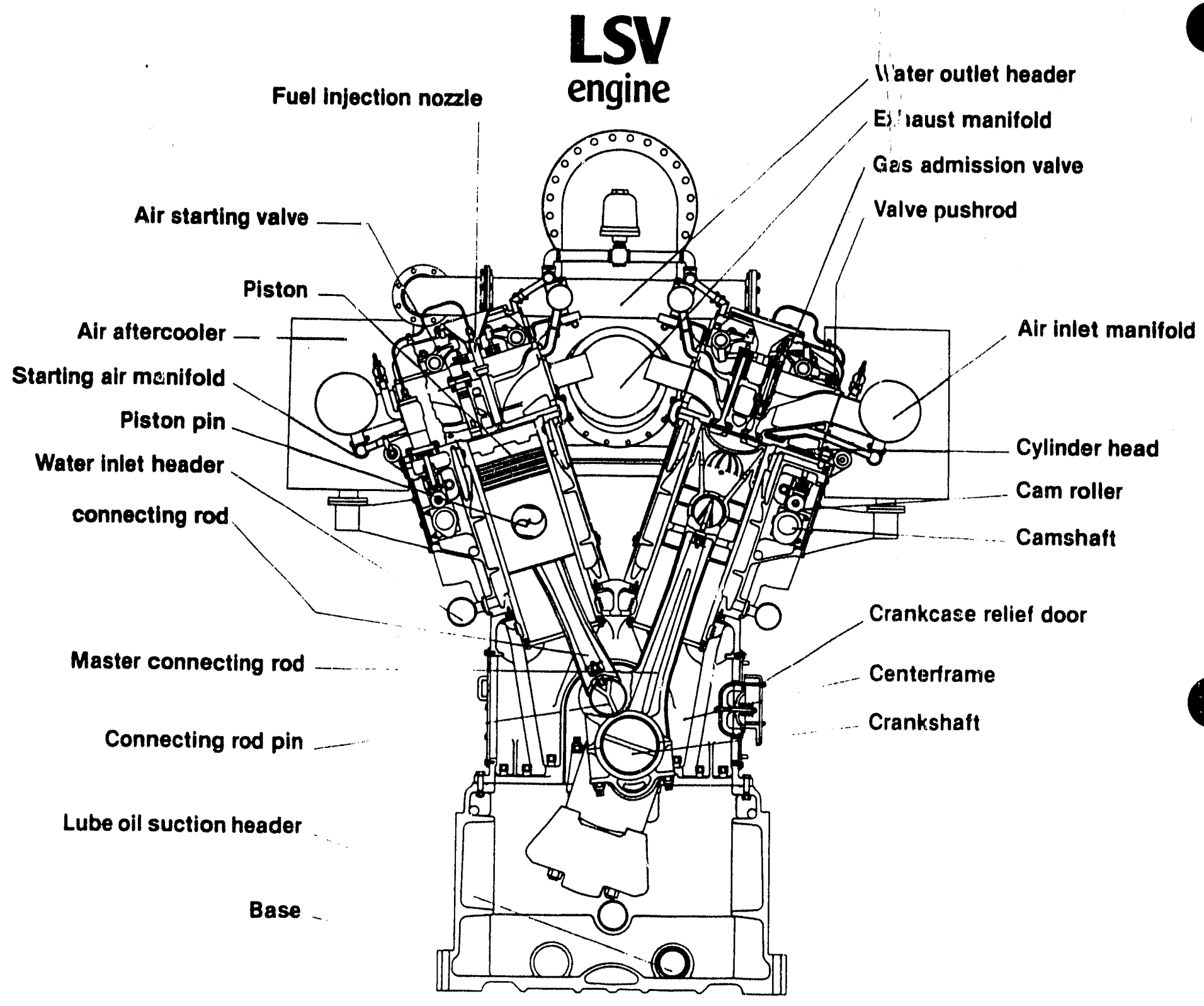

FIGURE II-1. COOPER-BESSEMER LSVB DUAL FUEL ENGINE CROSS SECTION 

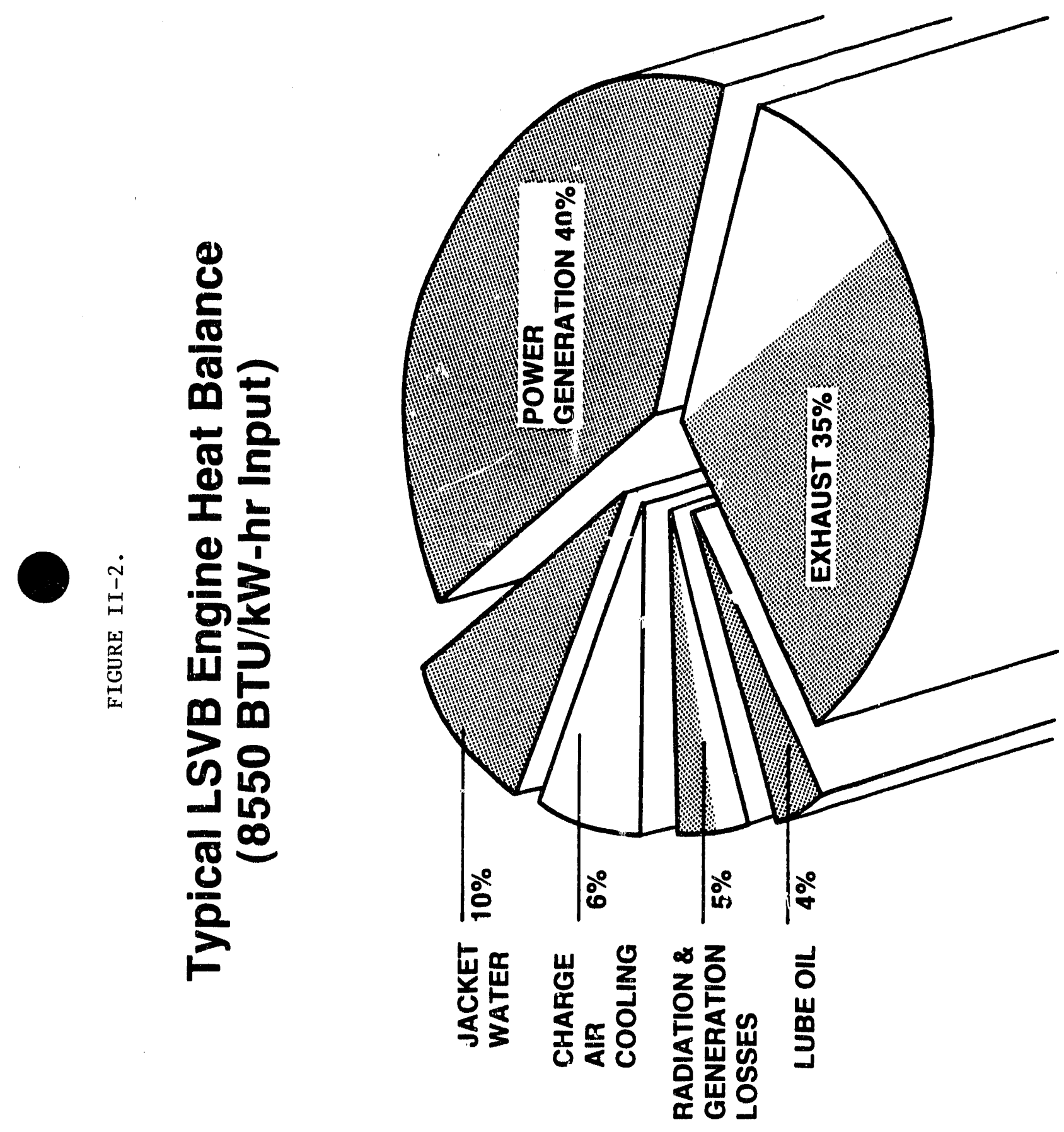

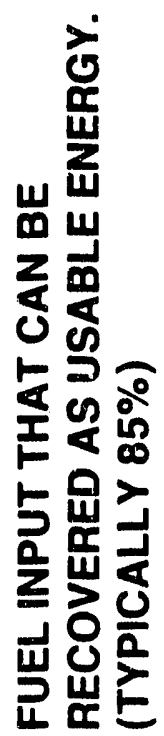




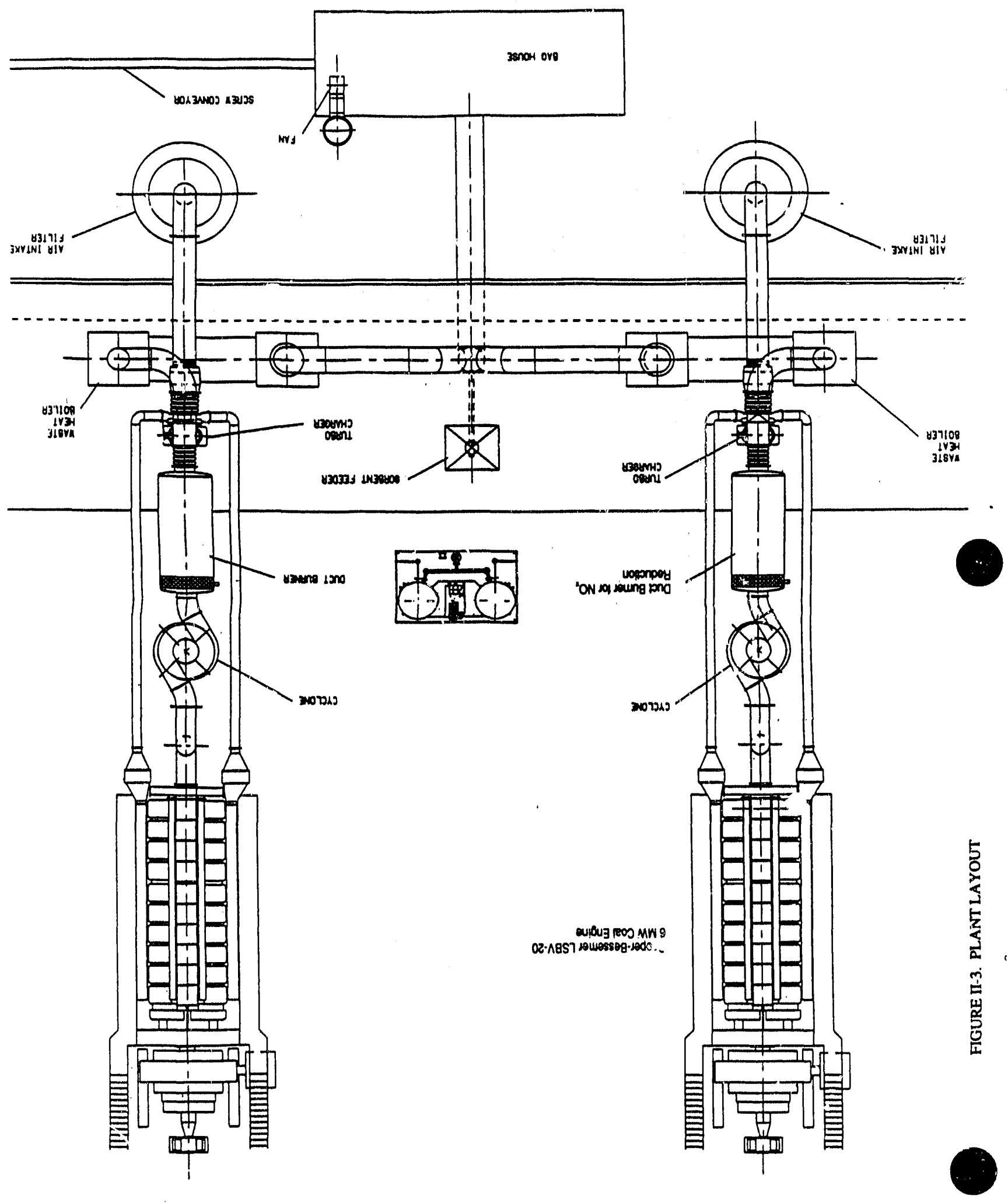


-

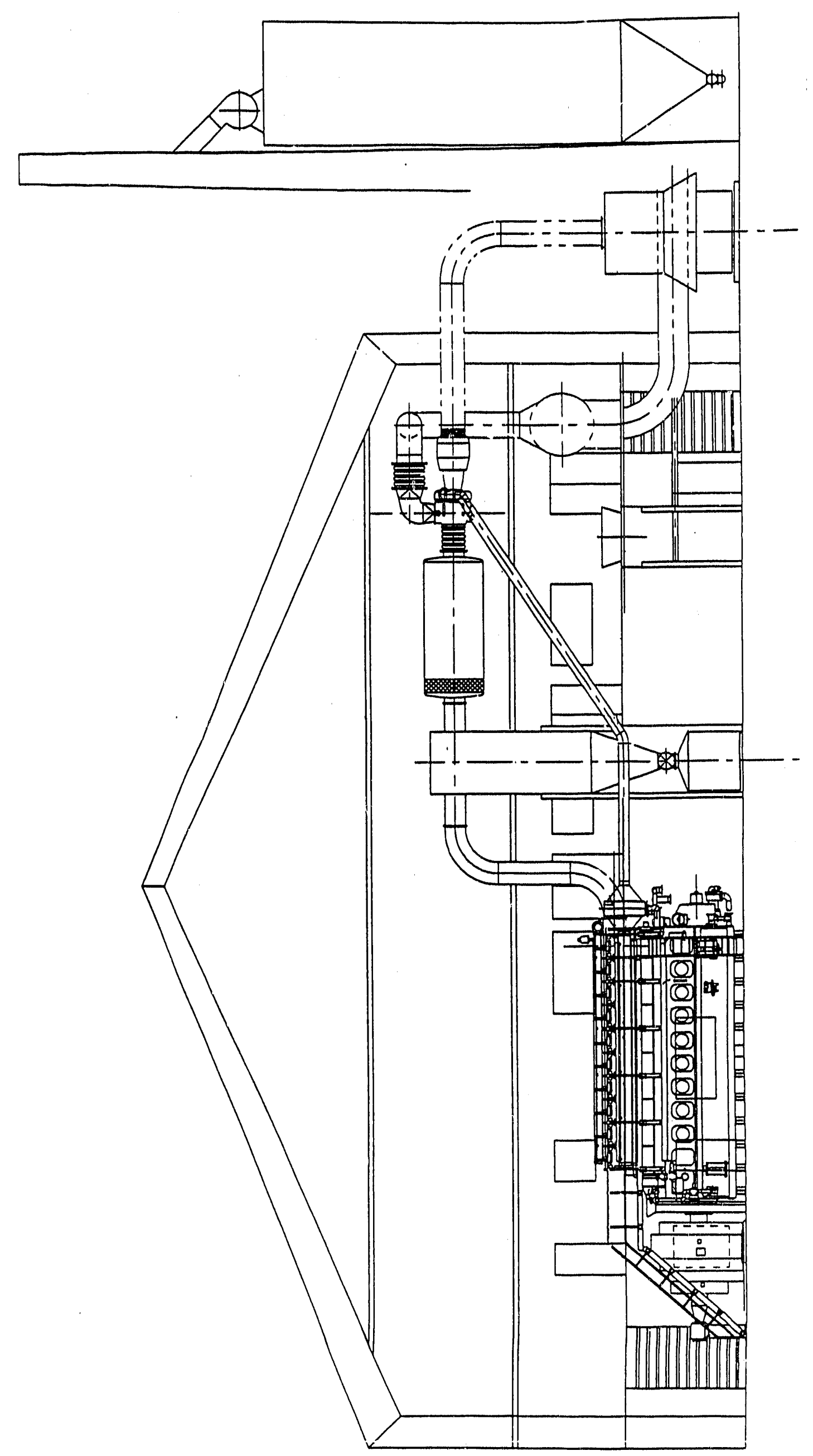

占 
The high availability and low maintenance of the Cooper-Bessemer engines was a critical decision for TDEC, because for district heating to be economical the engines must run constantly, as close to full load as possible. In the first 20 months of operation the engines ran almost continuously at a $92 \%$ load factor. Nearly all downtime was for scheduled preventive maintenance. No other engine we know of has been able to achieve performance like this for a cogeneration project of this size.

Another typical appreciation is the Indiana University project (four engines at $6430 \mathrm{kw}$ ). This cogeneration facility will produce not only enuugh steam and electricity to serve all campus buildings but also an excess of electricity which will be sold to the Pennsylvania Electric Company (PENELEC). Four natural gas-fired reciprocating engines will produce 24.3 megawatts of electricity. As the university requires approximately $1.3 \mathrm{MW}$, the remaining $20 \mathrm{MW}$ can be marketed. At present, a coal-powered steam plant produces energy to heat and cool the majority of the buildings on campus. All but 2 to 3 percent of the university's requires electricity is purchased from PENELEC. The cogeneration facility would reduce IUP's annual estimated electricity and steam costs from $\$ 2.7$ million to $\$ 506,000$. The savings, added to the revenue produced by the sale of excess electricity, could total $\$ 110$ million over the next 20 years. This additional income could be used for augmenting academic programs and facilities and would become a major factor in long-range planning.

\section{DIESEL ENGINE COMPONENTS MODIFIED FOR COAL}

There are five engine subsystems where the Cooper-Bessemer engine will be impacted by coal water slurry:

- Fuel System

- Combustion Chamber

- Lube Oil System

- Air/Exhaust System

- Emissions Control System

Working with the team of subcontractors, Cooper has selected a preliminary design philosophy for each subsystem, and in most cases has selected a design concept which reflects that philosophy. As test data from this program becomes available, the design concepts will be modified accordingly. Cooper's current outlook is as follows for each engine subsystem:

\section{(a) FUEL SYSTEM}

Table II-2 lists the components of the fuel system for a coal engine.

The fuel injection system for coal water slurry, as currently configured, has minimal changes from the standard Diesel F.I. system. The preliminary design used in the JS tests is shown in Figure II-5. An isolating piston protects the punip and metering mechanism from the abrasive slurry. The components include: 


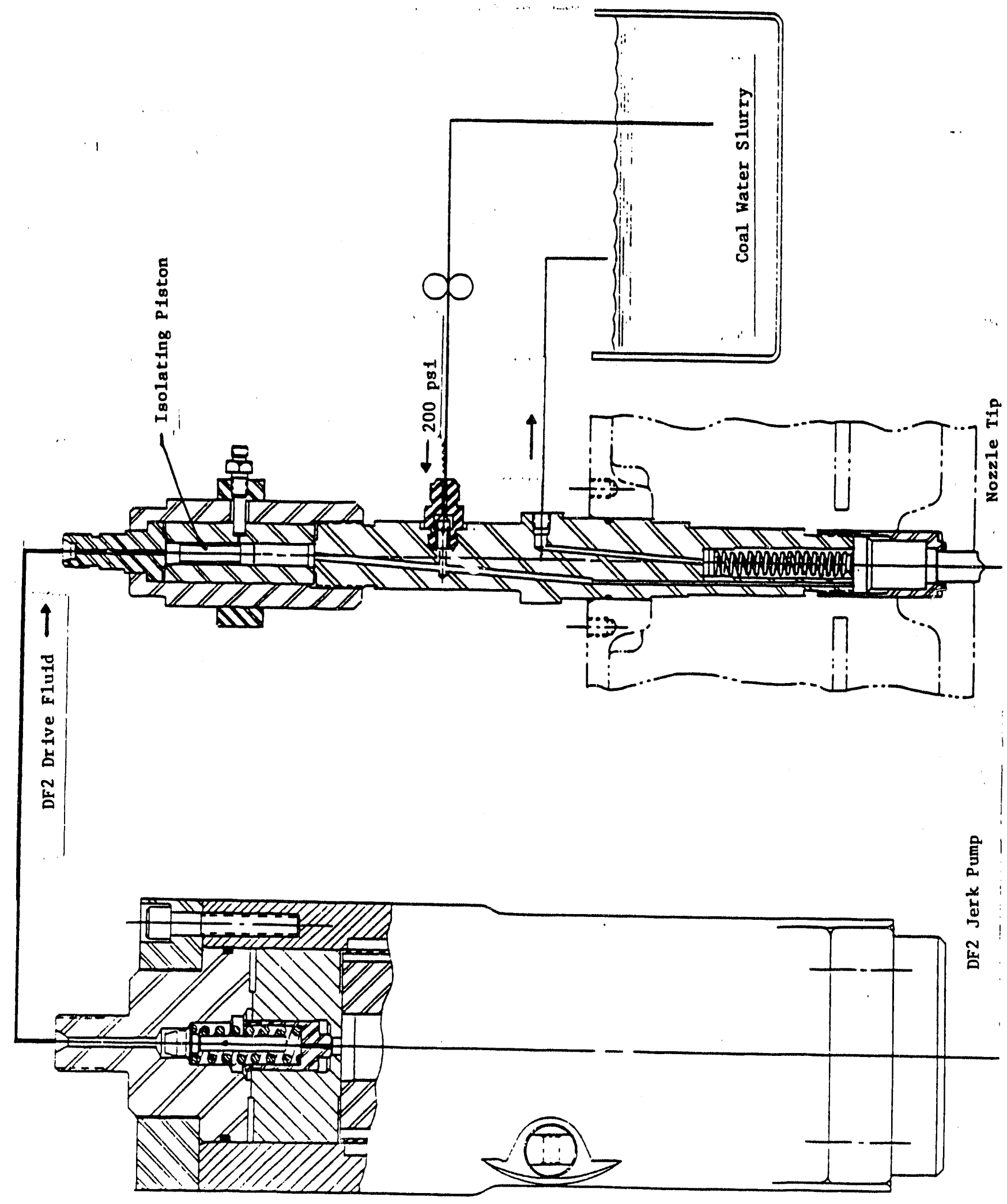


Table II-2

COAL ENGINE FUEL SYSTEM COMPONENTS

\begin{tabular}{lcl}
\hline \multicolumn{1}{c}{ Item } & $\begin{array}{c}\text { C-B Fabricated } \\
\text { or Bought }\end{array}$ & \multicolumn{1}{c}{$\begin{array}{c}\text { Modifications Required } \\
\text { for CWS }\end{array}$} \\
\hline Storage tank & B & $\begin{array}{l}\text { Modified design for continuous agitation; } \\
\text { design protects against settling and freez- } \\
\text { ing; extra DF2 tank. }\end{array}$ \\
Transfer pump, piping valves, etc. & B & $\begin{array}{l}\text { Moyno pump;.common rail leading to F.I. } \\
\text { pumps; dual system for DF2 and CWS. }\end{array}$ \\
Fuel injection pump & B & $\begin{array}{l}\text { Larger pumps, operate on DF2; extra } \\
\text { pump for DF2 pilot. } \\
\text { Injectors }\end{array}$ \\
\hline
\end{tabular}

- Conventional cam driven jerk pump.

- Injectors which are designed to handle either CWS/DF2 or DF2: Figure II-6 shows one of the ceramic injector tip designs which are intended to prevent cavitation and withstand abra-
sion.

- Conventional control system.

Since DF2, or natural gas will be used as pilot fuel for ignition, two entire fuel systems are included in the design. For example, if a DF2 pilot is selected, the engine will have two fuel rails (one for CWS and one for DF2); two sets of fuel pumps, two sets of injectors, and two storage tanks.

(b) COMBUSTION SYSTEM

Table II-3

COAL ENGINE COMBUSTION SYSTEM COMPONENTS

\begin{tabular}{|c|c|c|}
\hline Item & $\begin{array}{l}\text { C-B Fabricated } \\
\text { or Bought }\end{array}$ & $\begin{array}{l}\text { Modifications Required } \\
\text { for CWS }\end{array}$ \\
\hline $\begin{array}{l}\text { Cylinder heats } \\
\text { (see Figure III-7) }\end{array}$ & C-B & $\begin{array}{l}\text { Modified head design to allow gas torch or diesel } \\
\text { pilot ignition }\end{array}$ \\
\hline Air/exhaust valves & B & Special hard coatings to prevent erosion \\
\hline Cylinder line:s & C-B & Hard coatings to withstand abrasion \\
\hline Pistons & $\mathrm{C}-\mathrm{B} / \mathrm{B}$ & $\begin{array}{l}\text { Increased compression ratio to assist ignition; possi- } \\
\text { ble bowl in piston }\end{array}$ \\
\hline Piston rings & B & Hard coatings and special profiles \\
\hline
\end{tabular}




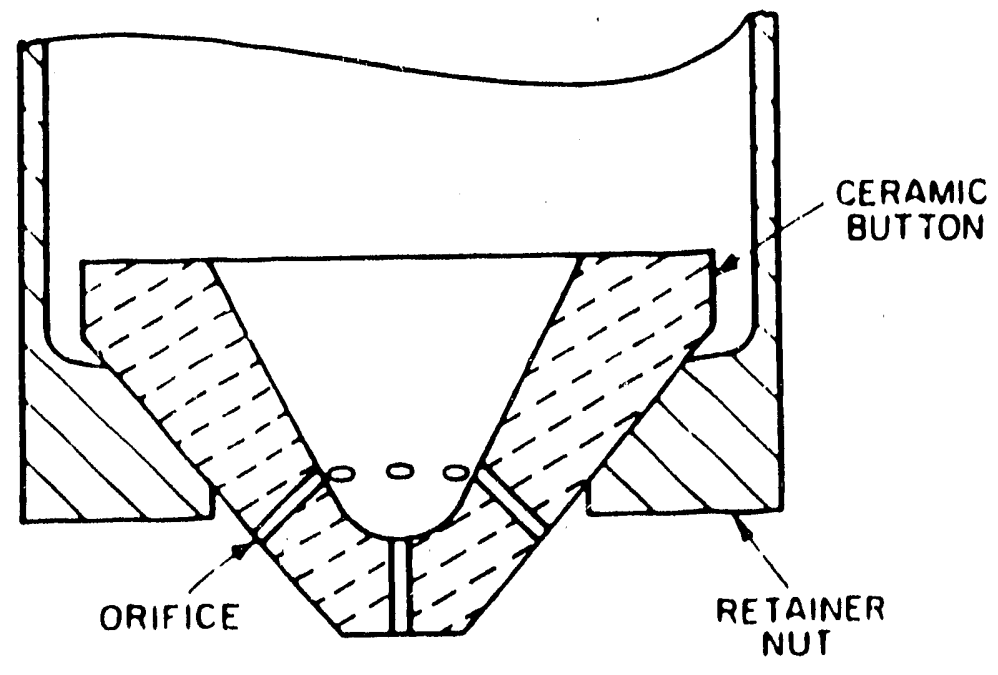

FIGURE II-6. "BUTTON" NOZZLE 


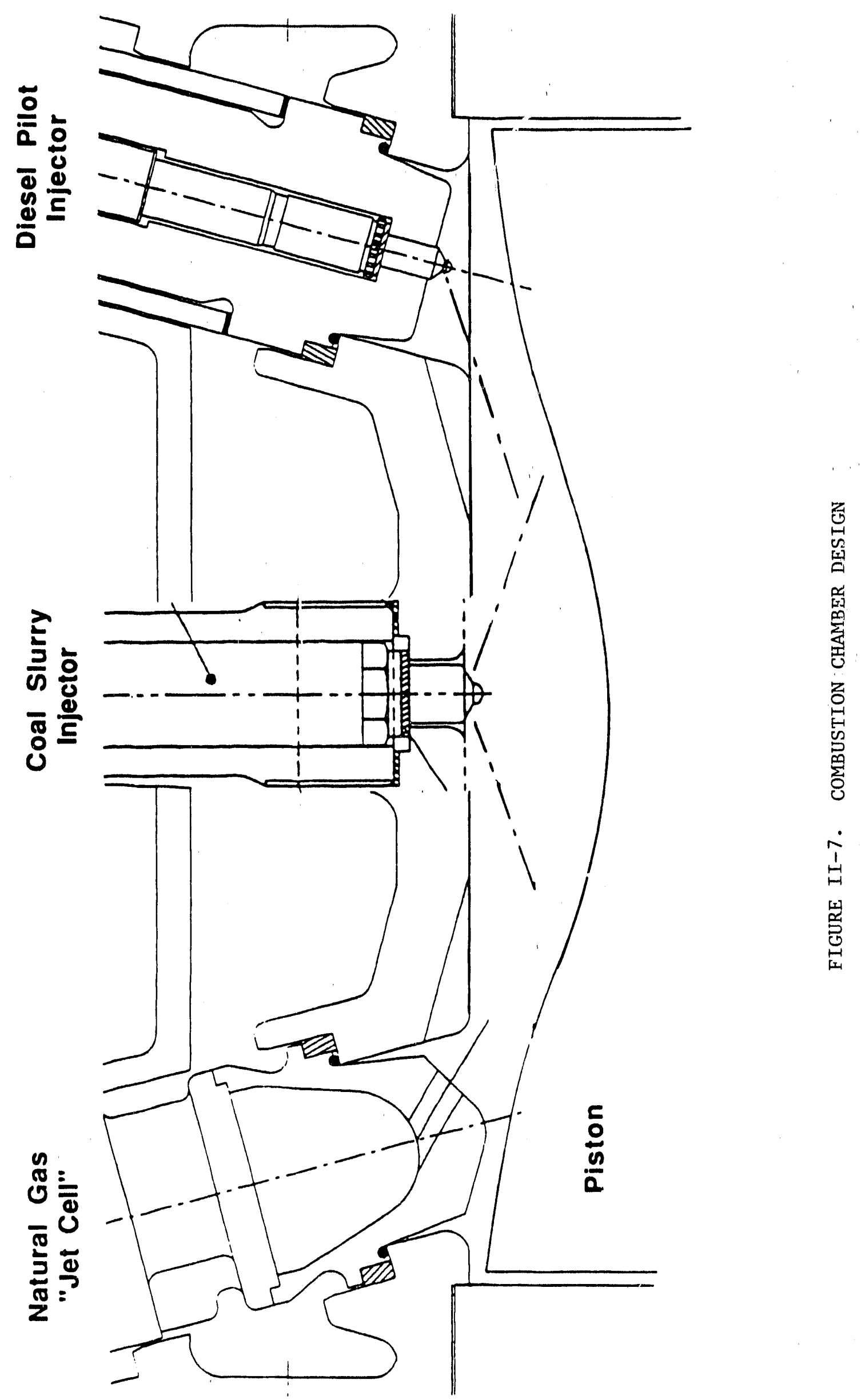




\section{(c) LUBE OIL SYSTEM}

Table II-4

COAL ENGINE LUBE SYSTEM COMPONENTS

\begin{tabular}{|c|c|c|}
\hline Item & $\begin{array}{l}\text { C-B Fabricated } \\
\text { or Bought }\end{array}$ & $\begin{array}{l}\text { Modifications Required } \\
\text { for CWS }\end{array}$ \\
\hline Lube oil & B & Special oil for enhanced ash removal \\
\hline Lube oil pump, piping valves, etc. & B & Standard design \\
\hline Lube oil injection design & C-B & $\begin{array}{l}\text { Possible modification design to flush ring } \\
\text { land area }\end{array}$ \\
\hline Filters & B & $\begin{array}{l}\text { Possible modification for higher ash loading } \\
\text { (2-stage) }\end{array}$ \\
\hline Bearings & B & Standard design \\
\hline
\end{tabular}

(d) INTAKE/EXHAUST SYSTEM

Table II-5

COAL ENGINE INTAKE/EXHAUST SYSTEM

\begin{tabular}{lcl}
\hline \multicolumn{1}{c}{ Item } & $\begin{array}{c}\text { C-B Fabricated } \\
\text { or Bought }\end{array}$ & \multicolumn{1}{c}{$\begin{array}{c}\text { Modifications Required } \\
\text { for CWS }\end{array}$} \\
\hline Intake manifold and aftercoders & C-B & $\begin{array}{l}\text { Modified for higher pressure and possible air pre- } \\
\text { heating after turbocharger }\end{array}$ \\
Intake filters manifolds, silencers, etc. & C-B/B & $\begin{array}{l}\text { Standard design } \\
\text { Turbocharger }\end{array}$ \\
Exhaust manifold & C-B & $\begin{array}{l}\text { Modified design with hard coatings; turbocharger } \\
\text { relocated to allow cyclone } \\
\text { Entirely new design; greater length; accommo- } \\
\text { dates emission control modules }\end{array}$ \\
\hline
\end{tabular}

\section{(e) EMISSIONS CONTROL SYSTEM}

Designs for the emission control system are described in Section V.

In summary, the major C-B manufactured components affected by CWS are as follows:

- Cylinder heads

- Cylinder liners

- Pistons

- Turbocharger

- Intake and exhaust manifolds

\section{ENGINE COMPONENT COST ESTIMATES}

The cost premiums associated with the critical engine parts are estimated in Table II-6. Note that the total premium is $\$ 1.1$ million ex-factory, and that the most expensive items, in terms of adapting the engine to coal fuel, are the turbocharger, the fuel pumps, the injectors and supply 
system, and the instrumentation. Installation costs will carry a premium for the coal diesel as well, because of extra slurry pumps, tanks, and piping; the offset turbocharger and related exhaust manifolding; the extra instrumentation; the diesel pilot system, etc. Permits and compliance testing will also be more costly. This is accounted for in Table 11.6 by applying $50 \%$ installation to the entire engine cost.

Table II-6

ESTIMATED COST PREMIUMS FOR COAL DIESEL ENGINE COMPONENTS ( 20 cylinder, $6 \mathrm{MW}$ engine)

\begin{tabular}{|c|c|c|c|}
\hline $\begin{array}{c}\text { Engine } \\
\text { Components }\end{array}$ & $\begin{array}{l}\text { Conventional } \\
\text { Diesel }^{(1)}\end{array}$ & $\begin{array}{l}\text { Coal } \\
\text { Diesel }\end{array}$ & Differential \\
\hline Lube System & $\$ 30,000$ & $\$ 65,000$ & \\
\hline Pistons and Piston Rings & 50,000 & 70,000 & \\
\hline Cylinder Liners & 100,000 & 200,000 & \\
\hline Cylinder Head(s) & 200,000 & 300,000 & \\
\hline Valves/Seats & 30,000 & 40,000 & \\
\hline Tuel Pumps, Injectors, Supply S & 100,000 & 300,000 & \\
\hline Instruments & 50,000 & 200,000 & \\
\hline Turbocharger & 200,000 & 600,000 & \\
\hline Cam Shaf: and Bearings & 50,000 & 100,000 & \\
\hline Miscellany & 200.000 & 250.000 & \\
\hline Subtotal Critical Parts & $\$ 1,010,000$ & $\$ 2,125,000$ & $\$ 1,115,000$ \\
\hline Non-Critical Parts & $1,350.000$ & 1.350 .000 & \\
\hline Total Engine Cost & $\$ 2,360,000$ & $\$ 3,475,000$ & \\
\hline Installation Costs (50\%) & 1.180 .000 & 1.737 .500 & \\
\hline Installed Engine Cost & $\$ 3,540,000$ & $\$ 5,212,500$ & $\$ 1,672,500$ \\
\hline
\end{tabular}

(1) Component costs for the conventional engine are nominal representative values based on C-B's broad experience, and do not necessarily correspond to prices of actual current engine parts of any specific C-B engine model.

\section{E. OVERHAUL COST ESTIMATES}

The overhaul and maintenance for a coal-fueled engine are significantly greater than for a conventional diesel. Not only are the parts replacement intervals shorter with coal, but the parts themselves are more costly. Four basic maintenance and overhaul service functions were considered:

- Injector tip inspection and replacement

- Inspection of filters, valve clearance, etc.

- "Top-end" overhaul (cylinder head rebuilds)

- "Bottum-end" overhaul (pistons, liners, crankcase bearings) 
Table II-7 shows the intervals and cost estimates which we have prepared for the coal diesel versus the conventional engine. The period we analyzed was 20 years; this is sufficient to allow bottom-end overhaul costs to enter the calculation. The total overhaul costs for the coal diesel over 20 years amounts to $\$ 3.9$ million versus $\$ 1.4$ million for the conventional diesel. The injectors are a significant factor (over $25 \%$ ) in this total; we have assumed $\$ 3200$ per set of twenty injector tips ( $\$ 160$ per injector tip) and a 500 hour replacement interval. Each of thes/ estimated numbers has a significant uncertainty at this stage of the program. 
Table II-7

ENGINE MAINTENANCE AND OVERHAUL COSTS

\begin{tabular}{|c|c|c|c|}
\hline Description & $\begin{array}{l}\text { Unit of } \\
\text { Measure }\end{array}$ & $\begin{array}{c}\text { Conal } \\
\text { Diesel }\end{array}$ & $\begin{array}{c}\text { Conventional } \\
\text { Diesel }\end{array}$ \\
\hline \multicolumn{4}{|l|}{ MAINTENANCE INTERVALS } \\
\hline Injector & Hours/Cyde & 500 & 2,000 \\
\hline Minor & Hours/Cycle & 4,000 & 8,000 \\
\hline Top End & Hours/Cycle & 12,000 & 25,000 \\
\hline Bowom End & Hour/Cycle & 25,000 & 100,000 \\
\hline \multicolumn{4}{|l|}{ COST PER SERVICING } \\
\hline Injectors & sss & $\$ 3,200$ & negl. \\
\hline Minor & sss & $\$ 10,000$ & $\$ 10,000$ \\
\hline Top End & sss & $\$ 60,000$ & $\$ 90,000$ \\
\hline Bottom End & sss & $\$ 290,000$ & $\$ 290,000$ \\
\hline \multicolumn{4}{|l|}{ SERVICING THROUGH IST REBUIID } \\
\hline Injucacr & "of Cycles & 50 & N/A \\
\hline Minor (excl of injertorn) & of Cycles & 6 & 13 \\
\hline Top End & " of Cycles & 2 & 4 \\
\hline Bowom End & "of Cycles: & 1 & 1 \\
\hline \multicolumn{4}{|l|}{ COST THROUGH IST REBUIID } \\
\hline Injectom & sss & $\$ 160,000$ & negl. \\
\hline Minor & ssss & $\begin{array}{r}560,000 \\
(\text { for } 6)\end{array}$ & $\begin{array}{r}\$ 130,000 \\
\text { (for 13) }\end{array}$ \\
\hline Top End & sss & $\begin{array}{r}\$ 120,000 \\
(\text { for } 2)\end{array}$ & $\begin{array}{r}\$ 360,000 \\
\text { (for 4) }\end{array}$ \\
\hline Bothom End & sss & $\$ 290,000$ & $\$ 290,000$ \\
\hline TOTAL THROUGH IST REBUIID & sss & $\$ 630,000$ & $\$ 789,000$ \\
\hline \multicolumn{4}{|l|}{ ALLOCATED MANTENANCE $\%$} \\
\hline Injecton & क & $25.40 \%$ & \\
\hline Minor & $\%$ & $9.52 \%$ & $16.67 \%$ \\
\hline Top End & $\Phi$ & $19.05 \%$ & $46.15 \%$ \\
\hline Botwon End & 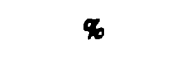 & $46.03 \%$ & $37.18 \%$ \\
\hline \multicolumn{4}{|l|}{ 20-YR SERVICE CYCLES } \\
\hline Injectors & of Cycles & 315 & \\
\hline Minor & of Cycles & 39 & 20 \\
\hline Top End & of Cycles & 13 & 7 \\
\hline Botrom End & "of Cycles & 6 & 2 \\
\hline \multicolumn{4}{|l|}{20 YEAR COST (SIX MAJOR REBUILDS) } \\
\hline Injectors & SSS $/ 20 \mathrm{yr}$ & $\$ 1,008,000$ & \\
\hline Minor & SSS/20 yr & $\mathbf{s} 390,000$ & $\$ 200,000$ \\
\hline Top End & $\$ \$ S \$ 20 \mathrm{yr}$ & $\mathbf{5 7 8 0 , 0 0 0}$ & $\$ 630,000$ \\
\hline Botom End & S\$S/20 yr & $\$ 1.740,000$ & $\$ 580,000$ \\
\hline TOTAL MAINTENANCE COST (20 yr) & & $\$ 3,918,000$ & $\$ 1,410,000$ \\
\hline TOTAL MADNTENANCE COST (per $\mathrm{kWh}$ ) & & so.0052 & $\$ 0.0019$ \\
\hline
\end{tabular}




\section{STATIONARY POWER MARKETS TO BE SERVED}

\section{A. SELECTION OF APPLICATIONS AND PLANT CONFIGURATIONS}

In previous reports we reviewed a full range of stationary and marine engire applications and analyzed the potential suitability of coal fueled engines for each application. Of all the applications studied to date, there are three which appear very suitable for the coal fueled diesel system:

- Independent power generating plants, or "IPPs" (5-50 MW)

- Capacity addition for municipal utilities (10-50 MW)

- Industrial cogeneration plants (2-50 MW)

These applications typically involve multiple engines at a single plant where requirements are favorable for coal firing: high annual utilization, existing infrastructure, space for coal handling and emission controls, and constant load operation.

Tirends in U.S. power requirements over the next 20 years or so appear to be highly favorable for the early adoption of these coal-fired diesel applications. The coal diesel stationary power plant is being developed at a time when there is an ongoing upheaval in the stationary power industry. This upheaval is in large part driven by the steady growth in U.S. power requirement, which continnes to grow at 2.2 to $2.6 \%$ per year nationwide, and up to $6 \%$ per year in certain regions. For perspective, each extra $0.2 \%$ of growth nationwide represents $10,000 \mathrm{MW}$ of new capacity on-line. Another driving force has been the major changes to the infrastructure such as PURPA and the rise of independent power plants (IPPs). Traditional procedures whereby utilities added stationary power capacity in the form of large central-station generators, in increments of 500 to $1300 \mathrm{MW}$, are gradually giving way to new procedures whereby modular plants are installed in the 50 to $406 \mathrm{MW}$ size range, and many of these are non-utility owned generators (IPPs). At the present time, the fuels of choice for these modular plants are natural gas and oil, due to two factors:

- Gas and oil are currently priced at attractive levels ( $\$ 2$ to $\$ 4$ per million Btu)

- There is no competitive coal-fueled modular power technology available with low emissions yet, particularly in the 2 to $50 \mathrm{MW}$ range. Circulating fluid bed coal plants are now competitive but are somewhat larger in size and not as efficient as diesel plants would be.

However, these two factors may change by the late 1990 s to early 2000 , which is the period when the coal diesel will be in position to gain rapid market acceptance. This Topical Report provides a preliminary design of a competitive clean coal modular diesel power plant, with low emissions, suitable for 2 to $50 \mathrm{MW}$ plant sizes, which is moving along the path to field demonstration in the mid-1990's. Continuing R\&D efforts have resulted in steady progress toward demonstration of the prototype engine and emission control system on clean coal water slurry. As for gas and oil prices, many energy forecasts are including the scenario of a sawtooth climb of oil and gas prices to over $\$ 30$ per barrel (as a sustained price) during the 1990's. According to 
our projections, when the industrial price of diesel fuel reaches about $\$ 0.79 /$ gallon

(\$5.50/MMBtu), the coal-fueled diesel plant can offer a competitive cosi of electricity. The current gas "bubble" in the U.S. is expected to be used up by the mid to late 1990's because of shrinking domestic gas production and increased gas demand. GRI forecasts (1988) show U.S. gas usage growing at a slow pace (0.5\% through 2000 and $0.3 \%$ from 2000 to 2010 ), conventional gas supply declining, LNG and gas pipeline imports increasing, and gas prices increasing faster than coal prices ( $4.5 \%$ vs. $1.7 \%$ in ral terms). These observations and scenarios leave a window of opportunity for clean coal slurry in the late 1990's and beyond, provided it can be produced at a delivered price of $\$ 3$ to $\$ 3.50$ per million Btu (current dollars).

As noted above, the coal diesel power plant is intended to serve three classes of applications:

(a) IPPs: The coal diesel could capture an increasing portion of the non-utility modular power market now served by gas and oil fueled 5-50 MW engines (gas turbine and reciprocating engines).

(b) Utility Incremental Added Power: The coal diesel could be considered by smaller utilities as an attractive alternative to other power plant types for adding up to $50 \mathrm{MW}$ smaller increments of capacity (such as the circulating fluidized bed boiler or gas-fueled turbine). The coal diesel is generally considered to be the only technology with the potential to reach a $45-50 \%$ overall electric power efficiency below $50 \mathrm{MW}$ with coal.

(c) Industrial Cogeneration: Where the heat-to-power ratio requirement is appropriate (say, 1.0 to 1.4), the clean coal diesel could be an attractive alternative as an industrial cogeneration prime mover.

Pipeline compressors, mechanical drive and irrigation engines do not appear attractive for coal diesel because of either engine size, population, or natural gas availability.

Whereas applications (a) and (b) call for straight power generation, application (c) calls for both heat and power. Cogeneration units being built today are designed either to meet the power needs at the host industrial site or intended primarily for sale of power to the grid.

For the purposes of this preliminary design study, five plant configurations were considered, as shown in Table III-1.

These applications typically would be larger than $6 \mathrm{MW}$, the largest Cooper-Bessemer engine, and thus would involve multiple engines at a single plant. These applications also offer favorable characteristics for coal firing (high annual utilization, existing coal infrastructure, space for coal-handling and emission controls, constant load operation). The number of IPP and small utility plants is expected to expand significantly over the 1995-2010 period, as described in Sections $\mathrm{B}$ and $\mathrm{C}$ below, and this presents an important opportunity for small clean coal plants to establish viability. 
Table III-1

COAL DIESEL PLANT CONFIGURATIONS

\begin{tabular}{llllll}
\hline \multicolumn{1}{c}{ Function } & \multicolumn{1}{c}{$\begin{array}{c}\text { Number and Output } \\
\text { of Engines }\end{array}$} & $\begin{array}{c}\text { Total } \\
\text { Power }\end{array}$ & Cogen & IPP & $\begin{array}{c}\text { Small } \\
\text { Utility }\end{array}$ \\
\hline Cogen & $1 \times 1.8 \mathrm{MW}(6 \mathrm{cyl} \mathrm{LSB})$ & $1.8 \mathrm{MW}$ & 0 & - & - \\
Cogen & $4 \times 1.8 \mathrm{MW}(6 \mathrm{cyl}$ LSB $)$ & $7.2 \mathrm{MW}$ & 0 & - & - \\
Power & $2 \times 6 \mathrm{MW}(20 \mathrm{cyl}$ LSVB) & $12 \mathrm{MW}$ & - & 0 & 0 \\
Cogen & $2 \times 6 \mathrm{MW}(20 \mathrm{cyl} \mathrm{LSVB})$ & $12 \mathrm{MW}$ & 0 & 0 & - \\
Cogen & $4 \times 6 \mathrm{MW}(20$ cyl LSVB) & $24 \mathrm{MW}$ & 0 & 0 & - \\
\hline
\end{tabular}

\section{B. COGENERATION PRIME MOVER REQUIREMENTS BY INDUSTRY}

Table III-2 shows six industries which are expected to expand their cogeneration capacity. Table III-3 presents one scenario of how the diesel and gas reciprocating engines could fit into these expansion plans. This scenario shows the potential for over 1,500 new engines and $6400 \mathrm{MW}$ of installed diesel capacity in cogeneration, about $55 \%$ of which is smaller engines of about $3 \mathrm{MW}$ size. The coal diesel is not expected to be technologically ready to be offered before 1997 to 2000 (except for field demonstration purposes); however, it is targeted for future cogeneration installations after that time, assuming fuel prices are favorable. Therefore, Table III-3 portrays the potential future cogeneration market for the coal diesel, to the extent that comparable industrial cogeneration growth continues into the next two decades (see Section F for further discussion of scenarios).

As will be shown in Section V, a complete emission control package for the coal diesel, including $90 \% \mathrm{NO}_{\mathrm{x}}$ reduction, is expected to be cost effective only above about $8 \mathrm{MW}$ plant size. If true, this would effectively exclude a large subset of cogeneration opportunities in the 1 to $8 \mathrm{MW}$ size range. However the 520 engines shown in Table III-3 associated with plants $10 \mathrm{MW}$ and up would still be an important market. Furthermore, certain cogeneration plants below $8 \mathrm{MW}$ would be suitable for a lower cost emissions control package.

\section{GROWTH IN ELECTRIC POWER CAPACITY - PROJECTED NEED FOR CAPACITY ADDITIONS}

Modular electric utility plants are also a very promising application for the coal-fueled diesel. A significant shortfall in electric generating capacity is projected to occur beginning in the mid 1990 's, according to our "most probable" scenario of $2.2 \%$ /year demand growth. Utilities have not yet announced their plans for new plants to satisfy this shortfall. Recent electric power surveys such as those by Mottley, Mycoff and Gumz ${ }^{(1)}$ and the Energy Information Agency ${ }^{(2)}$, without exception point to a challenging time period between 1994 and 2000 when available U.S. generating capacity will start to be strained to meet projected demand. Before going into the detailed numbers, what this means is that there is an unprecedented opportunity (some would call it a likely requirement) for new modular power. 
Table III-2

NUMBER OF EXISTING MANUFACTURING PLANTS WITH DIESEL COGENERATION POTENTIAL

\begin{tabular}{|c|c|c|c|}
\hline \multirow[b]{2}{*}{ Industry } & \multicolumn{3}{|c|}{ Cogeneration Plant Size } \\
\hline & $2.0-9.9 \mathrm{MW}$ & $10.0-19.9 \mathrm{MW}$ & $20.0 \mathrm{MW}$ anci Over \\
\hline Food & 450 & 48 & 84 \\
\hline Textile & 199 & 9 & 6 \\
\hline Chemical & 157 & 65 & 131 \\
\hline Petroleum Refining & 39 & 8 & 91 \\
\hline Rubber & 48 & 6 & 3 \\
\hline Metals & 107 & 19 & 34 \\
\hline Other & 40 & 15 & 11 \\
\hline Totals & 1,040 & 170 & 360 \\
\hline
\end{tabular}

Source: Department of Energy, 1984

Table III-3

POTENTIAL DEMA: ID FOR DIESEL ENGINES FOR COGENERATION IN EXISTING U.S. MANUFACTURING PLANTS

\begin{tabular}{|c|c|c|c|c|c|c|}
\hline \multirow[b]{2}{*}{ Plant Size } & \multirow[b]{2}{*}{$\begin{array}{c}\text { Potential } \\
\text { Number } \\
\text { of Plants } \\
\text { Installing } \\
\text { Cogeneration }\end{array}$} & \multicolumn{5}{|c|}{ Potential New Diesel Capacity } \\
\hline & & $\begin{array}{l}\text { Assumed Percent } \\
\text { Using } \\
\text { Diesel }^{(1)}\end{array}$ & $\begin{array}{l}\text { Assumed No. } \\
\text { and Size of } \\
\text { Diesels per } \\
\text { Plant }\end{array}$ & $\begin{array}{c}\text { Number of } \\
\text { Diesel } \\
\text { Cogen } \\
\text { Plants } \\
\end{array}$ & $\begin{array}{l}\text { Number of } \\
\text { Engines }\end{array}$ & $\begin{array}{l}\text { Added } \\
\text { Capacity }\end{array}$ \\
\hline 2.0-9.9 MW & 1,040 & $60 \%$ & $2 \times 3 \mathrm{MW}$ & 600 & $\begin{array}{c}1200 @ 3 \\
\text { MW }\end{array}$ & $3,600 \mathrm{MW}$ \\
\hline 10.0-19.9 MW & 170 & $50 \%$ & $4 \times 5 \mathrm{MW}$ & 85 & $\begin{array}{c}340 @ 5 \\
M W\end{array}$ & $1,700 \mathrm{MW}$ \\
\hline $\begin{array}{l}20.0 \mathrm{MW} \text { and } \\
\text { over }\end{array}$ & 360 & $10 \%$ & $5 \times 6 \mathrm{MW}$ & 36 & $\begin{array}{c}180 @ 6 \\
M W\end{array}$ & $1,100 \mathrm{MW}$ \\
\hline Totals & 1,570 & - & - & 721 & 1,720 & $6400 \mathrm{MW}$ \\
\hline
\end{tabular}

Source: Department of Energy, Arthur D. Litule, Inc., estimates.

${ }^{(1)}$ See Section E and Tables III-7 and III-8. 
Of course, there is uncertainty in both the degree and timing of the upcoming potential shortfall, and in the mix of solutions which will actually be implemented, such as:

- Utility capacity additions*

- Independent power plants (IPPs)

- Repowering of utility power plants, including fluidized bed retrofits

- Life extension of existing units

- Imports (mainly from Canada) and more extensive wheeling

- Load management and conservation

Whatever mix eventually materializes, the first two solutions above (noted *) will be important elements, and these are two key potential future markets for the coal diesel power plant. A shortfall in new capacity additions by utilities should create greater demand for cogen and IPP piants, including modular plants under $100 \mathrm{MiW}$. Coal-fueled heat engines, when developed and demonstrated, must compete against gas-fueled modular power and fluidized bed (coal) plants for share of this $4000-6000 \mathrm{MW}$ per year market (see Section E for a discussion of market share).

Growth in gas cost (in \$/million Btu), coupled with lower growth in coal cost, should favor adoption of coal-fired technologies.

The projections for new fossil fueled capacity additions, including both utility and IPPs, are expected to be at a relatively high level in 1991-2010, as shown in Table III-4.

Table III-4

FOSSL FUELED POWER PLANT ADDITIONS, 1991-2010 FORECAST

\begin{tabular}{|c|c|c|c|c|}
\hline Power Plant Type & $\begin{array}{l}1991-1995 \\
\text { (MW) }\end{array}$ & $\begin{array}{l}1996-2000 \\
\text { (MW) }\end{array}$ & $\begin{array}{l}2001-2005 \\
(\mathrm{MW})\end{array}$ & $\begin{array}{l}2006-2010 \\
(\mathrm{MW})\end{array}$ \\
\hline Utility coal steam turbine & 7,500 & 19,000 & 54,700 & 73,100 \\
\hline Utility combined cycle (gas, oil, dual fuel) & 6,300 & 30,600 & 7,600 & 8,600 \\
\hline $\begin{array}{l}\text { Utility combustion turbine and reciprocating } \\
\text { I.C. engine }\end{array}$ & 10,800 & 15,500 & & 7.600 \\
\hline $\begin{array}{l}\text { IPP/Non-utility natural gas (gas turbine, die- } \\
\text { sel) }\end{array}$ & 4,500 & 4,800 & 5,700 & 5,200 \\
\hline TOTALS & $29,100 \mathrm{MW}$ & $69,900 \mathrm{MW}$ & $74,900 \mathrm{MW}$ & $94,500 \mathrm{MW}$ \\
\hline
\end{tabular}

Source: EIA, Annual Energy Outlook 1990, Jan. 1990.

Note that a total $169,400 \mathrm{MW}$ in projected new fossil-fueled capacity is expected to be installed over the ten year period 2001 to 2010, when the coal diesel will first become available. Of this, $159,000 \mathrm{MW}$ will be required by utilities and another $10,400 \mathrm{MW}$ is forecast for IPP (non- 
utility). It should be noted that utilities do not have specific plans for most of the capacity needed after 1995. There is considerable flexibility to select new technologies which become proven.

The coal diesel is designed to compete for the smaller plant sizes in the 10-50 MW range, and will not be available until the late 1990s, except for demonstration. Therefore, the IPP and utility combustion turbine categories for 2001-2010 are the most likely targets for the 10-50 MW coal diesel plants (see shaded region in Table III-4). These two categories total 25,400 MW for this ten-year period. (It should be noted that utilities include stationary diesels in the "Combustion Turbine" category in the EIA and NERC database.) If the coal diesel earned even $10 \%$ market share of ais size plants over this ten-year period, this would amount to $2540 \mathrm{MW}$ or about 425 engines (over 40 engines per year), assuming $6 \mathrm{MW}$ engine size.

For several reasnns, utilities are showing interest in modular capacity expansion. There is an increasing probiem in finding suitable sites for large central power plants near urban areas, and the capital requirement for each of these large plants is also a problem. Earlier expectations that nuclear plants would grow to relieve this shortfall are now less certain. Modular plants are easier to find sites for, can be put on-line with relatively short lead time, can follow load swings more efficiently, have a lower first cost per $\mathrm{kW}$ installed, and, in the case of large diesels, offer efficiencies of $40-45 \%$ vs. $34-37 \%$ for modern coal steam electric. Proven availability is $90 \%$ for large stationary reciprocating engine generator sets.

\section{REGIONS OF GREATEST POTENTIAL}

Ten specific regions where IPP capacity additions expected to be greatest are listed in Table III-5. The coal diesel plant is considered to be particularly appropriate to compet: for future IPP sites because of the 5-50 MW size range and because of the flexibility exercised in plant design and fuel choice. Note that these ten regions are projected to account for 25,400 MW in new IPP capacity by 1997 . Also, another $9164 \mathrm{MW}$ in utility-owned new gas-fired and oil-fireci units is forecast for these regions. Assuming these trends persist into the 2000-2010 period, some of these utilities may elect coal diesel (for smaller sub-50 MW plants) when the price of oil and gas increases. The ten regions shown in Table III-5 are the prime target market opportunities for modular power in the 10-200 MW range. Four of these regions in Table III-5 marked ("high") are judged particularly suitable for clean coal modular power (such as the coal diesel design).

These four regions are as follows:

- PA, NJ, MD ("MAAC")

- VA, NC, SC ("SERC-VAC")

- $\mathrm{OH}, \mathrm{WV}, \mathrm{MI}, \mathrm{IN}, \mathrm{KY}$ ("ECAR")

- FL ("SERC-FL") 
Table III-5

REGIONS WITH CAPACITY ADDITIONS AND THEIR POTENTIAL FOR CWS DIESEL PLANTS

\begin{tabular}{|c|c|c|c|c|c|}
\hline \multirow[b]{2}{*}{ Region } & \multirow[b]{2}{*}{ States } & \multicolumn{2}{|c|}{$\begin{array}{l}\text { Forecasted Capacity Additions* } \\
\text { 1988-1997 }\end{array}$} & \multirow{2}{*}{$\begin{array}{c}\text { Some } \\
\text { Cundidate CWS } \\
\text { Metro Areas }\end{array}$} & \multirow{2}{*}{$\begin{array}{c}\text { Potential for } 500 \mathrm{MW} \\
\text { CWS Diesel } \\
\text { Capacity }\end{array}$} \\
\hline & & $\begin{array}{l}\text { IPP } \\
(\mathrm{MW})\end{array}$ & $\begin{array}{c}\text { Utility Gas } \\
\text { and Oil (MW) }\end{array}$ & & \\
\hline WSCC/CNV & California & 11,099 & 960 & - & Low \\
\hline MACC & $\begin{array}{l}\text { Pennsylvania, NJ, } \\
\text { Maryland }\end{array}$ & 3,513 & 2,302 & Pitusburgh, Philadelphia, Baltimore & High \\
\hline SERCVAC & $\begin{array}{l}\text { Virginia, } \\
\text { Carolinas }\end{array}$ & 3,508 & 704 & $\begin{array}{l}\text { DC, Richmond, } \\
\text { Raleigh-Dutham }\end{array}$ & High \\
\hline NPCCANY & NY & 2,459 & 238 & New York & Medium \\
\hline ECAR & $\begin{array}{l}\text { Ohio, WY, } \\
\text { Indima, } \\
\text { Kentucky, Michigen }\end{array}$ & 1,510 & 1,035 & Indimapolis, Detrait, Columbus & High \\
\hline $\begin{array}{l}\text { NPCCl } \\
\text { NE POOL }\end{array}$ & New England & 1,452 & 117 & $\begin{array}{l}\text { New Haven, Portland, Providence, } \\
\text { Boston }\end{array}$ & Medium \\
\hline SERC/FL & Florida & 902 & 3,000 & Miami, Tampa, Jacksonville & High \\
\hline SPP/WC & Oklahoma & 500 & 410 & Tulea & Low \\
\hline WSCC/RMP & Colorado & 466 & 108 & Denver & Low \\
\hline \multirow[t]{2}{*}{ SERC/SOU } & $\begin{array}{l}\text { Southem } \\
\text { (GA, AL, MS) }\end{array}$ & - & 290 & Allents & Medium \\
\hline & TOTALS & 25,409 & 9,164 & & \\
\hline
\end{tabular}

*Source: NERC, July 1989.

In these regions, there is not only a higher projected demand for new installations of modular power, but also a higher fuel price advantage for coal vis-a-vis natural gas. Also, each of these four regions offer several suitable barge terminals for coal delivery. These are also the regions where the actual electricity growth has exceeded utility forecasts by the greatest margins, as shown in Table III-6. What this means is that the utilities in these regions do not have new large central power stations being built to meet their demand growth, and they are most likely to turn instead to IPPs and modular power. These regions are shown on a U.S. map in Figure III-1, with the cross hatched areas representing significant potential for IPPs and modular power.

Note that the regions of greatest potential for the coal diesel essentially form a band about 800 miles wide down the Eastern U.S. If borne out by future trends, this would have a significant impact on the coal diesel commercialization plan and selection of source coals.

It should also be noted that environmental control considerations which evolve in each metropolitan area by 1995-2015 will play an important part in determining suitable regional markets for the coal diesel. That is, fuel choices for modular plants may be driven as much or more by local environmental considerations (and emission control costs) as by fuel cost (once coal slurry is in the competitive range). 


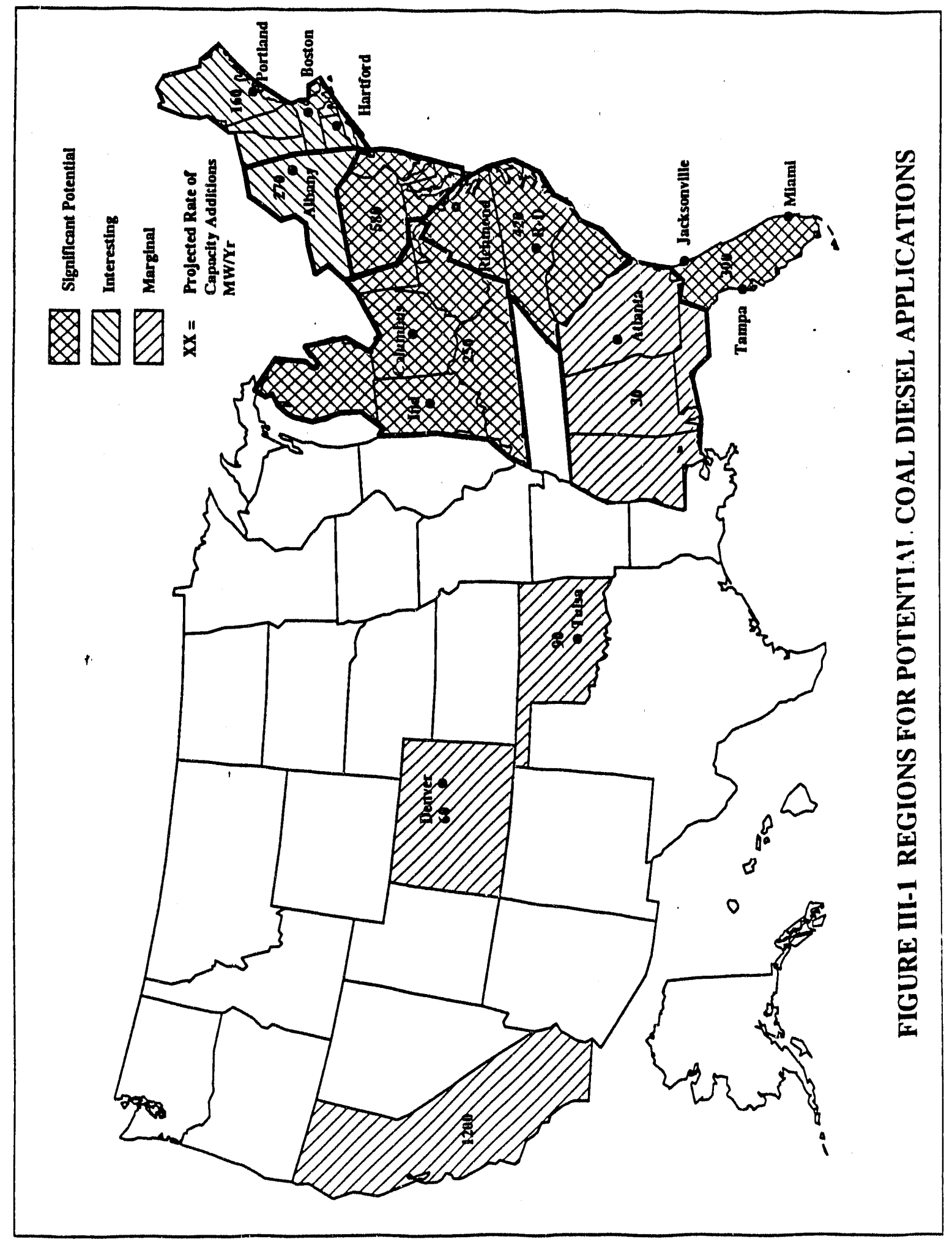


Table III-6

ACTUAL VS. FORECAST KWH DEMAND GROWTH (1983-1987)

\begin{tabular}{lccl}
\hline Region & $\begin{array}{c}\text { Forecast } \\
(\% / \mathrm{rr})\end{array}$ & $\begin{array}{c}\text { Actual } \\
(\% / \mathrm{Yr})\end{array}$ & \multicolumn{1}{c}{ Remarks } \\
\hline New England & 3.0 & 4.2 & Actively adding capacity \\
New York & 0.6 & 2.8 & Some problems \\
Mid-Atlantic & 1.2 & 3.8 & Actively adding capacity \\
Virginia-Carolina & 3.2 & 5.2 & $\begin{array}{l}\text { Actively adding capacity; competitive } \\
\text { bidding }\end{array}$ \\
Southern & 1.8 & 5.2 & Excess capacity \\
Florida & 2.9 & 5.7 & Adding cogen capacity \\
\hline
\end{tabular}

Source: EIA, 1988.

\section{E. MARKET SHARE FOR COAL DIESEL SYSTEMS - OTHER COMPETING TECHNOLOGIES}

The market share for coal diesels in the initial market period can be projected based on current trends in new orders for stationary reciprocating engines vis-a-vis gas turbines. That is, coal diesels would be expected to capture the same share of new stationary engine orders as diesels do now (once coal slurry is competitive with diesel oil and gas ${ }^{1}$ ). It is clear from Table III-7 that diesels and natural-gas spark recips dominate the power market below $2,000 \mathrm{~kW}$ engine size (equivalent to plant sizes from $2 \mathrm{MW}$ up to $12 \mathrm{MW}$, assuming 6 engines maximum per plant). Also, below $15,000 \mathrm{~kW}$ (15 to $90 \mathrm{MW}$ plant size), diesels and gas recips currently take $58 \%$ of the market in North America.

When oil and gas prices rise in the U.S., diesels, because of their higher efficiency, will capture even greater market share. This can be seen from the current market trends in Western Europe, where gas and oil are more costly than in the U.S. (see Table III-8). Here, diesels command 60\% of new engine orders below $15,000 \mathrm{~kW}$ engine size (15 to $90 \mathrm{MW}$ plant size).

The data shown in Tables III-7 and III-8 include orders for $3501 / 5000 \mathrm{~kW}$ gas turbines for compression and pumping (including offshore platform) for the oil and gas industry. Such applications are presumably outside the intended future market for coal diesel. Excluding these orders, the current market share of diesel engines for stationary power (under $15 \mathrm{MW}$ ) is even greater, approximately $75 \%$ in North America and Europe.

1 Our estimates of the cost-of-electricity (C.O.E.) suggest that clean coal slurry must be delivered to the site at a cost of $\$ 1.00-1.50 / \mathrm{mm}$ Btu below gas or oil in order for the C.O.E. to be lower for the coal-fueled diesel than for a diesel with conventional fuel (depending on plant size, location, emission controls, and other factors). 
Table III-7

RECENT TRENDS IN STATIONARY ENGINES (NEW ORDERS FOR NORTH AMERICA)

(Three-Year Period, June 86-May 89)

\begin{tabular}{|c|c|c|c|c|c|c|}
\hline \multirow[b]{2}{*}{$\begin{array}{r}\text { Output } \\
\text { Range, kW }\end{array}$} & \multicolumn{3}{|c|}{ Diesel } & \multicolumn{3}{|c|}{ Gas Turbine } \\
\hline & $\begin{array}{l}\text { Number } \\
\text { of } \\
\text { Engines }\end{array}$ & $\begin{array}{l}\text { Total } \\
\text { Power }\end{array}$ & $\begin{array}{c}\% \\
\text { Continuous } \\
\text { Duty }\end{array}$ & $\begin{array}{l}\text { Number } \\
\text { of } \\
\text { Engines }\end{array}$ & $\begin{array}{l}\text { Total } \\
\text { Power }\end{array}$ & $\begin{array}{c}\% \\
\text { Continuous } \\
\text { Duty }\end{array}$ \\
\hline $1000 / 2000$ & 384 & $576 \mathrm{MW}$ & $45 \%$ & 8 & $12 \mathrm{MW}$ & $20 \%$ \\
\hline $2001 / 3500$ & 36 & $99 \mathrm{MW}$ & $75 \%$ & 65 & $179 \mathrm{MW}$ & $70 \%$ \\
\hline $3501 / 5000$ & 18 & $77 \mathrm{MW}$ & $80 \%$ & 63 & $267 \mathrm{MW}$ & $85 \%$ \\
\hline $5001 / 7500$ & 13 & $81 \mathrm{MW}$ & $85 \%$ & 8 & $50 \mathrm{MW}$ & $75 \%$ \\
\hline $7501 / 10000$ & 2 & $18 \mathrm{MW}$ & $90 \%$ & 14 & $123 \mathrm{MW}$ & $100 \%$ \\
\hline $10001 / 15000$ & 6 & $75 \mathrm{MW}$ & $100 \%$ & 3 & $38 \mathrm{MW}$ & $100 \%$ \\
\hline TOTALS & .459 & $\begin{array}{c}925 \mathrm{MW} \\
(58 \%)\end{array}$ & - & 161 & $\begin{array}{c}669 \mathrm{MW} \\
(42 \%)\end{array}$ & - \\
\hline
\end{tabular}

Source: Diesel/Gas Turbine Worldwide, October 1987, 1988, 1989.

The earliest applications of coal diesels will probably be as dual fuel (gas-CWS) stationary reciprocating engines set up for field demonstration in the 1995 to 2000 period. At these early sites, the engines will be run on CWS part of the time (for demonstration) and on natural gas the rest of the year. During this period, relative fuel prices will dictate whether the coal diesel is competitive with the large gas-diesel engines running on natural gas and diesel fuel. In this period, commercial interest will depend upon how rapidly natural gas and oil prices rise and how soon the cost of producing clean CWS as engine fuel can be reduced to the competitive range of $\$ 3.00$ to $\$ 3.50 / \mathrm{MMBtu}$.

In the longer term, once high efficiency and reliability have been demonstrated, the coal diesel may become the preferred option for small, low-emission coal-fueled power (below 50MW plant size). In addition to merely displacing oil and gas stationary recips, the coal diesel may begin to capture market share from gas turbines, depending on the commercial status of coal-fueled turbines in this size range.

Other advanced coal-power technologies will compete with the direct coal-fired diesel for these future opportunities. These include:

- Conventional steam turbine with fluid-bed coal combustor.

- Closed-cycle air turbine, indirect-fired, with fluid-bed combustor.

- Coal-fueled combined cycle gas turbine systems with pressurized combustor or gasifier, and hot-gas clean-up. 
Table III-8

WESTERN EUROPE NEW ORDERS FOR STATIONARY ENGINES

(Three-year period, June 1986 - May 1989)

\begin{tabular}{rlllll}
\hline & \multicolumn{2}{c}{ Diesels } & & \multicolumn{2}{c}{ Gas Turbines } \\
\cline { 2 - 3 } \cline { 5 - 6 }$(\mathrm{kW})$ & Number & Total Power & & Number & Total Power \\
\hline $1000 / 2000$ & 485 & $726 \mathrm{MW}$ & & 31 & $47 \mathrm{MW}$ \\
$2001 / 3500$ & 53 & $146 \mathrm{MW}$ & & 12 & $32 \mathrm{MW}$ \\
$3501 / 5000$ & 20 & $85 \mathrm{MW}$ & & 73 & $311 \mathrm{MW}$ \\
$5001 / 7500$ & 5 & $32 \mathrm{MW}$ & & 38 & $238 \mathrm{MW}$ \\
$7501 / 10000$ & 17 & $149 \mathrm{MW}$ & & 9 & $79 \mathrm{MW}$ \\
$10001 / 15000$ & 7 & $\mathbf{8 8 \mathrm { MW }}$ & & 8 & $101 \mathrm{MW}$ \\
TOTALS & 587 & $1226 \mathrm{MW}$ & & 171 & $\begin{array}{l}808 \mathrm{MW} \\
(40 \%)\end{array}$ \\
\hline
\end{tabular}

Source: Diesel/Gas Turbine Worldwide, October 1987, 1988, 1989.

- Coal conversion to methanol or other liquid and gaseous fuels (e.g., "mild-gasification") to be used in conventional diesel and turbine engines.

- Stirling engine, indirectly fired with coal combustor.

The target coal-diesel applications were selected so as to exploit the anticipated competitive advantages of the diesel vis-a-vis these emerging technologies. For example, premium coalderived fuels ("mild gasification") may be most competitive for smaller engines (below 2000 hp), for high engine RPM, for transportation applications, and for variable load-speed and for stringent emissions requirements. Coal-fueled gas turbines and steam turbines with fluid beds may be more competitive at $30 \mathrm{MW}$ engine size and up (on a large enough scale to justify the hot gas clean-up and/or pressurized gasifier technology).

An in-depth critique of all five coal power technologies is beyond the intent of this section. It suffices to say that all five deserve continued intensive R\&D efforts to prepare for furure U.S. power requirements, including R\&D on improved air pollution controls. Our assessment is that neither the steam turbine nor the two gas turbine options will be able to compete with the diesel below 10 MW unit engine size (say 20-50 MW plant size). Only the coal diesel, the mildgasification reciprocating engine, and the Stirling engine are likely to be considered below 10 MW engine size. Of these, we assert that the coal diesel is an extremely attractive medium-risk/high reward technology.

\section{F. CAPACITY-GROWTH SCENARIOS FOR MODULAR COAL DIESEL PLANTS}

If the technology can be demonstrated, the future of stationary coal diesel plants is potentially bright indeed. The robust capacity growth for diesel cogeneration, small utility, and IPP power 
for all fuels is expected to amount to approximately $900-1,200 \mathrm{MW}$ per year during the next twenty years, as illustrated in Table III-9. This kind of engine production activity will revitalize engine production, which is now a mature low-growth industry, and this is expected to occur whether or not the coal diesel technology becomes available to participate in this market. The number of 2 to $6 \mathrm{MW}$ engines produced per year for U.S. installation would grow to about 200-400 units.

Table III-9

\section{SIGNIFICANT POTENTIAL GROWTH IN RECIPROCATING ENGINE POWER PLANT CAPACITY, ALL FUELS}

\begin{tabular}{lcccc}
\hline \multicolumn{1}{c}{ Potential Additions } & $1991-1995$ & $1996-2000$ & $2001-2005$ & $2006-2010$ \\
\hline Cogeneration & $1600 \mathrm{MW}$ & $1600 \mathrm{MW}$ & $1600 \mathrm{MW}$ & $1600 \mathrm{MW}$ \\
Small Utility and IPP & $3000 \mathrm{MW}$ & $\begin{array}{r}4000 \mathrm{MW} \\
2600 \mathrm{MW}\end{array}$ & $2600 \mathrm{MW}$ \\
$\begin{array}{l}\text { Annual Added Capacity, Reciprocat- } \\
\text { ing Engines, All Fuels }\end{array}$ & $920 \mathrm{MW} / \mathrm{yr}$ & $1120 \mathrm{MW} / \mathrm{yr}$ & $820 \mathrm{MW} / \mathrm{yr}$ & $840 \mathrm{MW} / \mathrm{yr}$ \\
\hline Planned Cual Diesel Status: & $\begin{array}{c}\text { Proof of } \\
\text { Concept }\end{array}$ & $\begin{array}{c}\text { Field } \\
\text { Demonstration }\end{array}$ & Commercial & Commercial \\
\hline
\end{tabular}

${ }^{1}$ Based on Table III-3, assumes $25 \%$ of plants are converted to cogen in each five-year period.

${ }^{2}$ Assumes $20 \%$ new capacity is recip., not gas turbine.

${ }^{3}$ Sum of first two rows divided by five years.

Engine installations will be more prevalent in certain regions of the U.S. (see Section D above), where the growth in electricity demand is greatest and the available sites for large plants are dwindling. The coal diesel development effort is being planned so as to achieve a favorable position for the CWS fuel and the Cooper-Bessemer engine technology.

The development of coal diesel market share can be expected to proceed in five stages, as shown in Table III-10. 
Table III-10

SCENARIO FOR COAL DIESEL MARKET PENETRATION

\begin{tabular}{|c|c|c|c|c|c|c|}
\hline \multirow[t]{2}{*}{ Stage } & \multirow[t]{2}{*}{ Scenario } & \multirow[t]{2}{*}{$\begin{array}{l}\text { Approx. } \\
\text { Timeframe }\end{array}$} & \multicolumn{3}{|c|}{$\begin{array}{c}\text { Market Share and Annual Capacity } \\
\text { Installed, Stationary Engines } \\
\text { Below } 15 \mathrm{MW}\end{array}$} & \multirow[t]{2}{*}{$\begin{array}{l}\text { Number of Coal } \\
\text { Diesel Engines } \\
\text { Per Year }\end{array}$} \\
\hline & & & $\begin{array}{l}\text { Coal } \\
\text { Recip }\end{array}$ & $\begin{array}{c}\text { Gas/Oil } \\
\text { Recip }\end{array}$ & $\begin{array}{l}\text { Gas/Oil } \\
\text { Gas Tur- } \\
\text { bine }\end{array}$ & \\
\hline 1 & $\begin{array}{l}\text { Field demonstration as natu- } \\
\text { ral gas/CWS dual fuel } \\
\text { engine }\end{array}$ & $1995-2000$ & - & $\begin{array}{c}60 \% \\
600 \mathrm{MW}\end{array}$ & $\begin{array}{c}40 \% \\
400 \mathrm{MW}\end{array}$ & N/A \\
\hline 2 & $\begin{array}{l}\text { Coal diesel proven as com- } \\
\text { petitive, captures say } 1 / 5 \text { of } \\
\text { new orders for stationary } \\
\text { recip engines as price of gas } \\
\text { and oil begins to rise }\end{array}$ & $2000-2005$ & $\begin{array}{c}10 \% \\
100 \mathrm{MW}\end{array}$ & $\begin{array}{c}50 \% \\
500 \mathrm{MW}\end{array}$ & $\begin{array}{c}40 \% \\
400 \mathrm{MW}\end{array}$ & -20 \\
\hline 3 & $\begin{array}{l}\text { Gas and oil prices continue } \\
\text { to rise; CWS stationary die- } \\
\text { sel captures half of new } \\
\text { orders for stationary recips }\end{array}$ & $2005-2010$ & $\begin{array}{c}30 \% \\
300 \mathrm{MW}\end{array}$ & $\begin{array}{c}30 \% \\
300 \mathrm{MW}\end{array}$ & $\begin{array}{c}40 \% \\
400 \mathrm{MW}\end{array}$ & -60 \\
\hline 4 & $\begin{array}{l}\text { Gas and oil prices rise fur- } \\
\text { ther so that clean CWS is } \\
\text { now the preferred choice; } \\
\text { gas turbines below } 15 \mathrm{MW} \\
\text { lose market share because of } \\
\text { lower efficiency }\end{array}$ & $2010-2015$ & $\begin{array}{c}55 \% \\
550 \mathrm{MW}\end{array}$ & $\begin{array}{c}20 \% \\
200 \mathrm{MW}\end{array}$ & $\begin{array}{c}25 \% \\
250 \mathrm{MW}\end{array}$ & $\sim 110$ \\
\hline 5 & $\begin{array}{l}\text { CWS diesel is preferred } \\
\text { over gas turbines for CWS } \\
\text { use below } 15 \mathrm{MW}\end{array}$ & $2015-2020$ & $\begin{array}{c}75 \% \\
750 \mathrm{MW}\end{array}$ & $\begin{array}{c}10 \% \\
100 \mathrm{MW}\end{array}$ & $\begin{array}{c}15 \% \\
150 \mathrm{MW}\end{array}$ & $\sim 150$ \\
\hline
\end{tabular}

Basis $1000 \mathrm{MW}$ per year new orders for stationary engines below $15 \mathrm{MW}$ (up to $90 \mathrm{MW}$ plant size). Critical assumptions include (a) coal diesel cost of electricity demonstrated to be competitive, e.g., about $6.5 \mathrm{f} / \mathrm{kWh}$ in 1989 dollars (stage 2), (b) gas and oil prices rise $20 \%$ in stage 3 vs. stage 2 without concomitant source coal price increase, and (c) average size of CWS-engine assumed to be $4.8 \mathrm{MW}$ (16 cylinder). 


\section{COAL PROCESSING AND TRANSPORTATION}

\section{A. COAL PROCESSING ANALYSIS METHODS}

This section describes the conceptual design and costing of an AMAX coal cleaning and processing plant that will produce engine-grade coal water slurries. This conceptual plant was sized to produce 2.4 million tons of CWS per year (180 tons/hour of clean, dry coal); this amount of slurry is ample to support $500 \mathrm{MW}$ of coal-fired, diesel-engine power capacity.

In the analysis presented below, two coal cleaning plant configurations are described. One configuration will produce an ultra-low ash $(<0.5 \%)^{*}$ slurry through the use of chemical cleaning. The other will produce a low-ash slurry $(<1.5 \%)$ by physically cleaning the coal. Both these products are (porentially) engine-grade fuels. The Cooper-Bessemer single cylinder research engine has run for more than 80 hours on ultra-low ash coal-fuel. This research engine has also run for a few hor on a $1.2 \%$ ash coal-fuel, with wear rates comparable to those of runs with the ultra-low ash coal. A third engine test on a coal with almost $4 \%$ ash proved unsuccessful; high wear rates and poor combustion limited the engine run to a few minutes. While a maximum ash level for the fuel has not been definitively set, our engine tests have indicated that $1.5 \%$ ash may be a safe upper limit for the engine-grade coal fuel.

The ultra-low ash slurry is prepared by subjecting the coal to physical cleaning, chemical cleaning and fine grinding. The $1.5 \%$ ash product is produced through fine grinding and physical cleaning only. A comparison of the two cleaning processes is presented because both fuels are candidates for engine use at this time. Each has advantages and disadvantages. The $1.5 \%$ ash slurry is very attractive economically, but its long term effect on engine wear is unknown. The ultra-low ash slurry has been found to be compatible with engine use, but its projected cost is significantly higher, according to current cost analysis.

This conceptual plant consists of a number of unit operation areas (e.g. grinding, physical cleaning, chemical cleaning etc.). The capital and operating costs of each operation area were estimated independently, making it possible to evaluate the cost impact of each coal processing step separately. A process plant cost model, based on the use of automated spread sheets, was developed to facilitate cost comparisons among various plant configurations.

The configuration of the plant (i.e. the sequence and inclusion of unit operation areas) depends on the desired characteristics of the CWS being produced. Because the necessary specifications of engine-grade CWS have not yet been finalized, we have structured our design and costing of the conceptual plant to allow flexibility in the specification of the CWS product. A cost/ benefit analysis of each additional degree of CWS refinement can now be assessed.

\footnotetext{
*All references to ash content are on a dry coal basis.
} 
It should be noted that the plant design described in this chapter is quite preliminary. The basis of the plant design is the experience that AMAX R\&D has gained while operating their 20 ton per day coal cleaning pilot plant and laboratory scale coal cleaning facilities. While these small scale facilities have provided valuable data, this information has to be extrapolated to predict performance of a full scale plant. In addition, only a few source coals have been cleaned and tested with the existing facilities. Because some coals are more cleanable than others, there will be some variability in plant output and efficiency. It must be remembered that the ash and sulfur specifications listed for each plant are targets. For example, future testing may show that the ' $1.5 \%$ ash coal' can be cleaned to $1 \%$ ash with a highly cleanable feedstock. Alternatively, with a less cleanable coal, tests may show that the coal process efficiency (Btu recovery) is lower in order to meet a given ash level specification.

Research work is currently being conducted to determine the economic and technical benefits of modifying various process steps. The costs presented in this chapter are a useful starting point for review and comparative purposes. These cost estimates can be expected to change as our understanding of the coal preparation process and the coal-engine requirements is improved.

\section{B. CWS SPECIFICATIONS}

The exact specifications of engine-grade CWS characteristics is the topic of ongoing research. These specifications are being developed on the basis of trade-offs between fuel price and engine performance. We have found that small changes in some specifications (e.g.. ash content, particle size) can have large impacts on CWS cost. As would be expected, these changes may also have large impacts on engine performance (efficiency, component durability, and emissions system performance).

Some specifications are integrally linked. For instance, with physically cleaned coal the degree of ash removal achieved is tied directly to the degree the coal has been ground. The smaller the coal particle size, the more the ash that can be removed from the coal. For extremely low ash levels, some coals may have to be ground to a 10 micron top size. For ash levels of about $1.5 \%$, the coal may be ground to a 30 micron top size. With chemically cleaned coals, the particle size and the clean-coal ash content are not linked. A $0.5 \%$ ash coal could have a top particle size of 75 - 100 microns, for example. Of course, if smaller particle sizes are desired, the coal can be ground finer, say to 30 microns, but this particle size reduction would not impact the coal cleaning steps.

The specifications of the two types of slurry that are applicable to a coal fired diesel engine are shown in Table IV-1. The ultra-low ash CWS has a 74 micron top size, and contains less than $0.5 \%$ ash and $0.7 \%$ sulfur (on a dry coal basis) The higher ash CWS has an ash content of about $1.5 \%$ and a sulfur content of less than $1 \%$ (dry coal basis). The top particle size will vary with coal type, but typically the top particle size will be between 20 and 44 microns. The higher ash slurry is prepared by physical cleaning; the ultra-low ash CWS is prepared by chemical cleaning. Both slurries are assumed to contain $52 \%$ solids and enough additives to maintain stability at viscosities of roughly $200-500$ centipoise at low shear rates. 
Table IV-1

ENGINE-GRADE CWS SPECIFICATIONS

\begin{tabular}{lcc}
\hline & Ultra-Low Ash CWS & Low Ash CWS \\
\hline Coal Type & High Volatile Bituminous & High Volatile Bituminous \\
$\begin{array}{l}\text { Ash Content (wt. \%, dry coal } \\
\text { basis) }\end{array}$ & $<0.5$ & $<1.5$ \\
$\begin{array}{l}\text { Sulfur Content (wt. \%, dry } \\
\text { coal basis) }\end{array}$ & $<1.0$ & $<1.0$ \\
Top Particle Size (microns) & 74 & 30 \\
Coal Loading (wt.\%) & $52 \%$ & $52 \%$ \\
Low Shear Viscosity & $200-300 \mathrm{cp}$ & $300-500 \mathrm{cp}$ \\
Stability & Negligible settling after one \\
& week storage & $\begin{array}{c}\text { Negligible settling after one week } \\
\text { storage }\end{array}$ \\
\hline
\end{tabular}


Experience at AMAX R\&D with their 20 ton/day plant indicates that the ultra-low ash CWS can be manufactured out of a wide range of bituminous coals. The higher ash slurry can be produced by a variety of coals, but some coal seams will not clean to as low an ash content as others. Typical CWS characteristics that AMAX R\&D has produced using their pilot plant are shown in Table IV-2.

\section{PLANT AND PROCESS DESCRIPTION}

The coal cleaning and processing plant will include up to 13 operation areas. Block diagrams of two different plant configurations are shown in Figures IV-1 and IV-2. These configurations are: 1) a fine grinding and physical cleaning plant that will produce a coal product with less than $1.5 \%$ ash and a top particle size of about 30 microns; and 2) a chemical cleaning plant that will produce a clean coal with less than $0.5 \%$ ash and a top size of 74 microns.

Figure IV-1 shows the plant in a configuration to produce clean coal with less than $1.5 \%$ ash. In this configuration, the coal is unloaded, crushed, ground (in two stages: initial and fine grinding), physically cleaned, and formulated into slurry with water and additives.

Figure IV-2 shows a plant configuration that produces an ultra-clean coal water slurry from coal with less than $0.5 \%$ ash. In this configuration, three additional steps are included: a caustic leach, an acid leach and a hot water wash. The sequence of cleaning and slurrying is as follows: the coal is unloaded, crushed and initially ground to 74 microns top size. After initial grinding, the coal is physically cleaned. The coal does not have to be finely ground before physical cleaning because the coal will be cleaned to only $2-4 \%$ ash in this step. The coal is further cleaned in three chemical cleaning steps: caustic leach, acid leach and hot water wash. After chemical cleaning, the coal is formulated into CWS, no additional grinding is necessary.

The refinement in particle size and ash content that occurs as the coal is processed through each of these steps is shown in Tables IV-3 and IV-4.

\section{DESCRIPTION OF PROCESS AREAS}

Each of the areas in the CWS processing plant are described in some detail below. More detail can be found in Reference 1. For each area, an equipment list and capital cost information is listed in Appendix A. As described above, the sequence of these areas, and the inclusion or exclusion of some areas from the conceptual plant, will depend on the desired CWS specification. Areas 500-700 are included in the ultra-low ash processing plant only.

\section{Area 100 Unloading and Storage}

The raw coal will be delivered to the cleaning plant by unit trains with bottom dump capabilities. Area 100 includes a railroad siding (where the train is stored while it is being emptied) and a thaw shed (for unloading in winter). It is assumed that the trains are owned and operated by the rail company. A car scale is on the track to verify coal shipment weights. The coal is held in storage piles until it is used in the plant. The rest of this area includes conveyers, feeders and bulldozers to move the coal. A complete equipment list and estimated equipment costs are shown in Table A1 of Appendix A. 
Table IV-2

TYPICAL CHARACTERISTICS OF TWO CWS FUELS PRODUCED BY AMAX

\begin{tabular}{lrr}
\hline Slurry Characteristics & $\begin{array}{r}\text { Ultra Low Ash } \\
(<0.5 \%)\end{array}$ & $\begin{array}{r}\text { Low-Ash } \\
(<1.5 \%)\end{array}$ \\
\hline Moisture (wt \%) & 47.2 & 47.4 \\
Coal Content (wt \%) & 52 & 52.0 \\
Additive Content (wt \%) & 0.8 & 0.6
\end{tabular}

Particle size (Microns)

Top (98\% passing) 44

Mean (50\% passing)

74

(10\% passing)

10

1

Viscosity (cp) @ 100 - $1000 \mathrm{sec}^{-1}$

200

400

Heating Value (Btu/lb, slurry basis)

7,700

7,600

Clean Coal Characteristics

Coal feedstock

Kentucky Splint Kentucky Blue Gem

Proximate analysis (wt. \% dry basis)

Ash

0.4

1.5

Volatiles

37.0

34.5

Fixed carbon

62.6

64.0

Sulfur content (wt \% dry basis)

0.7

0.5

Source: AMAX 


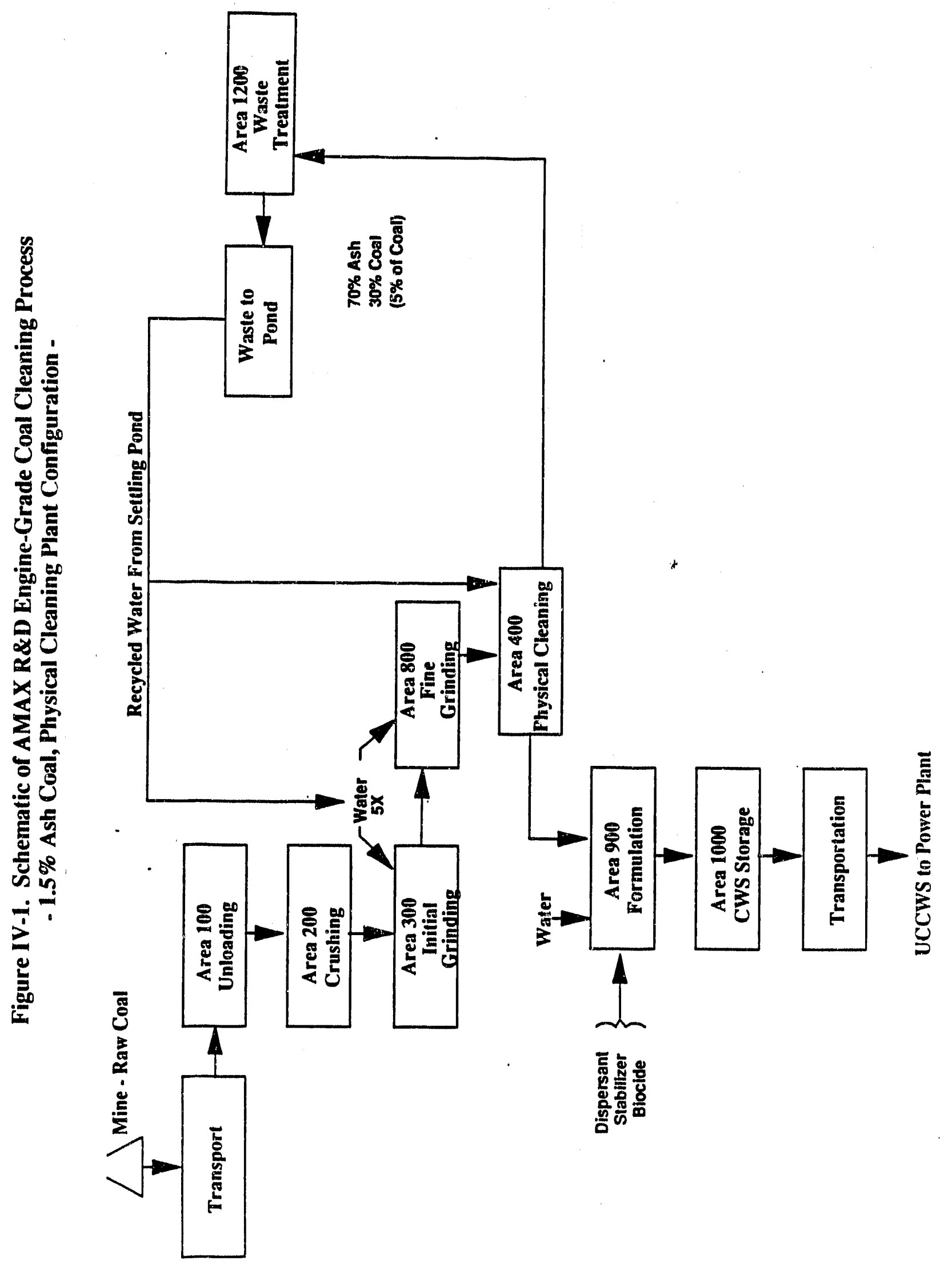




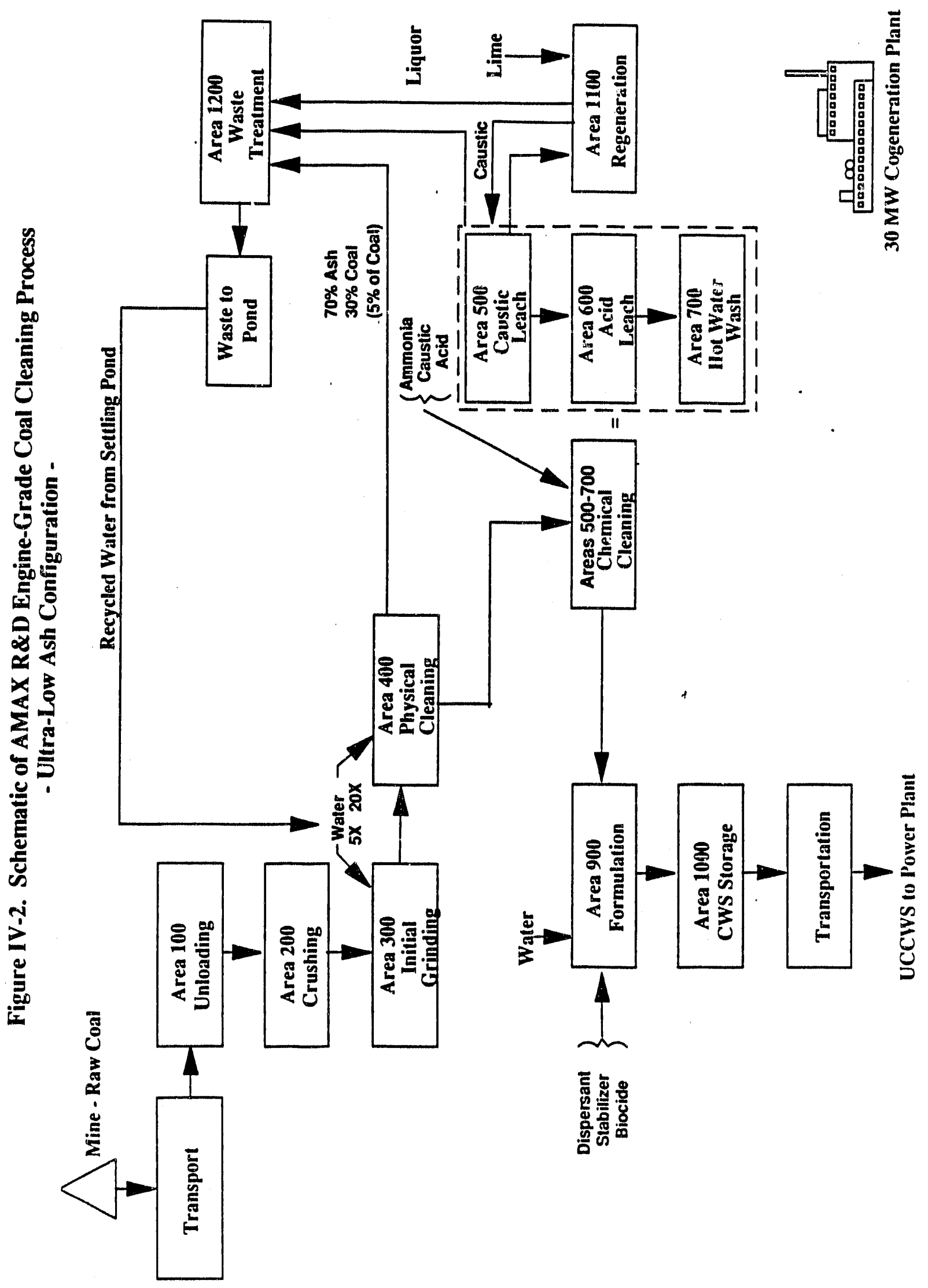


Table IV-3

PROCESS PLANT AREAS FOR $1.5 \%$ ASH CWS

\begin{tabular}{llll}
\hline Area \# & Area Description & $\begin{array}{l}\text { Typical } \\
\text { Coal Top Size }\end{array}$ & $\begin{array}{l}\text { Typical } \\
\text { Coal Ash Content }\end{array}$ \\
\hline 100 & Raw Coal Unloading and Storage & 2 inches & $10 \%$ (by wt., dry) \\
200 & Crushing & 0.25 inches & $10 \%$ \\
300 & Initial Grinding & 100 microns & $10 \%$ \\
800 & Fine Grinding & $30-70$ microns & $10 \%$ \\
400 & Physical Cleaning & no change & $1.5 \%$ \\
900 & Slurry Preparation & no change & no change \\
1000 & CWS Storage and Loading & n/a & n/a \\
1200 & Waste Treatment and Disposal & n/a & n/a \\
1300 & Utilities & n/a & n/a \\
\hline
\end{tabular}

Table IV-4

PROCESS PLANT AREAS FOR 0.5\% ASH CWS

\begin{tabular}{llll}
\hline Area \# & \multicolumn{1}{c}{ Area Description } & \multicolumn{1}{c}{$\begin{array}{c}\text { Typical } \\
\text { Coal Top Size }\end{array}$} & \multicolumn{1}{c}{$\begin{array}{c}\text { Typical } \\
\text { Coal Ash Content }\end{array}$} \\
\hline 100 & Raw Coal Unloading and Storage & 2 inches & $10 \%$ (by wt., dry) \\
200 & Crushing & 0.25 inches & $10 \%$ \\
300 & Initial Grinding & 74 microns & $10 \%$ \\
400 & Physical Cleaning & no change & $2-4 \%$ \\
$500-700$ & Chemical Cleaning & no change & $0.50 \%$ \\
900 & Slurry Preparation & no change & no change \\
1000 & CWS Storage and Loading & n/a & n/a \\
1100 & Caustic Regeneration & n/a & n/a \\
1200 & Waste Treatment and Disposal & n/a & n/a \\
1300 & Utilities & n/a & n/a \\
\hline
\end{tabular}




\section{Area 200 Crushing}

The two-inch top size coal is moved through Area 100 on a conveyer to a storage bin in Area 200 , where the coal will be crushed in a hammer mill to roughly one quarter of an inch in size (less than 6 mesh). The product coal is weighed and conveyed to a storage bin before it is ground. A complete equipment list and estimated equipment costs are shown in Table A2 of Appendix A.

\section{Area 300 Initial Grinding}

The coal is ground in this area with rod mills from a top size of six mesh to a top size of about 74 microns. The 74 micron product may contain some tramp oversize which is screened out with a 100 micron screen and fed back to the mill for regrinding. If the plant is configured for physical cleaning only (a coal product with 1.5\% ash), the coal will be ground further (in Area 800) prior to physical cleaning. In a processing plant that includes chemical cleaning, the fine grinding is not necessary. The ground coal is stored in a feed tank for feeding to physical cleaning area of the plant.

A complete equipment list and estimated equipment costs for Area 300 is shown in Table A3 of Appendix A.

\section{Area 400 Physical Cleaning}

Physical cleaning of the coal can be done either by column flotation or by heavy media separation. AMAX currently utilizes heavy media separation in their pilot plant for CWS preparation. In this process the mineral matter is separated from the coal gravimetrically; denser particles, containing higher percentages of mineral matter sink, while coal particles with less mineral matter float in the heavy media (magnetite) separator.

An alternative physical cleaning method that shows some promise is column flotation. Column flotation utilizes the coal's hydrophobic surface characteristics to separate the coal minerals from the coal maceral. Bubbles of air are introduced to a column of water (and 'other') with ground coal. Particles of coal attach themselves to the air bubbles and are carried to the top of the column. Mineral matter particles sink to the bottom of the column. This process becomes more effective as the coal is ground finer (and therefore more mineral matter is liberated from the coal matrix).

Equipment lists and estimated equipment costs for both the heavy media separation plant and the column flotation system are presented in Tables A4 and A5 of Appendix A. 


\section{Area 500 Chemical Cleaning - Caustic Leach and Filtration}

Chemical cleaning is required if the coal slurry ash specification is very low $(<1.5 \%)$ or if the ash level specified cannot be attained by physical cleaning for a particular coal. Area 500 , caustic leach and filtrating is the first step of the chemical cleaning process. Caustic leaching is done with a $4 \%$ solution of sodium hydroxide $(\mathrm{NaOH})$ for 25 minutes at $230^{\circ} \mathrm{C}$. This leaching step removes alumino-silicate materials (clays), quartz, and other metals such as iron, lead, magnesium etc that are bound to the clays. The sodium hydroxide binds strongly with the coal. Acid leaching and/or hot water washing ultimately removes the sodium precipitate from the coal.

An equipment list with estimated costs is shown in Table A6 of Appendix A.

\section{Area 600 Chemical Cleaning - Acid Leach and Filtration}

The acid leach step removes basic minerals, such as calcium or sodium compounds. It also helps remove some of the caustic that was introduced in Area 500. The acid leach is done with a 3\% solution of $\mathrm{HCl}$ for 10 minutes at $80^{\circ} \mathrm{C}$. An equipment list and estimated equipment costs for this area are shown in Table A7 of Appendix A.

\section{Area 700 Chemical Cleaning. Hot Water Wash and Filtration}

Hot water washing is conducted primarily to remove the $\mathrm{NaOH}$ and the $\mathrm{HCl}$ introduced in the caustic and acid leaching steps. The wash is conducted at $250^{\circ} \mathrm{C}$ for 30 minutes. In this step, ammonia is added to adjust the $\mathrm{pH}$ of the coal to 7.0. The coal is filtered for a final time and washed with water to remove as many of the undesirable ions as possible. An equipment list with estimated costs are shown below in Table A8 of Appendix A.

\section{Areas 800 and 200 . Fine Grinding and CWS Formulation}

If the coal is to be physically cleaned only, it is ground to about $20-44$ micron top size in a stirred ball mill in this area. The stirred ball mill has the largest power requirement of any area in the plant.

If the coal is to be chemically cleaned, fine grinding and/or CWS formulation are done together in this area. If a small particle size is desired, water, dispersant and stabilizer are added upstream of the stirred ball mill. Dispersant dosages are about $0.75 \mathrm{lbs}$ of dispersant per $100 \mathrm{lbs}$ of coal. The stabilizer is added at a rate of approximately 0.05 pounds per 100 pounds of coal. Other additives, such as a biocide and an oil antiagglomerant (to make the CWS compatible with DF-2) may also be added in this area.

If the CWS has been physically cleaned only (and has therefore been finely ground prior to cleaning), the CWS is only formulated in this area. Also, if the coal has been chemically cleaned and a top size of 74 microns is acceptable, the CWS is only formulated in this area. Tanks with agitators are used to mix the additives into the CWS.

An equipment list and equipment costs for these areas are shown in Table A9 of Appendix A. 


\section{Area 1000 - Storage and Load Out}

In this plant design, the CWS is stored in (10) one million gallon agitated tanks until it is loaded into fuel trucks for delivery to the power plant. The necessity of agitators in the holding tanks depends on the CWS formulation; if the slurry is highly stabilized, no agitators will be needed. The tank form is fitted with large load-out pumps to fill train cars for delivery to the customer. The equipment and estimated cost list is shown in Table A10.

\section{Area 1100 - Caustic Recovery and Waste Neutralization}

About one third of the total caustic feed to the caustic leach step can be recovered and recycled. $\mathrm{NaOH}$ is recovered by adding lime to the caustic filtrate which precipitates the dissolved silica and alumina and frees the $\mathrm{NaOH}$ into solution. This process is done at $70^{\circ} \mathrm{C}$.

Recovery of $\mathrm{HCl}$ from the acid leach step would not be economical. However, the waste stream from the acid leach step will be neutralized by mixing it with the caustic waste stream, making salt water. The equipment needed for these processes is shown in Table A11 of Appendix A.

\section{Area 1200 - Waste Treatment and Disposal}

All waste streams from the cleaning and processing plant are treated and disposed of in tailing ponds. These ponds will serve to settle out the solids from the waste streams. The solids settled in these ponds include the mineral matter wastes from physical cleaning and chemical cleaning steps. Cooling water and any other process water will also be disposed of in these ponds. The cost for this area is accounted for in the cost of the land purchase for the plant. The cost of land is currently estimated to be 5 to 10 percent of the cost of the buildings that house the process plant but is sensitive to geographic location and industrial proximity.

\section{Area 1300 - Utilities}

A chemical cleaning plant will include a fluidized-bed cogeneration facility that will generate steam and electricity from the high ash wastes of the physical cleaning step. This is a modular facility, completely fabricated and installed by an outside vendor (e.g.. Babcock and Wilcox). The FBC is specified to have a $30 \mathrm{MW}$ capacity and would generate enough steam for the chemical cleaning steps.

This cogeneration plant is estimated to cost $\$ 48$ million dollars and would only be economical in the case of a plant that includes chemical cleaning (and therefore has a steam requirement). A plant without a chemical cleaning steps will purchase power at local rates (assumed to be $\$ 0.04 / \mathrm{kWh}$ ) from the electricity grid. The plant will have smaller boilers for space and water heating.

Equipment lists and associated costs for this area are shown in Table A12 of Appendix A. 


\section{E. CAPITAL COST ESTIMATES}

The equipment described in the previous section and the costs listed in Appendix $A$ are, for the most part, bare equipment costs. There are additional capital costs for equipment installation, instrumentation, piping, electrical work, and paint and insulation. These additional plant costs are calculated on the basis of plant factors. These factors are taken from AMAX R\&D experience with similar plants and were cross checked with the current literature on process plant costs. These cost factors are consistent with cost factor ranges used in general chemical engineering practice for process plants (Reference 2).

'The factors used in the capital cost estimates are listed below. (Note: these cost factors are not applied to modular equipment that is delivered and installed as a package, such as the cogeneration plant.)

\begin{tabular}{lc}
\multicolumn{2}{c}{ Capital Cost Factors } \\
(Expressed in Terms of \% of Bare Equipment Cost) \\
\hline Installation & $24.8 \%$ \\
Instrumentation & $25.5 \%$ \\
Piping & $75.9 \%$ \\
Electrical & $33.5 \%$ \\
Paint and Insulation & $6.6 \%$
\end{tabular}

In addition, there are costs associated with construction of buildings, purchase of land, site development, and rail and road facilities. Buildings and land cost is related to the square footage and height of the building installed. The type of structure is assumed to be a prefabricated steel building for basic protection from the elements. Cost includes labor, materials, and supplies for construction. Costs for plumbing, heating, lighting, ventilation and other services are part of this factor. The cost as a function of purchased equipment ranges from 45 to $70 \%$ in the literature. Land cost is estimated to be 5 to $10 \%$ of fixed equipment cost.

The total of these costs plus installed equipment costs constitutes the total field cost of the plant. This subtotal capital cost is subjected to additional engineering and construction fees. These cost factors are tabulated below.

Engineering and Construction Cost Factors (Expressed in Terms of \% of Total Field Cost)

$\begin{array}{ll}\text { Engineering and Fees } & 13.8 \% \\ \text { Indirect Costs } & 18.3 \%\end{array}$

Finally, there are cost factors applied to the final construction costs. These cost factors are listed below. 


\section{Working Capital Cost Factors \\ (Expressed in Terms of \% of Total Construction Cost)}

Contingency
Working Capital

$20 \%$

$10 \%$

The work-up of the capital costs of a 2.4 million ton per year CWS processing plant are shown in Table IV-5. Two possible plant configurations to make engine grade CWS are shown: Option 1, a physically cleaned coal with a top size of 30 microns, and Option 2, a chemically cleaned CWS with a top size of 74 microns. The capital cost of the physical cleaning plant is estimated to be $\$ 135$ million. The capital cost of the chemical cleaning plant is estimated to be $\$ 287$ million. Assuming a 12-year amortization period at $10 \%$ interest (a capital cost factor of 0.15 ), these capital costs correspond to annual operating costs of $\$ 0.55 / \mathrm{mmBtu}$ and $\$ 1.18 / \mathrm{mmBtu}$, respectively.

Table IV-5

CAPITAL COSTS FOR CWS PROCESSING PLANT

(Costs in $\$ 1,000$ )

\begin{tabular}{|c|c|c|c|c|}
\hline \multirow[b]{3}{*}{ Capital Cost Item } & \multicolumn{4}{|c|}{$\begin{array}{c}\text { CWS Specification Option } \\
\text { (\% ash in coal and top particle size, microns) }\end{array}$} \\
\hline & \multicolumn{2}{|c|}{ Option 1} & \multicolumn{2}{|c|}{ Option 2} \\
\hline & $1.5 \%$ ash, & & $0.5 \%$ as & um \\
\hline $\begin{array}{l}\text { Delivered Equipment Cost } \\
\text { (by Area) }\end{array}$ & $\begin{array}{l}\text { Costs in Th } \\
(\$ 1,0\end{array}$ & ands & $\begin{array}{r}\text { Costs in } \mathrm{T} \\
(\$ 1,\end{array}$ & ands \\
\hline $\begin{array}{l}\text { Unloading and Storage } \\
\text { Crushing } \\
\text { Initial grinding } \\
\text { Physical Cleaning } \\
\text { Chemical Cleaning } \\
\text { Caustic Leach } \\
\text { Acid Leach } \\
\text { Hot Water Wash } \\
\text { Fine Grinding } \\
\text { CWS Preparation } \\
\text { Storage and Load Out } \\
\text { Caustic Regeneration } \\
\text { Waste Treatment } \\
\text { Utilities } \\
\text { A. Subtotal Equipment Cost } \\
\text { B. Installation Costs } \\
\text { C. Building, Land, Rail and Roads } \\
\text { D. Subtotal Field Costs (A+B+C+D) } \\
\text { E. Engineering, Fees and Indirect } \\
\text { F. Subtotal Construction Cost } \\
\text { G. Contingency } \\
\text { H. Total Capital Costs } \\
\text { I. Working Capital } \\
\text { J. Final Total Capital Costs }\end{array}$ & $\begin{array}{r}\$ 1,333 \\
\$ 389 \\
\$ 2,019 \\
\$ 1,325 \\
\$ 0 \\
\$ 0 \\
\$ 0 \\
\$ 9062 \\
\$ 358 \\
\$ 3,644 \\
\$ 0 \\
\$ 704 \\
\$ 1,641 \\
\$ 39,781 \\
\$ 13,594 \\
\$ 24,812 \\
\$ 20,421 \\
\$ 12,253\end{array}$ & $\begin{array}{r}\$ 23,921 \\
\$ 77,296 \\
\$ 102,108 \\
\$ 122,529 \\
\$ 134,782\end{array}$ & $\begin{array}{r}\$ 1,333 \\
\$ 389 \\
\$ 2,019 \\
\$ 1,325 \\
\\
\$ 11,242 \\
\$ 6,322 \\
\$ 8,312 \\
\$ 0 \\
\$ 358 \\
\$ 3,644 \\
\$ 2,917 \\
\$ 704 \\
\$ 48,335 \\
\$ 64,132 \\
\$ 13,594 \\
\$ 52,845 \\
\$ 43,494 \\
\$ 26,096\end{array}$ & $\begin{array}{r}\$ 86,899 \\
\$ 164,625 \\
\$ 217,470 \\
\$ 260,964 \\
\$ 287,060\end{array}$ \\
\hline
\end{tabular}




\section{F. OPERATING COST ESTIMATES}

Operating costs of the coal cleaning and processing plant include labor, power, chemical reagents, and maintenance materials. (Raw coal costs and coal transportation are not included in the plant operating costs. Coal and transportation costs are detailed in the next section.) For either the highly or less refined CWS, the cost of reagents dominates the operating costs. These chemical reagents are used in slurry formulation and coal cleaning. In this section the costs associated with each operating cost component are discussed in turn. The processing and operating cost factors used to calculate plant operating costs are shown in Table IV-6.

Table IV -6

Processing and Operating Cost Factors for CWS Plant

\begin{tabular}{|c|c|}
\hline Processing Factors & Operating Cost Factors \\
\hline $75 \%$ = Coal recovery factor (dry basis) & $0.35=\$ /$ (ton of dry coal) for rod mill maintenance \\
\hline \multirow[t]{4}{*}{$52 \%=$ Coal loading } & $\begin{array}{c}1.90=\$ /(\text { Ton of Dry Coal) for stirred ball mill mainte- } \\
\text { nance }\end{array}$ \\
\hline & $0.03=$ Capital multiplier for maintenance other than mills \\
\hline & $2080=\mathrm{Hr}$ of work/yr @standard wages \\
\hline & $0.04=\$ / k W h$ electricity purchased \\
\hline
\end{tabular}

Labor

Table IV-7 summarizes the estimated labor requirements for the conceptual coal cleaning and processing plant. The total labor cost for a physical cleaning plant producing a 'less refined' CWS product amounts to $\$ 0.09 / \mathrm{MMBtu}$ of CWS produced at the plant. For a chemical cleaning plant with fine grinding, this labor cost increases to $\$ 0.15 / \mathrm{MMBtu}$. In general, labor costs are roughly $10 \%$ of the plant operating costs.

\section{Power}

Power usage and costs are summarized in Table IV-8. The plant area that uses the most power is fine grinding. In a physical cleaning plant, fine grinding constitutes $80 \%$ of the electrical energy usage of the plant. In a chemical cleaning plant, significant electricity users are the caustic leach area (22\% of $\mathrm{kWhrs}$ used) and initial grinding (22\% of $\mathrm{kWhrs}$ used).

In the case of the chemical cleaning plant there is also a large steam requirement. It is therefore assumed that an on site cogeneration facility will produce the power and steam required for the plant. This cogeneration plant is designed to be a $30 \mathrm{MW}$ fluidized bed boiler that burns coal refuse from the physical cleaning step. Total costs to run this cogeneration plant are estimated to be $\$ 0.06 / \mathrm{MMBtu}$ of CWS produced (excluding labor, accounted for with the other labor costs). This cost does not include the amortized capital cost of the cogeneration facility. 


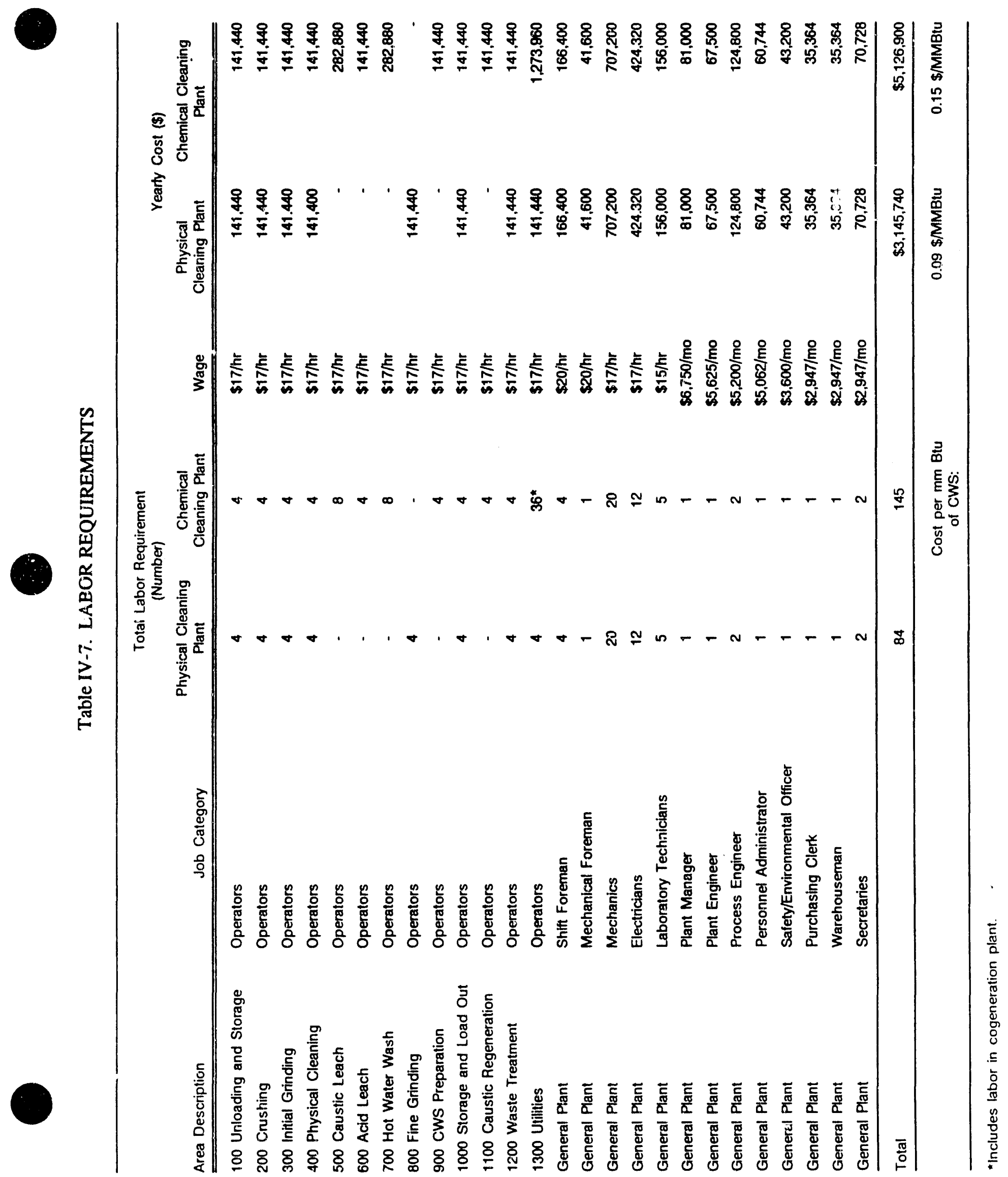




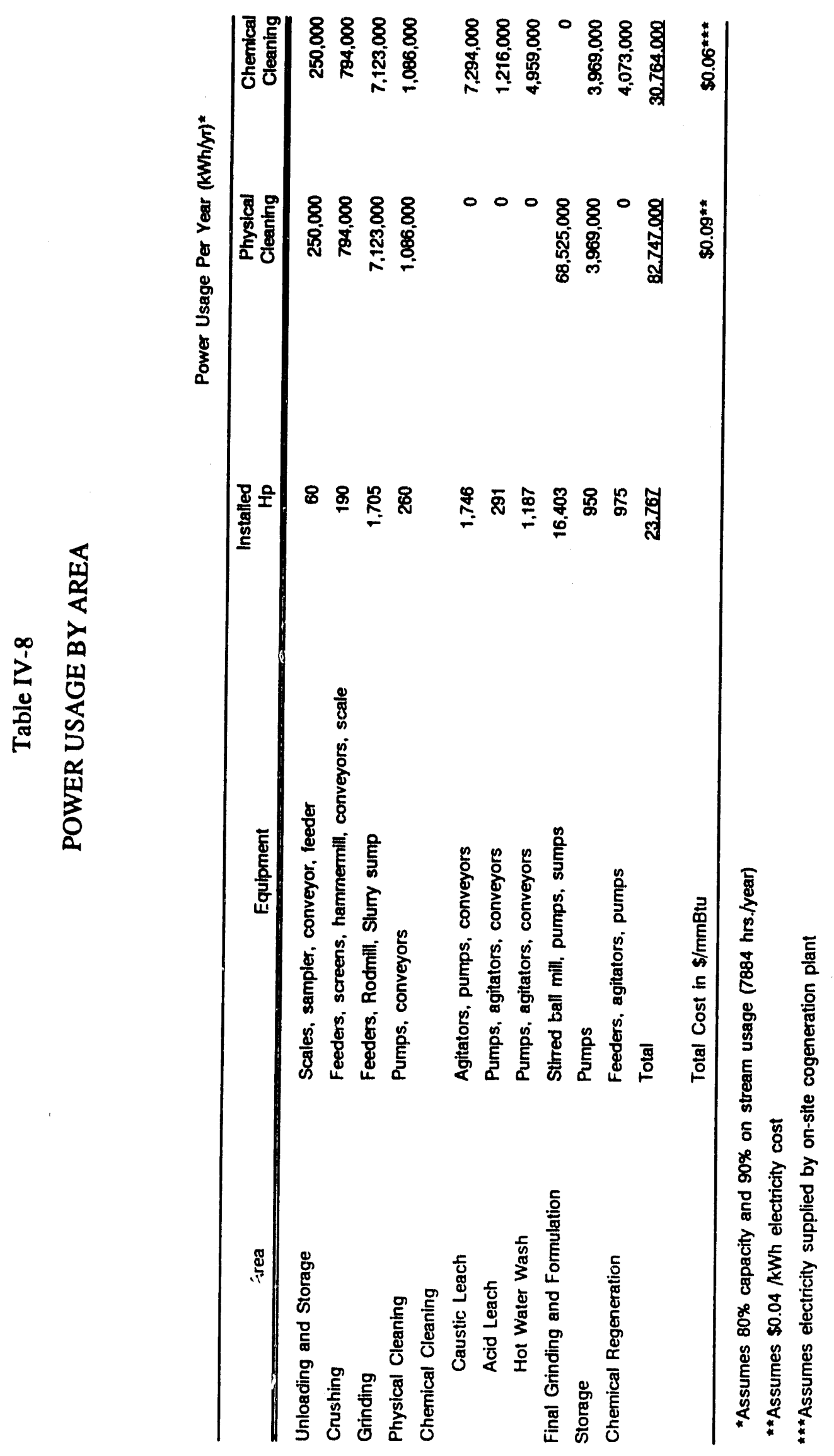


Power usage for the physical cleaning plant is more than for the chemical cleaning plant. Total electrical energy used in the physical cleaning plant is estimated to be about 80 million $\mathrm{kWhrs} /$ year. 'This energy usage corresponds to a cost of $\$ 0.09 / \mathrm{MMBtu}$ of CWS produced. It is assumed that the electricity for this plant is purchased from the local grid, given the reduced steam usage as cor vared to the chemical cleaning plant.

\section{Chemical Reagents}

The costs of additives used to formulate the slurries are projected to cost $\$ 0.41 / \mathrm{MMBtu}$ of CWS produced. This cost is independent of the degree of cleaning of the coal. The additive usage will vary slightly with coal grind.

The cost of reagents for the chemical cleaning steps are $\$ 1.08 / \mathrm{MMBtu}$. This includes caustic (assuming 30\% is recycled), acid (assuming no recycle) ammonia (to balance the $\mathrm{pH}$ ), lime and modifier for the caustic recovery. The cost of reagents for the physical cleaning plant are projected to be $\$ 0.02 / \mathrm{mmBtu}$. This cost includes frother and collector for the flotation column. A tabulation of the amounts and costs of chemicals used in the slurry plant are shown in Table IV-9.

\section{Maintenance}

Maintenance costs are estimated to be 3\% of the capital cost of the plant plus the cost of mill liners and media for the grinding mills. For the finely ground coal, mill maintenance is projected to cost $\$ 0.08 / \mathrm{MMBtu}$. For coal with a 74 micron top size, the mill maintenance is projected to cost \$0.01/MMBtu.

\section{Other}

Additional operating costs are $\$ 0.01 / \mathrm{MMBtu}$ for process and cooling water.

\section{Total Operating Costs}

A tabulation of the operating costs for the two CWS plant configurations is shown in Table IV-10. It can be seen that the cost of operating a chemical cleaning plant (@ \$1.93/MMBtu), even without fine grinding, is twice that of a physical cleaning plant(@ \$0.81/MMBtu). The added cost for the chemical cleaning plant is primarily in the cost of the reagents required for the caustic and acid leach steps of the cleaning process. For both plants, the cost breakdown is roughly: $10 \%$ labor; $5-10 \%$ utilities; $50-70 \%$ reagents and chemicals; and $10-20 \%$ maintenance. 
Table IV-9

CHEMICAL REAGENT/ADDITIVE COSTS

\begin{tabular}{|c|c|c|c|}
\hline & $\begin{array}{l}\text { Unit } \\
\text { Cost }\end{array}$ & $\begin{array}{r}\text { Physical } \\
\text { Cleaning } \\
\text { Plant }\end{array}$ & $\begin{array}{r}\text { Chemical } \\
\text { Cleaning } \\
\text { Plant }\end{array}$ \\
\hline Cleaning_Reagents & & S/mm_Btu CWS & S/mm Btu CWS \\
\hline Collector & $\$ 0.10 / 1 b$ & $<0.01$ & -- \\
\hline Frother & $\$ 0.50 / 1 b$ & 0.02 & -- \\
\hline Caustic & $\$ 285 /$ ton & -- & 0.56 \\
\hline Acid & $\$ 155 /$ ton & -- & 0.43 \\
\hline Ammonia & $\$ 210 /$ ton & -- & 0.06 \\
\hline Lime & $\$ 40 /$ ton & -- & 0.02 \\
\hline Modifier & $\$ 90 /$ ton & -- & 0.01 \\
\hline Subtotal & & $\$ 0.02$ & $\$ 1.08$ \\
\hline \multicolumn{4}{|l|}{ CWS Additives } \\
\hline Dispersant & $\$ 0.557 / \mathrm{lb}$ & 0.30 & 0.30 \\
\hline Stabilizer & $\$ 3.25 / 1 \mathrm{~b}$ & 0.09 & 0.09 \\
\hline Formaldehyde & $\$ 0.25 / 1 \mathrm{~b}$ & 0.02 & 0.02 \\
\hline Subtotal & & $\$ 0.41$ & $\$ 0.41$ \\
\hline Total & & $\$ 0.43$ & $\$ 1.49$ \\
\hline
\end{tabular}


Table IV-10

OPERATING COST SUMMARY FOR CWS PLANT

\begin{tabular}{|c|c|c|c|}
\hline \multicolumn{2}{|c|}{ Item } & $\begin{array}{r}\text { Physical } \\
\text { Cleaning } \\
\text { Plant } \\
\text { \$/MM Btu } \\
(\mathrm{HHV})\end{array}$ & $\begin{array}{r}\text { Chemical } \\
\text { Cleaning } \\
\text { Plant } \\
\$ / \text { MM Btu } \\
(\mathrm{HHV})\end{array}$ \\
\hline \multicolumn{4}{|l|}{ Labor } \\
\hline \multicolumn{2}{|c|}{ Operation \& Supervision, $17 \& 20 \$ / \mathrm{HR}$} & 0.04 & 0.06 \\
\hline \multicolumn{2}{|c|}{ Maintenance \& Supervision, $17 \& 20$ \$/HR } & 0.04 & 0.04 \\
\hline \multicolumn{2}{|l|}{ Analytical } & $<0.01$ & $<0.01$ \\
\hline \multicolumn{2}{|l|}{ Other Assignable Labor } & 0.01 & 0.01 \\
\hline \multicolumn{2}{|c|}{ Cogeneration Plant Labor, $17 \& 20$ \$/HR } & $=$ & 0.03 \\
\hline \multicolumn{2}{|l|}{ Subtotal } & 0.09 & 0.14 \\
\hline \multicolumn{4}{|l|}{ Utilities } \\
\hline \multicolumn{2}{|l|}{ Electricity and Steam } & $0.09^{*}$ & $0.06 * *$ \\
\hline \multicolumn{2}{|c|}{ Process and Cooling Water, $0.25 \$ / 1,000 \mathrm{gal}$} & 0.01 & 0.01 \\
\hline \multicolumn{2}{|l|}{ Subtotal } & Reagents & 0.07 \\
\hline Caustic & $285 \$ /$ ton & -- & 0.56 \\
\hline Acid & $155 \$ /$ ton & -- & 0.43 \\
\hline Ammonia & $210 \$ /$ ton & -- & 0.06 \\
\hline Dispersant & $0.557 \$ / 1 b$ & 0.30 & 0.30 \\
\hline Stabilize & $3.25 \$ / 1 b$ & 0.09 & 0.09 \\
\hline Formaldehyde & $0.25 \$ / \mathrm{lb}$ & 0.02 & 0.02 \\
\hline Lime & $40 \$ /$ ton & -- & 0.02 \\
\hline Modifier & $90 \$ /$ ton & -- & 0.01 \\
\hline Collector & $0.10 \$ / \mathrm{lb}$ & $<0.01$ & -- \\
\hline Frother & $0.50 \$ / 1 \mathrm{~b}$ & 0.02 & $\ldots$ \\
\hline Subtotal & & 0.43 & 1.49 \\
\hline \multicolumn{4}{|l|}{ Maintenance Materials } \\
\hline \multicolumn{2}{|l|}{ Mill Liners and Media } & 0.08 & 0.01 \\
\hline \multicolumn{2}{|c|}{$\begin{array}{l}\text { General Maintenance } 3 \% \text { of Capital } \\
\text { (excluding grinding equip.) }\end{array}$} & 0.11 & 0.22 \\
\hline \multicolumn{2}{|l|}{ Subtotal } & 0.19 & .23 \\
\hline \multicolumn{2}{|l|}{ Total Operating Cost } & $\$ 0.81$ & $\$ 1.93$ \\
\hline
\end{tabular}

* Power purchased from main grid.

** Power and steam generated in cogeneration plant. 


\section{G. FEEDSTOCK AND TRANSPORTATION}

\section{Feedstocks}

Table IV-11 lists a number of coal feedstocks that were used in the CWS costing estimates. The coals listed in this table fall under one of two sets of selection criteria. The first set of criteria is that the coals be highly cleanable so that it would be feasible to physically clean these coals to $1.5 \%$ ash and less than $1 \%$ sulfur. Two coals listed fall into this category: The Kentucky Blue Gem and the Kentucky Elkhorn. These coals have large mineral matter inclusions which are relatively easy to separate from the coal material. They also have low organic sulfur content. Appendix D gives detailed analyses of Elkhom, Splint, and Hazard coals, before and after cleaning.

The second set of selection criteria is that the coals be inexpensive and local to the slurry plant (and the coal diesel engine plants). For the conceptual plant analysis, 6 - 8 cites were selected as hypothetical plant locations: Boston, Pittsburgh, Atlanta, Chicago, Phoenix and Salt Lake City.

Coals were selected on the basis of cost and close proximity to these locations. These coals may be inexpensive at minemouth but they must undergo more extensive cleaning to be processed into engine grade slurry. All these coals have low organic sulfur contents.

\section{Transportation}

Estimated shipping costs between coal seam location and slurry plant location are shown in Table IV-12. Costs are based on quotations obtained by AMAX from railroads and barges assuming large shipping orders and long-term contracts.

\section{H. CWS COST SUMMARY}

Table IV-13 summarizes the capital, operating and process cost assumptions used to calculate CWS cleaning and slurrying costs. All of these factors and/or assumptions have been described previously in this section; they are listed here again in summary form for convenience. A summary of CWS production costs are presented in Tables IV-14 and IV-15. These tables include annualized capital costs (based on a 10\% cost of capital and 12-year recovery term), operation and maintenance costs, coal costs and transportation costs for two different CWS plant scenarios. The first scenario (Table IV-14) is a physical cleaning plant in Pittsburgh utilizing Kentucky Blue Gem coal. The second scenario (Table IV-15) is a chemical cleaning plant in Chicago utilizing Illinois \#5 coal. These cost summaries are examples. Costs will vary with location, coal source, CWS specification, etc.

The summary tables show that the physically cleaned, finely ground coal slurry is expected to cost $\$ 2.98 / \mathrm{MMBtu}$ (including coal, transportation, O\&M, and capital costs). The chemically cleaned coal is expected to cost $\$ 4.73 / \mathrm{MMBtu}$. 


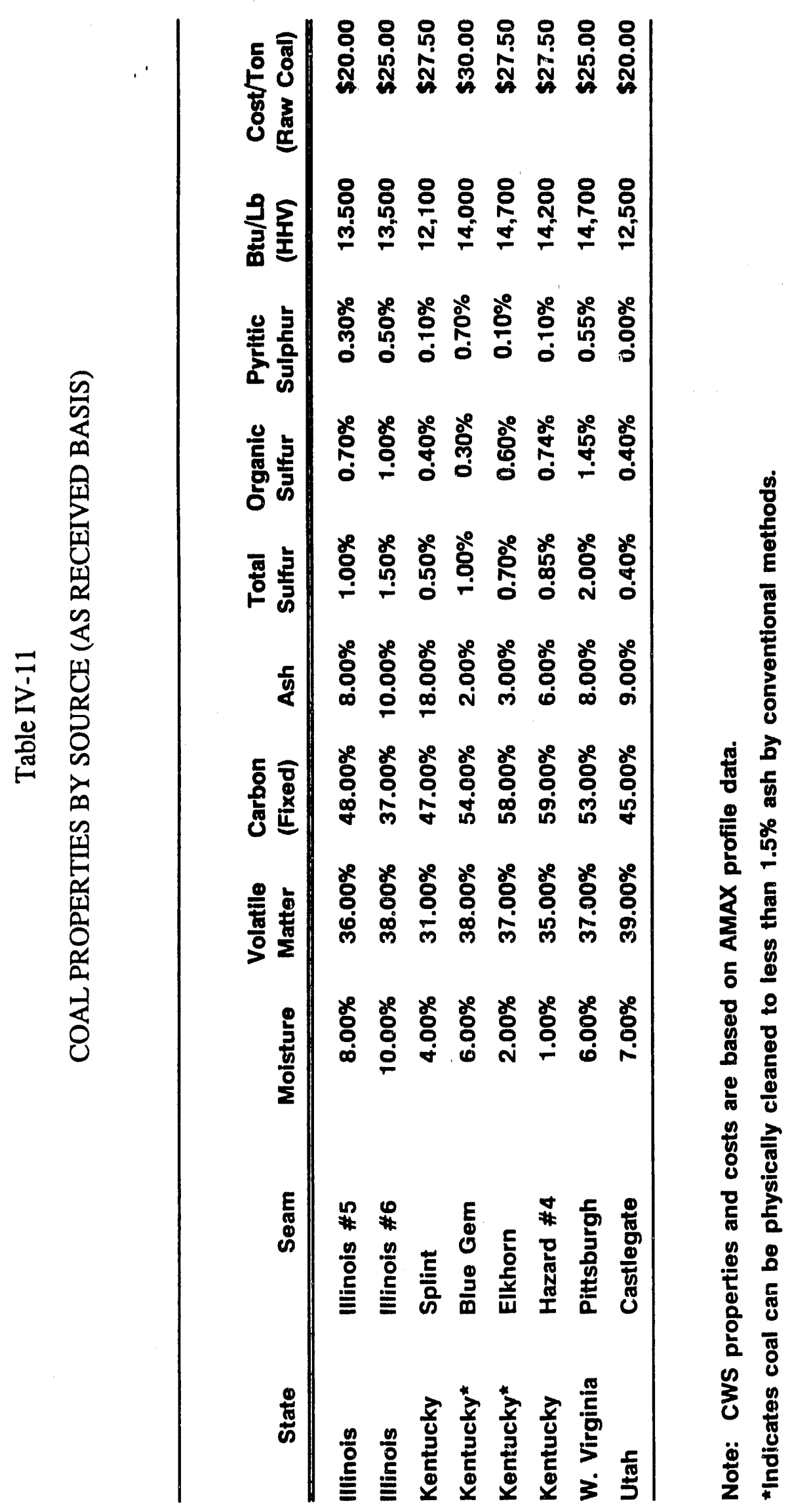


Table IV-12

COAL TRANSPORTATION COST ESTIMATES

\begin{tabular}{llll}
\hline \multicolumn{1}{c}{$\begin{array}{c}\text { Market Area/ } \\
\text { Coal Source }\end{array}$} & Coal & \multicolumn{1}{c}{ \$/ton Coal } & $\begin{array}{c}\text { (MMBtu } \\
\text { (AMA) }\end{array}$ \\
\hline Pittsburgh/Knox Kentucky & Blue Gem & $\$ 4 /$ ton via barge & $\$ 0.15$ \\
Pittsburgh/Perry Kentucky & Hazard & $\$ 3 /$ ton via barge & $\$ 0.11$ \\
Pittsburgh/Marshal W. VA. & Pittsburgh & $\$ 2 /$ ton via barge & $\$ 0.77$ \\
Boston/Knox Kentucky & Blue Gem & $\$ 28 /$ ton via rail & $\$ 1.04$ \\
Boston/Hazard Kentucky & Hazard \#4 & $\$ 24 /$ ton via rail & $\$ 0.89$ \\
Boston/Marshall W. VA. & Pittsburgh & $\$ 17 /$ ton via rail & $\$ 0.63$ \\
Atlanta/Knox Kentucky & Blue Gem & $\$ 7 /$ ton via rail & $\$ 0.26$ \\
Atlanta/Hazard Kentucky & Hazard \#4 & $\$ 8 /$ ton via rail & $\$ 0.30$ \\
Atlanta/Marshal W. VA. & Pittsburgh & $\$ 16 /$ ton via rail & $\$ 0.59$ \\
Chicago/Knox Kentucky & Blue Gem & $\$ 10 /$ ton via rail & $\$ 0.37$ \\
Chicago/Hazard Kentucky & Hazard \#4 & $\$ 11 /$ ton via rail & $\$ 0.41$ \\
Chicago/Marshal W. VA. & Pittsburgh & $\$ 10 /$ ton via rail & $\$ 0.37$ \\
Chicago/Sullivan Illinois & Illinois \#6 & $\$ 7 /$ ton via rail & $\$ 0.26$ \\
Salt Lake/Knox Kentucky & Illinois \#5 & $\$ 23 /$ ton via rail & $\$ 0.85$ \\
Salt Lake/Carbon Utah & Castlegate & $\$ 3 /$ ton via rail & $\$ 0.11$ \\
Phoenix/Knox Kentucky & Illinois \#5 & $\$ 28 /$ ton via rail & $\$ 1.04$ \\
Phoenix/Carbon Utah & Castlegate & $\$ 4 /$ ton via rail & $\$ 0.15$ \\
\hline
\end{tabular}


Table IV-13

\section{COSTING ASSUMPTIONS}

General $=7884 \mathrm{hr} / \mathrm{yr}$ equipment operation

Capital Cost Factors:

$24.8 \%=$ Capital Installation Factor

$25.5 \%=$ Capital Instrumentation Factor

75.9\% $=$ Capital Piping Factor

$33.5 \%=$ Capital Electrical Factor

$6.6 \%=$ Paint and Insulation Factor

$13.8 \%=$ Capital Engineering and Fees Factor

$18.3 \%=$ Capital Indirect Cost Factor

$20.0 \%=$ Capital Contingency Factor

$10.0 \%=$ Working Capital Factor

Processing Factors:

$75 \%=$ Coal Recovery Factor (dry basis)

$52 \%=$ Coal Loading

Operating Cost Factors:

$0.35=\$ /($ Ton of Dry Coal) for Rod Mill Maintenance

$1.90=\$($ Ton of Dry Coal) for Stirred Ball Maintenance

$0.03=$ Capital Multiplier for Maintenance Other than Mills

$2080=\mathrm{Hr} / \mathrm{Yr}$ Each Employee Works

$0.04=\$ / \mathrm{kWh}$ Electricity Cost

Indirect Cost Factors:

$0.027=$ Capital Multiplier for Taxes, Insurance, Supplies and Overhead

$0.03=\$ /$ Ton General Administration and Sales Cost

$0.15=$ Capital Cost Factor 
Table IV-14

CWS PLANT COST SUMMARY - PHYSICAL CLEANING PLANT

GENERAL ASSUMPTIONS

Plant Type

Plant Location

Plant Capacity

(tons/year of clean coal)

(MMBtu/year of CWS)

Coal Type

CWS Specifications:

Top coal size (micron)

$\%$ ash (wt\%, dry basis)

$\%$ sulfur (wt\%, dry basis)

CWS by heating value (Btu/lb)
Physical cleaning/fine grinding

Pittsburgh

1.25 million

36.5 million

Kentucky Blue Gem

(High volatile bituminous)
30

1.5

1.6

7,600

\section{Item}

A. Purchased coal used in slurry

B. Unrecovered coal (25\%)

C. Freight to CWS plant

D. Operation and maintenance (labor, utilities, reagents, maintenance)

E. Indirect costs (taxes, insurance, sup- $2.7 \%$ of capital plies, G\&A)

F. Annualized capital
Cost Summary

Basis/Unit Cost

$\$ 30 /$ ton raw coal

0.15 capital cost factor;

$\$ 135$ million

TOTAL
$\$ 1.03$

0.34

0.15

0.81

0.10

$\$ / M M B t u H H V$

0.55

$\$ 2.98$ 


\section{CWS PLANT COST SUMMARY - CHEMICAL CLEANING PLANT}

\section{GENERAL ASSUMPTIONS}

Plant Type

Plant Location

Plant Capacity

(tons/year of clean coal)

(MMBtu/year of CWS)

Coal Type

CWS Specifications:

Top coal size (micron)

$\%$ ash (wt\%, dry basis)

$\%$ sulfur (wt $\%$, dry basis)

CWS by heating value (Btu/lb)
Chemical cleaning

Chicago

1.25 million

36.5 million

Illinois \#6
74

0.5

0.5

7,700

\section{Item}
A. Purchased coal used in slurry
B. Unrecovered coal (25\%)
C. Freight to CWS plant
D. Operation and maintenance (labor, utilities, reagents, maintenance)

$\$ 25 /$ ton raw coal

$\$ 0.85$

0.29

E. Indirect costs (taxes, insurance, sup- $2.7 \%$ of capital plies, G\&A)

F. Annualized capital 


\section{COST ANALYSIS UNCERTAINTIES AND R\&D DIRECTIONS}

As noted at the beginning of this chapter, the plant design and costing described in the sections above is quite preliminary. There are uncertainties due to lack of experience with a full size plant and lack of experience with a number of coal feedstocks. In addition, a number of design decisions were not based on a comprehensive review of available technology, for instance grinding method. In this section, the uncertainties in our capital and operating cost estimates are outlined.

\section{Grinding Costs}

We have assumed that a stirred ball mill will be used to finely grind the coal. There are alternative methods that have not yet been completely evaluated, such as dry grinding or fluid energy milling. If alternative methods prove to provide overall cost reductions, the design of the fine grinding area would be modified. A change of design in this area would only serve to reduce the overall grinding costs since a least cost selection would ultimately be made.

One aspect of grinding that is uncertain is the maintenance cost of the ball mills. Estimates varying from $\$ 2$ to $\$ 32 /$ ton of coal processed for media and liner replacement have been quoced by people involved with ball mill designs. (References 3,4 ) The estimates presented in this chapter are on the low end of the spectrum, at $\$ 2.00$ per ton of coal processed. An increase in the cost of mill maintenance by $500 \%$ (to $\$ 10 /$ ton processed) would increase the cost of clean CWS by $\$ 0.32 / \mathrm{mmBtu}$.

\section{Physical Cleaning}

The costs of the flotation column for physical cleaning the coal are based on AMAX R\&D experience with a 40 pound per day, laboratory scale column. The efficiency of the process (i.e. the Btu Recovery) is expected to vary widely with different coals. While the selection of appropriate coals w:ll help to ensure that the plant maintains a high efficiency, it is possible that efficiencies will, at times, drop below estimated values.

In addition to performance, the costs of a full size column are uncertain. These costs are uncertain because they are based on the scale-up of a small facility. The design will undoubtedly become more complicated, and costly, as the process develops. A $50 \%$ increase in the cost of a physical cleaning step would increase the cost of CWS by about $\$ 0.25 / \mathrm{MMBtu}$.

\section{Chemical Cleaning}

The uncertainties in the cost of chemical cleaning step primarily from scaling issues. In addition, there is some uncertainty as to whether heat recovery potential exists which may reduce steam and utility needs.

\section{Additive Package}

Custs may go down as new formulations or mixing methods are developed. Also, depending on the storage and handling facilities of the engine plants, stabilizer may or may not be needed to be added to the slurry. The elimination of the stabilizer would reduce costs by about $\$ 0.09 / \mathrm{MMBtu}$. 
One additive that is currently used in laboratory scale engine testing which is not included in CWS cost estimates is an oil-antiagglomerant. This additive is used currently because of the frequent transitions between diesel and CWS operation in the research engine. Such transitions would be infrequent during actual, full scale operation of a CWS-fired engine. The oil-antiagglomerant is also used currently because oil is used in the injector to lubricate moving parts that contact CWS. The necessity of using the oil-antiagglomerant to prevent clogging of the CWS in the engine is not certain. The cost of this additive corresponds to about \$0.39/MMBtu.

\section{Waste Disposal/Caustic Regeneration}

Uncertainties in the cost of waste disposal are due to uncertainties in the cost of land in the various target areas and uncertainties in the cost and availability of waste disposal sites, such as landfills. Some states may have more stringent regulations on solids disposal than others. We currently envision the use of a settling pond to separate solids from water. This separation is essential in order to conserve the water usage of the plant and in order to dispose of ash wastes as a solid instead of a liquid effluent. The size of these ponds has not been incorporated into the cost of the land required for the plant site. This issue needs to be clarified.

It is being assumed that $30 \%$ of the caustic used in the first chemical cleaning step can be regenerated. This number is fairly 'soft' and needs to be solidified by testing.

\section{Utilities}

The current cost estimates assume the need for a cogeneration facility for a chemical cleaning plant. Without a fine grinding step in the chemical cleaning plant, however, there is probably not enough power consumption to justify the large capital cost of a FBC cogeneration plant. Substituting the cost of a cogen plant with conventional steam boilers (and the purchase of electricity from the grid) could reduce utility cost estimates by $\$ 0.20$.

A summary of the cost uncertainties is presented in Table IV-16. The cost impact of each uncertainty is listed as the approximate impact of a 50\% cost change. This shows the relative importance of each process in question to the total cost of CWS. It must be kept in mind as more is learned and these uncertainties become resolved, the result may be either more or less than the $50 \%$ cost change indicated.

\section{J. COST MODELING RUNS}

Cost information developed by AMAX R\&D for the production of coal-water slurry has been converted into automated spreadsheets for use on personal computers. The automated spreadsheet format allows the user to evaluate the impact of various process options, coal feedstock characteristics, fuel characteristics, plant location sites, and plant sizes on the fuel cost. These spreadsheets constitute a process model that is very useful in the analysis and comparison of clean coal costs. The model flexibility reduces the time and labor required to determine the fuel costs and provides a basis to compare fuels manufactured by different processes. 
Table IV-16

CWS COSTING UNCERTAINTIES

\begin{tabular}{|c|c|c|c|}
\hline $\begin{array}{l}\text { Potential Impact } \\
\text { on CWS Cost }\end{array}$ & Item & Uncertain Factor & $\begin{array}{c}\text { Approximate } \\
\text { Impact of 50\% Cost } \\
\text { Change }\end{array}$ \\
\hline Decrease & Coal Cost & $\begin{array}{l}\text { - If plant run by coal company the } \\
\text { profit would be on CWS only, not } \\
\text { raw coal also. }\end{array}$ & $\$ 0.25 / \mathrm{MMBtu}$ \\
\hline $\begin{array}{l}\text { Increase or } \\
\text { Decrease }\end{array}$ & $\begin{array}{l}\text { Grinding } \\
\text { Methods }\end{array}$ & $\begin{array}{l}\text { - Optimum grinding method not } \\
\text { selected yet: dry grinding? Ball } \\
\text { mill? }\end{array}$ & Under \$.10/MMBtu \\
\hline Increase & $\begin{array}{c}\text { Mill } \\
\text { Maintenance }\end{array}$ & - Media replacement rates uncertain. & Under \$.10/MMBtu \\
\hline Increase & $\begin{array}{l}\text { Physical } \\
\text { Cleaning }\end{array}$ & $\begin{array}{l}\text { - Efficiency of froth flotation is not } \\
\text { certain. } \\
\text { - Cost of full-sized F.F. column not } \\
\text { certain. }\end{array}$ & Under $\$ .25 / \mathrm{MMBtu}$ \\
\hline Decrease & $\begin{array}{l}\text { Chemical } \\
\text { Cleaning }\end{array}$ & $\begin{array}{l}\text { Utility needs uncertain/heat } \\
\text { recover potential uncertain. }\end{array}$ & $\$ .12 / \mathrm{MMBtu}$ \\
\hline Decrease & $\begin{array}{l}\text { Formulation of } \\
\text { Additive Package }\end{array}$ & $\begin{array}{l}\text { Costs may go down as } n \in N \text { fonau- } \\
\text { lations or mixing methods are } \\
d: \text { veloped. }\end{array}$ & $\$ .20 / \mathrm{MMBtu}$ \\
\hline Increase & $\begin{array}{c}\text { Caustic } \\
\text { Regeneration }\end{array}$ & $\begin{array}{l}\text { - Cost of chemicals, best process is } \\
\text { being investigated. }\end{array}$ & $\$ .12 / \mathrm{MMBtu}$ \\
\hline Increase & Waste Disposal & $\begin{array}{l}\text { Depends on location of coal } \\
\text { cleaning facility. Some states may } \\
\text { have more stringent regulations on } \\
\text { solids disposal. }\end{array}$ & $\$ .01 / \mathrm{MMBtu}$ \\
\hline Decrease & Cost of Power & $\begin{array}{l}\text { - Cogeneration only appropriate in } \\
\text { certain geographic sites and with } \\
\text { both chemical cleaning and find } \\
\text { grinding together. }\end{array}$ & $\$ .15 / \mathrm{MMBtu}$ \\
\hline
\end{tabular}


The model requires input of specific information in order to complete the various cost calculations. The required infornation includes coal characteristics, plant flowsheet definition, plant size, and market 'ocation. Based upon these inputs, certain unit operations are selected for processing the coal. A total of 13 different unit operations are availabie for inclusion in the cost. Equipment size and cost is also a function of the required inputs. Output from the model includes a capital cost summary sheet and an operating cost summary sheet which provide a detailed breakdown of each cost and provide scenario background data.

A description of the unit operation area has been presented previously. Details of the equipment used in these areas is presented in Appendix A. Details of the model configuration, the spreadsheets used and the necessary inputs are presented in Appendix B. The results of runs made with this model are discussed below.

\section{Cost Model Case Evaluations}

Cost summaries were prepared using the automated spreadsheet model for the targeted market locations shown in Figure IV-3. A cost look-up table was prepared from the case runs to compare the sensitivity of plant loc tion, plant size, fuel quality, and feedstock selection. A plant capital cost and operating cost summary sheet was prepared for each scenario. Sample summary sheets can be found in Appendix $\mathbf{C}$.

The effect of "fuel quality" was evaluated by comparing the costs to produce three different slurries, each differing by their degree of beneficiation. The specifications of these three fuels are shown in Table IV-17. A minimally refined fuel is assumed to have $3 \%$ ash, $2 \%$ sulfur and a top particle size of 100 microns. A nominally refined slurry has an ash level of $1 \%$, a sulfur content of $1 \%$, and a top particle size of 74 microns. The highly refined CWS has less than $0.5 \%$ ash, less than $0.5 \%$ sulfur, and a top particle size less than 30 microns.

For the purposes of this comparative study, it was assumed that the minimally and nominally refined slurry were both physically cleaned while the highly refined slurry was chemically cleaned. It must be noted that there are limited number of coals that can be physically cleaned to less than $1 \%$ ash with a top size of 74 microns. Most coals would have to be ground much finer to clean them to these levels with high energy recovery. This scenario of varying degrees of CWS refinement was useful, however, for making cost comparisons.

\section{K. COST LOOK-UP TABLE AND IMPACT OF VARIABLES}

Results from the model runs are presented in Table IV-18, the CWS Cost Look-Up table. The following sections discuss the significance of the effects of three key variables:

- Plant size

- Fuel quality

- Plant location

Table IV-18, the CWS Cost Lonk-Up table, is set up to compare the results of the different case runs based upon the variable of interest. The following variables were analyzed: 


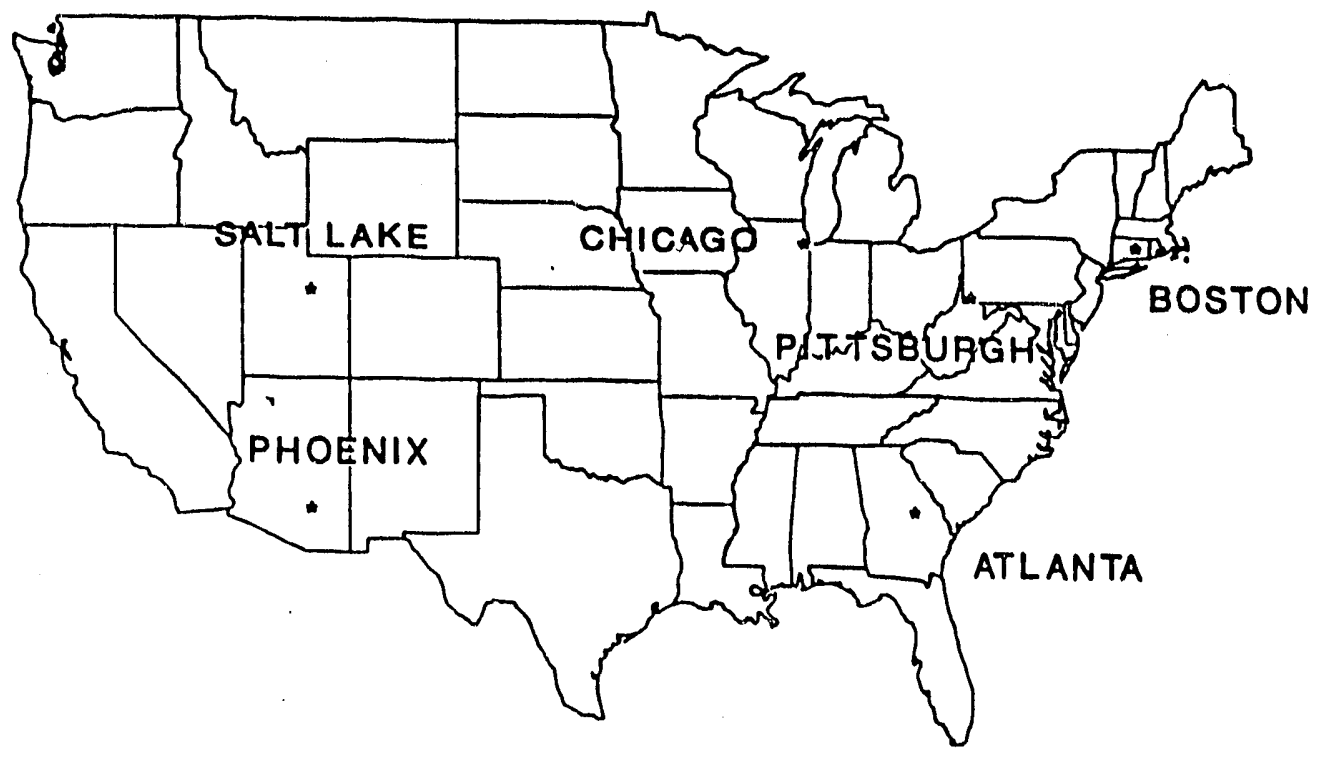

FIGURE IV-3. MARKET LOCATIONS

Table IV-17

ASSUMPTIONS FOR CWS SPECIFICATIONS USED IN COST MODELING RUNS

\begin{tabular}{|c|c|c|c|}
\hline CWS Quality & Minimally Refined & $\begin{array}{c}\text { (Base Case) } \\
\text { Nominally Refined }\end{array}$ & Highly Refined \\
\hline Top particle size & 100 microns & 74 & 30 \\
\hline Ash content & $3 \%$ & $1 \%$ & $0.5 \%$ \\
\hline Sulfur content & $2 \%$ & $1 \%$ & $0.5 \%$ \\
\hline Viscosity $(\mathfrak{c p})$ & 800 & 400 & 100 \\
\hline $\begin{array}{l}\text { Potential coal feed- } \\
\text { stocks }\end{array}$ & $\begin{array}{l}\text { Lower grade coals, local to } \\
\text { cleaning plant and CWS } \\
\text { engine }\end{array}$ & $\begin{array}{l}\text { High quality Kentucky } \\
\text { coals (e.8., Blue Gem, } \\
\text { Taggart, or Elkhorn } \\
\text { seams) }\end{array}$ & Virtually any coal \\
\hline $\begin{array}{l}\text { Cleaning methods } \\
\text { used }\end{array}$ & Physical cleaning & Physical cleaning & $\begin{array}{l}\text { Chemical cleaning/ } \\
\text { fine grinding }\end{array}$ \\
\hline
\end{tabular}




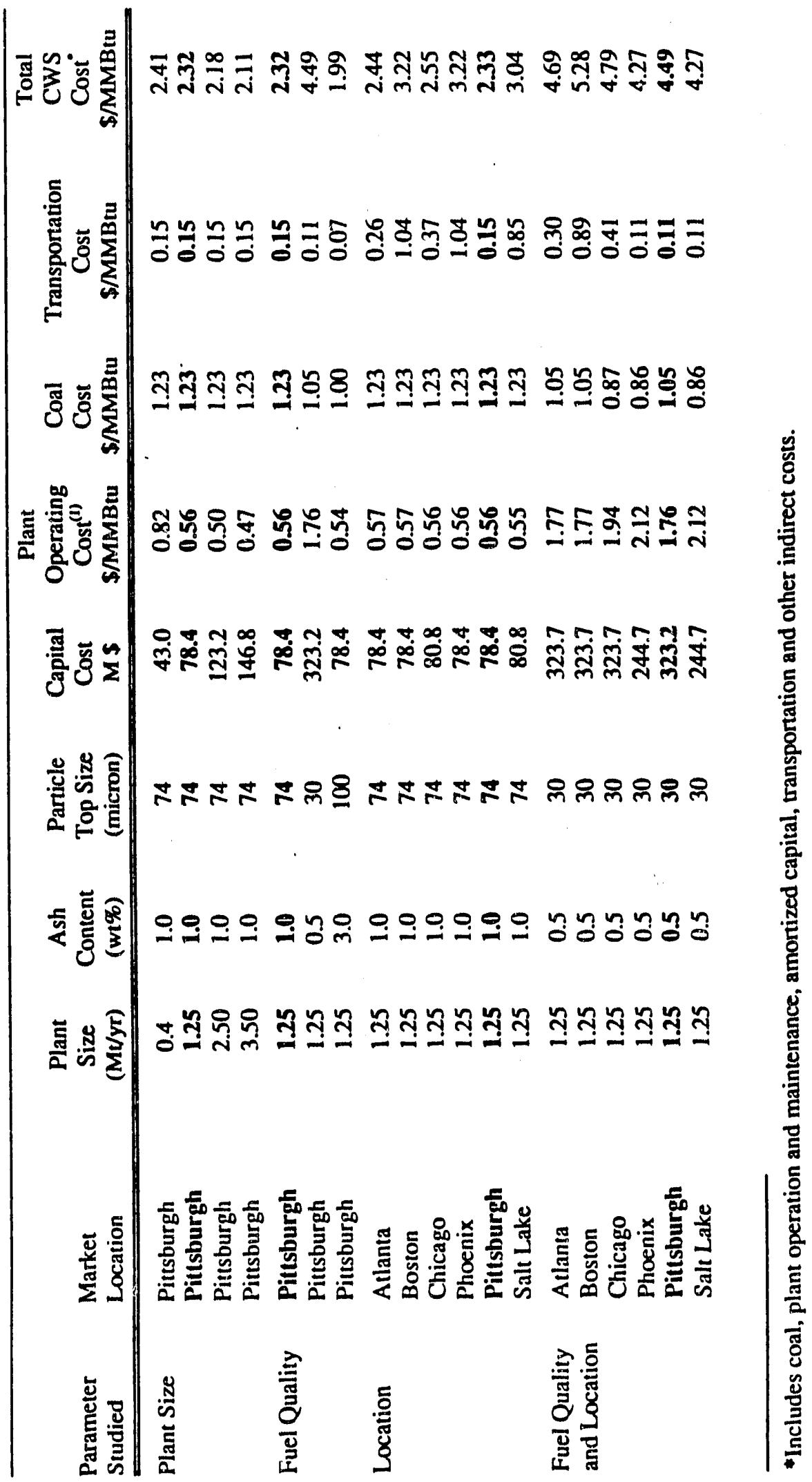




\section{Plant Size}

The base case is a 1.25 million ton per year (dry coal in the product slurry) plant. The plant site is near the Pittsburgh area and uses Blue gem seam coal from Kentucky. The coal is cleaned to $1.0 \%$ ash via column flotation and crushed to a top size of 74 micron in a rod mill. The comparative cases are for plants producing between 0.4 to 3.5 million tons per year of coal in the slurry.

Cost adjustments were made to the capital cost by factoring the cost of the equipment using the 0.6 tenths power rule or using step functions where more precise data were available. Certain site direct costs such as buildings and site improvements were adjusted on an individual case basis. Cost adjustments in the operating costs are based upon a unit of coal. Labor costs were adjusted on an individual case basis.

Plant operating costs increased as the plant size decreased, as expected. The economies of scale, however, were more apparent at the lower end of the range evaluated. The operating cost decreased from $\$ 0.82$ to $\$ 0.56$ when the plant size tripled from $0.4 \mathrm{Mt} / \mathrm{yr}$ to $1.25 \mathrm{Mt} / \mathrm{yr}$. The operating costs decreased only 9 cents/MMBtu when the plant size was nearly tripled from 1.25 $\mathrm{Mt} / \mathrm{yr}$ to $3.5 \mathrm{Mt} / \mathrm{yr}$. The reduction in operating cost in the first plant size increase was a result of labor costs ( 21 cents/MMBtu) and utilities ( 4 cents/MMBtu) which are more efficiently utilized in a larger operation. After the plant reaches the 1.25 million ton per year size, the labor and utility costs are only 17 cents/MMBtu of the total operating cost. Savings in these areas will no longer show any significant improvement in the total operating cost.

The capital recovery cost for the plant also decreases (per unit of fuel produced) with increasing plant size. The annualized plant cost decreases from $\$ 0.38 / \mathrm{MMBtu}$ for the 1.25 million $\mathrm{T} / \mathrm{yr}$ plant to $\$ 0.30 / \mathrm{MMBtu}$ and $\$ 0.26 / \mathrm{MMBtu}$ for the 2.5 million $\mathrm{T} / \mathrm{yr}$ and 3.5 million $\mathrm{T} / \mathrm{yr}$ plant, respectively.

\section{Fuel Quality}

The base case scenario for fuel quality is shown in Table IV-19 along with the comparison scenarios:

$\begin{array}{ll}\text { Coal feedstock } & \begin{array}{l}\text { Blue Gem Seam (Base) } \\ \text { Kentucky 4A Seam (Low) } \\ \text { Pittsburgh \#8 Seam (High) }\end{array} \\ \text { Plant Capacity } & 1.25 \mathrm{Mt} / \mathrm{yr} \\ \text { Plant Location } & \text { Pittsburgh }\end{array}$

(Feedstock analyses for the coals used in the model evaluations are presented in Appendix D.)

The greatest impacts to both the capital and operating costs were a result of utilizing chemical cleaning to reduce the ash content below $0.5 \%$. The chemical cleaning circuit increased the Total Plant Capital Cost from $\$ 78$ million for the base case to $\$ 324$ million. The total CWS cost increased from $\$ 2.32 / \mathrm{MMB}$ tu to $\$ 4.49 / \mathrm{MMBtu}$. 
Table IV-19

FUEL QUALITY SCENARIOS

\begin{tabular}{ccccc}
\hline $\begin{array}{c}\text { Fuel } \\
\text { Quality }\end{array}$ & $\begin{array}{c}\text { Ash } \\
\text { Content } \\
(w t \%)^{1}\end{array}$ & $\begin{array}{c}\text { Fulfur } \\
\text { Content } \\
(\text { wt\%) }\end{array}$ & $\begin{array}{c}\text { Particle } \\
\text { Size } \\
(\text { micron) }\end{array}$ & $\begin{array}{c}\text { Viscosity } \\
\left(\mathrm{cp} @ 100 \mathrm{sec}^{-1}\right)\end{array}$ \\
\hline Base Case & 1.0 & 1.0 & 74 & 400 \\
High & 0.5 & 0.5 & 30 & 100 \\
Low & 3.0 & 2.0 & 100 & 800 \\
\hline
\end{tabular}

${ }^{1}$ Dry coal basis

Other assumptions standard for all scenarios were as follows:

The extra capital cost and operating cost is a result of chemical cleaning equipment and reagents required for processing, additional fine grinding equipment, and cogeneration installation. This equipment includes autoclaves, filters, heat exchangers, pumps, stirred ball mills, and a cogeneration plant to provide steam and electrical power. The increase in capital cost can be broken down as follows:

$\begin{array}{ll}\text { Chemical Cleaning } & 34 \% \\ \text { Fine Grinding } & 11 \% \\ \text { Cogeneration } & 55 \%\end{array}$

Cogeneration was used in all chemical cleaning scenarios except in the western cities where very low cost gas is available, making cogeneration less attractive.

Additional chemical cleaning costs include operating costs associated with chemical reagents, power costs, and extra labor.

Reducing the fuel quality further, as in the case shown for Pittsburgh scenario with $3 \%$ ash in the coal, reduces the cost from $\$ 2.32 / \mathrm{MMBtu}$ to $\$ 1.99 / \mathrm{MMBtu}$, nearly $15 \%$. The savings are realized by using a lower quality fuel, increasing recovery, and reducing grinding costs. 


\section{Plant Location}

The trade-off between coal costs and transportation costs is the critical issue for plant location. Inexpensive local coals may reduce feedstock costs but may need to be chemically cleaned for sufficient beneficiation. Specialty coals that could be physically cleaned to adequate ash levels may be associated with high transportation costs. The most important comparison here is the use of western versus eastern coals for CWS plants located in the western part of the country. It was found, in fact, to be less expensive to ship a Kentucky coal to Salt Lake city based physical cleaning plant than to use a western coal in a chemical cleaning plant. (Few western coals can be physically cleaned to less than $1 \%$ ash.) The trade-offs for this analysis are shown in Table IV-20.

Table IV-20

\section{COMPARISON OF COSTS FOR EASTERN VS. WESTERN COALS IN WESTERN COAL PLANT}

Plant Location:

CWS Specifications:

Top particle size

Ash content

Sulfur content

Coal Cleaning Method

Coal Used:

Coal Cost:

Mine to Plant Transportation Cost

Plant Operating Cost

Indirect Costs

G\&A

Capital recovery

TOTAL
Salt Lake City, Utah

74 microns

$1 \%$

$1 \%$

\begin{tabular}{|c|c|}
\hline Chemical & Physical \\
\hline Utah Castlegate & Kentucky Blue Gem \\
\hline$\$ 0.86$ & $\$ 1.37$ \\
\hline \$0.11 & $\$ 0.85$ \\
\hline$\$ 2.22$ & $\$ 0.55$ \\
\hline$\$ 0.21$ & $\$ 0.10$ \\
\hline SLel & $\$ 0.33$ \\
\hline$\$ 4.41$ & $\$ 3.20$ \\
\hline
\end{tabular}




\section{EMISSION CONTROL SYSTEM DESIGN}

\section{A. INTRODUCTION AND EMISSION TARGETS}

The development of a low-cost emission control system for the coal-fueled diesel engine is necessary for its commercial success in small power generation systems. Because the coal-fueled diesel engine is a new technology, no emission limits have yet been imposed. Regulations are currently applied to all new coal-fired stationary sources larger than $250 \mathrm{MMBtu} / \mathrm{hr}$ fuel input, and we expect that regulations in some form will be extended to all new small coal-fired stationary power sources in the near future. When this occurs, the coal-fueled diesel system must be competitive with other technologies for power generation in terms of exhaust emissions. Competing technologies for power generation in the range below $100 \mathrm{MW}$ include coal-fueled fluidized bed steam plants, as well as internal combustion engines and gas turbines designed to burn gas or oil. Coal-fired gas turbine plants below $100 \mathrm{MW}_{\mathrm{e}}$ are currently under development and may compete in the same timeframe as the Cooper Bessemer coal diesel.

Technical and economic criteria govern the design of an emission control system for the coalfueled diesel engine. To be competitive, the coal-fueled diesel engine must be as environmentally sound as the other combustion technology alternatives. The current EPA New Source Performance Standards (NSPS) for coal-fired utility boilers can be met by the conventional combustion technologies, and for the purposes of this study, we have elected to design the emission control system to meet these standards. The current NSPS for the major pollutants, $\mathrm{NO}_{\mathrm{x}}$, $\mathrm{SO}_{2}$, and particulate matter, are given in Table $\mathrm{V}-1$. To reduce the major pollutants in the engine exhaust to meet the NSPS, one can choose among many technologies. However, pollution control technologies must meet two further criteria, one economic and the other technical. The cost of the emission control system has a powerful influence on the commercial feasibility of the coal-fueled diesel system. Both the capital and operating cost of the coal-fueled diesel system must be on par with that of other combustion sources. Technically, the control technologies chosen must be compatible with one another (for system integration) and must be compatible with the coal-fueled diesel engine operation.

The goal of this conceptual design study is to provide quantitative guidelines for selecting the emission control system for the coal-fueled diesel engine. For each of the three major pollutants, control technologies are identified that meet the preliminary technical and economic criteria discussed above. From these various technologies a number of integrated emission control system options are chosen for further study. The system options represent a spectrum of both anticipated cost and probability of technical success. We go on to formulate quantitative means to assess the cost and the probability of technical success for the system options. This allows intercomparison of the candidate options and prioritization of experimental work for the R\&D program (Task 2 of Phase I). 
Table V-1

NEW SOURCE PERFORMANCE STANDARDS FOR STATIONARY SOURCES

\begin{tabular}{|c|c|c|}
\hline Pollutant & $\begin{array}{c}\text { Required Emission Level } \\
\text { Coal-Fired Utility Boilers (over } 250 \\
\text { MMBtu/hr-input) }\end{array}$ & $\begin{array}{c}\text { Proposed Levels for Smal } \\
\text { Industrial Boilers (30-75 } \\
\text { MMBtu/hr-input) }\end{array}$ \\
\hline $\mathrm{NO}_{x}$ & $0.6 \mathrm{lb} / \mathrm{MMBtu}\left(150 \mathrm{ppm} \text { at } 15 \% \mathrm{O}_{2}\right)^{*}$ & $1.0 \mathrm{lb} / \mathrm{MMBtu}$ \\
\hline $\mathrm{SO}_{2}$ & $\begin{array}{l}1.2 \mathrm{lb} / \mathrm{MMBtu} \text { and } 90 \% \text { reduction, or } \\
70 \% \text { reduction if less than } 0.6 \\
\mathrm{lb} / \mathrm{MMBtu} \text { is achieved }\end{array}$ & $1.2 \mathrm{lb} / \mathrm{MMBtu}$ \\
\hline Particulate & $0.03 \mathrm{lb} / \mathrm{MMBtu}$ & $0.05 \mathrm{lb} / \mathrm{MMBtu}$ \\
\hline
\end{tabular}

*The sum of $\mathrm{NO}$ plus $\mathrm{NO}_{2}$ is converted from measured concentration to lb/MMBtu by using the molecular weight of $\mathrm{NO}_{2}$ (as if all $\mathrm{NO}$ were converted to $\mathrm{NO}_{2}$ ) 


\section{B. EMISSION CONTROL TECHNOLOGIES FOR PRELIMINARY CONCEPTUAL DESIGN}

\section{Engine Operating Parameters}

Since the cost of the emission control system depends on the size of the overall system, several system sizes in the range of 2 to $50 \mathrm{MW}$ power output have been chosen for study. The engine systems have been selected by Cooper-Bessemer as representative of future commercial opportunities. The engine (or engines) are assumed to be the LSB 6 or LSVB 20 design. These engines have a 15.5 inch bore and a 22 inch stroke. Table V-2 details the engine operating parameters that are independent of engine size such as the speed, compression ratio, and brake-specific fuel consumption. Also included in Table V-2 are the pioperties of the coal-water slurry and the expected emissions of the major pollutants. The $\mathrm{NO}_{\mathrm{x}}$ emission is based on tests results from the JS-1 engine. ${ }^{(1)}$ The $\mathrm{SO}_{2}$ emission is calculated from a sulfur mass balance, assuming that all the fuel sulfur is converted to $\mathrm{SO}_{2}$. The particulate emission is calculated from the ash content of the coal and from an assumed burnout of 98 percent which is representative of JS-1 engine results.

Table V-2 presents the anticipated reduction required to meet NSPS for the three major pollutants. The $\mathrm{SO}_{2}$ reduction required may be less than the 70 percent shown if a credit is allowed for the sulfur removed from the coal during the production of the coal-water slurry.

The cost of emission control equipment relative to the power output of the system (e.g., the cost per kilowatt of electricity generated) decreases as the size of system increases. In general, the relationship between cost and system capacity is not linear. Therefore, the cost calculations are performed for five systems that span the range of interest for small stationary engines. Table $\mathrm{V}-3$ details the size-dependent operating parameters for the five systems of interest. Each system consists of one or more engine (either LSB 6 or LSVB 20 engine). Systems 1, 2, 3, and 5, labeled as cogeneration systems, include a waste heat boiler which makes 125 psig steam for process applications from the exhaust gas. System 4, a power generation system, does not have a waste heat boiler. In this configuration, no heat recovery from the exhaust gas takes place and a water quench unit is employed to reduce gas temperatures as required by pollution control equipment.

Currently, diesel-fueled stationary engines are not equipped with the kind of emission control technology that we have assumed will be needed to meet NSPS with the coal-fueled engine. The emission control devices will have to be integrated with the engine system components. A general schematic of the integrated system is illustrated in Figure V-1. Only one engine is shown; in this study, we have made the preliminary decision that emission control equipment downstream of the turbocharger will be common to all engines in the system, i.e., exhaust gases from all engines are combined after the turbocharger. Approximate temperatures are indicated in the figure, although the exact temperature will depend on the optimum temperature required for the individual emission control subsystems and on the engine exhaust conditions.

\section{Selection Of Emission Control Technologies}

The available technology for reducing exhaust gas pollutant levels has rarely been applied to small stationary engines. Most of the experience in removing the major pollutants comes from larger applications such as utility boilers. The emissions from the coal-fueled diesel engine are more closely similar to those from coal-fired utility boilers than to those from stationary engines 


\section{ASSUMED ENGINE OPERATING CONDITIONS}

\section{Coal Properties}

Ultimate Analysis:

$$
\begin{array}{r}
81.2 \% \mathrm{C} \\
5.53 \% \mathrm{H} \\
10.07 \% \mathrm{O} \\
1.83 \% \mathrm{~N} \\
0.91 \% \mathrm{~S} \\
0.38 \% \\
\text { Ash }
\end{array}
$$

Lower Heating Value: 13,736 Btu/lb

Coal-Water Slurry Composition: 53 wt\% coal (preliminary spec.)

Engine Operating Parameters

Compression Ratio:

BMEP:

Power:

BSFC:

Speed:

\section{Combustion Conditions}

Manifold Air Temperature:

Exhaust Gas Temperature:

Stoichiometry:
10.8

200 psi

$419 \mathrm{hp} /$ cylinder

\begin{tabular}{|c|c|c|c|c|}
\hline & \multicolumn{2}{|c|}{$\begin{array}{c}\text { Expected } \\
\text { Concentration: } \\
\text { (preliminary) }\end{array}$} & $\mathrm{lb} / \mathrm{MMBtu}$ & $\begin{array}{l}\text { Assumed } \\
\text { Reduction } \\
\text { Required }\end{array}$ \\
\hline \multirow[b]{2}{*}{$\begin{array}{l}\mathrm{NO}_{x} \\
\mathrm{SO}_{2} \\
\text { Solids } \\
\end{array}$} & $\mathrm{ppm}$ & $\mathrm{mg} / \mathbf{l}$ & & \\
\hline & $\begin{array}{l}900 \\
305\end{array}$ & 1.05 & $\begin{array}{l}2.8 \\
1.3 \\
1.5\end{array}$ & $\begin{array}{l}79 \% \\
70 \% \\
98 \%\end{array}$ \\
\hline \multicolumn{5}{|c|}{ Notes: } \\
\hline \multicolumn{5}{|c|}{$\begin{array}{l}\text { Reduction may be less than this if a credit for sulfur removal during piviuction of coal- } \\
\text { water slumy is allowed }\end{array}$} \\
\hline
\end{tabular}

$6300 \mathrm{Btu} / \mathrm{hp}-\mathrm{hr}$

$400 \mathrm{rpm}$

\section{Pollutant Levels}

$250^{\circ} \mathrm{F}$ (preliminary)

$880^{\circ} \mathrm{F}$

231\% Theoretical Air 
Table V-3

SYSTEMS FOR COAL-FUELED DIESEL OPERATION

\begin{tabular}{|c|c|c|c|c|c|}
\hline Engine $\rightarrow$ & $\begin{array}{c}1 \\
\text { LSB } 6\end{array}$ & $\begin{array}{c}2 \\
\text { LSB } 6\end{array}$ & $\begin{array}{c}3 \\
\text { LSVB 20 }\end{array}$ & $\begin{array}{c}4 \\
\text { LSVB } 20\end{array}$ & $\begin{array}{c}5 \\
\text { LSVB } 20\end{array}$ \\
\hline Application & Co-gen & Co-gen & Co-gen & Power & Co-Gen \\
\hline Number of Engines & 1 & 4 & 2 & 2 & 4 \\
\hline Net Power Output (MW $)$ & 1.8 & 7.2 & 12 & 12 & 24 \\
\hline Total Horsepower & 2,516 & 10,064 & 16,772 & 16,772 & 33,544 \\
\hline Coal Flow (lb/hr) & 1,154 & 4,616 & 7,692 & 7,692 & 15,384 \\
\hline Heat Inpr: (MMBtu/hr) & 15.86 & 63.44 & 105.66 & 105.66 & 211.32 \\
\hline $\begin{array}{l}\text { Exhaust Gas Flow (scfm) } \\
\text { Single Engine }\end{array}$ & 6,979 & 6,979 & 23,260 & 23,260 & 23,260 \\
\hline Total (all engines) & 6,979 & 27,916 & 46,520 & 46,520 & 93,040 \\
\hline $\begin{array}{l}\text { Exhaust Gas Flow }(\mathrm{klb} / \mathrm{hr}) \\
\text { Single Engine }\end{array}$ & 30.9 & 30.9 & 103.0 & 103.0 & 103.0 \\
\hline Total (all engines) & 30.9 & 123.7 & 206.1 & 206.1 & 412.2 \\
\hline $\begin{array}{l}\text { Emissions }(\mathrm{lb} / \mathrm{hr}) \\
\mathrm{SO}_{2}(0.9 \% \mathrm{~S} \text { in coal, } \\
1.3 \mathrm{lb} / \mathrm{MMBtu})\end{array}$ & 21 & 84 & 140 & 140 & 280 \\
\hline $\begin{array}{l}\mathrm{NO}_{\mathrm{x}}, \text { as } \mathrm{NO}_{2}(900 \mathrm{ppm} \text { or } \\
2.8 \mathrm{lb} / \mathrm{MMBtu})\end{array}$ & 45 & 178 & 297 & 297 & 594 \\
\hline $\begin{array}{l}\text { Solids }(0.4 \% \text { ash and } 98 \% \\
\text { burnout) }\end{array}$ & 27 & 110 & 183 & 183 & 365 \\
\hline
\end{tabular}




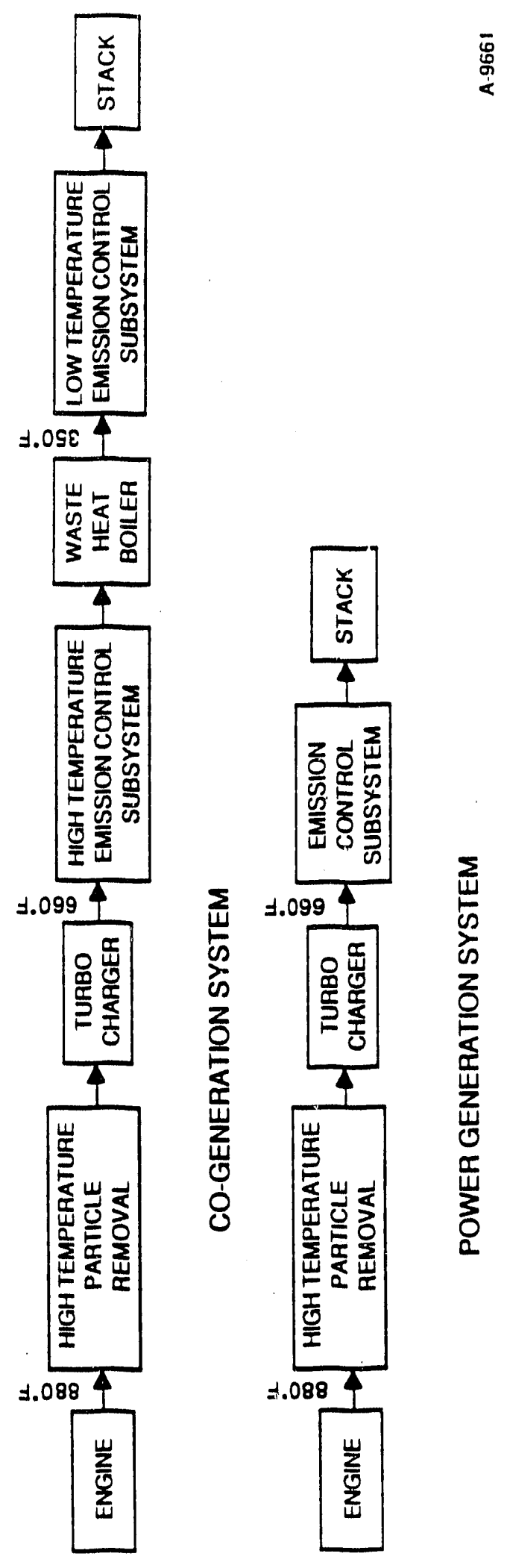

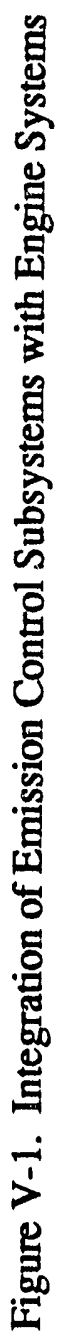


fueled by natural gas and diesel fuel. The $\mathrm{NO}_{\mathrm{x}}$ level from a coal-fueled diesel engine is much less than that from an existing engine burning natural gas or diesel fuel. However, the emissions of $\mathrm{SO}_{2}$ and solids are greater than those of existing engines. Thus, the candidate technologies for removing the major pollutants are drawn from the experience in utility boilers and industrial process gases. Table V-4 summarizes the emission control technologies considered in this design study.

In this section, the individual emission control technologies are discussed. Appendix I contains process diagrams of each technology as applied to the coal-fueled diesel engine. The reader may wish to consult the appendix for further information on each technology.

\subsection{NO Control Technologies}

The most cost-effective means for $\mathrm{NO}_{\mathrm{x}}$ control is to modify the engine combustion process through staged combustion, prechambers or other means. Although this will be attempted, the target of $85 \% \mathrm{NO}_{\mathrm{x}}$ reduction points to the probable need for exhaust gas $\mathrm{NO}_{\mathrm{x}}$ treatment. The removal of $\mathrm{NO}_{\mathrm{x}}$ from exhaust gas streams can be accomplished in two ways: reduction to $\mathrm{N}_{2}$ or absorption. The former route is most commonly used on a commercial scale. In one class of processes, termed selective reduction, a nitrogen-containing compound (typically ammonia) is added to the exhaust gas stream where it reacts with the oxides of nitrogen to form $\mathrm{N}_{2}$. Depending on whether or not a catalyst is employed, the process is called either Selective Noncatalytic Reduction (SNR) or Selective Catalytic Reduction (SCR).

The SNR process occurs in a narrow temperature window, from about 1600 to $2000^{\circ} \mathrm{F}^{(2)} \mathrm{This}$ process has been applied on a commercial scale to utility boilers ${ }^{(3)}$ where the upper portion of the furnace provides the correct temperature range, and ammonia is utilized (Exxon "Denox" process). Recently, the minimum temperature for SNR has been lowered to about $1350^{\circ} \mathrm{F}$ by replacing ammonia with cyanuric acid in the presence of a large amount of $\mathrm{CO} .{ }^{(4)}$ Under low $\mathrm{CO}$ conditions, the reaction window is still 1600 to $2000^{\circ} \mathrm{F}$. This process will certainly be more expensive than ammonia injection due to the cost of the cyanuric acid. The maximum temperature expected in the coal-fueled diesel exhaust gas is $880^{\circ} \mathrm{F}$ (see Table V-2). The SNR process is not considered as a feasible $\mathrm{NO}_{\mathrm{x}}$ removal technology for the coal-fueled diesel engine because the exhaust gas temperature is too low.

The SCR process employs a catalyst to lower the temperature window of the reduction process. SCR has been applied to boilers and process heaters in Japan and in Europe. There is extensive experience in Japan with the application of SCR to coal-fired boilers. Commercialization of SCR in the United States lags behind Japan and Europe, mainly because of the high cost and technical problems with coal ash found in the United States. Recently, tougher standards for $\mathrm{NO}_{\mathrm{x}}$ reduction, especially in California, have dramatically increased the experience with SCR in the United States.

In commercial applications of SCR, the catalyst is typically a metal such as platinum or vanadium placed on a metal or ceramic substrate which is arranged as parallel plates or in a honeycomb. The process temperature range is 600 to $750^{\circ} \mathrm{F}$ and ammonia is used as an additive. The molar ratio of ammonia to $\mathrm{NO}_{x}$ is approximately unity. The amount of ammonia injected depends on the inlet NOx concentration, the desired $\mathrm{NO}_{\mathrm{x}}$ reduction, and the allowable ammonia 
NOx Control

- Reburning

- SCR: Commercially available unit

- SCR: Ammonia injection over engine particulate catalyst at $450^{\circ} \mathrm{F}$ in baghouse

- SCR: Ammonia injection over CuO catalyst at $750^{\circ} \mathrm{F}$ in granular bed reactor (Shell/UOP) process

- Adsorption on engine particulate bed at $275^{\circ} \mathrm{F}$ in baghouse

Joint $\mathrm{NO}_{2}-\mathrm{SO}_{2}$ Control

- Ammonia injection over carbon catalyst at $450^{\circ} \mathrm{F}$ in reactor (Takeda process)

SO2 2 Control

- Commercially available spray dryer

- Low Temperature (150 to $\left.300^{\circ} \mathrm{F}\right)$ Sorbent Injection

- High Temperature $\left(900\right.$ to $\left.1000^{\circ} \mathrm{F}\right)$ Sorbent Injection

- Calcium Fuel Additive

\section{Particle Control}

- Baghouse

- Cyclone

- Granular Bed Filter

- Ceramic Cross Flow Filter

Auxiliary Equipment

- Induced Draft Fan

- Waste Heat Boiler: Differential Cost Relative to Diesel-fueled Baseline Case 
slip (the amount of unreactud ammonia that exits the reactor). $\mathrm{NO}_{\mathrm{x}}$ removal efficiencies of up to 90 peicent can be obtained with SCR. The major operational problems with SCR are degradation of catalyst performance, ammonia slip, and ammonium sulfate formation. In application of SCR to conventional diesel engines, fouling of the catalyst by the diesel soot has been severe. ${ }^{(5)}$ However, the particulate emissions of the coal-fueled engine are different in character from those of a diesel-fueled engine. The experience in coal-fired boilers with SCR is more applicable to the coal-fueled engine. In coal-fired utility boilers, erosion of the catalyst support necessitates replacing the catalyst every one to five years and catalyst replacement cost is the major component of SCR operating costs. The main advantage to using the SCR process described above for the coal-fueled diesel engine is that the process is available commercially and has demonstrated the required $\mathrm{NO}_{\mathrm{x}}$ reduction. Cost is the primary disadvantage; both capital and operating costs are expected to $b$ relatively high.

In order to assess whether the $\mathrm{NO}_{\mathrm{x}}$ reduction requirements of the emission control system can be met with a less expensive SCR process, two alternative technologies are considered. The first alternate SCR process involves using the carbon-containing particulate matter from the engine exhaust as a catalyst. The second involves a copper oxide catalyst supported on alumina pellets which incorporates a novel means for removing particles.

Recently, the catalytic activity of coke and carbon-containing particulate matter from utility boilers has been demonstrated on a laboratory scale ${ }^{(6,7)}$. Using coke activated with sulfuric acid, a 70 versent reduction of NO by ammonia at $300^{\circ} \mathrm{F}$ has been demonstrated. ${ }^{(6)}$ Particulate matter from nidustrial boilers containing 2 percent to 30 percent carbon by weight has been used as a catalyst for reduction of $\mathrm{NO}$ with ammonia. ${ }^{(7)}$ In the temperature range 570 to $750^{\circ} \mathrm{F}$, NO reductions from 40 to 60 percent have been demonstrated. Because of the low ash content of the processed coa' used in the engine, the particulate matter contains a very large umount of carbon. The carbon content of the ash is calculated to be 80 percent at 98 percini i arnout and 67 percent at 99 percent bumout, based on a mass balance using 0.5 percent as the ash content. Thus, it may be possible to exploit the ash as a reduction catalyst. This process has not been applied on an industrial scale and is expected to have a low probability of technical success. However, the cost is very low, providing the impetus for choosing this technology for further study.

Universal Oil Pr sducts (UOP) has developed a process (based on the Shell CuO process) for removal of NOx alone or for removal of $\mathrm{NO}_{2}$ and $\mathrm{SO}_{2} \cdot{ }^{(8)}$ The reduction catalyst is $\mathrm{CuO}$ supported on alumina. In the presence of $\mathrm{SO}_{2}$, the $\mathrm{CuO}$ is converted to $\mathrm{CuSO}_{4}$ which acts as a catalyst for $\mathrm{NO}_{\mathrm{x}}$ reduction by ammonia. $\mathrm{NO}_{\mathrm{x}}$ removal efficiencies of 90 percent or greater have been demonstrated on both oil and coal-fired utility boilers. $\mathrm{SO}_{2}$ can be removed simultaneously if the catalyst is regenerated periodically " sing hydrogen and steam. The simultaneous $\mathrm{NO}_{\mathrm{x}}-\mathrm{SO}_{2}$ process will not be considered here because of the cost and complexity of the regeneration step and the sulfur recovery plant.

Without simultaneous $\mathrm{SO}_{2}$ removal, the Shell/UOP process is similar in cost to the cornmercial SCR processes discussed previousiy. However, if the catalyst is supported on alumina pellets, the pellets can be used as a filter medium for particulates. The technology for hot gas filtration has been developed for application to coal-fired gas turbines. ${ }^{(9,10)}$ In the granular bed filter process, a bed of alumina pellets rernoves particles from the gas stream. The filter media are continuously 
withdrawn from the filtration vessel, cleaned, and returned to the vessel. The granular bed filtration process has been demonstrated on a pilot scale. Combination of the Shell/UOP process with granular bed filtration is relatively expensive, but will remove two of the three major pollutants in the exhaust gas stream and thus obviate the need for additional particle removal equipment.

A third kind of reduction process is called reburning. In this process, no chemical additives are used; instead, the exhaust gas passes through a secondary combustion zone. In typical applications the secondary fuel is natural gas and accounts for 10 to 20 percent of the total heat input to the system. The mixing rate of the exhaust gas and secondary fuel is designed to be slow enough so that fuel-rich regions are created. When $\mathrm{NO}_{\mathrm{x}}$ in the fuel-lean gas diffuses into the fuel- $1, \mathrm{ch}$ zones, hydrocarbon radicals react with NO to produce nitrogen-containing species such as $\mathrm{HCN}$ and $\mathrm{NH}_{3}$ which subsequently react with $\mathrm{NO}$ to form $\mathrm{N}_{2}$. Reburning has not been applied to reduce $\mathrm{NO}_{\mathrm{x}}$ in diesel engines, but the process has been used extensively on combined-cycle gas turbine systems where $\mathrm{NO}_{\mathrm{x}}$ reductions of up to 50 percent have been demonstrated. ${ }^{(11)}$ The diesel operating conditions are different from those in boilers and furnaces in two important regards: the oxygen content of the exhaust gas is higher and the temperature is lower. These differences need to be explored on a laboratory scale to determine if reburning can be applied successfully to the coal-fueled diesel engine. It has been shown that under process conditions of high excess air for application to industrial process heaters ${ }^{(12)}$ reductions of up to 50 percent in $\mathrm{NO}_{\mathrm{x}}$ can be achieved.

Reburning has several advantages that provide the impetus for further study in the coal-fueled engine application. First, the capital cost should be relatively low compared to other candidate $\mathrm{NO}_{\mathrm{x}}$ removal technologies. The operating cost will consist solely of the cost of the secondary fuel. Second, the reburning process will increase the gas temperature and some of the added heat will be recovered in the waste heat boiler. The higher temperatures will increase the overall thermal efficiency of the process. Finally, the secondary combustion process will reduce the particulate loading in the exhaust gas through partial combustion of the carbon-containing particles in the engine exhaust gas.

In addition to chemical reduction, there are other methods for rernoving $\mathrm{NO}_{\mathrm{x}}$ from exhaust gases. In the temperature range of 275 to $300^{\circ} \mathrm{F}, \mathrm{NO}_{\mathrm{x}}$ is adsorbed by activated carbon, as used in the Foster Wheeler-Bergbau-Forschung process. $^{(8)}$ This process is not judged to be economical for systems below $50 \mathrm{MW}$. However, the carbon-containing particulate matter from the coal-fueled diesel exhaust might have the capability for removing $\mathrm{NO}_{\mathrm{x}}$ via adsorption. Feasibility must be demonstated under the engine exhaust operating conditions. The cost of such a system would be inconsequential. Even if adsor 7 ion does not produce the required $\mathrm{NO}_{\mathrm{x}}$ reducion $\mathrm{i}_{\mathrm{j}}$ itself, it could be combined with another $N \cup_{x}$ reduction technique.

\subsection{Joint $\mathrm{NO}_{\mathbf{x}}-\mathrm{SO}_{2}$ Control Technologies}

Many techniques have been proposed to simultaneously remove $\mathrm{NO}_{\mathrm{x}}$ and $\mathrm{SO}_{2}$. As mentioned above, most of these are not suitable for small engine systems because they involve expensive regeneration and recovery plaris which are not economical on a small scale. We consider one combined removal method which has a relatively inexpensive sulfur removal step. The Takeda process $^{(8)}$ uses an activated carbon catalyst for reduction of $\mathrm{NO}_{\mathrm{x}}$ with ammonia at $450^{\circ} \mathrm{F}$ and absorption of $\mathrm{SO}_{2}$. The $\mathrm{NO}_{\mathrm{x}}$ removal efficiency for this process is 90 percent and that for $\mathrm{SO}_{2}$ is 
80 percent. The catalyst regeneration is accomplished by washing with water. The water is then mixed with lime and the resulting $\mathrm{CaSO}_{4}$ is thrown away. This process has the advantage of removing two of the three major pollutants and has been demonstrated on a pilot scale in Japan. Major disadvantage are the cost and complexity of the process.

\section{3 $\mathrm{SO}_{2}$ Control Technologies}

The most common method for the removal of $\mathrm{SO}_{2}$ from exhaust gas streams is absorption. The techisiques investigated as part of this study involve absorption of $\mathrm{SO}_{2}$ followed by chemical reaction with an alkaline material. Large flue gas desulfurization systems that are used in applications such as power plants usually employ wet limestone scrubbers. Dry scrubbers or spray dryers are also commercially available and are cheaper than wet scrubbers, particularly on the scale of engine-based systems. However, the capital cost for spray dryers is high: $\$ 150$ to $\$ 200 / \mathrm{kW}$ for large boiler systems. The cost per kilowatt will be substantially higher for the small systems in this study. Thus, spray dryers are commercially available, but the high cost provides incentive for examining alternate $\mathrm{SO}_{2}$ removal techniques.

Direct injection of a sorbent material into a duct or into the furnace itself reduces the capital cost of $\mathrm{SO}_{2}$ removal systems dramatically. The chemistry remains the same: a calcium or sodium compound (carbonate, hydroxide, or oxide) reacts with $\mathrm{SO}_{2}$ in the gas to form a sulfate. A baghouse collects the spent sorbent, which may be recycled or thrown away. Sorbent injection has been demonstrated in three temperature regimes which in boilers correspond to one of the following locations, the upper furnace $\left(1600\right.$ to $\left.2200^{\circ} \mathrm{F}\right)$, the economizer $\left(800\right.$ to $\left.1200^{\circ} \mathrm{F}\right)$, and downstream of the air preheater $\left(300^{\circ} \mathrm{F}\right)$. In the coal-fueled diesel engine, only the last two temperature regimes fran be achieved. In the context of the engine, we refer to sorbent injection at either high $\left(800\right.$ to $\left.1200^{\circ} \mathrm{F}\right)$ or low $\left(250\right.$ to $\left.400^{\circ} \mathrm{F}\right)$ temperatures. In the former situation, the sorbent is injected upstream of the waste heat boiler. A duct burner may be required to raise the gas temperature to the optimum temperature. For low temperature injection, sorbent is injected upstream of a baghouse.

Both sodium and calcium sorbents have been used for direct injection processes. The former are more likely to be used in regenerable schemes, the latter in throw-away schemes. In this study, only throw-away schemes employing calcium-containing sorbents are considered. Calcium utilization (defined as the amount of calcium converted to $\mathrm{CaSO}_{4}$ ) in the range of 35 to 40 percent has been demonstrated from the injection of calcium hydroxide at 800 to $1200^{\circ} \mathrm{F}^{(13)}$ In other words, a molar calcium-to-sulfur ratio of two is required to remove 70 percent of the sulfur at these temperatures. Sodium sorbents give similar results in the high temperature regime $e^{(14)}$ and show higher utilizations at the low temperature regime. ${ }^{(15)}$

A slightly different approach to sorbent injection involves adding a calcium compound directly to the fuel. Thus the sorbent contacts $\mathrm{SO}_{2}$ at the very high temperatures in the cylinder. Organic compounds such as calcium acetate would be readily compatible with the coal-water slurry. The calcium oxide aerosol that forms during combustion would consist of very small particles and might be very efficient at removing $\mathrm{SO}_{2}$. This process has not been demonstrated in an engine. The effect of the calcium oxide aerosol on the turbocharger and other engine components is also not known. 


\subsection{Particulate Control Technologies}

For removal of particulates, a baghouse is the control technology of choice. Units are commercially available in the sizes required for the coal-fueled diesel engine with operating temperatures up to $450^{\circ} \mathrm{F}$. However, since the baghouse would be located downstream of the turbocharger, a significant question concerns whether the turbocharger can tolerate the larger particles (say 5 to 50 microns) that may be present in the engine exhaust gas. Gas turbines cannot tolerate particles in excess of approximately 5 microns. ${ }^{(16)}$ Even though diesel turbochargers operate under much less severe temperature and density conditions than gas turbines, it is possible that the turbocharger will not be able to withstand particles larger than 5 microns without wear. In this case, a cyclone will be placed between the exhaust manifold and the turbocharger to remove larger particles.

Cyclones do not remove particles efficiently below 1 to 5 microns. However, if the loading of submicron particles is high, the turbocharger may be compromised even with the use of a cyclone. In the event that all particles have to be removed upstream of the turbocharger, a technique will have to be used that removes all particles at a temperature of $880^{\circ} \mathrm{F}$. Baghouses are not made to withstand these temperatures, but several technologies are under development for coal-fired gas turbines that may be applicable to the engine system. Neither of the two technologies discussed here are available commercially, but both have undergone extensive testing at higher temperatures and pressures than found in the coal-fueled diesel engine system.

The granular bed filter has been discussed already. In brief, it consists of a moving bed of alumina pellets. The filter media are continuously withdrawn from the filtration vessel, cleaned, and returned to the vessel. The system has been operated successfully at $1600^{\circ} \mathrm{F}$ over a $1500 \mathrm{hr}$ time period. ${ }^{(9)}$ An alternative to the granular bed filter is the ceramic cross flow filter. ${ }^{(10)}$ Dirty gas is forced through a porous ceramic material, trapping particles. High pressure air is backflushed through the filter to remove the particles which are subsequently collected. A filter element performed successfully at 1400 to $1450^{\circ} \mathrm{F}$ for over $250 \mathrm{hr}$, which included over 1000 cleaning cycles.

\section{SELECTION OF INTEGRATED SYSTEM DESIGN OPTIONS}

The various technologies for reducing the three major pollutants must be combined into a complete emission control system. Several system configurations were considered. The goal in the selection of system options is to provide emission control system designs that span a range of cost and probability of technical success. Some of the technologies that promise to be low in cost are not available on a commercial scale and thus pose a higher technical risk of development. Figure V-1A shows an example of one of many design configurations that were analyzed.

The probability of technical success of a technology can be derived from the state of its development. We have presented an overview of the individual technologies above. Table V-5 summarizes the progress toward commercialization for each of the candidate control technologies. Technologies that are commercially available for stationary diesel engines are given a probability of one for technical success. For non-commercial technologies, the size of the largest demonstration and its applicability to the coal-fueled diesel cperating conditions determines the probability of technical success. 

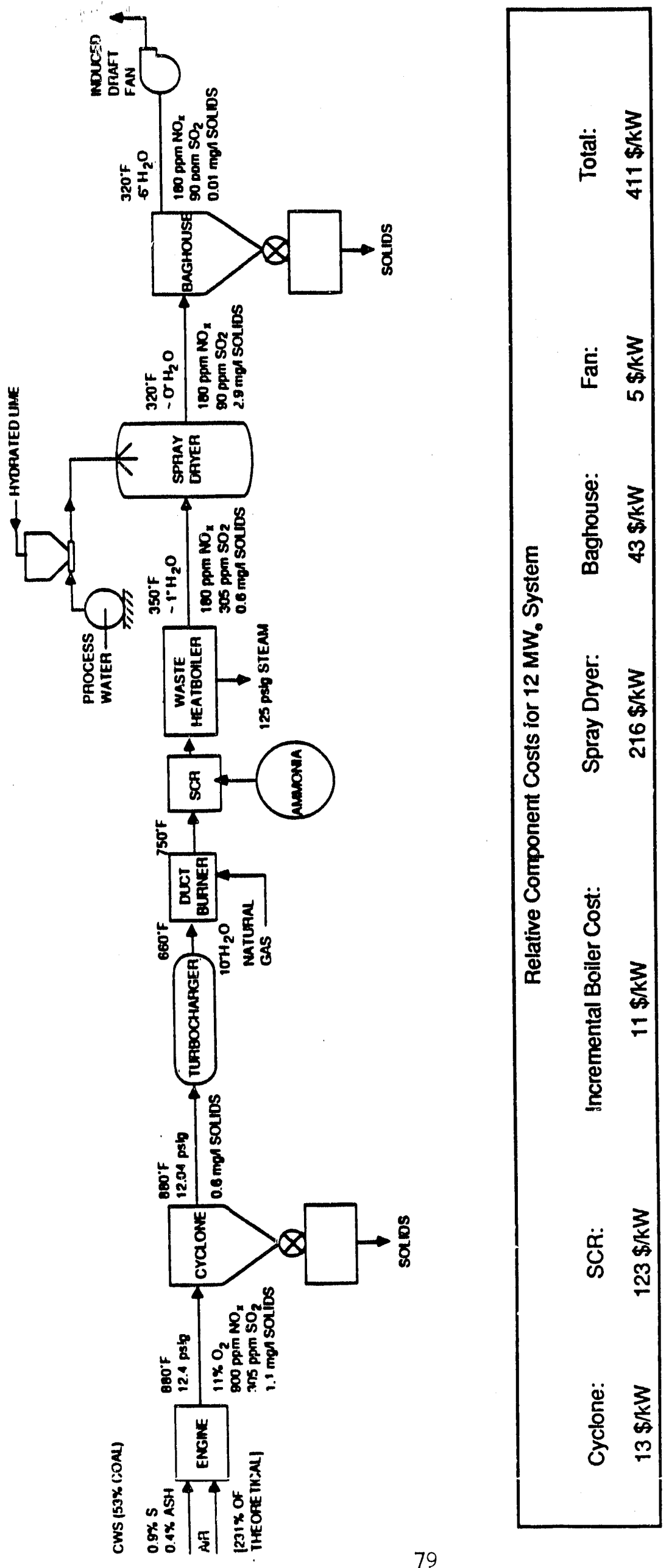

局 
Table V-5

PROBABILITY OF TECHNICAL SUCCESS FOR EMISSION CONTROL TECHNOLOGIES

\begin{tabular}{|c|c|c|c|c|c|c|}
\hline Subsystem Option & $\begin{array}{l}\text { Robability } \\
\text { of sudcess }\end{array}$ & $\begin{array}{c}\text { Unit } \\
(20-100 \mathrm{MW})\end{array}$ & $\begin{array}{l}\text { Demo. } \\
\text { (ca. } 1 \mathrm{MW} \text { ) }\end{array}$ & $\begin{array}{l}\text { Pilot } \\
\text { Demo }\end{array}$ & $\begin{array}{l}\text { Bench } \\
\text { Scale }\end{array}$ & $\begin{array}{l}\text { Lab } \\
\text { Demo }\end{array}$ \\
\hline \multicolumn{7}{|l|}{ NOx Control: } \\
\hline Rebuming & 0.75 & No & No & Yes $^{(1)}$ & Yes & Yes \\
\hline $\begin{array}{l}\mathrm{NH}_{3} \text { Injection in } \\
\text { Baghouse at } 450^{\circ} \mathrm{F}\end{array}$ & 0.25 & No & No & No & No & Yes \\
\hline $\begin{array}{l}\text { Adsorption of } \mathrm{NO}_{x} \text { at } \\
275^{\circ} \mathrm{F} \text { (Baghouse) }\end{array}$ & 0.20 & No & No & No & No & Yes \\
\hline $\begin{array}{l}\mathrm{NH}_{3} \text { Injection in Gran- } \\
\text { ular Bed Filter } \\
\text { (Shell/UOP) }\end{array}$ & 0.50 & No & Yes $^{(2)}$ & Yes & Yes & Yes \\
\hline Commercial SCR & 0.95 & $\mathrm{Yes}^{(3)}$ & Yes & Yes & Yes & Yes \\
\hline \multicolumn{7}{|l|}{ NOx-SO2 Control: } \\
\hline $\begin{array}{l}\mathrm{NH}_{3} \text { Injection at } 450^{\circ} \mathrm{F} \\
\text { (Takeda) }\end{array}$ & 0.60 & No & No & Yes & Yes & Yes \\
\hline \multicolumn{7}{|l|}{ SO2 Control: } \\
\hline Lime Injection $\left(300^{\circ} \mathrm{F}\right)$ & 0.85 & No & Yes & Yes & Yes & Yes \\
\hline $\begin{array}{l}\text { Lime Injection } \\
\left(1000^{\circ} \mathrm{F}\right)\end{array}$ & 0.50 & No & No & Yes & Yes & Yes \\
\hline Ca Additive in Fuel & 0.20 & No & No & No & No & Yes \\
\hline $\begin{array}{l}\text { Commercial Spray } \\
\text { Dryer }\end{array}$ & 1.0 & Yes & Yes & Yes & Yes & Yes \\
\hline \multicolumn{7}{|l|}{ Particle Control: } \\
\hline Cyclone & 1.0 & Yes & Yes & Yes & Yes & Yes \\
\hline Baghouse & 1.0 & Yes & Yes & Yes & Yes & Yes \\
\hline Ceramic Filter & 0.70 & No & No & Yes & Yes & Yes \\
\hline Granular Bed Filter & 0.65 & No & No & Yes & Yes & Yes \\
\hline
\end{tabular}

Notes:

(1) Not demonstrated under CFD operating conditions

(2) Not demonstrated with granular bed filter

(3) Limited work with diesel engines 
The expected cost of each technology also affects the selection of integrated emission control system options. Without further information about the degree of particle removal required, it seems prudent to use a cyclone upstream of the turbocharger, in addition, a baghouse will be used at low temperatures $\left(300\right.$ to $\left.400^{\circ} \mathrm{F}\right)$. As additional information on turbocharger wear becomes available, the decision to use a cyclone may be re-examined.

Table V-6 contains a matrix of $\mathrm{NO}_{\mathrm{x}}$ and $\mathrm{SO}_{2}$ control technologies. Option A represents a combination of two commercially available technologies: SCR for $\mathrm{NO}_{\mathrm{x}}$ control and a spray dryer for $\mathrm{SO}_{2}$ control. Two alternative technologies, direct injection of sorbent and reburning are estimated to be inexpensive and to have a reasonable probability of technical success. They are combined with one another in Options $B$ and $C$ and paired with a commercially available technology in Options $\mathrm{K}$ and $\mathrm{L}$. Option $\mathrm{M}$ consists of the Takeda process alone since it is a joint $\mathrm{NO}_{\mathrm{x}}$ and $\mathrm{SO}_{2}$ removal technique. Option $\mathrm{N}$ combines the spray dryer with $\mathrm{NO}_{\mathrm{x}}$ absorption on a carbon bed. Option $\mathrm{D}$ combines the Shell/UOP process for $\mathrm{NO}_{\mathrm{x}}$ removal with the addition of a calcium additive to the coal-water slurry. Direct injection of lime is also included in Option D in the event that only a limited amount of calcium compound can be added with the fuel. The cost of direct injection will be much less than the cost of the $\mathrm{NO}_{\mathrm{x}}$ control unit or the calcium additive. In the economic analysis, the cost of equipment is calculated for each technology and then capital and operating costs are figured for each option. The basis for these calculations is discussed in the next section. Appendix $\mathrm{G}$ crntains process diagrams corresponding to the system options discussed here.

\section{COST ANALYSIS METHODOLOGY AND ASSUMPTIONS}

\section{Methodology}

The method used to arrive at capital costs in this study is based on the methodology recommended by Electric Power Research Institute (EPRI) ${ }^{17}$. Appendix $\mathrm{H}$ provides the details of each calculation, by option and by system size. The reader may wish to refer to the appendix for an example of the format that is discussed here.

The Total Capital Investment (TCI) is one of the most important results of the economic analysis. The TCI represents the sum of the Total Plant Cost (TPC), royalties (where applicable), preproduction costs, inventory capital, and initial catalyst and chemical charge. The cost of land is not included here as it is in the EPRI Methodology. A royalty allowance equal to 0.5 percent of the process capital is used on proprietary processes. Process capital is defined as the total cost of each unit, including equipment and all installation costs (labor and materials). The preproduction costs consist of the following: one month of fixed operating costs, one month of variable operating costs at full capacity, and 2 percent of TPC. The last charge covers modification to the equipment needed at start-up. The inventory capital is equal to 60 days of variable operating costs, excluding power, steam, process water, and disposal costs. The initial supplies and materials cost accounts for supplies needed for start-up of the unit. In the case of processes requiring a catalyst. the equipment cost does not include the catalyst cost. Instead, the initial catalyst is accounted for in the start-up costs. For process chemicals, a fifteen day supply is assumed as an initial charge. The Total Plant Cost (TPC) is the sum of Process Capital, General Facilities Cost, Engineering and Home Office Fees, and Project Contingency Cost. The Process Contingency used in the EPRI Methodology accounts for the effect of the status of process 

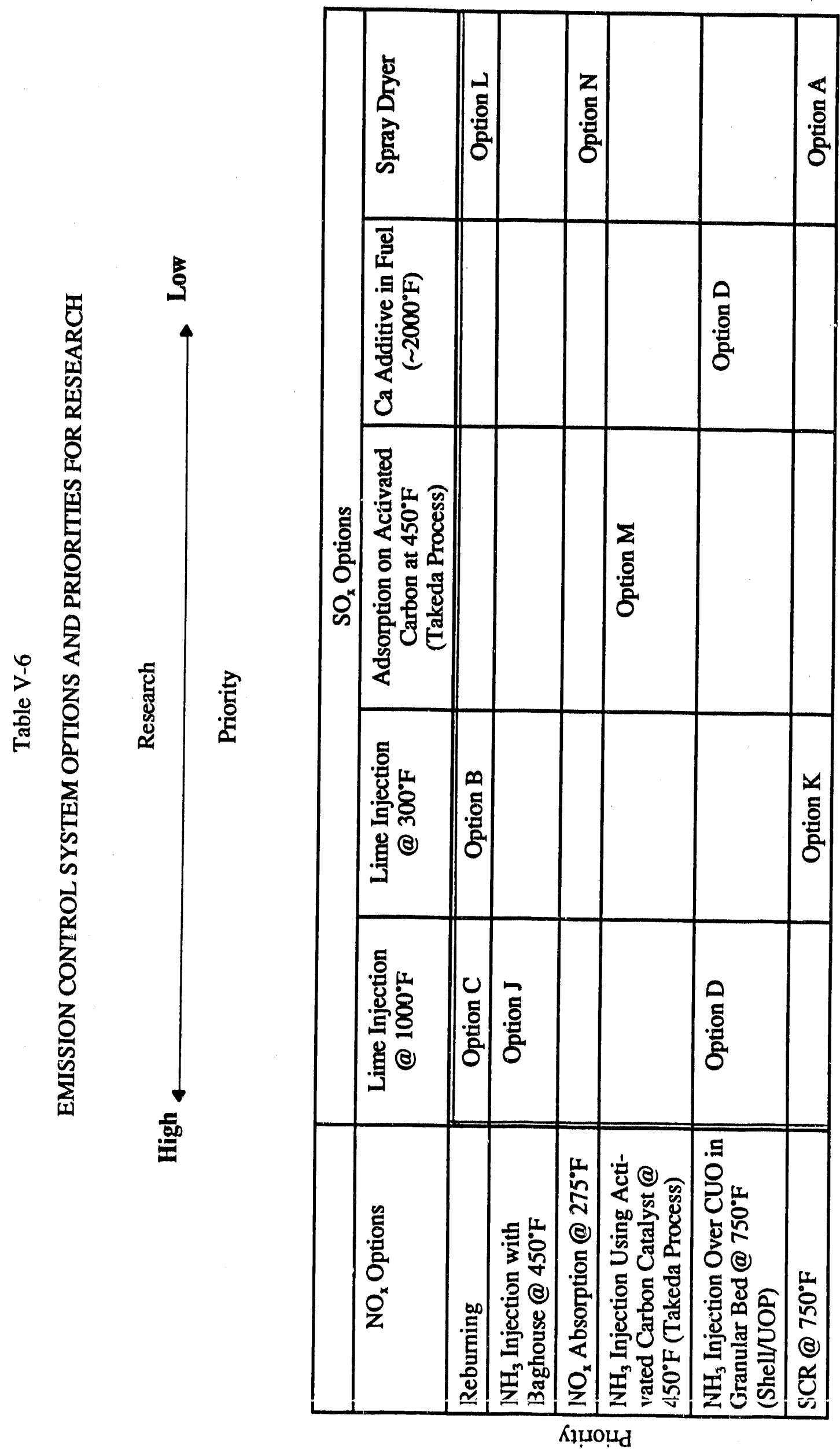

บริ!H

чวreวsəy 
development on the design and cost of commercial-scale equipment. We do not apply a process contingency to the capital cost; instead we use the probability of technical success as a separate measure of the status of process development. In addition, the EPRI Methodology includes an allowance for escalation of construction costs over the construction period which is not used in this analysis because the construction period for small power plants is expected to be short. The General Facilities charge and the Engineering and Home Office Fees are assessed at 5 and 10 percent of the Process Capital, respectively. The Project Contingency Cost is computed as 20 percent of the sum of the Process Capital and General Facilities costs as appropriate for a preliminary design (as defined in Table V-7). The Process Capita' (sometimes referred to as the installed equipment cost) is the total constructed cost of all equipment, including direct and indirect construction costs. Fees for freight and sales tax are included in the equipment cost. Direct installation costs account for the labor and materials costs of installation, including costs for site preparation and buildings. Indirect installation costs consist of the following: engineering and supervision labor, construction and field labor, aisy construction fees, and a small contingency fee. Reference 18 gives values for the direct and indirect installation cost components for most types of pollution control units.

The Operating and Maintenance Cost is the sum of operating labor, maintenance (labor and materials), and overhead labor. The annual maintenance costs are estimated as a percentage of the process capital cost. The EPRI methodology suggests maintenance cost factors for different technologies. The maintenance cost is broken down as 40 percent labor and 60 percent materials. The overhead charge is computed as 30 percent of the operating and maintenance labor and is a charge for administrative and support labor. Following the EPRI methodology, the Operating and Maintenance Cost is broken down into a fixed component and a variable component. The fixed Operating and Maintenance cost is the product of the capacity factor (or the utilization) and the annual Operating and Maintenance Costs; the balance of the cost is assumed to be variable. The Variable Operating cost has two components: consumables (power, chemicals, etc.) and operating and maintenance, as described above.

The total annual operating cost is the sum of the fixed Operating and Maintenance cost, the Variable Operating cost, and the cost of capital. The cost of capital is based on a 12 year allowable depreciation period for paying the debt at 10 percent interest. Accordingly, the yearly charge for the cost of capital is 15 percent of the total capital investment. The operating cost is expressed in millions of dollars per year or in mills $/ \mathrm{kWh}$. The latter unit is the annual operatin $n_{\xi}$ cost (expressed as thousandths of a dollar) divided by the total hours that the equipment runs (at 65 percent utilization this is equal to $5694 \mathrm{hr}$ ) and the power output of the facility (in kW).

\section{Cost Estimation For Individ ual Subsystems}

The system capital and operating cost estimates depend on the actual cost of the equipment, being proportional to the equipment costs. In general, equipment costs are derived in two different ways. First, a study estimate is one based on previous cost data, but scaled for the particular system size (see Reference 19 for examples of scaling factors and Reference 18 for cost correlations for specific equipment); this type of estimate has probable accuracy oi 30 to 50 percent. Second, a scope estimate is based on specific equipment costs, usually obtained in quote form from the manufacturer; this type of estimate has a probable accuracy of 10 to 20 percent. 


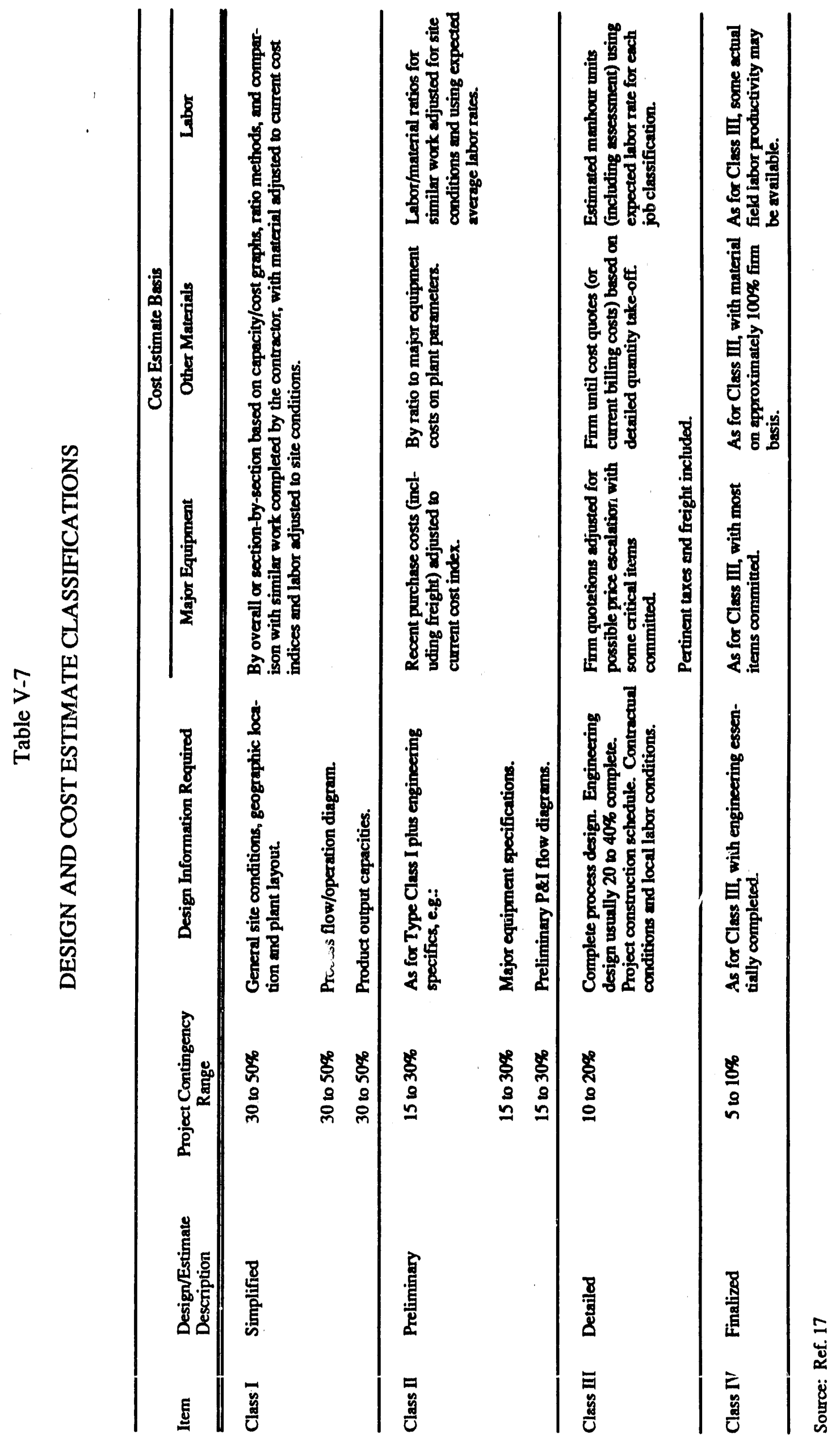


Most cost data used in this study are based on conditions at some time in the past. Prices change with time and some method must be used to convert prices applicable at some time in the past to prices at some later time. For this study, the Chemical Engineering Index was used to convert all prices to March, 1988 prices. Prices are scaled by multiplying by the ratio of the March, 1988 index to the index at the original date of the price.

Table V-8 lists the methods used to calculate equipment costs for individual subsystems. Most of the study estimates are based on the methods in Reference 18, wherein specific correlations between cost, size, and operating parameters are provided for gas conditioning equipment such as baghouses, fans, and water quench units.

The cost for reburning is the sum of the cost of a duct burner and $\mathrm{NO}_{x}$ monitoring equipment. One duct burner is used per engine. For the LSB 6 engine, the burner must supply $4 \mathrm{MMBtu} / \mathrm{hr}$ of heat if the reburning process represents 20 percent of the total heat input. For the LSVB 20 engine, the burner must supply $13 \mathrm{MMBtu} / \mathrm{hr}$. Three burner manufacturers were contacted; one quote was used for the duct burner costs because it was the most complete of the three.

For all SCR processes, a standard cost for the ammonia injection and storage system was used. This cost was drawn from the detailed cost breakdown of commercial SCR units. The sources of the commercial SCR costs are discussed below.

The cost for ammonia injection in the baghouse at $450^{\circ} \mathrm{F}$ is the sum of $\mathrm{NO}_{\mathrm{x}}$ monitoring equipment and ammonia injection and storage equipment. In addition, the system option that incorporates this technology uses an insulated baghouse which is more expensive than the baghouses used for other systems. The insulated baghouse costs were estimated using correlations from Reference 18.

The cost for the Shell/UOP process is the sum of costs for an ammonia injection and storage system, NOx monitoring equipment, and a granular bed filter unit sized by using a design value of the face velocity from Reference 20 . The granular bed filtration unit equipment costs are discussed below.

In the case of the commercial SCR technology, cost data are available for engines in the range of 2000 to $60,000 \mathrm{hp}$. SCR costs are scaled by engine size using data on several engine sizes. The three data sets provide detailed equipment costs, but do not include complete capital cost information. ${ }^{(2122)}$ An EPRI report ${ }^{(23)}$ gives equipment and capital costs for a $80 \mathrm{MW}$ utility boiler. The power boiler rating can be converted to an equivalent engine size by using the total exhaust flow throw the SCR unit and a typical engine exhaust flow of $13 \mathrm{lb} / \mathrm{hp}$-hr. The two estimates given in the EPRI report show a detailed breakdown of the capital costs. One (reference 24) gives SCR capital costs for a range of engine sizes. No detailed equipment costs are given.

The costs from all SCR data sets are given in March, 1988 dollars in Table V-9. The capital, equipment (excluding catalyst), and catalyst costs are displayed as a function of the system horsepower in Figure V-2. The capital costs fall on straight line with slope equal to 0.49 . The equipment costs seem to be low for the smaller two systems by comparison with the capital cost data. A line with slope equal to 0.3 has been drawn through the equipment cost data. The rela- 
Table V-8

\section{METHODS USED TO ESTIMATE SUBSYSTEM EQUIPMENT COSTS}

\begin{tabular}{|c|c|c|c|}
\hline Subsystem Option & Estimation Method & References & Accuracy \\
\hline \multicolumn{4}{|l|}{$\mathrm{NQ}_{3}$ Control: } \\
\hline Reburning & Quotes from bumer manufacturer & & $30 \%$ \\
\hline $\begin{array}{l}\mathrm{NH}_{3} \text { Injection in Baghouse at } \\
450^{\circ} \mathrm{F}\end{array}$ & $\begin{array}{l}\mathrm{NH}_{3} \text { injection based on SCR cost; study estimate } \\
\text { for baghouse }\end{array}$ & 18 & $30 \%$ \\
\hline $\begin{array}{l}\text { Adsorption of } \mathrm{NO}_{x} \text { at } 275^{\circ} \mathrm{F} \\
\text { (Baghouse) }\end{array}$ & Based on estimate of differential disposal cost & & $20 \%$ \\
\hline $\begin{array}{l}\mathrm{NH}_{3} \text { Injection in Granular Bed } \\
\text { Filter (Shell/UOP) }\end{array}$ & $\begin{array}{l}\mathrm{NH}_{3} \text { injection based on SCR cost; study estimate } \\
\text { scaled down }\end{array}$ & 20 & $50 \%$ \\
\hline Commercial SCR & Cost vs. engine size discussed in text & $21,22,23$ & $30 \%$ \\
\hline \multicolumn{4}{|l|}{$\mathrm{NO}_{3}-\mathrm{SO}_{2}$ Control: } \\
\hline $\begin{array}{l}\mathrm{NH}_{3} \text { Injection at } 450^{\circ} \mathrm{F} \\
\text { (Takeda) }\end{array}$ & Study estimate on cost of components & $8,18,20$ & $50 \%$ \\
\hline \multicolumn{4}{|l|}{$\mathrm{SO}_{2}$ Control: } \\
\hline Lime Injection $\left(300^{\circ} \mathrm{F}\right)$ & $\begin{array}{l}\text { Manufacturer quotes for small size; larger sizes } \\
\text { scaled up }\end{array}$ & 15,18 & $30 \%$ \\
\hline Lime Injection $\left(1000^{\circ} \mathrm{F}\right)$ & Same as $300^{\circ} \mathrm{F}$ case & & \\
\hline Ca Additive in Fuel & Bulk price estimated from Aldrich catalog & & $50 \%$ \\
\hline Commercial Spray Dryer & Budgetary estimate from manufacturer & & $20 \%$ \\
\hline \multicolumn{4}{|l|}{ Particle Control: } \\
\hline Cyclone & Quote from manufacturer & & $10 \%$ \\
\hline Baghouse & Quote from manufacturer & & $10 \%$ \\
\hline Ceramic Filter & Study estimate on cost of components & 18,25 & $50 \%$ \\
\hline Granular Bed Filter & Study estimate on cost of components & 18,20 & $50 \%$ \\
\hline \multicolumn{4}{|l|}{ Auxiliary Equipment: } \\
\hline Induced Draft Fan & Study estimate & 18 & $30 \%$ \\
\hline $\begin{array}{l}\text { Water Quench } \\
\text { (for power system) }\end{array}$ & Study estimate & 18 & $30 \%$ \\
\hline Waste Heat Boiler & Scaled from LSVB 20 size & 19 & $30 \%$ \\
\hline
\end{tabular}


Table V-9

SUMMARY OF SCR COST DATA

\begin{tabular}{|c|c|c|c|c|}
\hline \multirow{2}{*}{ Reference } & \multirow{2}{*}{ Horsepower } & \multicolumn{3}{|c|}{ Cost in $\$ / \mathrm{hp}^{(1)}$} \\
\cline { 3 - 5 } & Catalyst Cost & $\begin{array}{c}\text { Equipment } \\
\text { Cost }^{(2)}\end{array}$ & Capital Cost \\
\hline 24 & 1,072 & - & - & 746 \\
21 & 2,000 & 25 & 52 & - \\
21 & 5,500 & 25 & 27 & - \\
24 & 9,600 & 29 & 26 & - \\
24 & 11,796 & - & - & 172 \\
23 & 28,150 & - & - & 145 \\
23 & $65,210^{(3)}$ & 29 & 24 & - \\
\hline
\end{tabular}

Notes:

(1) March 1988 \$

(2)Excluding catalyst cost

${ }^{(3)}$ Calculated from exhaust flow using $13 \mathrm{lb} / \mathrm{hp}-\mathrm{hr}$ 


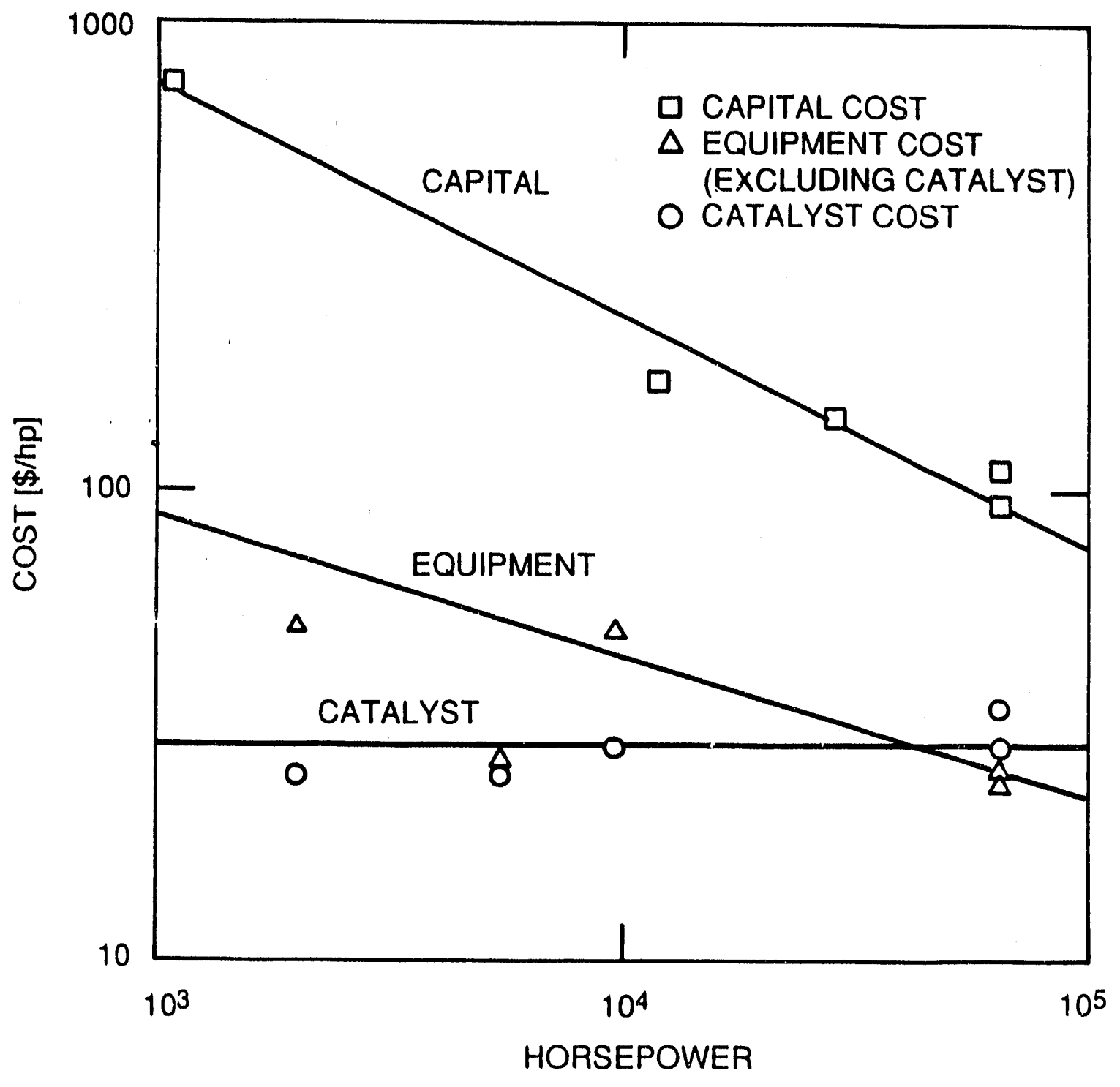

A.9671

Figure V-2. Cost of SCR for Engine Emission Control 
tive cutalyst costs are almost constant with system horsepower and are taksn to be $\$ 29 / \mathrm{h}$ p. Based on these data, the equipment and catalyst costs for four coal-fueled diesel systems wire determined from the graph (Table V-10).

Capital and operating costs for the Takeda process for one $33 \mathrm{MWe}$ unit are given in Refererce 8 , but no details are given. The costs presented here are study estimates based on the process diagram; the costs of individual pieces of equipment are computed using estimation methods from References 18 and 19. Reference 18 gives a method for calculation of cost of a gas absorber consisting of a bed of activated carbon; the unit has two such absorbers. Reference 15 gives a detailed process diagram for a sorbent injection system from which the equipment list is derived for this estimate. Three manufacturers were contacted for quotes on a sorbent injection system for a single LSB 6 engine (approximately $100 \mathrm{lb} / \mathrm{hr}$ of sorbent). One qucte was for a complete system and the other two included only the feeder itself. The cost of a sorbent feeding system for the smallest system is based on the cost of the feeder and auxiliary equipment (except duct work which is included in installation costs). Equipment costs for larger systems are computed by scaling the solid feed rate using an exponent of 0.6 .

Cost $_{2}=$ Cost $_{1} \times\left(\frac{\text { FeedRate }_{2}}{\text { FeedRate }_{1}}\right)^{0.6}$

Spray dryer equipnnent cost quotes were provided by one manufacturer for all four system sizes. Although several nianufacturers of spray dryers were contacted, only one soid equipment in the size range of the erigine systems.

Quotes were obtained from two manufacturers for cyclones. One manufacturer provided data for both the LSB 6 and LSVB 20 engine size. Both quotes agreed well with the calculation methad given in Reference 18. Since the cyclone is upstream of the turbocharger, emission control systems have one cyclione per engine. Therefore the cost of cyclones is the number of engines multiplied by the single byclone cost.

Reference 18 gives detailed methods for estimating the cost of baghouses. The cost is based on the gas flow rate, the gas face velocity (or air-to-cloth ratio), the type of baghouse (reverse air or pulsed jet), and the filter material. Costs for both pulsed jet and reverse air were calculated for all four system sizes. For this study, the reverse air baghouse was chosen because it was cheaper than the pulsed jet baghouse for the flow rates in question. A quote was also received from a manufacturer of pulsed jet baghouses detailing the cost for all four system sizes and the quoted costs were within about 5 percent of the calculated costs from Reference 18. The cost of insulated reverse air baghouse was also calculated for system Option J.

Equipment cost estimates for the ceramic cross flow filter units were assembled from the detailed component cost data in Reference 25. The principal sizing parameter utilized for calculating the total filter area and the vessel size is the filter face velocity, taken to be $10 \mathrm{ft} / \mathrm{min}$ as suggested in Reference 25 . One cross flow filter unit is used for each engine. 
Table V-10

SCR EQUIPMENT AIID CATALYST COSTS USED IN ECONOMIC ANALYSIS

\begin{tabular}{|c|c|c|}
\hline $\begin{array}{c}\text { System Power } \\
\text { [hp] }\end{array}$ & $\begin{array}{c}\text { Equipment Cost } \\
{[\$ / \mathrm{hp}]}\end{array}$ & $\begin{array}{c}\text { Catalyst Cost } \\
{[\$ / \mathrm{hp}]}\end{array}$ \\
\hline 2,516 & 66 & 29 \\
10,064 & 43 & 29 \\
16,772 & 38 & 29 \\
\hline 33,544 & 31 & 29 \\
\hline
\end{tabular}


Component cost data presented in Reference 20 are employed to determine equipment cost estimates for the granular bed filter. Sizing of the units was based on the recommended value for filter face velocity of $110 \mathrm{ft} / \mathrm{min}$. The cost per filter element as well as typical costs for vessels and back end cleanup are provided in Reference 20. As with the cross-flow filter, total equipment costs for multiple-engine systems are calculated as the product of the cost per unit and the number of engines in the system.

\section{Cost Of Auxiliary Equipment And System Integration}

Auxiliary equipment is common to all systems, independent of which emission control subsystems are chosen. Because of the pressure drop through the various emission control modules, an induced draft fan will be needed to draw gas through the exhaust system. The cost of the fan is based on a static pressure of 10 inches of water. Using the methods outlined in Reference 18, the cost of a fan, motor, and starter are calculated for each system size.

In the case of the system for power generation only, there is no waste heat boiler to cool the exhaust gases down to approximately $350^{\circ} \mathrm{F}$. A water quench unit can be used to lower the exhaust gas temperature for those components requiring a temperature less than that at the turbocharger exhausit. A correlation for the cost of water quench units (including a chamber, supports and controls) with gas flow is given in Reference 18. One manufacturer was contacted concerning water quench units and the quote was lower than the calculated costs. In order to be conservative for this cost estimate, the calculated cost was used.

The goal of the economic analysis is to compare the added cost of the coal-fueled diesel emission control system to the baseline diesel-fueled system. In cogeneration applications, the amount of steam generated and the size of use waste heat boiler depend on the temperature drop through the heat exchanger and the total gas flow. The exhaust gas temperatures at the inlet and outlet of the waste heat boiler vary depending on which subsystems are used. For example, if reburning is employed as the $\mathrm{NO}_{\mathrm{x}}$ control method, the gas temperature at the boiler inlet is higher than that in the baseline case. In terms of cost, this means a higher stcam credit (because more steam is generated) and a higher boiler cost (because more heat transfer surface is required).

In order to compare the system options to one another, a differential cost relative to the dieselfueled baseline is calculated. Table V-11 shows the results of these calculations for all four cogeneration system sizes. The differential steam flow is expressed in terms of millions of dollars per year, using a steam price of $\$ 5.64$ per thousand pounds of 125 psig steam. The differential capital cost is based on an assumed boiler cost for the diesel-fueled baseline system. This baseline boiler cost is calculated from a cost of $\$ 93,650$ for a single LSVB 20 engine; the boiler cost was supplied by Cooper Bessemer and has been converted to March, 1988 dollars. A scaling exponent of 0.6 is used to obtain the costs for other system sizes. One waste heat boiler per system is assumed. The differential boiler cost (in millions of dollars) is calculated from the ratio of the heat exchange areas of the coal-fueled system relative to the diesel-fueled system and a scaling exponent of 0.6 .

Cost $_{2}=$ Cost $_{1} x\left(\frac{\text { SurfaceArea }}{\text { Surface }} \text { Area }_{1}\right)^{0.6}$ 


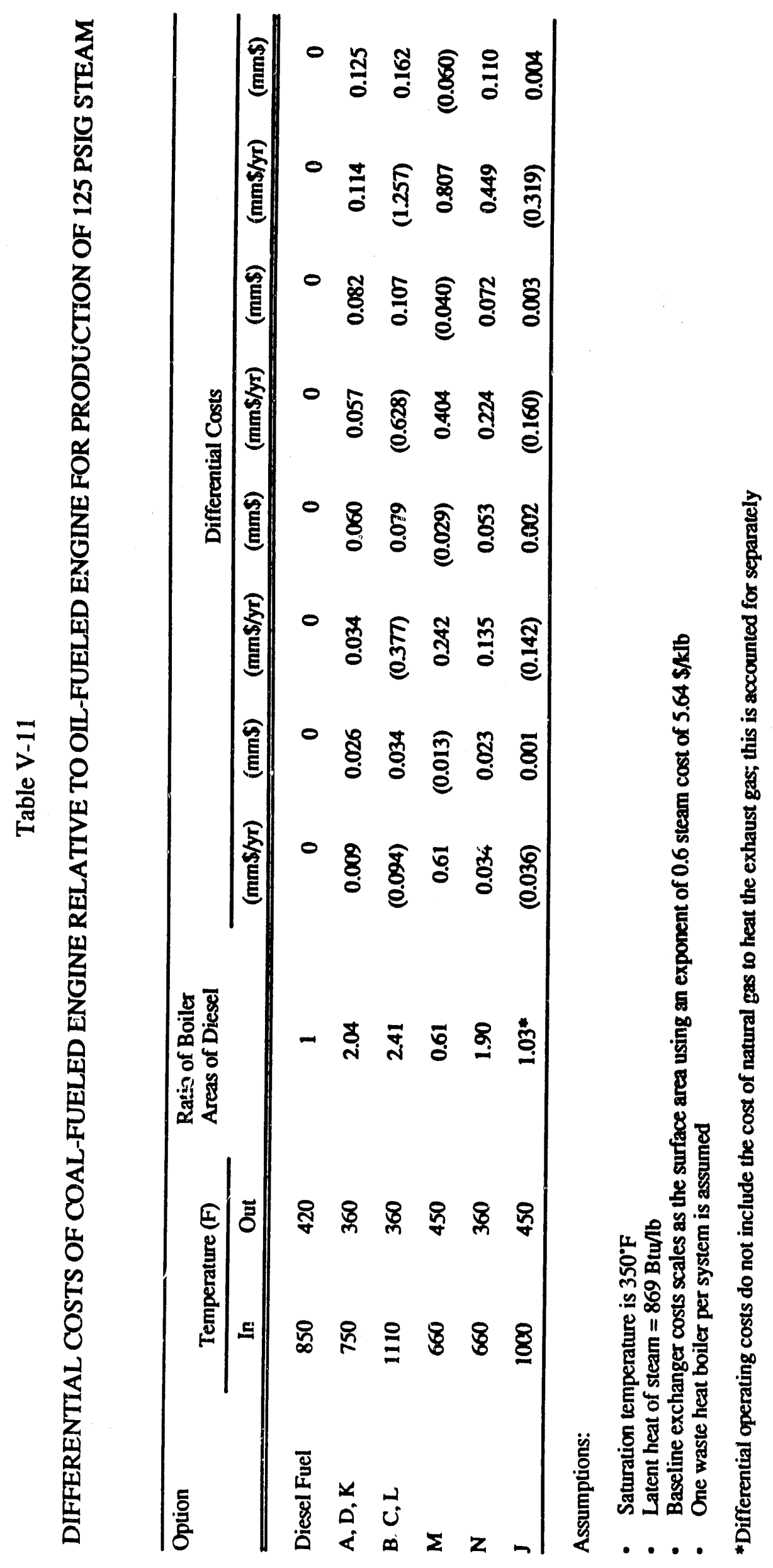




\section{Assembly Of System Costs}

The installed equipment costs for individual subsystems have been calculated as discussed in the previous two sections. The results of these calculations (Table V-12) will be used to compute costs for the integrated emission control systems.

Several assumptions of signiff ance are used in the system cost calculations. First, a decision has been made to combine the exhaust gases downstream of the turbocharger. Second, we have placed the duct burners upstream of the turbocharger to take advantage of the higher gas temperature there. Therefore one duct burner is required for each engine. The duct burner could be placed downstream of the turbocharger without changing the exhaust gas temperatures or pressures. Finally, all control equipment (except the cyclone and duct burner) and the waste heat boiler are common to all engines.

A distinction has been made betwecn power and cogeneration systems. A cogeneration system has a waste heat boiler that produces 125 psig steam. The cost of the waste heat boiler is not included in the system, except if the cost is more (or less) than the diesel-fueled baseline case. The differential equipment cost of the boiler relative to 'he baseline is included in the equipment cost. Likewise, the cost of producing more (or less) steam than the baseline case is included as an operating cost.

The cost of operating labor is based on one half-time operator for the smallest (1.8 $\mathrm{MW}_{\mathrm{e}}$ ) system and one full-time operator for the others. Maintenance factors used to calculate maintenance labor and materials can be found in Appendix $\mathrm{H}$.

Table V-13 lists the prices for consumables used to calculate variable operating costs. The steam cost is based on the replacement value for a utility boiler burning natural gas at $\$ 3.50 / 1000$ cubic feet. The prices for ammonia and activated carbon are from manufacturers. The calcium fuel additive is assumed to be calcium acetate and the cost is equal to one-tenth of the current price for kilogram quantities. Much uncertainty exists about the bulk price for this chemical since it is not intended for large-scale distribution currently. All other costs were taḳen from Reference 17.

The details of all the system cost calculations are given in Appendix $\mathrm{H}$. This procedure will be illustrated with an example, Option A with one LSB 6 engine (1.8 MW $)$.

The calculation begins with a list of equipment. Costs are taken from Tables V-11 and V-12. The installation cost is the sum of the installation costs for each unit. Each subsystem has an installation factor used to calculate the direct and indirect costs, equal to product of the equipment cost and the installation factor. This factor is based on the complexity of the equipment and on industry experience. Reference 18 suggests installation cost factors for some pollution control equipment. References 21 through 23 give installation costs for commercial SCR units. The Total Plant cost is computed as discussed above.

The installed equipment cost is used to calculate the Operating and Maintenance Cost (O\&M) as discussed above. The O\&M cost is divided into fixed and variable costs as a function of the utilization. A utilization of 65 percent is employed throughout. The variable operating cost due to consumable items (power, chemicals, disposal) is computed in terms of dollars per hr of operation. For processes employing a catalyst and for the baghouse, the cost of replacing the catalyst 
Table V-12

EQUIPMENT COSTS FOR SUBSYSTEMS

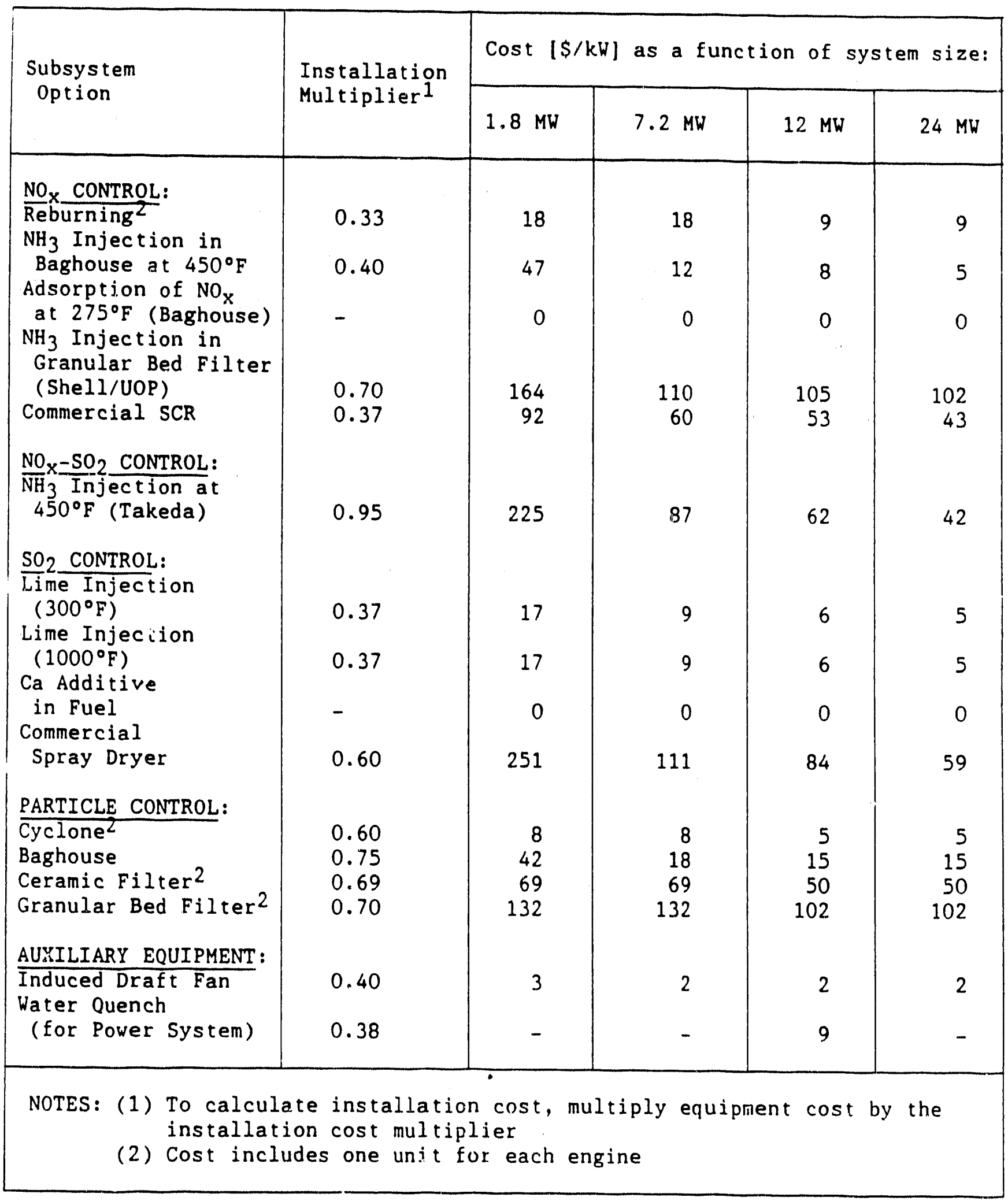


Table V-13

COMMODITY PRICES FOR OPERATING COST CALCULATION

\begin{tabular}{|ll|}
\hline Commodity & Value/Units \\
\hline Operating Labor & $\$ 21.55 /$ hour \\
Natural Gas & $\$ 3.50 / 1000$ cu. ft. \\
Raw Water & \\
Cooling Water & $\$ 0.60 / 1000$ gallon \\
Steam (125 psig) & $\$ 0.15 / 1000$ gallon \\
Power & $\$ 5.64 / 1000 \mathrm{lb}$ \\
& \\
Copper Oxide Catalyst & $\$ 0.05 / \mathrm{kWh}$ \\
Activated Carbon & $\$ 8000 /$ ton \\
Ammonia & $\$ 4000 /$ ton \\
Hydrated Lime & $\$ 500 /$ ton \\
Lime & $\$ 70 /$ ton \\
Calcium Acetate & $\$ 65 /$ ton \\
Waste Disposal & $\$ 4140 /$ ton \\
- Fry Solids & $\$ 6.50 /$ ton \\
- Gypsum & $\$ 9.50 /$ ton \\
\hline Sludge & \\
\hline
\end{tabular}


or bags is included in the consumables. In Option A, the SCR catalyst is assumed to have a 2-year life; the hourly rate is the replacement cost divided by the number of hours of running time in two years. The bags (which are NOMEX cloth) have a one year life. Each calculation in Appendix $\mathrm{H}$ includes an itemized list of consumables.

The variable operating costs and fixed O\&M costs are used to calculate the pre-production and inventory capital costs as described above. These costs and the initial supplies cost are added to the total plant cost to give the total capital cost. Finally, the cost of capital is computed as 15 percent per year of the total capital cost. The total operating cost is the sum of variable, fixed O\&M, and capital costs. To facilitate comparisons among different systems, the total capital costs and operating costs are expressed on a cost per unit of electricity generated in Tables V-14 through V-18.

\section{E. DISCUSSION OF ECONOMIC ANALYSIS}

\section{Cost Vs. System Size}

The goal of this study, as stated earlier, was to quantify the cost and probability of success for the emission control system options. In this section, the analysis of the costs takes several forms. First, the cost of the equipment for the component technologies is presented. From these costs comparisons are made among the various technologies for controlling the three major pollutants. Second, the capital and operating costs for integrated emission control systems are presented as a function of system size. Finally, the probability of technical success for system options is introduced and combined with the operating costs for each system. The discussion of these results provides recommendations for the most favorable emission control options.

Table V-12 gives the cost of equipment for individual control technologies expressed on a per kilowatt basis. For the three major pollutants, several technologies are evaluated, providing a range of costs for controlling each pollutant. Of the $\mathrm{NO}_{\mathrm{x}}$ control technologies, the Shell/UOP process is by far the most expensive. It must be noted, however, that this subsystem also includes removal of all particles is well as control of $\mathrm{NO}_{x}$. Commercial SCR technology is 2 to 5 times more expensive than reburning or ammonia injection in the baghouse. The Takeda process, which removes both $\mathrm{NO}_{\mathrm{x}}$ and $\mathrm{SO}_{2}$, is very expensive for the smallest system, but the capital cost is comparable to that of the commercial SCR for the 12 and $24 \mathrm{MWe}$ systems. The commercial spray dryer for $\mathrm{SO}_{2}$ control is 12 to 15 times more expensive than direct injection of sorbent into the duct.

Although the ceramic cross-flow filter and the granular bed filter are not included in any of the proposed systems, the costs are of interest in the event that the turbocharger needs more protection than offered by a cyclone. These technologies remove all particles upstream of the turbocharger and therefore the cost should be compared against the sum of the cyclone and baghouse costs. The ceramic cross-flow filter is 1.4 to 2.5 times more expensive than the cyclone/baghouse combination. The granular bed filter is 2.6 to 5 times more expensive than the commercially available option. If total particle removal is needed upstream of the turbocharger, the ceramic cross-flow filter is preferred due to the simplicity, relatively affordable cost, and nearcommercial status of the technology. 


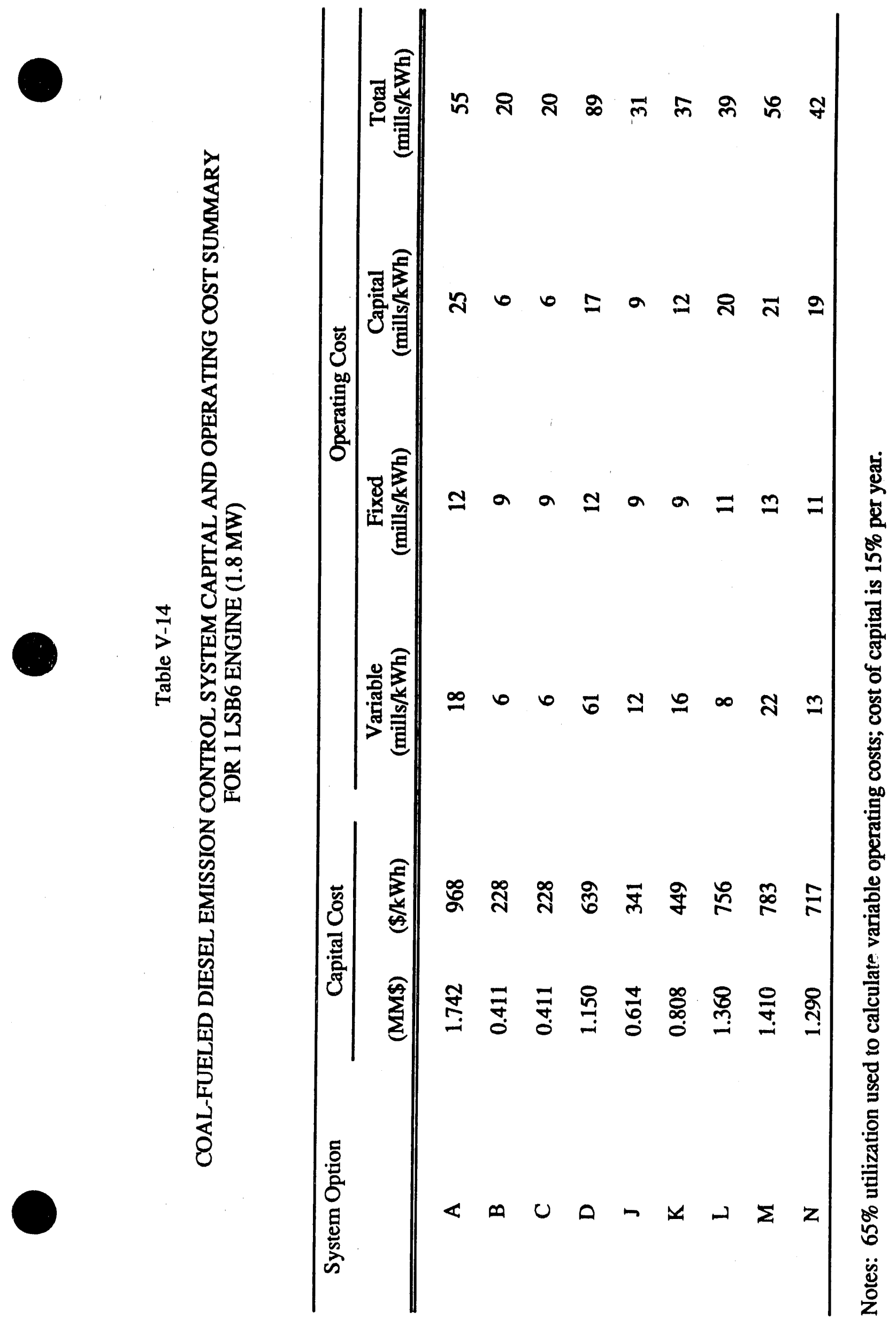




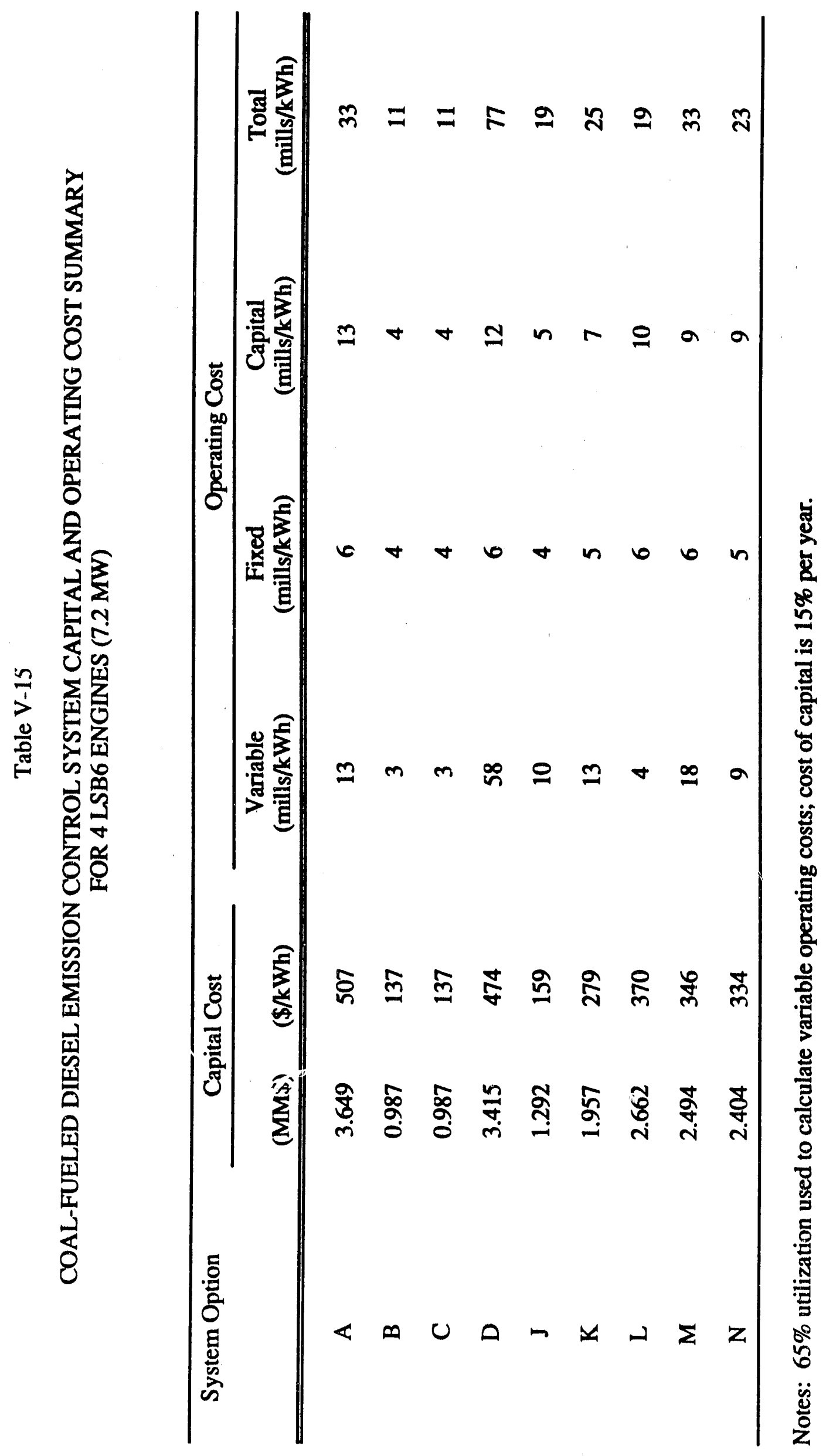




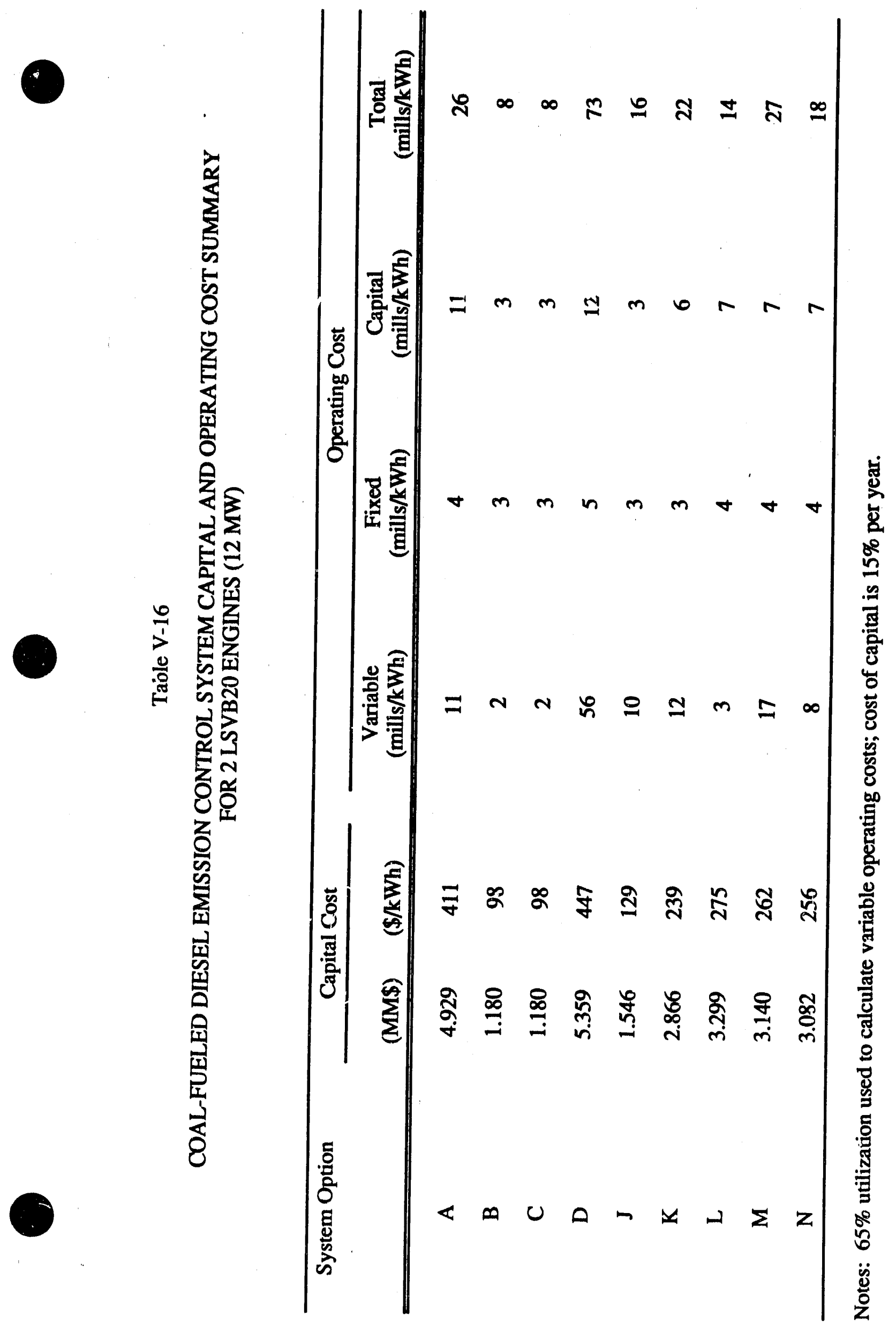




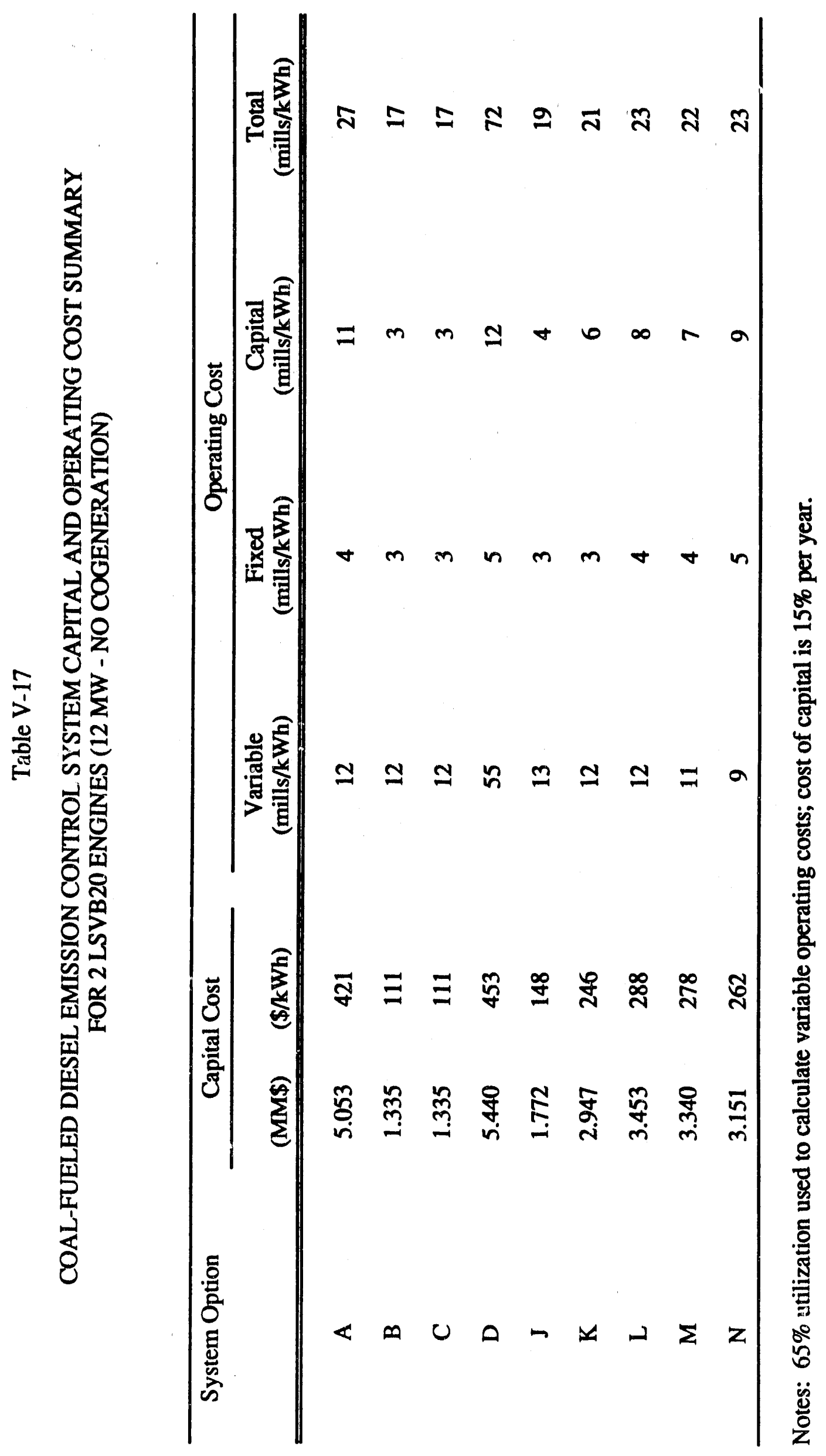

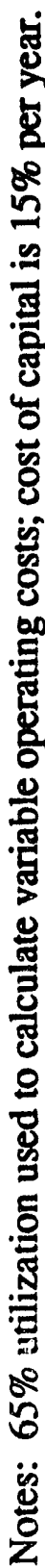




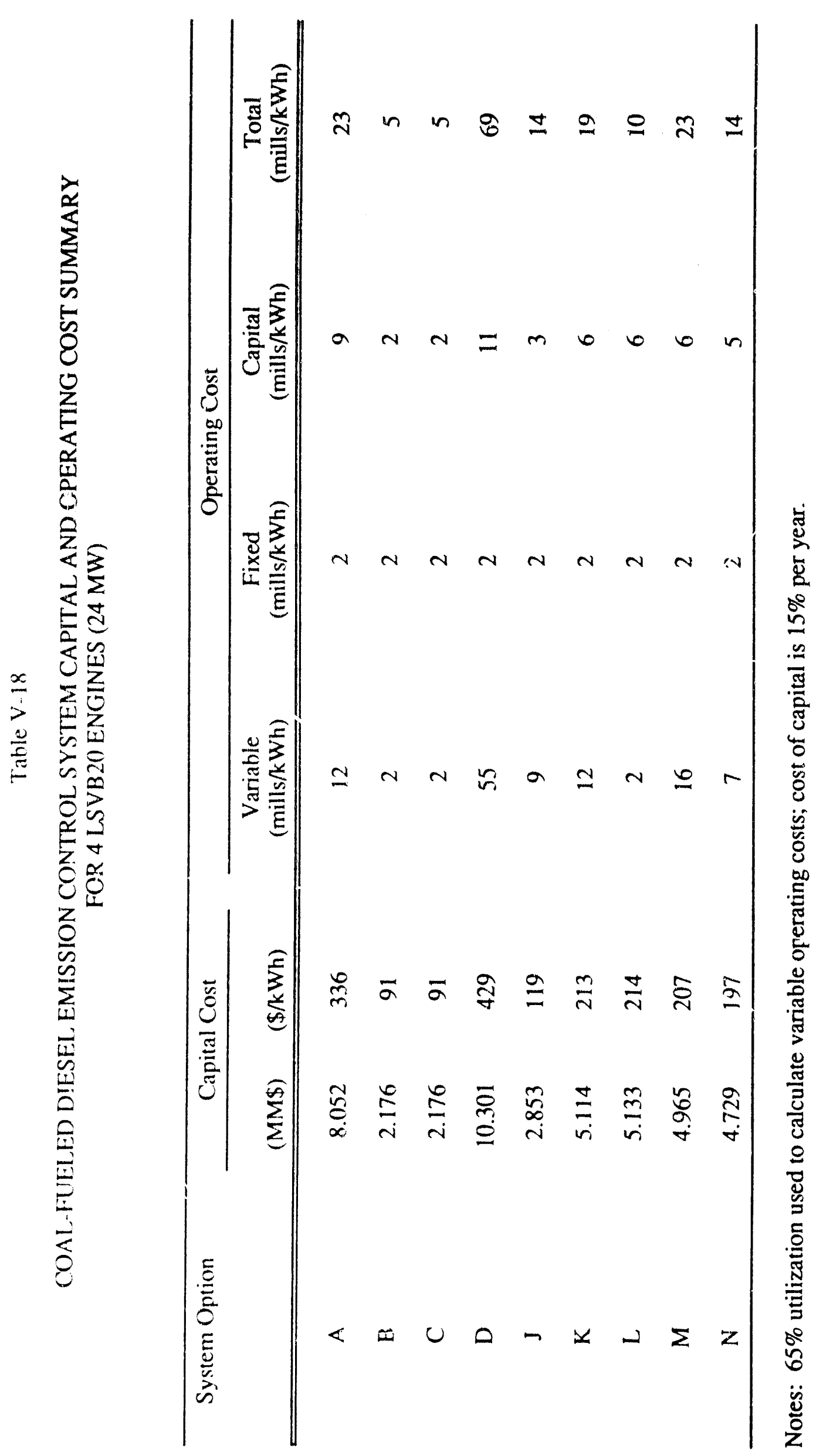


From the equipment cost of individual technologies, the discussion moves to the capital costs of complete emission control systems (Tables V-14 through V-18). Figure V-3 shows that the cost per kilowatt derreases by about a factor of two as the system size increases from 1.8 to $24 \mathrm{MW}$. for the four cogeneration sysiem options studied. The capital cost per kilowatt for the single LSB 6 system (1.8 MW ) is almost twice as expensive as the cost of the next largest system (four LSB 6 engines or $7.2 \mathrm{MW}_{\mathrm{e}}$ ). The cost per kilowatt continues to decrease as the system size increases to 12 and $24 \mathrm{MW}_{\mathrm{e}}$, but the decline is more gradual. System options that include the spray dryer or the Takeda process unit show the strongest dependence of cost on system size.

In terms of capitr' ' cost per kilowatt, Options B, C, J, and K are favored for all system sizes. In addition, Options $\mathrm{L}, \mathrm{M}$, and $\mathrm{N}$ appear promising for the 12 and $24 \mathrm{MW}_{\mathrm{e}}$ systems.

The annual operating costs also decrease with increasing system size (Figure V-4). The operating costs for the smallest system $(1.8 \mathrm{MW})$ are about three times higher than those for the largest system (24 MW $)$. For the systems containing a commercial SCR unit, the cost of catalyst is the single largest operating cost. The cost of natural gas to raise the exhaust gas temperature to $750^{\circ} \mathrm{F}$ (the optimum SCR operating temperature) is also one of the major operating costs.

Options B, C, and $\mathrm{L}$, which include the reburning technology, have low operating costs because of the credit for steam produced in excess of the diesel-fueled baseline case. The steam credit applies only to the four cogeneration systems; System 4, as defined in Table V-3, does not recover heat from the exhaust gas and no steam is produced. The appeal of these three options is diminished if the steam price goes down or if there is no steam production, as in the power generation sy:.iem.

The high operating cost fo: Option D reflects the cost of the calcium acetate fuel additive. There is a high degree of uncertainty about what the bulk cost of a calcium fuel additive might be and these operating costs could be lower than indicated. As explained previously, we assume this reactant cost is 10 percent of the commodity chemical cost.

Option $M$ has a favorable capital cost for the two largest systems, but the operating cost is significantly higher than most other systems. There are two reasons why the operating cost is so high. The primary factor is cost of steam; Option M produces less steam than the diesel-fueled baseline case because the temperature drop through the waste heat boiler is about half that of the baseline case. The replacement cost for the activated carbon is another important factor in the high operating cost.

In terms of total annual operating costs, Options B, C, and $\mathrm{J}$ are favored for all system sizes. In addition, Options $\mathrm{K}, \mathrm{L}$, and $\mathrm{N}$ appear promising for the 12 and $24 \mathrm{MW}_{\mathrm{e}}$ systems.

In the final set of figures, the annual operating costs are displayed with the probability of technical success for each system option. The probability of success is computed by multiplying the probabilities of the technologies for removal of the three major pollutants (Table V-5). In the case of a process that removes two pollutants simultaneously, the subsystem probability is squared. 


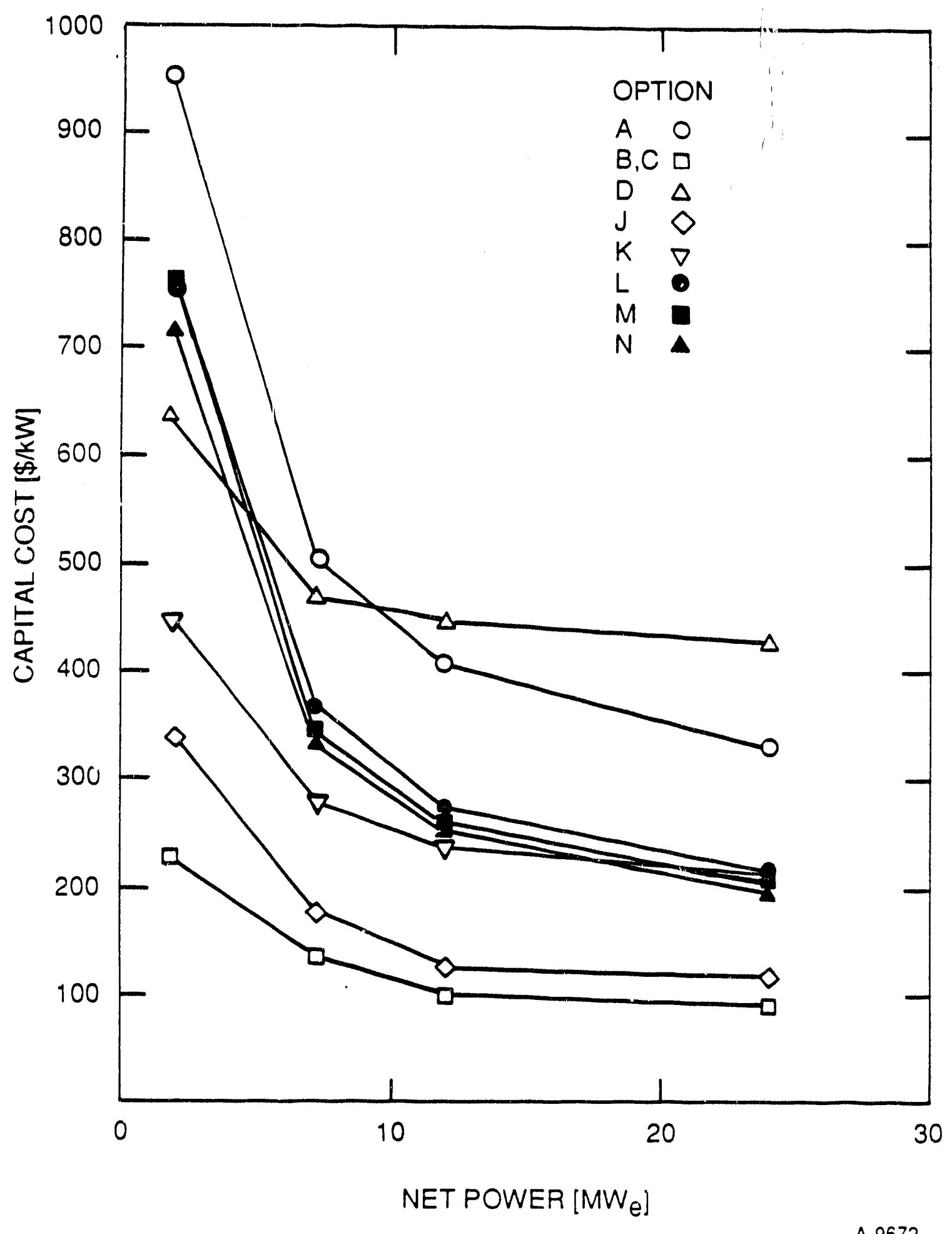

Figure V-3. Capital Cost for Cogeneration System 


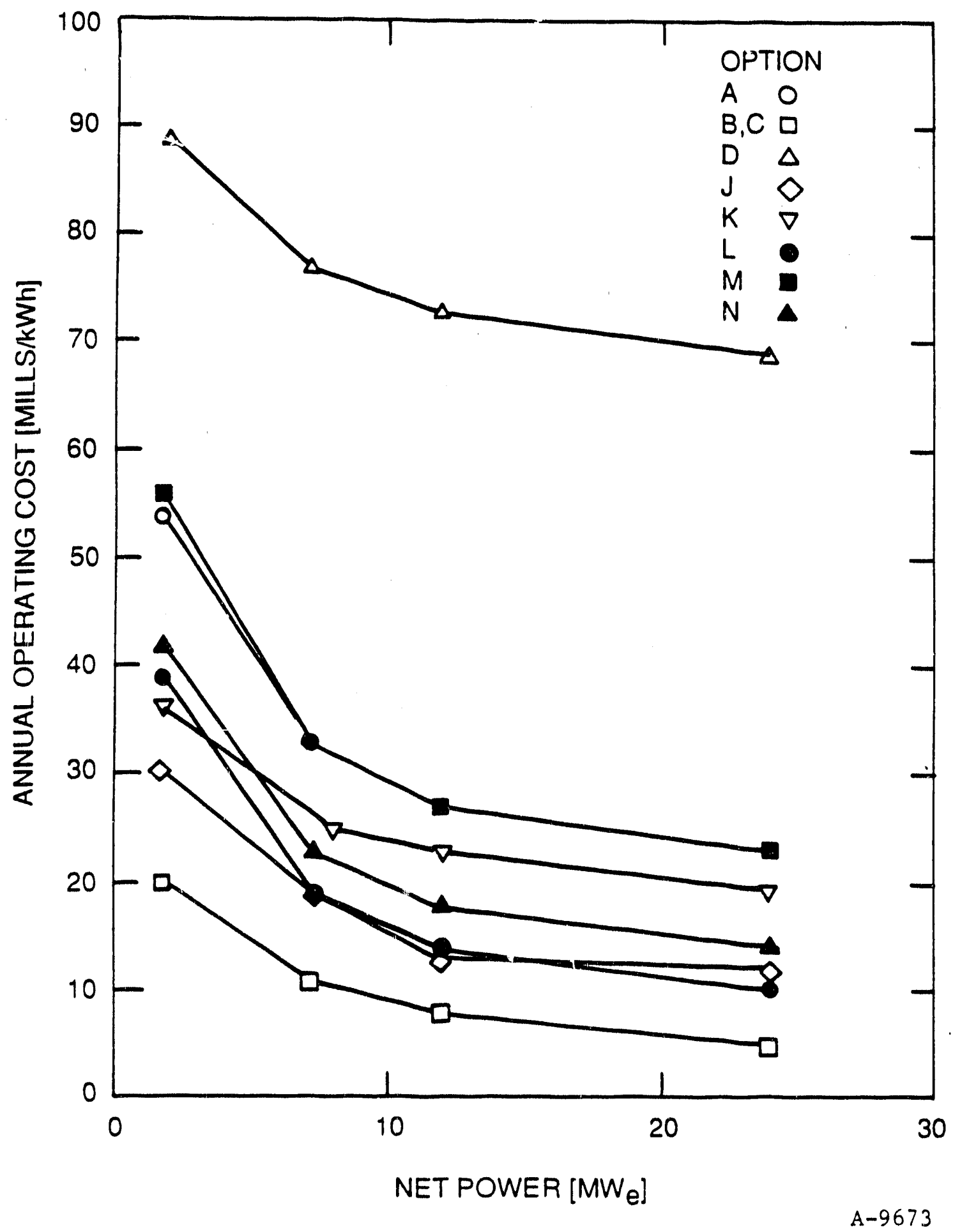

Figure V-4. Annual Operating Cost for Cogeneration System 
In Figures V-5 through V-9, the annual operating cost is plotted against the probability of technical success for all five systems. Options that have a probability of technical success greater than 50 percent are considered favorable. The cogeneration systems exhibit the same trends. Options $\mathrm{C}, \mathrm{D}, \mathrm{J}$, and $\mathbf{N}$ have a probability less than 50 percent for the technical success control system. Of the options with a probability greater than 50 percent, Options A and $M$ have the highest operating costs.

In the case of the power generation system, no heat is recovered from the exhaust gas and no steam is generated. The operating costs for systems including reburning $(B, C$, and $L)$ increase because the steam credit taken in the case of cogeneration no longer offsets the cost of natural gas. On the other hand, the operating costs for Option $M$ are lower in the power generation system than in the cogeneration system. The cost of additionai steam (as compared to the dieselfueled baseline) is not an cperating cost in the power generation system.

In terms of the probability of technical success, Options $B, K$, and $\mathrm{L}$ are favored for cogeneration systems. For power generation systerns, Option $M !$ is also favored in addition to the three systems listed for cogeneration applications.

\section{Sensitivity Of Results}

Since this study represents a preliminary design, with 20 to 30 percent uncertainty in the calculated costs, a formal sensitivity analysis is not performed. However, two aspects of the sensitivity of the economic calculations to input data are discussed. First, the engine operating parameters and system configuration may change as a result of the on-going JS-1 test program. Second, the process parameters for control technologies may change as a result of experiments performed as part of Task 2 and of more detailed discussions with manufacturers of commercially available technology.

Preliminary desiga decisions that have been made about the configuration of the integrated system are subject to change as engine development proceeds. Several elements of the preliminary design impact the cost and feasibility of the emission control system: manifold air temperature, assumed particle removal needed upstream of the turbocharger, placement of the reburning unit with respect to the turbocharger, and the decision to combine the gas streams from all engines for most of the emission control modules.

The manifold air temperature (MAT) has not been optimized as yet. The baseline MAT for these calculations is $250^{\circ} \mathrm{F}$, but, as Table V-19 shows, variations in the manifold air temperature have an impact both on $\mathrm{NO}_{\mathrm{x}}$ emissions and on the exhaust gas temperature. The variation of $\mathrm{NO}_{\mathrm{x}}$ levels and exhaust gas temperatures with changes in MAT in the table are drawn from the JS-1 test results to date.

The required reduction of $\mathrm{NO}_{\mathrm{x}}$ to meet NSPSi varies from 63 to 84 percent as the MAT is varied from 150 to $300^{\circ} \mathrm{F}$. Several elements of the cost of $\mathrm{NO}_{\mathrm{x}}$ control technology depend on the required reduction: the reactor size, the amount of ammonia required for SCR-type processes, and the amount of reburning fuel used. For example, if a lower $\mathrm{NO}_{\mathrm{x}}$ reduction is requircd than in the MAT baseline case, the residence time in the reactor (and hence the size of the reactor) can be reduced, resulting in lower capital costs. 'The operating costs also decrease because iess 


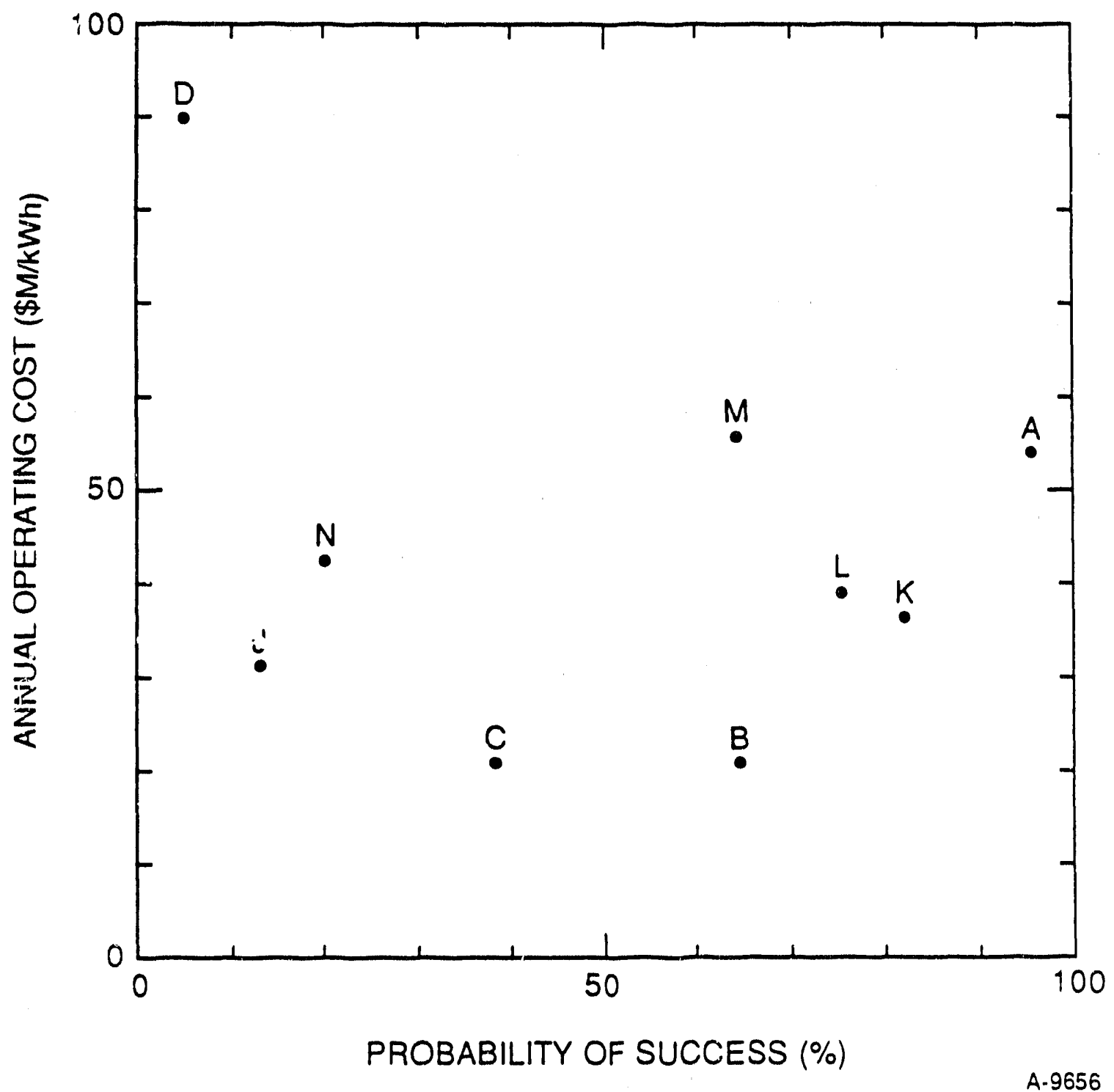

Figure V-5. Annual Operating Cost vs. Probability of Technical Success for 1.8 MWe Cogeneration System 


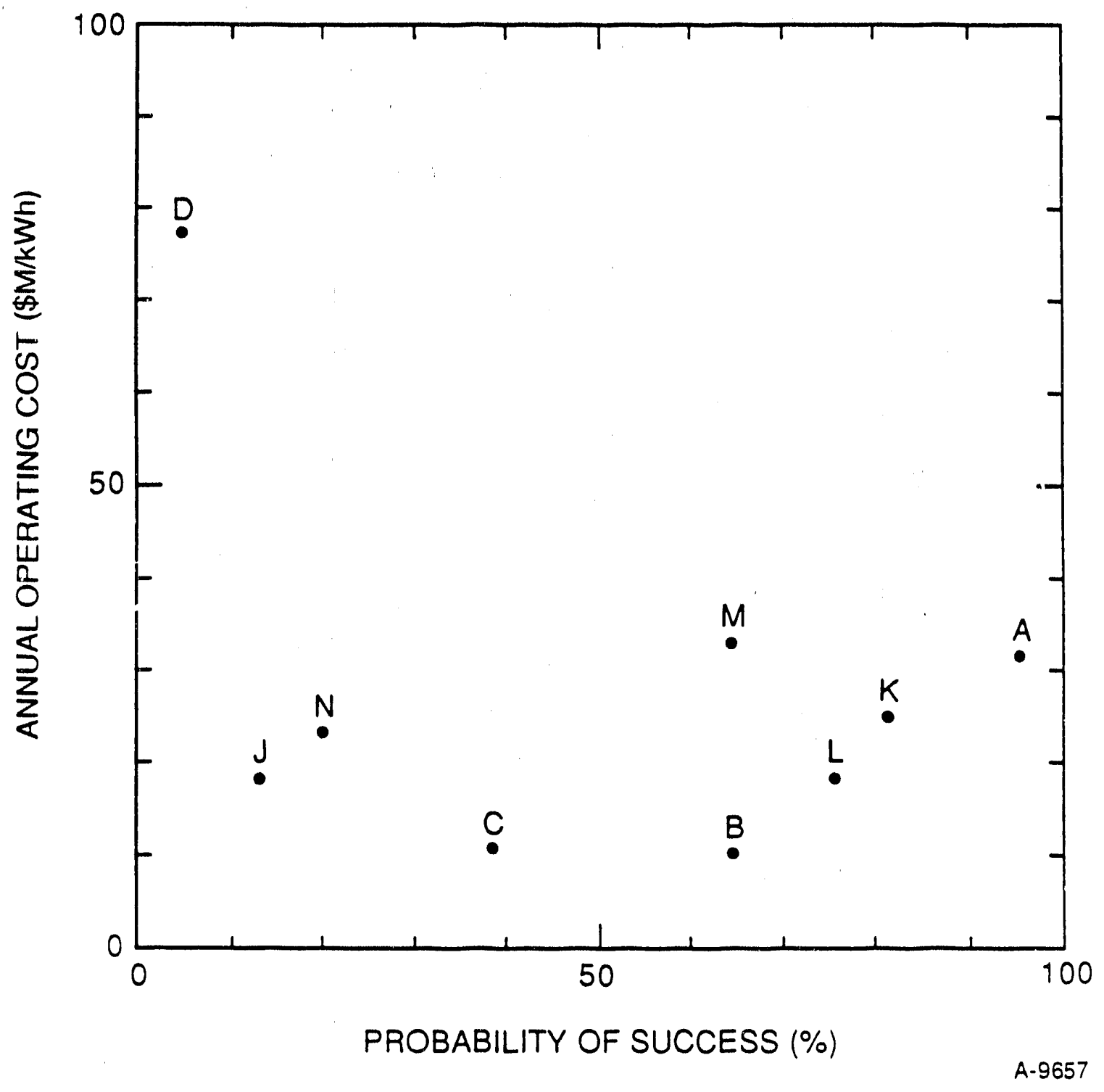

Figure V-6. Annual Operating Cost vs. Probability of Technical Success for 7.2 MWe Cogeneration System 


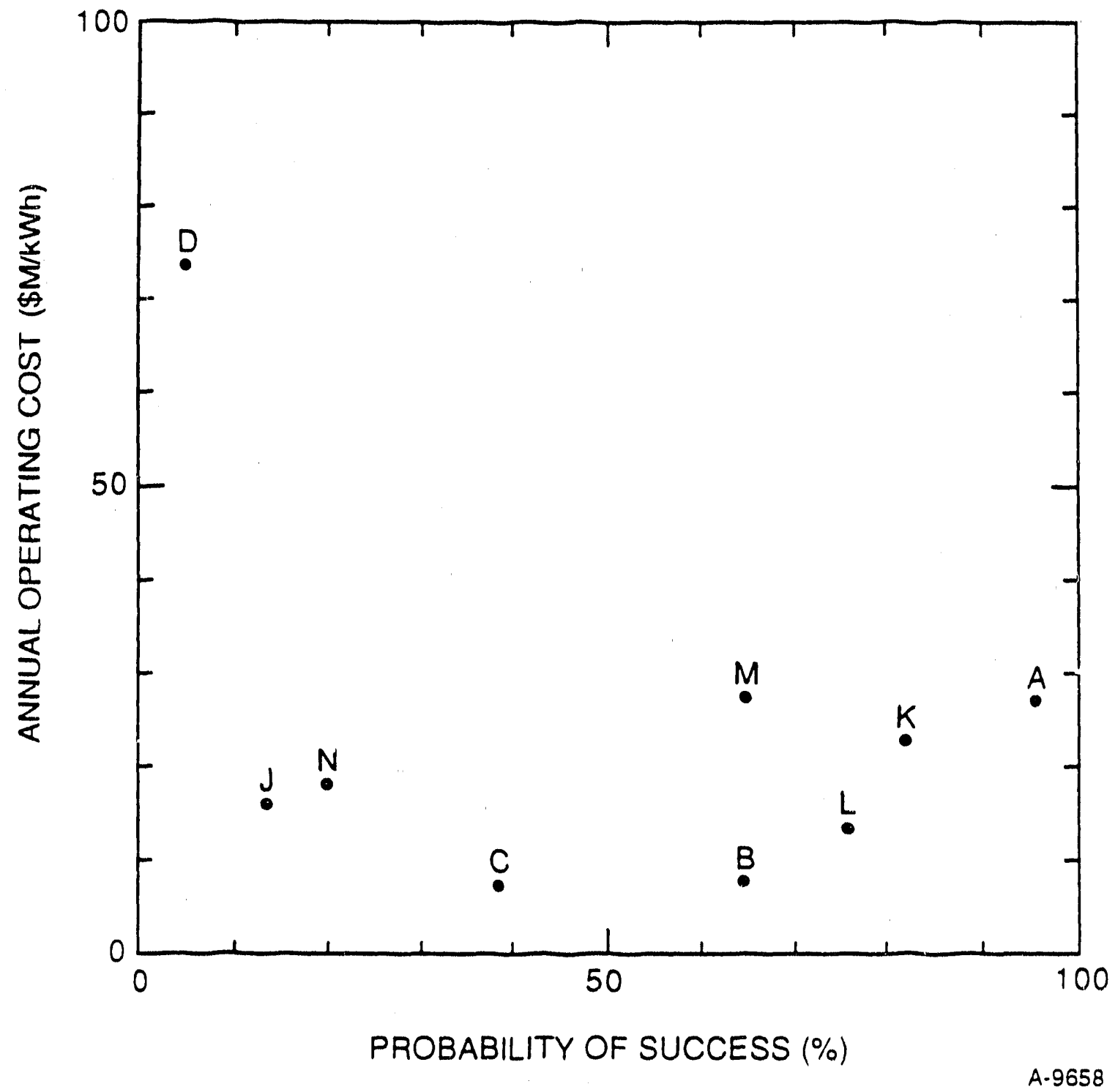

Figure V-7. Annual Operating Cost Vs. Probability of Technical Success for $12 \mathrm{MW}_{\mathrm{e}}$ Cogeneration System 


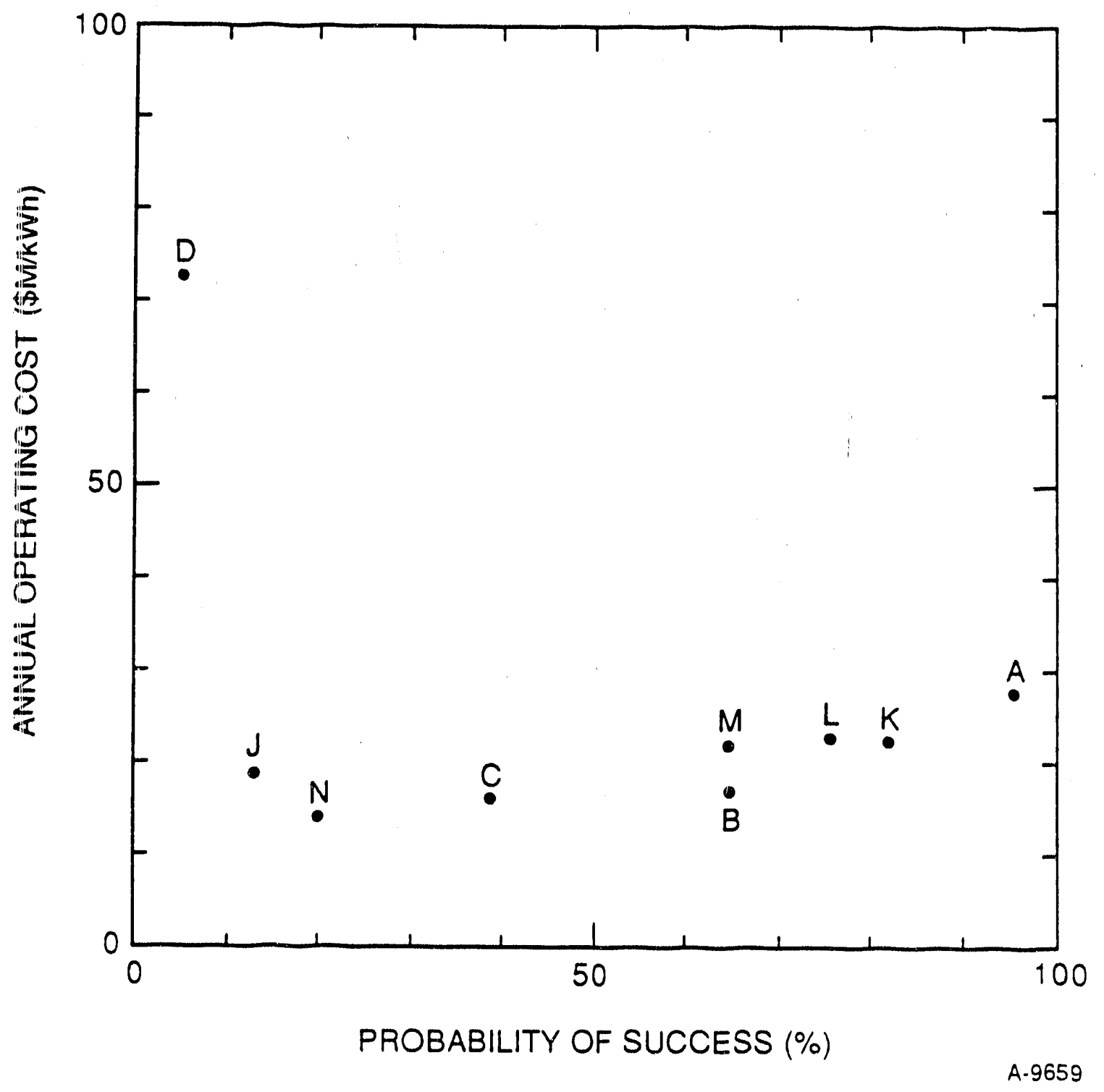

Figure V-8. Annual Operating Cost vs. Probability of Technical Success for $12 \mathrm{MW}_{\mathrm{e}}$ Power System 


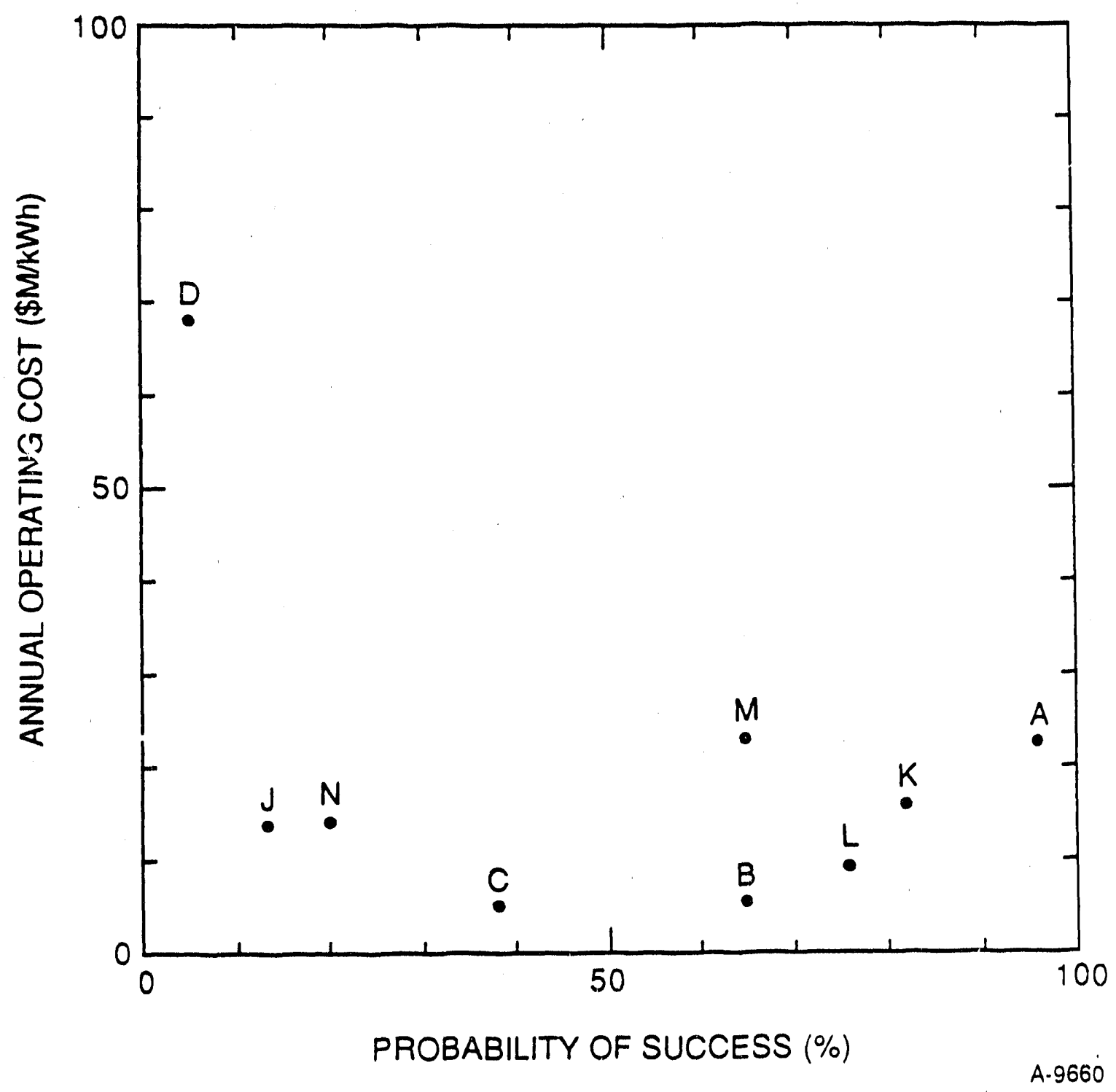

Figure V-9. Annual Operating Cost vs. Probability of Technical Success for 24 MWe Cogeneration System 
Table V-19

EFFECT OF MANIFOLD AIR TEMPERATURE ON PROCESS HISTORY

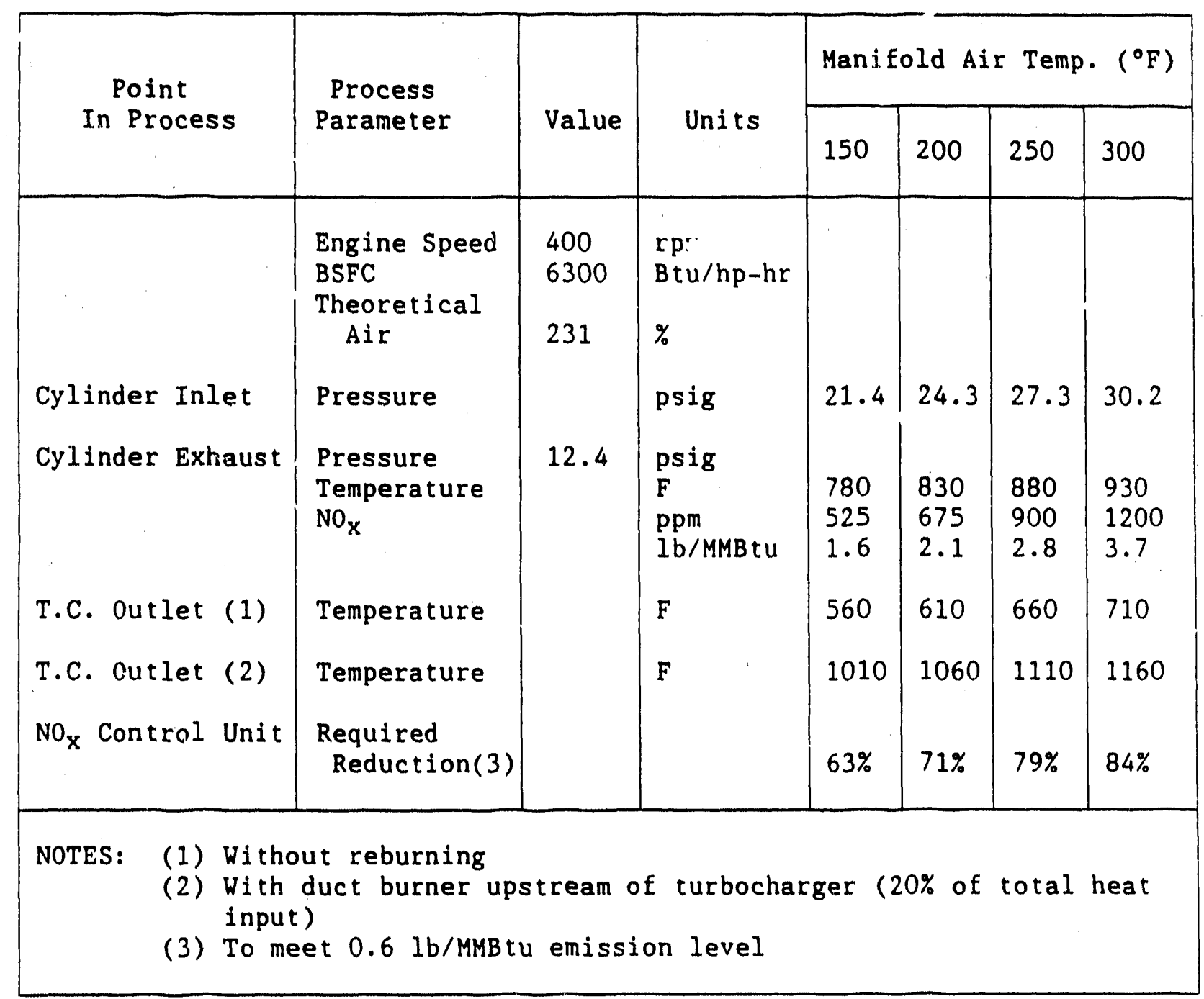


ammonia is needed and the catalyst replacement costs are lower than in the baseline case. For the commercial SCR process (Options $A$ and $K$ ) and the Takeda process (Option M), the cost of catalyst is a significant portion of the operating costs. The operating costs of the options employing reburning may be reduced if a lower $\mathrm{NO}_{x}$ reduction is required. Although the use of a steam credit in the cogeneration system calculations means that a decrease in natural gas costs is offset by a decrease in the amount of steam generated in excess of the diesel-fueled baseline. It should also be noted that the feasibility of reburning may become questionable if the required NOx reduction becomes too high. Currently, the maximum reduction that can be achieved within the constraints of the coal-fueled diesel operating parameters is unknown.

The cost of particle removal equipment could increase by a factor of 2 if a cyclone is found to be insufficient to protect the turbocharger from erosion. In this case, the cyclone and the baghouse are replaced by a ceramic cross-flow filter located upstream of the turbocharger.

The reburning unit has been placed upstream of the turbocharger, if the duct burner must be placed downstream of the turbocharger, the inlet temperature for the reburning process would be lower than assumed here by approximately $200^{\circ} \mathrm{F}$. This means that more reburning fuel would be required to achieve temperatures at which free radical formation and subsequent $\mathrm{NO}_{\mathrm{x}}$ reduction could occur. Perhaps, in this case, the reburning process would not be feasible or cost-effective.

Finally, the systems are designed to combine the exhaust gas streams of all engines upstream of the waste heat boiler. If this is not possible, the systems with more than one engine would require more than one pcllution control module (e.g., SCR, spray dryer, etc.). As an example, consider the SCR unit applied to System 2 (four LSB 6 engines). The cost of equipment for a single SCR unit is $\$ 60 / \mathrm{kW}$ or $\$ 432,000$. If the exhaust gases from individual engines are not combined, four small SCR units are required at a cost of $\$ 92 / \mathrm{kW}$ or $\$ 662,400$.

The goal of Task 2 is to assess the performance of specific control technologies under conditions of the coal-fueled diesel engine exhaust. The calcium-to-sulfur $(\mathrm{Ca} / \mathrm{S})$ ratio needed to achieve the desired $\mathrm{SO}_{2}$ reduction by direct injection of sorbent may be revised. This would directly affect the operating costs of Options B, C, J, and D, although the impact is significant only to Options B and C. Since reburning has not been applied to the specific operating conditions of the coal-fueled diesel engine, it is difficult to predict the outcome of the experiments. If less reburning fuel than assumed here is required, the operating costs may decrease.

\section{F. CONCLUSIONS/DIRECTIONS FOR EMISSIONS R\&D PROGRAM}

System Option A, which relies on conventional technology (SCR and spray dryer), is low risk, and this analysis shows the cost is high but not excessive. Therefore, until other options are demonstrated as feasible, Option $\mathrm{A}$ has been adopted as the nominal baseline emission control system in our plant design. However, it is not a "preferred" option in the real sense of the word because of relatively high cost. Based on the present economic analysis, the most attractive emission control system options in terms of cost and probability of success are Options $n, K$, and L. Options L and K combine a commercially available technology (SCR or spray dryer) with a technology that is less well-developed but inexpensive (reburning or sorbent injection). Option B uses reburning for $\mathrm{NO}_{\mathrm{x}}$ control and sorbent injection for $\mathrm{SO}_{2}$ control; this is the least expensive option, but it also has a lcwer probability of success than Options $\mathrm{K}$ or $\mathrm{L}$. The capital costs for 
these three emission control systems are in the range of $\$ 750 / \mathrm{kW}$ to $\$ 225 / \mathrm{kW}$ for the $1.8 \mathrm{MWe}$ system, but decrease to $\$ 250 / \mathrm{kW}$ to $\$ 100 / \mathrm{kW}$ for the larger systems. The operating costs for these emission control systems are in the range of 20 to 40 mills/kWh for the $1.8 \mathrm{MWe}$ system, but decrease to 5 to 20 mills $/ \mathrm{kWh}$ for the larger systems.

Options J, D, N, and M should be eliminated as a result of the analysis. The first three have a probability of success less than 50 percent computed by the methods of this analysis and Option $\mathrm{M}$ is too expensive relative to its probability of technical success. A careful examination of Option $\mathrm{C}$ should be performed before proceeding further, the system is inexpensive, but the technology for sorbent injection at 900 to $1000^{\circ} \mathrm{F}$ is still under development. Recent work ${ }^{(13)}$ has shown that the degree of agglomeration of sorbent particles in the feeding system markedly affects the amount of $\mathrm{SO}_{2}$ capture in the duct. If total particle removal is needed upstream of the turbocharger, the ceramic cross-flow filter is preferred. Using the ceramic cross-flow filter approximately doubles the cost of particle removal equipment.

On a per kilowatt basis, the cost of an emission control system for a single LSB-6 engine system $(1.8 \mathrm{MW})$ is about twice the cost of larger systems. If the emission control system cost is so high that it threatens the commercial viability of the $1.8 \mathrm{MW}_{\mathrm{e}}$ system, tile entire engine system should be closely examined with respect to reducing costs. There may be modifications in combustion conditions, fuel type, or engine design that, while increasing the cost of the engine or the fuel, result in a decrease in the cost of the emission control system. Thus, the overall system cost could be lowered to a level that would encourage commercialization.

Two commercially available pollution control technologies appear favorable but relatively expensive: SCR for $\mathrm{NO}_{x}$ and spray dryer for $\mathrm{SO}_{2}$. These should be explored further with manufacturers to determine if the cost of systems specifically designed for the coal-fueled diesel engine can be reduced. SCR processes have undergone accelerated development recently as pollution regulations have gotten tougher, especially in Europe and Japan. The cost of an SCR process may decrease in the near term.

In summary, the conclusions of this design study are as follows:

Baseline Selected Option:

Preferred but must be proven:

Judged not worth pursuing:
A (SCR and Spray Dryer)

$\mathrm{K}$ (substitutes sorbent injection for $\mathrm{SO}_{2}$ )

L (substitutes reburning for $\mathrm{NO}_{\mathrm{x}}$ )

B (substitutes both the above technologies)

$\mathrm{J}$ (ammonia injection in baghouse for $\mathrm{NO}_{\mathrm{x}}$ )

D (calcium fuel-additive for $\mathrm{SO}_{2}$; shell/UOP process for $\mathrm{NO}_{\mathrm{x}}$ )

$\mathrm{M}$ (Takeda process for $\mathrm{SO}_{2}$ and $\mathrm{NO}_{\mathrm{x}}$ )

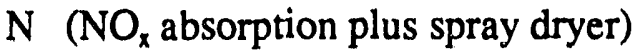

C (same as Option B but injection at $1000^{\circ} \mathrm{F}$ ) 
The experimental program should focus on direct injection of sorbent and reburring. However, experiments with sorbent injection at 900 to $1000^{\circ} \mathrm{F}$ should be scaled back. Sorbent injection in this temperature range is not favored as a result of this analysis. The optinium temperature range cannot be attained in the coal-fueled diesel exhaust without reheating the gas. The system option featuring reburning and a waste heat boiler is the only cost-effective way tc utilize sorbent injection at high temperatures for $\mathrm{SO}_{2}$ removal, Reburning appears very attractive from a cost standpoint. However, this tecinology has not been domonstrated under coal-fueled diesel operating conditions. In particular, the experimental program should examine the temperature sensitivity and auxiliary fuel requirements of the process. Placement of the duct burner with respect to the turbocharger strongly affects the temperature in the reburning process (and the $\mathrm{NO}_{\mathrm{x}}$ reduction). If the desired $\mathrm{NO}_{\mathrm{x}}$ reduction is not achieved with reburning using up to 20 percent of the total heat input as rebur ing fuel, consideration should be given to combining reburning with another technique such as adsorption at $275^{\circ} \mathrm{F}$ or ammonia injection at $450^{\circ} \mathrm{F}$ in the baghouse. Both of these technologies, even when combined with reburning, are less expensive than a commercial SCR unit. Also, if the temperature proves to be too low for much reduction of $\mathrm{NO}_{\mathrm{x}}$ by the actual reburning process, additives (such as urea or ammonia) might be used to increase the $\mathrm{NO}_{\mathrm{x}}$ removal by non-calalytic reduction.

Finally, as shown in Figure $\mathrm{V}-10$, the $\mathrm{NO}_{\mathrm{x}}$ target for coal diesels if achieved, will still leave gas turbines at a considerable advantage with respect to $\mathrm{NO}_{\mathrm{x}}$.

Therefore, further $\mathrm{NO}_{x}$ methods should be explored, possibly including SNR and in-cylinder $\mathrm{NO}_{\mathrm{x}}$ control.

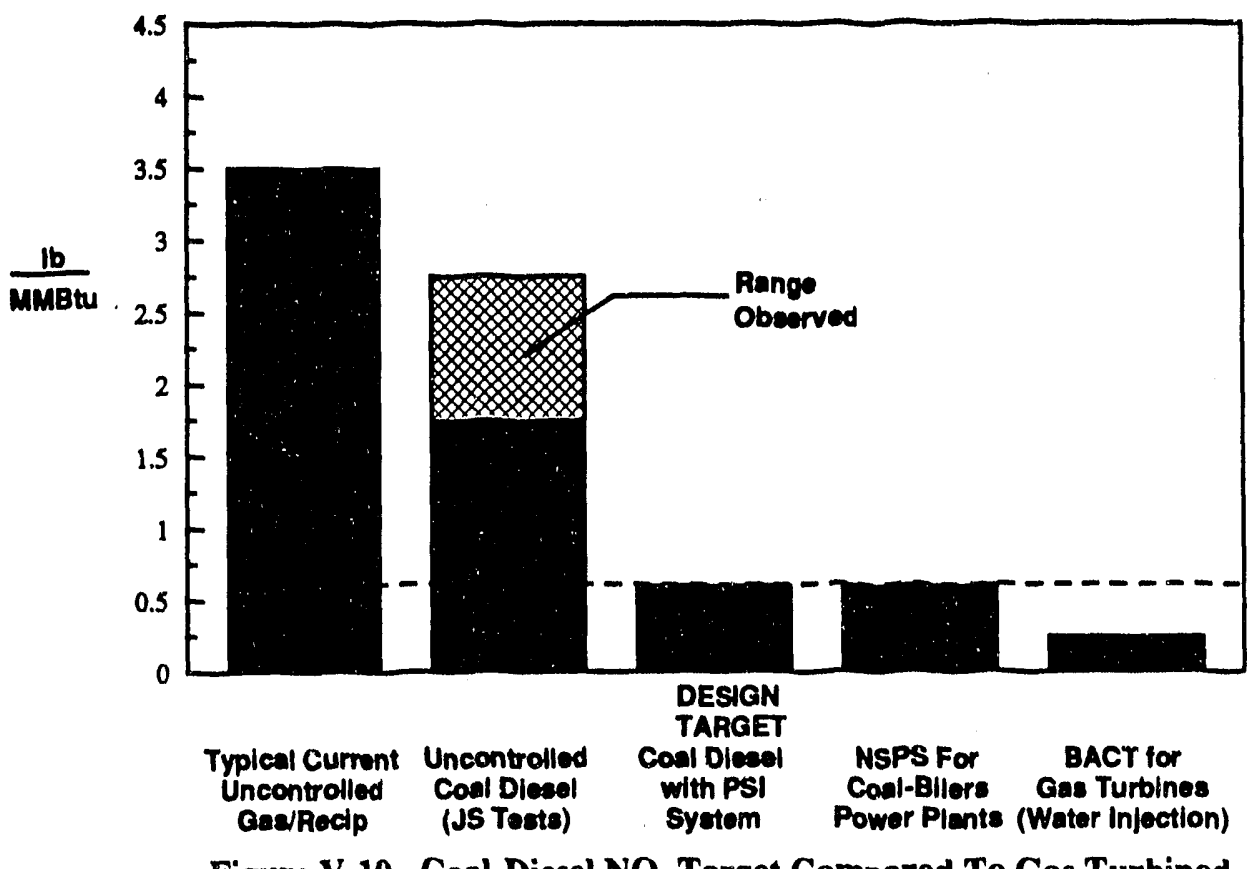

Figure V-10. Coal-Diesel $\mathrm{NO}_{\mathbf{x}}$ Target Compared To Gas Turbined 


\section{ANALYSIS OF ECONOMICS}

\section{A. SUMMARY}

The economics of the coal-fueled diesel plant has been continually re-evaluated as new information has come to light on coal fuels, emission control, engine component performance, and other factors. The analysis methodology includes the use of a sensitivity analysis to explore trade-offs between coal fuel price, emission control costs, maintenance costs, etc. The framework for the economic analysis originally was formulated in 1986, and the analysis was then repeated with revised assumptions in 1988 and again in 1989. Our analysis in 1986, including the complete methodology and framework, can be found in the Systems Study published as a METC report ("Coal Fueled Diesel Systems for Stationary Power Appíications," Task 1 - Topical Report, Assessment of Merit," DOE/MC/22181-2242). Following that report, in 1988, the economics analysis was repeated after the JS engine test results on coal fuel enabled us to revise certain key assumptions in the economic model (e.g., engine efficiency and injector replacement intervals). Further changes since the 1988 analysis, reported here, resulted from two comprehensive reviews by subcontractors:

- AMAX revised their coal processing cost estimates (also, delivered and minemonth prices for likely source coals were updated) - see Section IV.

- Physical Sciences (PSI) prepared detailed estimates of emission control costs for specific configurations (SCR, spray dryer, etc.) - see Section V.

Table VI-1 summarizes the revised cost estimates. Our conclusions, is explained in more detail below, are that (1) the projected cost of coal diesel power is $6.45 \mathrm{k} / \mathrm{kWh}$, which is virtually equal to the $6.54 \mathrm{c} / \mathrm{kWh}$ estimated in the 1988 analysis and $6.20 \mathrm{k} / \mathrm{kWh}$ in the original 1986 analysis, (2) economic viability hinges on the cost of CWS production (engine-grade slurry price must be kept below about $\$ 3.50$ /million Btu), and (3) emission control costs have emerged as an equally important parameter, they could "make or break" the economic success. As shown in Table VI-1, the emissions control cost at $\$ 2.50 / \mathrm{MMBtu}$ is converging toward the CWS fuel cost. The economic analysis gave a new perspective on the conditions under which the coal diesel could be cost competitive with oil or gas-fueled stationary engines. The complete revised model printout is included in this report as Appendix I.

\section{B. ENGINE COMPONENT COST PREMIUMS ASSOCIATED WITH COAL}

The use of beneficiated coal slurry will necessitate certain modifications to the standard large diesel engine, both in terms of special components and special maintenance practices. Although the precise 1ature of these modifications cannot be determined until the research and development is complete, it is still useful to project approximate cost premiums based on CooperBessemer's best judgment at this time. Table II- 6 above listed the engine components expected 
to be affected by coal fuel; these are generally "moving parts" which are exposed to either the fuel or the products of combustion. The estimated cost premium associated with the modification of these components is $\$ 1.67$ million (the same assumption as in the 1988 analysis). That is, the standard 6 megawatt engine costs $\$ 3.5$ million, whereas the future coal-fueled version is projected to cost $\$ 5.2$ million, on an installed basis.

Table VI-1

KEY MODIFICATIONS TO ECONOMIC MODEL

\begin{tabular}{|c|c|c|c|c|}
\hline Modification & $\begin{array}{c}1988 \\
\text { Estimate }\end{array}$ & $\begin{array}{c}1989 \\
\text { Estimate }\end{array}$ & Revisions Based on & $\begin{array}{l}\text { Impact on Cost } \\
\text { of Power }\end{array}$ \\
\hline \multirow[t]{2}{*}{$\begin{array}{l}\text { Revised emission control } \\
\text { costs (PSI) }\end{array}$} & $\$ 1.18 / \mathrm{MMBtu}$ & $\$ 2.50 / \mathrm{MMBtu}$ & $\begin{array}{l}\text { Detai'ed design of emission } \\
\text { control system (see Chapter } \\
\text { IV) }\end{array}$ & $\begin{array}{l}\text { Higher by } \\
\$ .0116 / \mathrm{kWh}\end{array}$ \\
\hline & & & $\begin{array}{l}\text { This cost is for SCR and } \\
\text { spray dryer configuration on } \\
2 \times 20 \text { cyl engines }\end{array}$ & \\
\hline \multirow[t]{2}{*}{$\begin{array}{l}\text { Revised coal water slurry } \\
\text { costs (AMAX) }\end{array}$} & \$4.33/MMbtu & $\$ 2.90 / \mathrm{MMBtu}$ & $\begin{array}{l}\text { Detailed analysis of } 1.8 \mathrm{mil}- \\
\text { lion TPY processing plant }\end{array}$ & $\begin{array}{l}\text { Lower by } \\
\$ .0125 / \mathrm{kWh}\end{array}$ \\
\hline & & & $\begin{array}{l}\text { This CWS cost is for } \\
\text { physically-cleaned } 1 \% \text { ash } \\
\text { product }\end{array}$ & \\
\hline $\begin{array}{l}\text { Resulting cost of power after } \\
\text { all other assumptions }\end{array}$ & $\$ .0654 / \mathrm{kWh}$ & $\$ .0645 / \mathrm{kWh}$ & & $\begin{array}{l}\text { Lower by } \\
\$ .0009 / \mathrm{kWh}\end{array}$ \\
\hline
\end{tabular}

On a per-kWh basis, this capital cost translates to 1.21 cents per $\mathrm{kWh}$ vs. 0.81 cents per $\mathrm{kWh}$ for the standard oil or gas engine, based on 20-year life and $80 \%$ load factor. This premium of 1.21-0.81 $=0.40$ cents per $\mathrm{kWh}$ is exclusive of emission control equipment costs, which are accounted for separately below.

The present maintenance practices for a 6 megawatt Cooper engine are compared to the expected coal diesel practices (as revised in view of JS test results) in Table VI-2.

The cost associated with this increased level of maintenance and overhaul is projected to be $\$ 3.9$ million over a 20 -year period, vs. $\$ 1.4$ million for a standard $6 \mathrm{MW}$ diesel, which translates to $\$ .0052 / \mathrm{kWh}$ for the coal engine vs. $\$ .0019 / \mathrm{kWh}$ for the standard. It is recognized tha : injector life would be limited on coal fuel ( $500 \mathrm{hr}$ is the assumed injector life). The projected interval between major overhauls was also reduced to $25000 \mathrm{hr}$. See Table II-7 for detailed maintenance costs.

In summary, the total cost for purchasing, installing and maintaining a 6 megawatt CooperBessemer coal diesel (exclusive of fuel and emissions control) is expected to be $\$ .0163 / \mathrm{kWh}$, compared to $\$ .0100 / \mathrm{kWh}$ for an oil-fired diesel of comparable size, including both capital cost and maintenance. Since the standard busbar cost of producing power with diesel fuel or natural gas can range from about 5 to $7 \not / \mathrm{kWh}$, depending on prevailing fuel prices, this premium of $\$ .0063 / \mathrm{kWh}$ for a coal-tolerant engine would represent about a $10 \%$ increase in power cost, 
Table VI-2

IMPACT OF COAL FUEL ON MAINTENANCE AND OVERHAUL PRACTICES

\begin{tabular}{lrrr}
\hline \multicolumn{1}{c}{ Item } & $\begin{array}{r}\text { Standard } \\
\text { 6 MW Diesel }\end{array}$ & $\begin{array}{r}\text { Coal Diesel } \\
\text { Projections }\end{array}$ & $\begin{array}{r}\text { 20-Year } \\
\text { Overhaul Costs }\end{array}$ \\
\hline Injectors & $2,000 \mathrm{hr}$. & $500 \mathrm{hr}$. & $\$ 1,008,000$ \\
Minor Maintenance Checks & $8,000 \mathrm{hr}$. & $4,000 \mathrm{hr}$. & 390,000 \\
Top-End Overhaul & $25,000 \mathrm{hr}$. & $12,000 \mathrm{hr}$. & 780,000 \\
Major Overhaul & $100,000 \mathrm{hr}$. & $25,000 \mathrm{hr}$. & $1,740,000$ \\
$\quad$ Total & - & - & $\$ 3,918,000$ \\
\hline
\end{tabular}

*1989 estimate for coal diesel

according to our analysis. This premium is by no means prohibitive. In fact, if emission control costs or fuel costs could be reduced significantly by the use of more expensive engine parts or more frequent maintenance, this could be easily justified according to the economics.

\section{COST TO PRODUCE ENGINE-GRADE COAL FUELS}

An essential ingredient in the future of coal-fueled diesels is the eventual emergence of a price advantage of the engine-grade coal fuel. Recognizing that (a) fuel oil and natural gas prices will almost certainly rise by 1995-2000, and (b) the extent and timing of the oil price increase is virtually unpredictable, we focussed our attention on the coal slurry fuel cost and how it might be reduced as much as possible. Our findings are based on detailed inputs from AMAX and other leading manufacturers of coal slurries. Key parameters were as follows:

- Physical cleaning (resulting in a $1.0-1.5 \%$ ash product) is now assumed to be sufficient for the CWS to be compatible with the Cooper-Bessemer engine. This eliminates expensive chemical cleaning steps.

- Dedicated engine-grade slurry facility; plant incorporates cogeneration using reject char and oversize coal.

- Plant capacity: 1.8 million tons per year (supports 100 engines at $5 \mathrm{MW}$, operating at $80 \%$ load factor)

- Capital cost of plant: $\$ 78$ million

- Typical coal price: $\$ 1.81$ per million Btu, delivered to slurry plant (includes $\$ .57 / \mathrm{MMBtu}$ for transportation cost (\$0.273/ton-mile for 590 miles) plus $\$ 34.50 /$ ton for minemouth coal).

- Electricity cost: $\$ 0.04 \mathrm{kWh}, 175 \mathrm{kWh} / \mathrm{ton}$.

- Total operating cost of plant: $\$ 0.57 / \mathrm{MMBtu}$ (excludes amortized capital cost)

- Capital recovery costs: $10 \%$ interest/12 year payback. 
- Assume process development costs are already paid off, so that the plant costs are for the "nth plant." Here it is assumed that the R\&D investment in coal cleaning technology by AMAX, Otisca, or other slurry suppliers will be fully recovered by the time the first two or three plants reach full capacity.

The results of this analysis indicate that engine grade slurry will cost about $\$ 2.90$ per million Btu (which is about \$1.10/MMBtu more than the source coal). "Low" and "high" estimates for the CWS cost are $\$ 2.50$ and $\$ 3.70$ per million Btu (these estimates correspond to $50 \%$ less and $100 \%$ greater overall coal cleaning cost).

There are two areas where further process developments could reduce the cost of engine-grade slurries: First, the additives and reagents which currently account for about $30 \%$ of the slurry cost have not been optimized. These additives and reagents are needed to keep the coal pa ${ }^{\cdots}$ icles in suspension and to tailor viscosity. Second, further effort is needed to identify lower cost slurry formulations which are compatible with the engine.

\section{COST OF EMISSION CON'ROL SYSTEMS}

Based on PSI's design and cost estimates reported in Section V, we selected four emission control design options for further study as part of the overall plant economics. Table VI-3 summarizes these designs and gives the basic capital and operating costs for each option.

Table VI-3

EMISSIONS CONTROL SUBSYSTEM COSTS

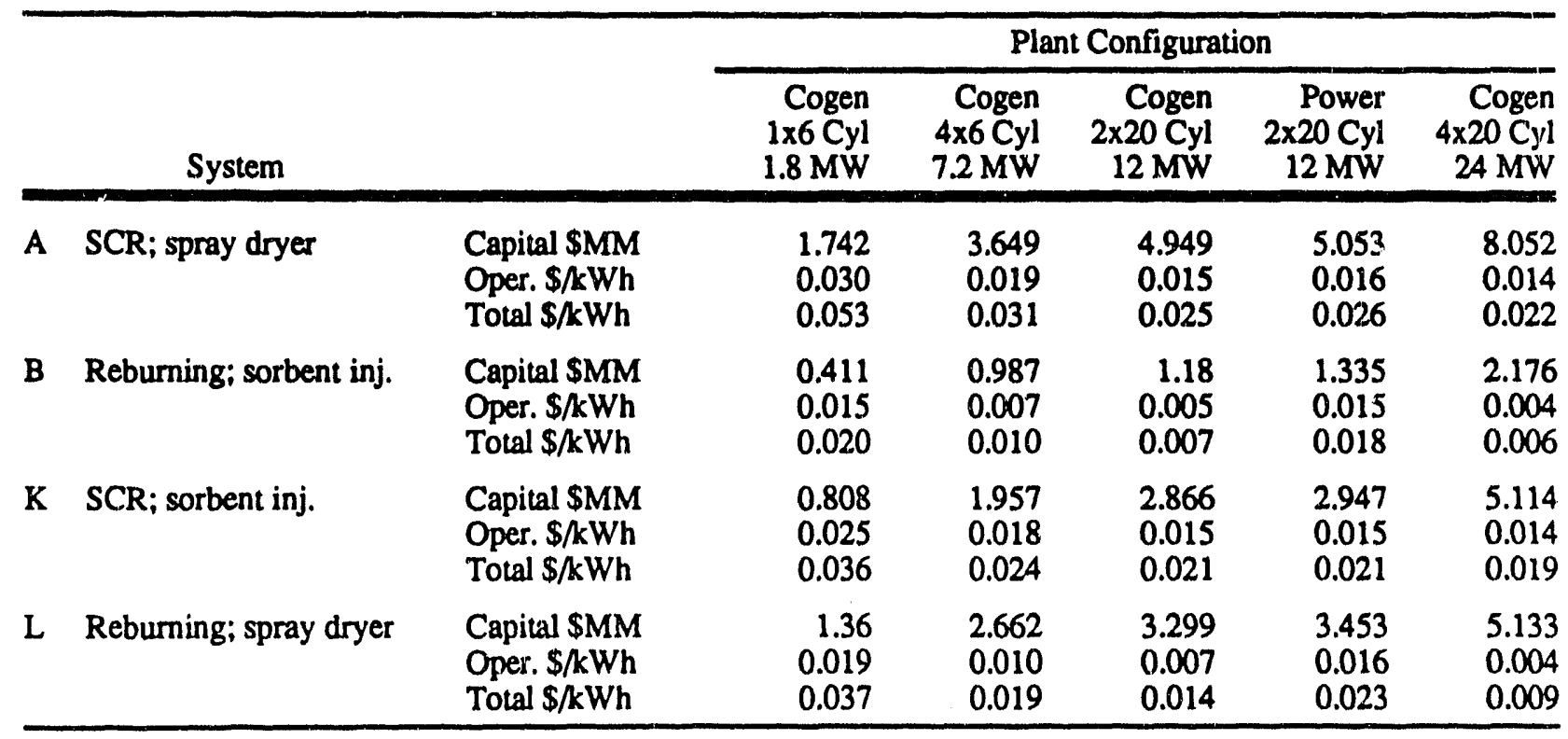




\section{E. PROJECTED COST OF COAL-FUELED DIESEL POWER}

Based on the individual cost premiums for installing and operating a diesel engine designed for coal fuel, it is possible to project the total cost of power and determine the relative importance of each economic parameter. Our key findings from this analysis can be presented in the form of Table VI-4, wh.ch lists the elements which contribute to the cost of power. Note that the coal engine designer can afford to consider more expensive components if that results in an engine which tolerates lower cost coal fuel. Also note that the coal-fueled engine is projected to be competitive with the standard diesel at $\$ 5.50 / \mathrm{MMB}$ tu fuel oil price.

Table VI-4

PROJECTED COST OF POWER FOR COAL-FUELED DIESEL PLANT

\begin{tabular}{|c|c|c|c|c|}
\hline \multirow[b]{2}{*}{ Cost Element } & \multicolumn{2}{|c|}{ Coal Fueled } & \multicolumn{2}{|r|}{ Gas or Oil Fueled } \\
\hline & $\$ / k W h$ & $\begin{array}{l}\text { Cost } \\
\text { (6 MW Engine) }\end{array}$ & $\$ / k W h$ & $\begin{array}{l}\text { Cost } \\
\text { (6 MW Engine) }\end{array}$ \\
\hline Engine capital cost (installed) & .0121 & $\$ 5.2$ million & .0081 & $\$ 3.5$ million \\
\hline Maintenance and overhaul & .0052 & $\begin{array}{l}\$ 3.9 \text { million over } 20 \\
\text { years }\end{array}$ & .0019 & $\begin{array}{l}\$ 1.4 \text { million over } 20 \\
\text { years }\end{array}$ \\
\hline Emission . Itrol & .0219 & $\$ 2.50 / \mathrm{MMBtu}$ & .0032 & $\$ 0.37 / \mathrm{MMBtu}$ \\
\hline $\begin{array}{l}\text { Engine Fue: (delivered); } \\
\text { including: }\end{array}$ & .0253 & $\begin{array}{l}\text { \$2.90/MMBtu; } \\
\text { including }\end{array}$ & .0481 & $\begin{array}{l}\$ 5.50 / M M B t u \text { for natu- } \\
\text { ral gas or fuel oil }\end{array}$ \\
\hline - Slurry processing & & \$0.80/MMBtu & & $\cdot$ \\
\hline - Raw coal; transportation & & \$1.81/MMBtu & & - \\
\hline - Slurry transportation & & $\$ 0.29 / \mathrm{MMBtu}$ & & - \\
\hline Total Cost of Power & .0645 & & .0613 & \\
\hline
\end{tabular}

Key. Assumptions: Heat rate $8,754 \mathrm{Bt}:$ / $\mathrm{kWh}, 80 \%$ load factor, and $90 \%$ availability. Future oil or natural gas price $\$ 5.50 / \mathrm{MMBtu}$.

It is clear from our analysis (see Table VI-4) that the most important parameters are the cost to clean the coal fuel and the emissions control, which essentially dominate the economics. If engine-grade slurry costs can be brought below $\$ 2 /$ million Btu above the source coal, then the coal diesel can probably be competitive with diesel fuel by the late 1990's, given long-range oil and natural gas price trends.

\section{F. PARAMETRIC SENSITIVITY ANALYSIS}

A series of runs using the economic model revealed which parameters were most sensitive in calculating the cost of power for a coal-fueled diesel plant. These runs also defined the circumstances under which the coal-diesel option would be most attractive economically. The following parameters were explored: 
- Source coal and type of CWS process

- Distance from source coal to power plant

- Type of emission control system

- Size and type of power plant (12 MW, $24 \mathrm{MW}$ power only or cogeneration, etc.)

- Load factor

- Natural gas and oil price

The effect of source coal on the economics is shown in Table VI-5. Note that the Blue Gem source coal can be physically cleaned and delivered at $\$ 2.56 / \mathrm{MMBtu}$ for the Atlanta market. If shipped across the U.S. to Phoenix, the same Blue Gem based CWS would carry a price tag of \$4.11/MMBtu (because of the added transportation cost). The other three source coals in Table VI-5 must be chemically-cleaned to yield an engine grade slurry, and this is reflected in the higher prices. For example, if Kentucky Hazard coal is used in Atlanta, the slurry cost increases about $60 \%$ and the cost of power increases $25 \%$ (from $\$ .0604$ to $\$ .0751 / \mathrm{kWh}$ ).

Table VI-5

COST OF POWER DEPENDS ON SOURCE COAL AND CWS PROCESS

\begin{tabular}{|c|c|c|c|c|c|c|}
\hline \multirow[b]{2}{*}{ Source Coal } & \multirow[b]{2}{*}{ CWS Process } & & \multicolumn{2}{|c|}{ Phoenix } & \multicolumn{2}{|c|}{ Atlanta } \\
\hline & & & $\begin{array}{l}\text { CWS } \\
\text { Cost }\end{array}$ & $\begin{array}{l}\text { Cost of } \\
\text { Power }\end{array}$ & $\begin{array}{c}\text { CWS } \\
\text { Cost }\end{array}$ & $\begin{array}{l}\text { Cost of } \\
\text { Power }\end{array}$ \\
\hline \multirow[t]{3}{*}{ Biue Gem (KY) } & Physically Cleaned & Delivered coal & $\$ 3.30$ & $\$ .0740 / \mathrm{kWh}$ & $\$ 1.76$ & $\$ .0604 / \mathrm{kWh}$ \\
\hline & & Process cost & 0.82 & & .80 & \\
\hline & & Total & 4.11 & & 2.56 & \\
\hline \multirow[t]{3}{*}{ Castlegate (Utah) } & Chemically Cleaned & Delivered coal & 1.27 & $\$ .0757 / \mathrm{kWh}$ & - & - \\
\hline & & Process cost & 2.96 & & & \\
\hline & & Total & 4.23 & & & \\
\hline \multirow[t]{3}{*}{ Illinois \#5 } & Chemically Cleaned & Delivered coal & 2.01 & $\$ .0894 / \mathrm{kWh}$ & - & - \\
\hline & & Process cost & 3.01 & & & \\
\hline & & Total & 5.82 & & & \\
\hline \multirow[t]{3}{*}{ Hazard (KY) } & Chemically Cleaned & Delivered coal & - & - & $\$ 1.53$ & $\$ .0751 / \mathrm{kWh}$ \\
\hline & & process cost & & & 2.70 & \\
\hline & & Total & & & 4.23 & \\
\hline
\end{tabular}

Basis: $12 \mathrm{MW}$ cogen, Configuration $\mathrm{K}, \$ 5.50 / \mathrm{MMBtu}$ gas price 
The effect of coal transportation has only a 5-10\% impact on the cost of power, as shown in Table VI-6. For Blue Gem source coal, which is transported from Kentucky, the lowest power cost is for Chicago (\$.0627/kWh for the SCR/spray dryer plant design). This increases by $\$ .0081 / \mathrm{kWh}$ for the extreme case of transporting Kentucky coai to Phoenix, Arizona.

Table VI-6 also illustrates that the choice of emission control technology has a large impact on cost of power. Two extreme cases are compared, the most expensive, off-the-shelf emission technology (Option A) and the least expensive emission technology (Option B) which is actually still in the R\&D phase. Note that the use of Option A raises the cost of power about $25 \%$ compared to Option B for all cities, for the $12 \mathrm{MW}$ cogeneration plant. For straight power plants, where the use of reburning in Option B imposes a net fuel cost, the difference between Option A and Option B is only about $10 \%$, as shown in Table VI-7. This is still a significant difference, and underscores the importance of further R\&D on emission control system alternatives (particularly those which are less expensive than $\mathrm{SCR}$ for $\mathrm{NO}_{\mathrm{x}}$ control and the spray dryer for $\mathrm{SO}_{\mathrm{x}}$ control.

Note that the power costs in Tables VI-6 and VI-7 were given for $12 \mathrm{MW}$ plants. This is because smaller plants (7.2 MW or $1.8 \mathrm{MW}$ ) are less attractive economically, because of the fixed expenses associated with emission control systems. In fact, PSI's analysis indicates that the emission control costs alone would be as high as $\$ .05 / \mathrm{kWh}$ for a $1.8 \mathrm{MW}$ plant (one 6-cylinder coul diesel). Therefore, the emission control system would double the cost of power for a 1.8 MrV plant; this would almost certainly be unacceptable. Figure VI-1 illustrates the effect of plant size on emission control costs. Effectively, this important conclusion eliminates many smaller cogeneration sites from future market consideration. However, other smaller cogeneration systems may not require the fill $90 \% \mathrm{NO}_{\mathrm{x}}$ reduction built into this design package.

Table VI-6

COAL TRANSPORTATION TO VARIOUS CITIES AFFECTS COST OF POWER BY 5-10\%

\begin{tabular}{lrr}
\hline & \multicolumn{2}{c}{ Emission Control System } \\
\cline { 2 - 3 } & $\begin{array}{r}\text { Baseline System - } \\
\text { SCR/Spray } \\
\text { Dryer (A) }\end{array}$ & $\begin{array}{r}\text { Low } \\
\text { Atlanta }\end{array}$ \\
\cline { 2 - 3 } Boston & $\$ .0632 / \mathrm{kWh}$ & $\begin{array}{r}\text { System - } \\
\text { Reburn/ } \\
\text { Sorbent (B) }\end{array}$ \\
Chicago & .0678 & $\$ .0489 / \mathrm{kWh}$ \\
Phoenix & .0627 & .0535 \\
Salt Lake & .0708 & .0484 \\
Pittsburgh & .0682 & .0539 \\
\hline
\end{tabular}

Basis: Blue Gem, Physical Cleaning, 12 MW Cogen 
Table VI-7

CHOICE OF EMISSION CONTROL SYSTEM AFFECTS COST OF POWER

(Reburning is particularly attractive for cogen plants)

\begin{tabular}{lrr}
\hline \multicolumn{1}{c}{ Emissions Systems } & $12 \mathrm{MW}$ Power & $12 \mathrm{MW}$ Cogen \\
\hline SCR/Spray Dryer (A) & $\$ .0639 / \mathrm{kWh}$ & $\$ .0627 / \mathrm{kWh}$ \\
Reburn/350'F Sorbent (B) & .0586 & .0484 \\
SCR/350\%F Sorbent (K) & .0605 & .0604 \\
Reburn/Spray Dryer (L) & .0620 & .0529 \\
\hline
\end{tabular}

Basis: Chicago, Blue Gem

The impact of load factor is significant, but not as important as other parameters such as slurry cost or emissions control. Table VI-8 illustrates that as load factor swings from $65 \%$ to $95 \%$, the cost of power goes from $\$ .0684 / \mathrm{kWh}$ to $\$ .0592 / \mathrm{kWh}$. While the total difference is about $15 \%$, the variation around cost of power for the standard assumption of $80 \%$ load factor is only about $\pm 7 \%$.

Table VI-8

INCREASED LOAD FACTOR CAN LOWER POWER COSTS BY ABOUT 5-10\%

\begin{tabular}{cc}
\hline Load Factor & $\begin{array}{c}\text { Coal Diesel with } \\
\text { SCR/Spray Dryer } \\
\text { (Config. A) }\end{array}$ \\
\hline $65 \%$ & $\$ .0684 / \mathrm{kWh}$ \\
$80 \%$ (STD) & $\$ .0627 / \mathrm{kWh}$ \\
$95 \%$ & $\$ .0592 / \mathrm{kWh}$ \\
\hline
\end{tabular}

Basis: Chicago, Blue Gem, 12 MW Cogen

Another important parameter is the engine efficiency associated with coal fuel. Based on the JS test results, our best estimate is that the coal engine efficiency will be $39 \%$, identical to the standard Cooper engine. The penalty derived from slurry water evaporation (2-3\%) appear to be compensated by faster heat release and other thermodynamic processes.

Table VI-9 shows the uncertainties assigned to each of seven key assumptions. For most assumptions, our uncertainty bounds are narrower (i.e., confidence level has increased) since 1988. 


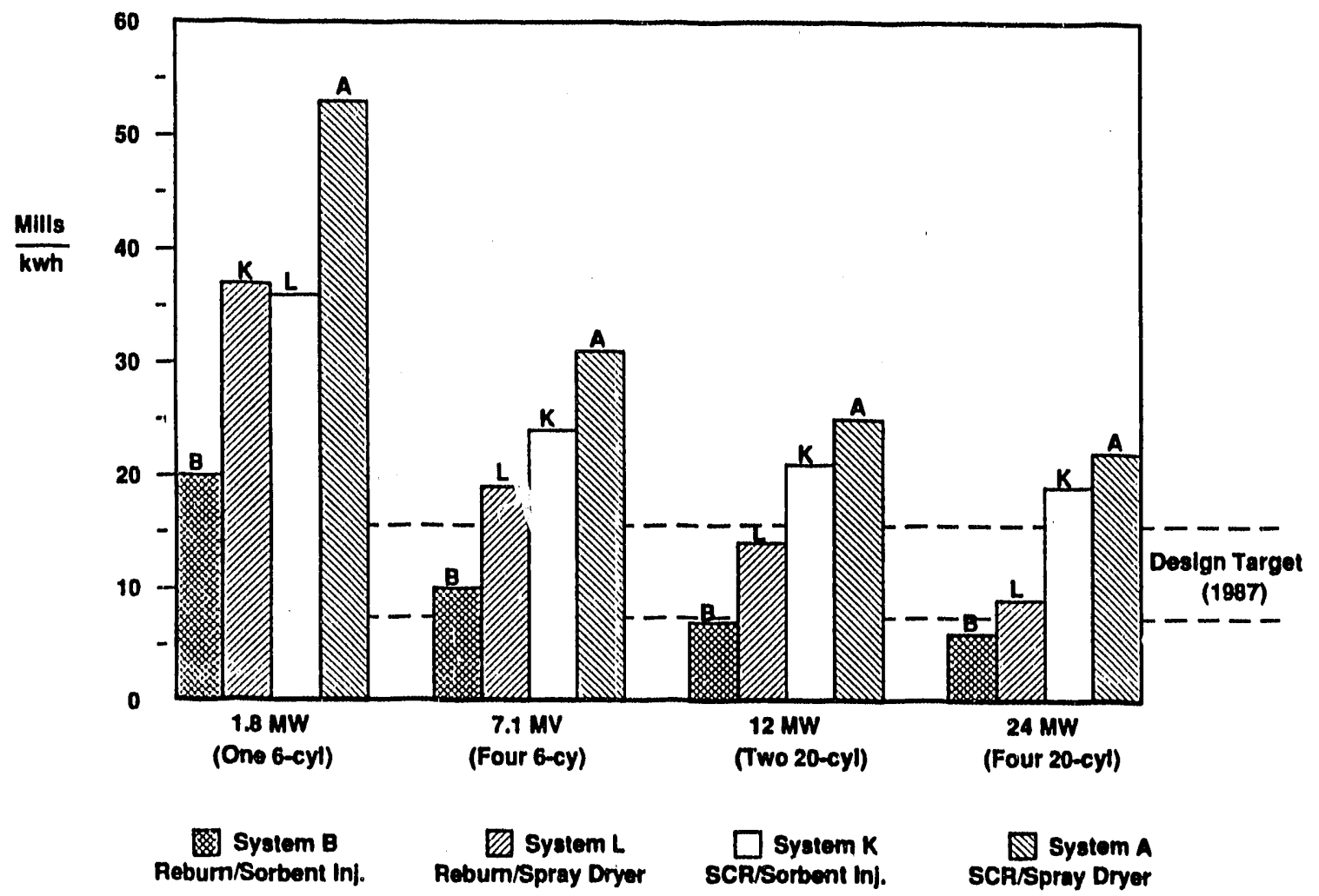

Figure VI-1. Emission Control Costs Appear Acceptable Above About 7 MW Plant Size 


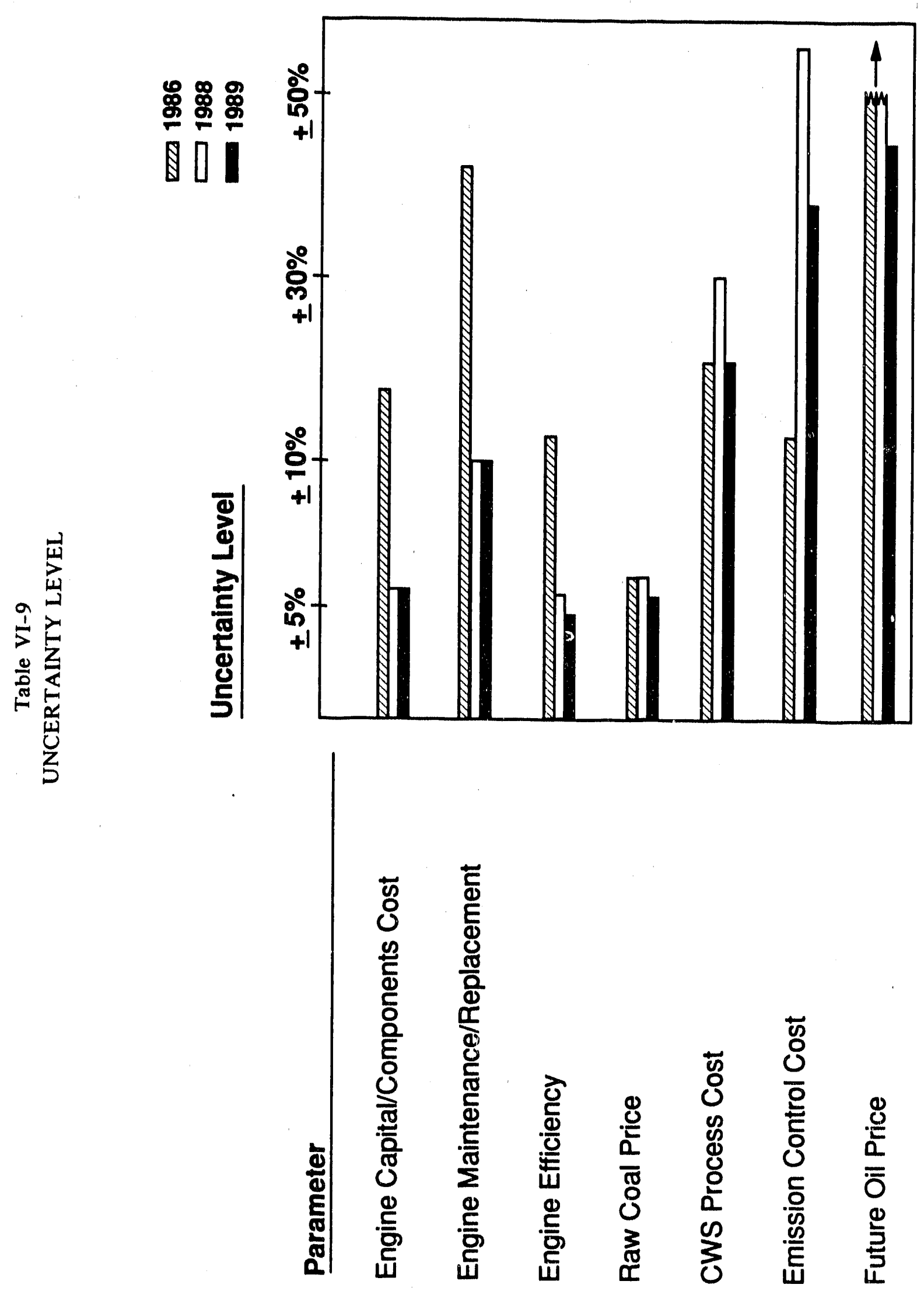




\section{TECHNOLOGY GAPS AND HIGH PRIORITY R\&D DIRECTIONS}

This preliminary design for a coal-fueled diesel engine power plant has revealed not only the most critical components or subsystems but also certain critical information about these components which is missing or poorly understood. Figure VII-1 summarizes our current priorities. In planning our R\&D for the balance of Phase I and Phase II, we can focus on these critical "technology gaps":

\section{Emissions Control}

1. In-cylinder $\mathrm{NO}_{\mathrm{x}}$ control: $\mathrm{NO}_{\mathrm{x}}$ can be lowered by up to $50 \%$ by reduced air temperature, timing of injection, prechamber for staged combustion, or piston shape.

2. Low-cost SCR for $\mathrm{NO}_{\mathrm{x}}$ control: the available SCR systems are very costly below $10 \mathrm{MW}$ engine size; further $R \& D$ may correct this.

3. SNR for $\mathrm{NO}_{\mathrm{x}}$ control at engine exhaust temperature $\left(850^{\circ} \mathrm{F}\right)$ : current $\mathrm{SNR}$ agents are not effective at this condition and further $R \& D$ is needed.

4. Small scale $\mathrm{SO}_{2}$-capture and baghouse modules: exhaust treatment will certainly be needed for $\mathrm{SO}_{\mathrm{x}}$ and particulate control. Appropriate exhaust treatment technologies exist for larger boiler plants, and the development strategy will require scaling these down to the 2-20 MW size of the engine.

5. Low-emission coals: emissions control R\&D strategies must exploit the source coal selection an cleaning process as much as possible. For example, the specific clean coal formulation affects both $\mathrm{NO}_{\mathrm{x}}$ and $\mathrm{SO}_{\mathrm{x}}$ levels through fuel nitrogen and sulfur content.

6. The cost of emission control is also critical to the economic viability of this technology. Target costs are about one cent per $\mathrm{kWh}$. An important remaining effort will be to design and develop the emissions control technology to accomplish the required emission reductions at reasonable projected installed and operating costs. Test results indicate that over $70 \% \mathrm{NO}_{x}$ and $\mathrm{SO}_{\mathrm{x}}$ reduction will probably be required along with over $99 \%$ particulate capture.

\section{Durable Engine Components}

1. Cost of critical parts: further development work will allow Cooper to better define the probable cost of coal tolerant parts. This system study suggests that there is room for increased parts cost if this results in either lower CWS cost or emission cost.

2. Injector tip replacement: the systems study showed a $\$ 1.0$ million cost of injector tips over 20 years of engine operation. Can the replacement interval be increased over 500 hours? Can the tip cost be reduced below $\$ 160$ ? The nozzle wear R\&D strategy will involve not only hard materials for nozzle tips but also lower injection pressures and modified orifice geometry.

3. Turbocharger durability: the turbocharger has been given a premium of $\$ 400,000$ for hardened parts. Further R\&D is needed to determine the actual severity of the wear problem. 
Figure VII-1

Coal-Fueled Dlesel R\&D Priorities

Events in

Chronoliogical Order

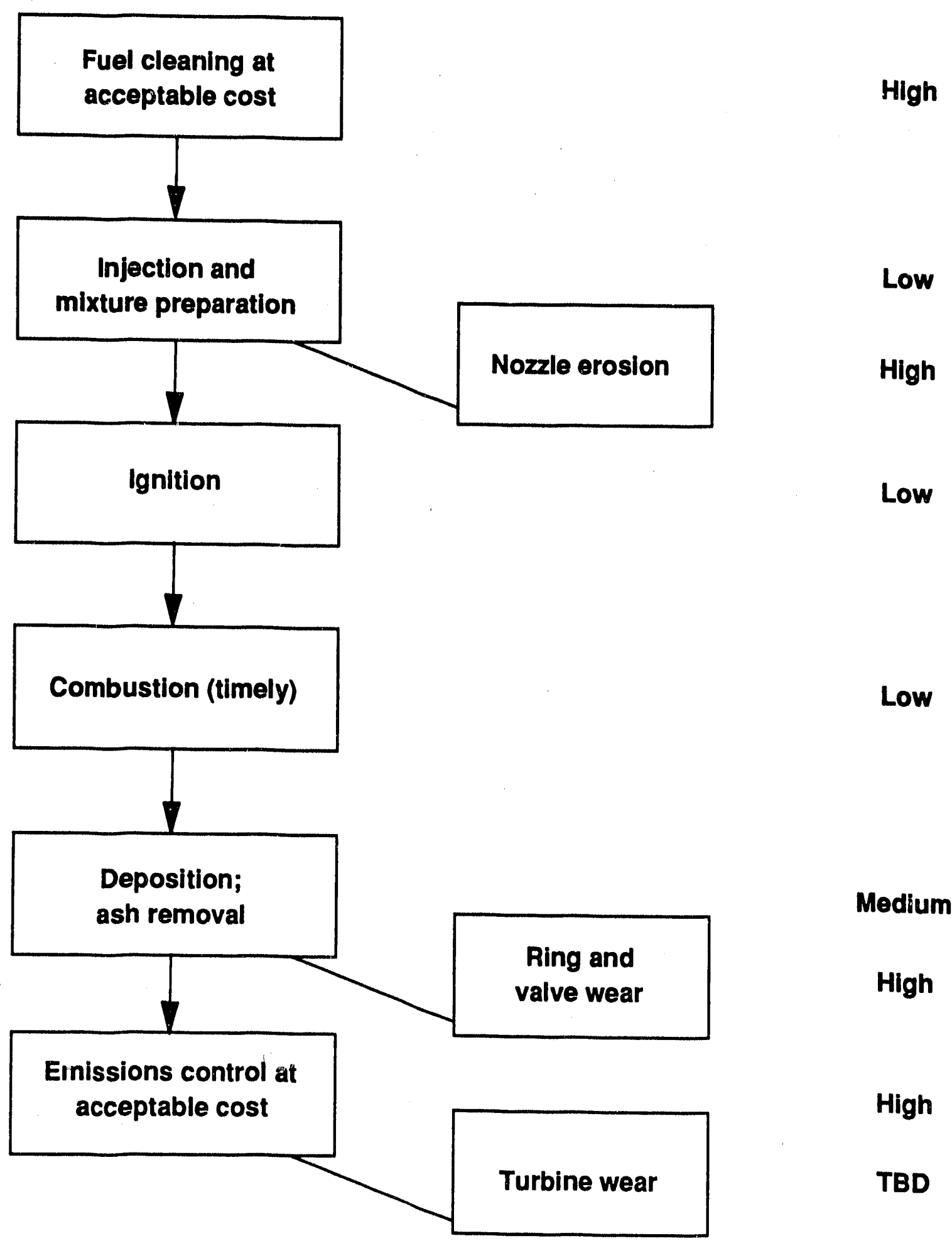


4. Multi-cylinder fuel system: AMBAC must design and develop a dual-fuel injection system capable of either DF2 or coal-water slurry operation.

5. Ring and liner durability: further R\&D is needed to define the overhaul interval (the current target is $25000 \mathrm{hr}$.) and the cost of hard rings and liners.

\section{CWS Process R\&D Priorities}

- Engine tolerance for higher ash slurry: the AMAX cleaned engine-grade coal-water fuel up to 1.5 ash proved to be an excellent starting point, and gave us no significant problem during the JS engine tests. This leads us to the issue of whether the engine will accept a lower cost, lower grade coal slurry fuel formulation.

- AMAX cleaning process modifications: the actual process steps need more R\&D to determine the efficiency and throughput rates that are feasible.

- Cleanability of source coals: to date, very few coals have been tested for cleanability in the AMAX process, with or without the chemical step. Further R\&D is needed.

- Additives package: the cost of the additives is significant and there is room for fine tuning in this area.

- Power cost and merits of cogeneration: this is an area of uncertainty in the AMAX cost model. 
Table VIII-1 illustrates the commercialization plan and shows the ongoing program in this perspective. Following the 100-hour proof-of-concept test in 1992, Cooper-Bessemer will further develop the coal-fueled engine to meet more stringent targets (1000 hour maintenance interval on injection system, for example). Current technology allows diesel (noncoal) engines to operate at greater than $92 \%$ availability at full load operation. The key to achieving this level of availability is the development and implementation of a preventative maintenance program to maintain those parts with a lesser life at intervals that preclude unscheduled breakdown. This same philosophy of development would be applied to the coal engine. The multicylinder version will be designed and a prototype four-cylinder or six-cylinder will be built and tested. The first installation on a customer site is targeted for 1994. This will initiate field demonstration.

During the ten-year period, 1995-2005, Cooper will plan to introduce coal-fueled diesel systems into selected customers' sites, both new and retrofit installations. Basic development and integrated testing will occur in the R\&D laboratory, however, the physical size of the medium speed engine precludes exhaustive testing in the laboratory environment. Therefore, the Cooper approach in the sale of initial models of new units and of conversion kits is to enlist the cooperation of customers and to establish an aggressive field follow-up support program to solve problems that are not evident in the laboratory in order to achieve the desired service life between maintenance intervals. We assume total sales of coal diesels will increase to the level of about $100 \mathrm{MW} / \mathrm{year}$ by the year 2005 , based on the assumptions that cogeneration and IPP/small utility installations of reciprocating engines will occur as projected in Tables III-9 and III-10 for the period 1995-2005. The commercialization plan is designed so that the coal diesel will be proven and in position to capture a small share of these by the 2000-2010 timeframe. This will grow to approximately 110 engines per year by the year 2010-2015.

Other engine manufacturers will follow suit and, if necessary, license the technology from Cooper. Years 2005-2015 define the time period when the coal diesel system may become widely used both by utilities for modular power and by industries for cogeneration. Based on Cooper's dominant position in the U.S. large stationary engine market for the last 40 years, it is reasonable to assume that $40 \%$ of all coal diesel systems produced from year 2005 to 2015 will be produced by Cooper-Bessemer. This may represent 60-110 large stationary coal engine systems per year (see Table III-10). 


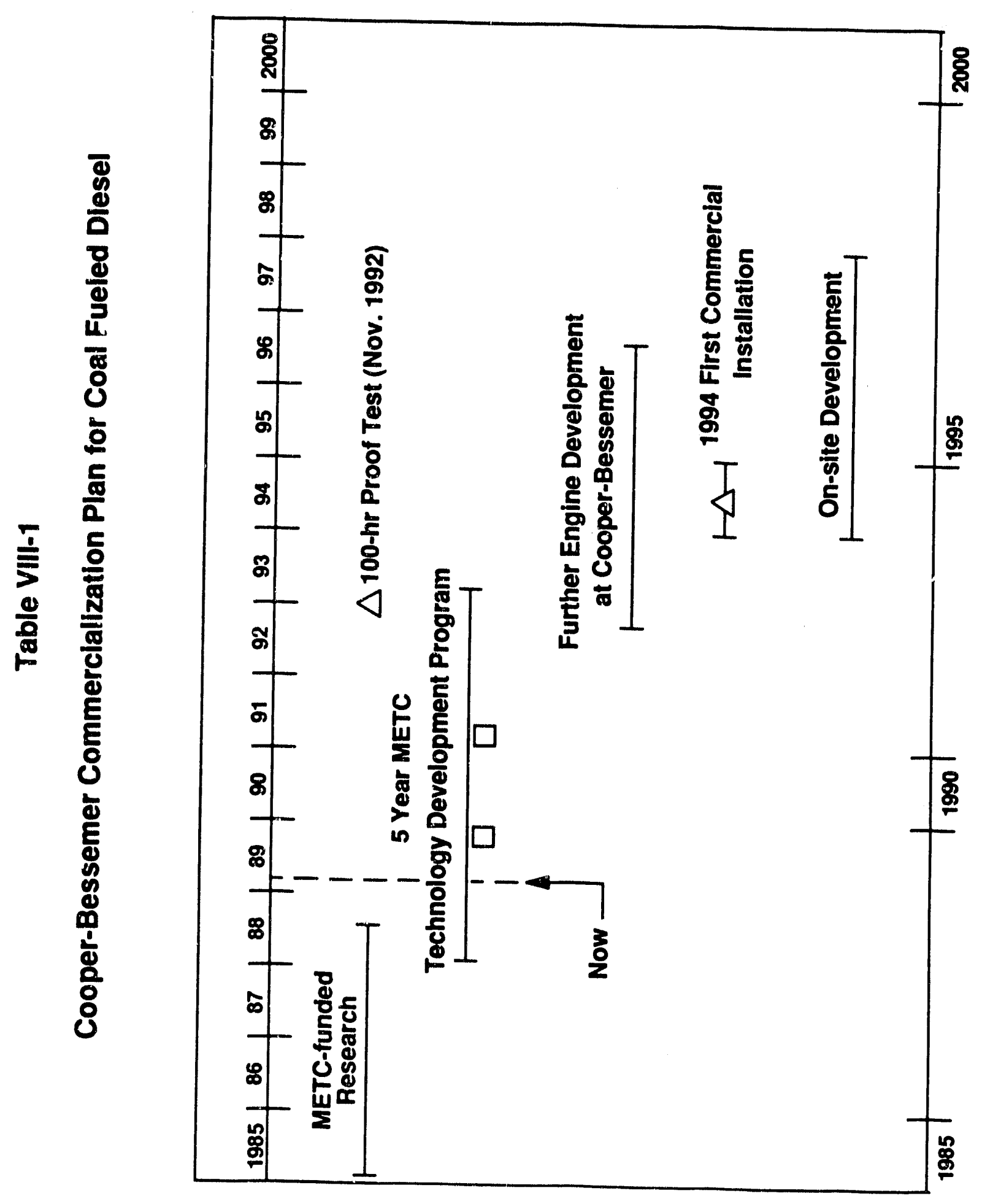




\section{REFERENCES}

\section{Chapter III}

1. Mottley, Mycoff, and Gumz, "U.S. Generation in the 1990's," Westinghouse, 1988.

2. Annual Energy Outlook, January 1990, pg. 46.

\section{Chapter IV}

1. Bhasin, A.K., Et al., "Chemical Coal Cleaning Process and Costs Refinement for CWS Manufacture," December 31, 1985 DOE Contract \#DEAC21-83-MC20700, DOE Report \#DOE/MC/20700.

2. Perry and Chilton, "Chemical Engineering Handbook," Fifth Edition.

3. Hagy, John, Personal Communication, Fort Pitt Machine Company.

4. Quotation from Dreyss Corporation.

\section{Chapter V}

1. Rao, A.K., Melcher, C.H., Wilson, R.P., Balles, E.N., Schaub, F.S., and Kimberly, J.A. (1988), "Operating Results of the Cooper-Bessemer JS-1 Engine on Coal-Water Slurry" presented at the Energy-Sources and Technology Conference, New Orleans, Louisiana.

2. Salimian, S. and Hanson, R.K. (1980), "A Kinetic Study of NO Removal from Combustion Gases by Injection of NHi-Containing Compounds", Conb.Sci.Tech. 23:225.

3. Markansi, J. (1988), "Reducing NOx Emissions", Power (September, 1988).

4. Caton, J.A. and Siebers, D.L. (1988), "Reduction of Nitrogen Oxides in Engine Exhaust Gases by the Addition of Cyanuric Acid", in Engine Emissions Technology for the 1990's (K.J. Springer ed.), American Society of Mechanical Engineers, New York.

5. Wasser, J.H. and Perry, R.B. (1987), "Diesel Engine NOx Control: Selective Catalytic Reduction and Methanol Emulsion", presented at 1987 Joint Symposium on Stationary Combustion NOx Control. New Orleans, Louisiana.

6. Mochida, I., Ogaki, M., Fujitsu, H., Yoshinobu, Y., and Ida, S. (1983), "Catalytic Activity of Coke Activated with Sulphuric Acid for the Reduction of Nitric Oxide", Fuel 62:867.

7. Davini, P. (1988), "Reduction of Nitrogen Oxides with Ammonia: the Activity of Certain Soots", Fuel 67:24.

8. Faucett, H.L., Maxwell. J.D., and Burnett, T.A. (1977), Technical Assessment of NOx Removal Processes for Utility Applications EPA-600/7-77-127. 
9. Wilson, C., Cooper, J., and Placer, F. (1987), "Performance Evaluation of a Screenless (Counter-Current) Granular Bed Filter on a Subpilot-Scale PFBC" in Proceedings of the Seventh Annual Gasification and Gas Stream Cleanup Systems Contractors Review Meeting DOE/METC/-87/6079, Vol. I.

10. Meyer, J.H., Westervelt, D., and Anestis, T. (1987), "Evaluation of a Ceramic CrossFlow Filter in a Bench-Scale Gasifier" in Proceedings of the Seventh Annual Gasification and Gas Stream Cleanup Systems Contractors Review Meeting DOE/METC/-87/6079, Vol. I.

11. McElroy, M.W. (1977), "Oklahoma Gas and Electric Full-Scale Demonstration of NOx Destruction in Fuel-Rich Burners", EPRI Program RP-782, PAlo Alto, California.

12. Yang, R.J., Arand, J.K., and Garcia, F.J. (1984), "Laboratory Evaluation of In-FurnaceNOx-Reduction for Industrial Combustion Applications", ASME Paper 84-JPGC-FU-12, October.

13. Bortz, S.J., Roman, V., and Offen, G.R. (1988), "Hydrate and Process Parameters Controlling SO2 Removal during Hydroxide Injection Near $1000^{\circ} \mathrm{F}^{\prime \prime}$, presented at First Combined FGD and Dry SO2 Control Symposium, St.Louis, Missouri.

14. Simons, G.A., Ham, D.O., Parker, T.E., Morency, J.R., Moniz, G., and Boni, A.A. (1987), "Alternative SO2 Sorbents", PSI Technical Report TR-744.

15. Muzio, L.J. and Sonnichsen (1983), "Dry SO2-Particulate Removal for Coal-Fired Boilers, Volume 1: Demonstration of SO2 Removal on a 22-MW Coal-Fired Utility Boiler by Dry Injection of Nahcolite", EPRI Report CS-2894, Volume 1.

16. LeCren, R.T., Hanson, A.M., and Hendrix, H.L. (1988), "Environmental Control Systems in Coal-Fueled Gas Turbines: Solar Turbines Technical Progress Report," presented at Annual Coal Fuel Heat Engines and Gas Stream Cleanup Systems Annual Contractors Review Meeting sponsored by DOE, Morgantown Energy Technology Center.

17. Electric Power Reasearch Institute (1982), Technical Assessment Guide, EPRI Report No. P-2410-SR.

18. Vatavuk, W.M. (1984), "Control Costs" in Handbook of Air Pollution Control Technology (S. Calvert and H.M. Englund, eds.), John Wiley and Sons, New York.

19. Peters, M.S. and Timmerhaus, K.D. (1980), Plant Design and Economics for Chemical Engineers, McGraw-Hill, Inc., New York.

20. Ciliberti, D.C., Smeltzer, E.E., Alvin, M.A., Keairns, D.L., and Bachovchin, D.M. (1983), Hot Gas Cleanup Using Ceramic Cross Flow Filters, Final Report, DOE/METC$85 / 6025$.

21. Wilson, R.H. (1984) Arthur D. Little, Inc. and Southern California Gas, personal communication. 
22. Wilson, R.H. (1987) Arthur D. Little, Inc., personal communication.

23. Swann, D.R and Drissel, G.D. (1980), Feasibility of Retrofitting Catalytic Postcombustion NOx Control on an 80-MW Coal-Fired Utility Boiler, EPRI Report No. CS-1372.

24. Wilson, R.H. (1987) NESCAUM Workshop on Cogeneration and Emission Control.

25. Rubow, L.N., Border, M., Buchanan, T.L., Cramp, J.A.C., Fischer, W.H., Klett, M.G., Maruvada, S.M., Nelson, E.T., Weinstein, R.E., and Zuharchuk, R. (1984), Technical and Economic Evaluation of Ten High-Temperature, High-Pressure Particulate Cleanup Systems for Pressurized Fluidized-Bed Combustion, DOE/MC/19196-1654. New Source Performance Standards for Stationary Sources 
APPENDIX A

CWS PLANT EQUIPMENT LISTS 
Table A.l

EQUIPMENT LIST AREA 100 - UNLOADING \& STORAGE

\begin{tabular}{lrr}
\hline Item Description & $\begin{array}{r}\text { Total Power } \\
\text { Requirement }(\mathrm{HP})\end{array}$ & $\begin{array}{r}\text { Total } \\
(\$ 1,000)\end{array}$ \\
\hline Rail Siding & -- & 472 \\
Thaw Shed & -- & 115 \\
Load-Out Scale & 2 & 39 \\
Sampler & 5 & 5 \\
Storage Piles & -- & - \\
Conveyors & 50 & 67 \\
Vibrating Feeder & 3 & 133 \\
Reclaim Pit & -- & 129 \\
Dozers & -- & 300 \\
Subtotal & & 1,260 \\
Delivery \& Taxes (@ 4\%) & & 50 \\
TOTALS & 60 & 1,310 \\
\hline
\end{tabular}


Table A2

EQUIPMENT LIST, AREA 200 - CRUSHING

\begin{tabular}{lrr}
\hline \multicolumn{1}{c}{ Item Description } & $\begin{array}{r}\text { Total Power } \\
\text { Requirement (HP) }\end{array}$ & $\begin{array}{r}\text { Total } \\
\text { Cost } \\
(\$ 1,000)\end{array}$ \\
\hline Storage Bin & -- & 24 \\
Vibrating Feeder & 3 & 10 \\
Scalping Screen & 25 & 21 \\
Hammer Mill & 150 & 144 \\
Feed Conveyors & 5 & 17 \\
Product Conveyors & 5 & 40 \\
Conveyor Scale & 2 & 16 \\
Subtotal & & 272 \\
Delivery \& Taxes (@ 4\%) & & 11 \\
TOTALS & 190 & 283 \\
\hline
\end{tabular}


Table A3

EQUIPMENT LIST, AREA 300 - GRINDING

\begin{tabular}{lrr}
\hline Item Description & $\begin{array}{c}\text { Total Power } \\
\text { Requirement (HP) }\end{array}$ & $\begin{array}{r}\text { Total } \\
\text { Cost \$ } \\
(\$ 1,000)\end{array}$ \\
\hline Mill Feed Bin & -- & 24 \\
Apron Feeders & 5 & 40 \\
Rod Mill & -- & 870 \\
Rod Mill Motor & 1600 & 159 \\
Rod Mill Starter & -- & 50 \\
Rod Mill Charge & -- & 88 \\
Slurry Sump & -- & 60 \\
Subtotal & 1605 & 1,291 \\
Delivery \& Taxes (@ 4\%) & & 52 \\
TOTALS & 1605 & 1,343 \\
\hline
\end{tabular}


Table A4

AREA 400 - PHYSICAL CLEANING (COLUMN FLOTATION)

\begin{tabular}{lcr}
\hline \multicolumn{1}{c}{ Item Description } & $\begin{array}{c}\text { Total Power } \\
\text { Requirement (HP) }\end{array}$ & $\begin{array}{r}\text { Total } \\
\text { Cost } \\
(\mathbf{\$ 1 , 0 0 0 )}\end{array}$ \\
\hline Frother Tank & -- & 25 \\
Frother Pump & 30 & 1 \\
Collector Tank & -- & 19 \\
Collector Pump & 30 & 2 \\
Conditioner & -- & 375 \\
Conditioner Pump & 50 & 3 \\
Column Flot Cells & -- & 250 \\
Blowers & -- & 70 \\
Filters & -- & -- \\
Conveyors & 50 & -- \\
Recycle Sump Pump & 100 & 70 \\
Thickener & -- & -- \\
Subtotal & & $\mathbf{8 1 5}$ \\
Delivery \& Taxes & & 33 \\
TOTALS & & $\mathbf{8 4 8 .}$ \\
\hline
\end{tabular}


Table A5

- EQUIPMENT LIST, AREA 400 - PHYSICAL CLEANING (HEAVY MEDIA)

\begin{tabular}{lcr}
\hline \multicolumn{1}{c}{ Item Description } & $\begin{array}{c}\text { Total Power } \\
\text { Requirements }(H P)\end{array}$ & $\begin{array}{r}\text { Total } \\
\text { Cost } \\
(\mathbf{1 , 0 0 0 )}\end{array}$ \\
\hline Heavy Media Plant & 222 & 979. \\
Subtotal & & 279 \\
Delivery \& Taxes & & 39 \\
TOTALS & $\mathbf{2 2 2}$ & $\mathbf{1 , 0 1 8 .}$ \\
\hline
\end{tabular}


Table A6

Equlpment List, Area 500, Caustlc Leach and Filtration

\begin{tabular}{|c|c|c|c|}
\hline Description & $\begin{array}{l}\text { Number } \\
\text { Required }\end{array}$ & $\begin{array}{c}\text { Total } \\
\text { HP }\end{array}$ & $\begin{array}{r}\text { Total Cost } \\
(\$ 1,000)\end{array}$ \\
\hline Feed Slury Mix Tank, 58,700 galeach - CS & 2 & $\cdot$ & 70 \\
\hline Feed Slurry Tank Agitator - CS & 2 & 120 & 68 \\
\hline Recycle Caustic Tank, $42,300 \mathrm{gal}$ - CS & 1 & $\cdot$ & 34 \\
\hline Recycle Caustic Transfer Pump, 350 gpm - CS & 1 & 15 & 4 \\
\hline Caustic Storage Tank, $476,000 \mathrm{gal}$ - CS & 1 & - & 89 \\
\hline Caustic Feed Pump - Piston, 45 pgm & 1 & 30 & 75 \\
\hline $\begin{array}{l}\text { High Pressure Feed Pump 1,530 gpm } \\
\text { Total }\end{array}$ & 2 & 1,200 & 760 \\
\hline $\begin{array}{l}\text { Heat Exchanger - Stage 1, 2, } 910 \mathrm{tt}^{2} \\
\text { Total, Inconel Tubes - CS Shell }\end{array}$ & 4 & - & 210 \\
\hline $\begin{array}{l}\text { Heat Exchanger - Stage 2, 3,280 } \mathrm{ft}^{2} \\
\text { Total, Inconel Tubes - CS Shell }\end{array}$ & 4 & $\cdot$ & 237 \\
\hline $\begin{array}{l}\text { Heat Exchanger - Stage 3, 3,260 } \mathrm{tt}^{2} \\
\text { Total, Inconel Tubes - CS Shell }\end{array}$ & 4 & $\cdot$ & 237 \\
\hline Autoclave, 12' ID $\times 78^{\prime}$ long, Refractory Lined & 1 & $\cdot$ & 930 \\
\hline Agitators, Autoclave, 5HP Inconel & 6 & 30 & 346 \\
\hline Ist Flash Vessel/Steam Separator - Inconel Clad & 1 & $\cdot$ & 187 \\
\hline 2nd Flash Vessel/Steam Separator - Inconel Clad & 1 & $\cdot$ & 156 \\
\hline 3rd Flash Vesselvteam Separator - Inconel Clad & 1 & $\cdot$ & 123 \\
\hline Slurry Cooler, $1,000 \mathrm{ft}^{2}$ - CS & 1 & $\cdot$ & 28 \\
\hline Filter Food Tank, $32,000 \mathrm{gal}$ - CS & 1 & $"$ & 30 \\
\hline Filter Foed Tank Agitator & 1 & 30 & 17 \\
\hline Filter Feed Pump, 1,420 gpm, Centrifugal & 1 & 150 & 16 \\
\hline Filter Presses, $76,460 \mathrm{ft}^{2}$, Polyprop & 12 & 120 & 6,000 \\
\hline Cake Conveyors, $3^{\prime} \times 45^{\prime}$ & 12 & 36 & 422 \\
\hline Transfer Conveyors, $3^{\prime} \times 90^{\prime}$ & 2 & 10 & 95 \\
\hline Elevating Conveyor, $3^{\prime} \times 60^{\prime}$ & 1 & 5 & 48 \\
\hline Delivery and Taxes, $4 \%$ & & - & 407 \\
\hline Total & & 1,746 & 10,593 \\
\hline
\end{tabular}


Table A7

Equipment LIst, Area 600, Acld Leach and Filtration

\begin{tabular}{|c|c|c|c|}
\hline Description & $\begin{array}{l}\text { Number } \\
\text { Required }\end{array}$ & $\begin{array}{c}\text { Total } \\
\text { HP }\end{array}$ & $\begin{array}{r}\text { Total Cost } \\
(\$ 1,000)\end{array}$ \\
\hline Acid Leach Tanks, 8,500 gal each & 4 & $\cdot$ & 241 \\
\hline Leach Agitators & 4 & 60 & 78 \\
\hline Fllter Foed Pumps, 1,410 gpm - RL & 2 & 100 & 32 \\
\hline Acid Storage Tank, 1,330,000 gal & 1 & $\cdot$ & 382 \\
\hline Acid Pump, 135 gpm & 1 & 5 & 3 \\
\hline Filter Presses, 57,340 $\mathrm{tt}^{2}$, Polyprop & 9 & 90 & 4,500 \\
\hline Cake Conveyors, $3^{\prime} \times 45^{\prime}$ & 9 & 21 & 316 \\
\hline Transfer Conveyor, $3^{\prime} \times 200^{\prime}$ & 1 & 10 & 122 \\
\hline Tripper Conveyor, $3^{\prime} \times$ 40' & 1 & 5 & 54 \\
\hline Dellivery and Taxes, $4 \%$ & & & 229 \\
\hline Total & & 291 & 5,957 \\
\hline
\end{tabular}


Table A8

Equipment Llst, Area 700, Hot Wash and Filtration

\begin{tabular}{|c|c|c|c|}
\hline Description & $\begin{array}{l}\text { Number } \\
\text { Required }\end{array}$ & $\begin{array}{r}\text { Total } \\
\text { HP } \\
\end{array}$ & $\begin{array}{r}\text { Total Cost } \\
(\$ 1,000) \\
\end{array}$ \\
\hline Mix Tanks, 62,000 gal/each - RLCS & 2 & - & 224 \\
\hline Mix Tank Agitator - RL & 2 & 100 & 76 \\
\hline $\begin{array}{l}\text { High Pross Slurry Pump, } 1,540 \text { gpm } \\
\text { Total }\end{array}$ & 2 & 800 & 805 \\
\hline $\begin{array}{l}\text { Heat Exchanger - Stage 1,2,910 } \mathbb{t}^{2} \\
\text { Total, Ti-Gr } 7 \text { - GS Shell }\end{array}$ & 4 & - & 210 \\
\hline $\begin{array}{l}\text { Heat Exchanger - Stage 2, 3,280 } \mathrm{t}^{2} \\
\text { Total, TI-Gr } 7-\mathrm{CS} \text { Shell }\end{array}$ & 4 & - & 237 \\
\hline $\begin{array}{c}\text { Heat Exchanger - Stage 3, 3,260 } \mathbb{t}^{2} \\
\text { Total, Ti-Gr } 7-\mathrm{CS} \text { Shell }\end{array}$ & 4 & '- & 237 \\
\hline Autoclave, 12' ID X 78' long, Refractory Lined & 1 & - & 1,550 \\
\hline Autoclave Agitators, Ti-Gr 7,5 HP each & 6 & 30 & 378 \\
\hline Ist Flash Vessel/Steam Separator & 1 & $\cdot$ & 199 \\
\hline 2nd Flash Vessel/Steam Separator & 1 & - & 166 \\
\hline 3rd Flash Vessel/Steam Separator & 1 & - & 132 \\
\hline Slurry Cooler, 1,000 $\mathrm{tt}^{2}, \mathrm{TI}-\mathrm{Gr} 7$ & 1 & - & 72 \\
\hline Filter Feed Tank, 32,000 gal - RLCS & 1 & $\cdot$ & 46 \\
\hline Filter Feed Tank Agitator, $30 \mathrm{HP}$ & 1 & 30 & 17 \\
\hline Filter Foed Pumps, $1,380 \mathrm{gpm}$ - RL & 2 & 100 & 32 \\
\hline Filter Presses, $57,340 \mathrm{ft}^{2}$, Polyprop & 9 & 90 & 4,500 \\
\hline Cake Conveyors, $3^{\prime} \times 45^{\prime}$ & 9 & 27 & 316 \\
\hline 'Transter Conveyor, 3' x 230' & 1 & 10 & 141 \\
\hline Ammonia Storage Tank, $14^{\prime}$ diameter $\times 75^{\prime}$ - CS & 1 & - & 120 \\
\hline Delivery and Taxes, $4 \%$ & & - & 378 \\
\hline Total & & 1,187 & 9,837 \\
\hline
\end{tabular}

$A-8$ 
Table A9

EQUIPMENT LIST, AREAS 800 and 900 FOR GRINDING AND FORMULATION

\begin{tabular}{|c|c|c|}
\hline Item Description & Total HP & $\begin{array}{r}\text { Total } \\
\text { Cost } \\
(\$ 1,000)\end{array}$ \\
\hline Mix Tanks & -- & 70 \\
\hline Mix Tank Agitator & 120 & 68 \\
\hline Dispersant Storage Tank & -- & 70 \\
\hline Dispersant Feed Pump & 7.5 & 1 \\
\hline $\begin{array}{l}\text { Stirred Ball Mills with feed } \\
\text { Pumps }\end{array}$ & 16,000 & 8,000 \\
\hline $\begin{array}{l}\text { Mix Tank Feed Pumps \& } \\
\text { Sumps }\end{array}$ & 150 & 36 \\
\hline Stabilizer Mix Tanks & -- & 110 \\
\hline \multicolumn{3}{|l|}{ Stabilizer Mix Tank Agitators } \\
\hline Stabilizer Storage Tank & -- & 90 \\
\hline Stabilizer Feed Pump & 5 & 2 \\
\hline Formaldehyde Storage Tanl & -- & 7 \\
\hline Formaldehyde Feed Pump & 1 & 2 \\
\hline Subtotal & & $\mathbf{8 . 5 2 7}$ \\
\hline Delivery and Taxes, $4 \%$ & & 349 \\
\hline Total & $16,403.5$ & 8,876 \\
\hline
\end{tabular}


TABLE A 10

EQUIPMENT LIST, AREA 1000, PRODUCT STORAGE AND LOAD-OUT

\begin{tabular}{lcr}
\hline \multicolumn{1}{c}{ Item Description } & Total HP & $\begin{array}{r}\text { Total } \\
\text { Cost } \\
(\$ 1,000)\end{array}$ \\
\hline Product Storage Tanks & -- & 1,845 \\
Product Storage Tank Agitators & 600 & 1,100 \\
Product Delivery Pumps & 750 & 142 \\
Product Delivery Pumps & 200 & 214 \\
Subtotal & & $\mathbf{3 , 3 0 1}$ \\
Delivery and Taxes, 4\% & & 132 \\
Total & $\mathbf{1 , 5 5 0}$ & $\mathbf{3 , 4 3 3}$ \\
\hline
\end{tabular}


Table A11

Equipment Llat, Area 1100, Cauzile and Heat Rocovery and Wasto Noutrallzation

\begin{tabular}{|c|c|c|c|}
\hline Description & $\begin{array}{r}\text { Number } \\
\text { Required }\end{array}$ & $\begin{array}{c}\text { Total } \\
\text { HP }\end{array}$ & $\begin{array}{r}\text { Total Cost } \\
(\$ 1,000)\end{array}$ \\
\hline Modffier Hopper, 21,400 cu ft - CS & 1 & - & 16 \\
\hline Modifier Feeder (Weigh) & 1 & 1.25 & 12 \\
\hline Lime Hoppers, $25,000 \mathrm{cu} f t$ Total - CS & 2 & - & 105 \\
\hline Lime Foeders (Weigh) & 2 & 2.5 & 24 \\
\hline Precipitation Tanks & 4 & - & 89 \\
\hline Precipitation Tank Agltators & 4 & 40 & 41 \\
\hline Milters, $5,310 \mathrm{tt}^{2}$ & 2 & 20 & 683 \\
\hline Discharge Conveyors, $3^{\prime} \times 45^{\circ}$ & 2 & 6 & 70 \\
\hline Caustic Evaporation System" & 1 & 5 & 1,600 \\
\hline Neutralization Taniks, 173,000 gal/each - RL & 3 & $\cdot$ & 318 \\
\hline Noutralization Tank Agitators - RL & 3 & 600 & 285 \\
\hline $\begin{array}{l}\text { Neutralization Waste Pump, } 9,000 \mathrm{gpm} \\
\text { Total - CS }\end{array}$ & 3 & 300 & 35 \\
\hline \multicolumn{4}{|l|}{ Delivery and Taxes, $4 \%$} \\
\hline & & 974.75 & 3,412 \\
\hline
\end{tabular}

- Installed cost 
Table A12

Equlpment Llst, Area 1300, Utilities

\begin{tabular}{lrrr}
\hline Description & $\begin{array}{r}\text { Number } \\
\text { Required }\end{array}$ & $\begin{array}{r}\text { Total } \\
\text { HP }\end{array}$ & $\begin{array}{r}\text { Total Cost } \\
(\$ 1,000)\end{array}$ \\
\hline Compressors-Centrifugal, 1,000 HP & 4 & 4,000 & 667 \\
Recycle Water Tank, 30' diameter X 24' h & 1 & - & 50 \\
Recycle Water Pump, 2,500 gpm & 1 & 200 & 17 \\
Heat Recovery Exchangers, 13,500 $\mathrm{ft}^{2}$ Ti \& CS & - & - & 212 \\
Heat Recovery Exchangers, 27,000 $\mathrm{ft}^{2}$ - CU \& CS & - & - & 447 \\
Heat Recovery Pumps, 1,000 gpm each & 8 & 370 & 90 \\
Delivery and Taxes, 4\% & & & 62 \\
Cogeneration Plant* & & 2,000 & 44,000 \\
$\quad$ Total & & 6,570 & 45,545 \\
\hline
\end{tabular}

"Installed included building 
APPENDIX B

CWS PROCESS COST MODEL 
The cost model consists of a set of automated spread sheets. Each spread sheet contains information which is used to feed costs into the two output spread sheets, the capital and operating cost summaries. Figure 2 shows how the model uses various inputs and assumptions to carry out the calculations necessary for the capital and operating case summaries. By altering the input information, it is very easy to perform sensitivity analyses.

\section{User Defined Variables}

Each case evaluation requires input data from the user for use in the calculations. These variables are user defined variables, and they must be updated before each case is run. The variables are related to the fuel specification, production rate, and market location. A list of user defined variables are shown below:

\author{
Requested Information \\ Raw Coal : \\ Coal Type \\ Coal purchase price \\ Moisture in Coal \\ sulfur in coal \\ Ash in Coal \\ Btu Value
}

Slurry Plant :

Plant Location

Distance from :

Capacity

Chemical cleaning

Final Grinding

Mine

User Site

Fuel Specification :

Particle Top Size

Ash Content

sulfur Content

viscosity

\section{Typical Data set}

Seam Name

\$/Ton

Wt:

Wt:

Wt\%

HHV

City Name

Miles
Miles
Tons/Yr
Yes/No
Yes/No

$\operatorname{um}_{\text {Wt\% }}$
wt\%

These inputs do not have defaults and must be updated for each case evaluation. Adjusting an input, such as plant capacity, will adjust the capital and operating costs of the plant and allow comparison with different size facilities producing the same fuel in different quantity. Similar variable evaluations can be performed with other inputs, making single variable impact sensitivity possible. 


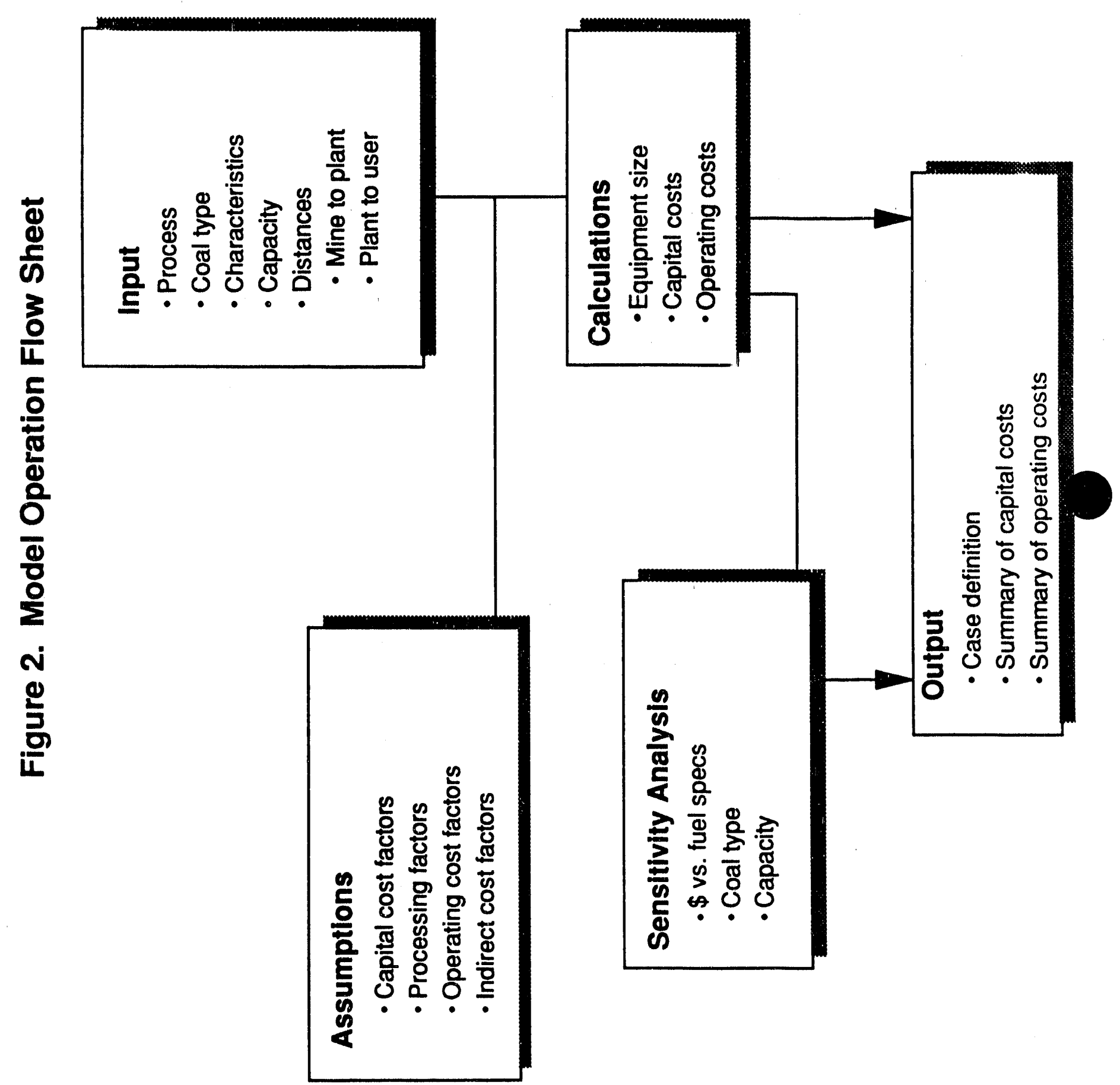


The following section describes how the automated spread sheets work together to estimate the capital and operating costs for a slurry preparation plant.

\section{Defined Model Assumptions}

Certain calculations relating to capital, processing, operating, and indirect costs contain default assumptions. These assumptions are defined in the spread sheet and can be altered if desired. The assumptions are not part of the normal user inputs and must be accessed separately by the user. Most of the assumptions are factors which form the basis for the capital and operating costs. Equipment sizing and selection are not contained in the assumptions and are inflexible to user alteration. The assumptions are listed in Table 1.

Material balances and costs included for operation of the plant were based upon 7,884 hours of operation per year. This is derived by using a 90 percent on stream factor and 365 dayper-year, round-the-clock operation.

Capital cost factors are taken from AMAX experience with similar plants and cross checked with current construction estimation manuals. Building costs are based upon equipmentlayout drawings and on internal AMAX cost files. Engineering fees and indirect costs are also based upon AMAX experience.

Processing factors are based upon pilot plant operation experience. The processing factors can be altered for different coals or processing unit applications if desired. A middling credit is included in case a credit is taken for the down grade material from the physical separation step. This credit is used mainly for heavy media separation rather than column flotation.

operating cost factors include maintenance, freight, and utilities. The factors are derived from operating experience at AMAX processing plants and from specific transportation and utility rates for the market location. The values shown in Table 1 are examples of rates used for the Pittsburgh market area. 
Indirect cost factors include cost of operation pertaining to overhead, profit, and administration. These cost factors are determined by the user and are very specific to the particular case being investigated. It is important to review the indirect cost factors before comparing fuel costs to ensure they are on the same basis.

\section{Calculations}

Capital and operating cost calculations are performed by the model, utilizing the inputs and assumptions described previously. Each of the thirteen areas of the plant have separate equipment capital and operating cost equations. The capital cost equations include a size factor or step functions depending upon the type of equipment and the size range. operating cost equations utilize input information including labor rates, plant capacity, coal cost, transportation cost, and chemicals.

A review of the capital cost summary sheet and the operating cost summary sheet helps define the various calculations included in the cost model. These summary sheets are presented in Tables 3 and 4 . The scenario which is presented in these tables represents the base case conditions for a plant in Pittsburgh Pennsylvania. The base case conditions are:

- Medium Quality Fuel

$1.0 \%$ ash in the coal

74 micron top size particles

$1.0 \%$ sulfur

$400 \mathrm{cp}$ at $100 \mathrm{sec}^{-1}$

- 1.25 million tons per year dry coal in slurry

- Coal feedstock which requires physical separation to achieve the desired fuel quality 


\section{Capital Cost Summary for CWS Fuel Plant}

Plant Location: PITTSBURGH

Local Type: Blue Gem

Capacity: 1.25 Million T/ (Coal in Fuel)

Raw Coal Characteristics:

Slurry Fuel Specifications:

6 Percent Moisture 74 um Top Size

2 Percent Ash

0.7 Porcent Sulfur

14,042 HHV (Btu/lb)

1 Percent Ash

1 Percent Sulfur

MED Viscosity

$35 \%$ Solids

"No Finish Grinding or Chemical Cleaning Required

Item

Cost,

A. Subtotal Delivered Equipment Cost

$\$$ Million

Unloading \& Storage

Crushing

13.971

Initial Grinding

Physical Cleaning

1.333

0.389

Caustic Leach \& Filtration

2.019

Acid Leach \& Filtration

1.325

Hot Water Wash \& Filtration

0.000

Fine Grinding

Slurry Preparation

0.000

0.000

Storage \& Load Out

0.000

0.000

Caustic Regeneration

3.644

Waste Treatment \& Disposal

2.917

0.704

Utilities

1.641

B. Less Modularized Equipment Cost

$-3.518$

C. Bare Delivered Equipment Subtotal (A-B)

10.453

D. Installation $(24.8 \%$ of $\mathrm{C})$

E. Instrumentation $(25.5 \%$ of $\mathrm{C})$

2.592

2.665

F. Piping $(75.9 \%$ of $\mathrm{C})$

G. Electrical $(33.5 \%$ of $\mathrm{C}$ )

H. Paint and Insulation (6.6\% of C)

I. Subtotal $(A+D+E+F+G+H)$

7.934

3.502

0.690

J. Building

31.354

K. Land and Site Development

10.443

$L$. Rail and Road Facilities

M. Total Field Cost $(1+J+K+L)$

1.451

1.710

N. Engineering and Fees (13.8\% of $\mathrm{M}) \quad 6.204$

O. Indirect Costs $(18.3 \%$ of $\mathrm{M})$

P. Subtotal Construction Cost $(\mathrm{M}+\mathrm{N}+\mathrm{O})$

8.227

Q. Contingency $(20 \%$ of $P)$

R. Total Capital Cost $(P+Q)$

59.389

S. Working Capital ( $10 \%$ of R)

11.878

71.267

7.127

$T$. Final Total Capital Cost $(R+S)$

70.894 


\section{Capltal Cost Summary Sheet}

below:

Each of the costs found in the capital cost summary sheet are described

\section{Item $\mathrm{A}$}

The total delivered equipment cost is presented for each of the areas Included in the flowsheet. Equipment is first selected based upon fuel quality requirements and then sized based upon plant production rates. A cost is assigned to each piece of equipment based upon information taken from AMAX internal files or equipment costing information such as Richardson Process Plant Estimating Standards. A size cost adjustment is assigned to each plece of equipment based upon incremental size factors or step functions depending upon the type of equipment. In some cases the equipment cost includes installation costs. Equipment costs which are installed costs do not require adjustment for installing. Some unit operations do not have an equipment cost if they are not required for the specific scenario.

Item_B

The costs for modular equipment, which is already installed, are summed for exclusion during installation costing.

\section{Item C}

Total equipment cost used for installation costing is equal to the total equipment cost (Item A) minus the modular equipment cost (Item B). This value is then used with the installation cost factors, Items $D$ through $H$.

\section{Item_D}

The Installation Cost Factor is multiplied tirnes the bare delivered equipment cost. The cost includes installation of all delivered equipment including structural support, insulation, and paint. Installation factors re available for individual pieces of equipment. A general plant installation factor was used based upon the equipment type required for slurry manufacture. Based on AMAX experience, this factor is 24.8 percent.

\section{Item E}

Instrumentation and controls typically vary from 6 to 30 percent of the delivered equipment costs depending upon the amount of control and the complexity of the circuit. The slurry preparation plant would require a solid. liquid, and some gas control, as well as multiphase controls for the slurry streams. The cost includes the cost of the control equipment, installation, and auxiliary equipment and materials. AMAX experience suggests a factor of $\mathbf{2 5 . 5}$ percent for instrumentation.

\section{Item $\mathrm{E}$}

Piping cost factors can range from 15 percent to 100 percent and may significantly impact the overall plant cost. The cost for piping covers labor, valves, fittings, pipe supports, and materials used in installing the process plant piping. Since the plant is heavily dependent upon piping for material handling, the factor used is on the high end of the range (75.9 percent). 


\section{Item $\mathrm{G}$}

Electrical installation costs include labor and materials for building power, transformers, lighting, and instruments. The electrical installation factor can range from 10 to 40 percent. Based on AMAX knowledge of plants of this general type, a factor of 33.5 percent was assumed for electrical.

\section{Item $\mathrm{H}$}

Insulation and paint costs for the plant are affected by plant location. The cost is approximately 8 to 9 percent for chemical plants. The slurry production plant does not require the same insulation most chemical plants require, since outdoor containment is primarily for product storage and not piping intensive. Therefore, we assumed 6.6 percent for paint and insulation.

\section{Item I}

Item I is a summation of the equipment related installation factored costs (A, D, E, F, G, and H).

\section{Item J}

Buildings and Land cost is related to the square footage and height of the bullding. The type of structure is assumed to be a prefabricated steel building for basic protection from the elements. Cost includes labor, materials, and supplies for construction. Costs for plumbing, heating, lighting, ventilation, and other services are part of this factor. Land cost is not as production rate sensitive as other cost factors, since rail siding and coal storage is required regardless of the plant size, and is sensitive to geographic location and industrial proxdmity.

This cost, along with Items $K$ and $L$, are step functions for which AMAX estimated the costs. The building and land cost do not have a direct relationship to the equipment cost or the subtotaled factored cost. Items $\mathrm{J}, \mathrm{K}$. and $L$ relate to the equipment cost but not directly, since a plant with twice the equipment cost will not require twice as much rall trackage, roads, buildings, or land.

\section{Item_K}

Land and site development includes grading, fencing, roads, sidewalks, landscaping, and auxiliary buildings such as change house, office, laboratory, warehouse, and shop. AMAX estimated land and site development costs.

\section{Item L}

Rail and road facilities include the cost of a rail switch, rail siding, and roads on site and from local access. Some of these costs are accounted for in the capital equipment cost of Area 100. Rail and road costs were estimated by AMAX and used as step functions as the plant output increased. 


\section{Item M}

The total field cost is a summation of the equipment cost, equipment installation costs, plant erection, and site development costs. These are direct costs involved with building the plant (items I, J, K, and L).

Item N

The cost of design, engineering, drafting, purchasing, accounting, construction, travel, communications, on site office and home office expense, permitting and overhead are included in Engineering and Fees. This is an indirect cost that can range from 4 percent to 21 percent of the fixed capital cost. AMAX assumes a factor of 13.8 percent for engineering and fees.

Item 0

Indirect Costs include field expenses such as contractors fee, construction tools, temporary assignments to the field office, construction payroll, travel and living expenses, taxes and insurance, and the other related overhead expenses. Based on plant experience, AMAX assumed a factor of 18.3 percent for indirect costs.

Itemp

Total Construction cost includes the direct and indirect expenses. Item $Q$

A contingency of 20 percent is included which is multiplied times the total Construction Cost. This could be reduced as the level of engineering increases and specific site related issues are more clearly defined. Figure 3, from Stearns Rogers, relates the level of engineering with the accuracy of the cost estimate. The figure shows that the level of engineering information known for this model reflects a confidence range of + or -25 percent. For this reason, a higher than normal (10 percent) contingency factor is used.

Item $B$ costs.

The total capital cost is the sum of the direct, indirect, and contingency

\section{Item S}

Working Capital is required for start up of the plant. It is used to purchase raw materials, stock the warehouse with spare parts and replacement equipment, and for changes required during start up. AMAX assumed 10 percent for working capital.

\section{Item $\mathrm{T}$}

The Final Total Capital cost is the sum of the Total Capital Cost and the Working Capital. 


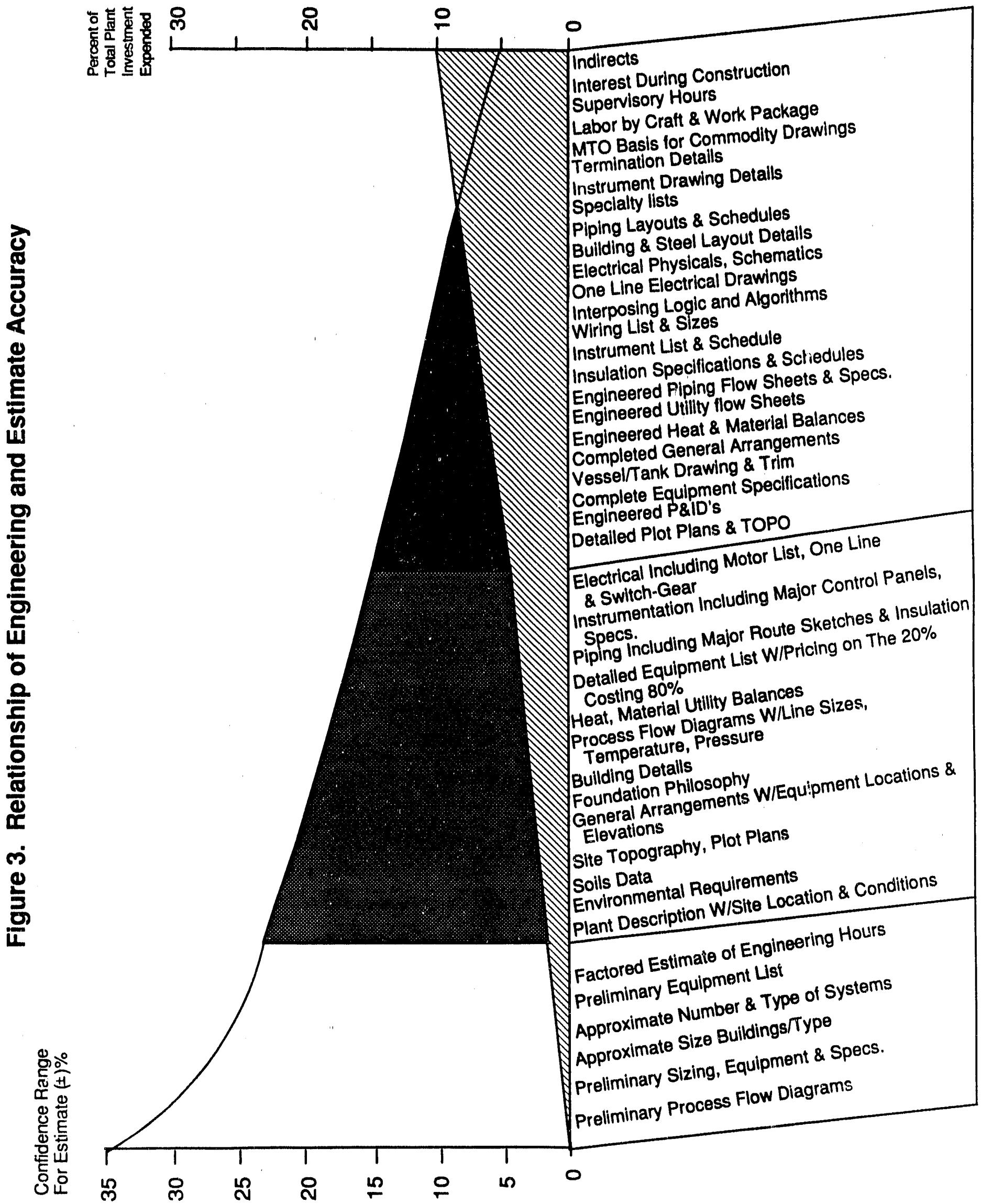




\section{Operating Cost Summary for CWS Fuel Plant}

Plant Location: PITTSBURGH

Coal Type: Blue Gern

Capacity: 1.25 Million T/Y (Coal in Fuel)

Raw Coal Characteristics:

6 Percent Moisture

2 Percent Ash

0.7 Percent Sulfur

14,042 HHV (Btu/lb)

Distance in miles from:

Mine to Slurry Plant

Slurry Plant to User Site
Slurry Fuel Specifications: 74 um Top Size

1 Percent Ash

1 Percent Sulfur

MED Viscosity

$55 \%$ Solids

0

20

27.8 MMBtu/ton (coal in fuel)

"No Finish Grinding or Chemical Cleaning Required

\begin{tabular}{|c|c|c|c|c|c|}
\hline \multicolumn{2}{|c|}{ Item } & \multicolumn{2}{|c|}{ Unit Cost } & \multirow{2}{*}{$\begin{array}{r}\begin{array}{r}\$ / \text { Ton Dry } \\
\text { Coal in Fuel }\end{array} \\
34.22\end{array}$} & \multirow{2}{*}{$\begin{array}{r}\begin{array}{r}\text { \$MMBtU } \\
\text { HHV }\end{array} \\
1.23\end{array}$} \\
\hline A. & Purchased Coal & 30.00 & \$/ton raw & & \\
\hline B. & Freight to Slurry Plant & 0.00 & \$/ton raw & 0.00 & 0.00 \\
\hline c. & $\begin{array}{l}\text { Subtotal Labor } \\
\text { Operation \& Supervision } \\
\text { Maintenance \& Supervision } \\
\text { Analytical } \\
\text { Other Assignable Labor } \\
\text { Cogeneration Plant Labor }\end{array}$ & $\begin{array}{r}17 \& 20 \\
17 \& 20 \\
15 \\
17 \& 20\end{array}$ & $\begin{array}{l}\$ / \mathrm{hr} \\
\$ / \mathrm{hr} \\
\$ / \mathrm{hr} \\
\$ / \mathrm{hr}\end{array}$ & $\begin{array}{l}2.46 \\
1.08 \\
0.99 \\
0.12 \\
0.26 \\
0.00\end{array}$ & $\begin{array}{l}0.09 \\
0.04 \\
0.04 \\
0.00 \\
0.01 \\
0.00\end{array}$ \\
\hline D. & $\begin{array}{l}\text { Subiotal Utilities } \\
\text { Electrical and Steam }\end{array}$ & 0.25 & $\$ / 1,000 \mathrm{gal}$ & $\begin{array}{l}2.32 \\
2.13 \\
0.19\end{array}$ & $\begin{array}{l}0.08 \\
0.08 \\
0.01\end{array}$ \\
\hline$E$. & $\begin{array}{l}\text { Subtotal Reagents } \\
\text { Caustic } \\
\text { Acid } \\
\text { Ammonia } \\
\text { Dispersant } \\
\text { Formaldehyde } \\
\text { Lime } \\
\text { Modifier }\end{array}$ & $\begin{array}{r}285 \\
155 \\
210 \\
0.557 \\
0.25 \\
40 \\
90\end{array}$ & $\begin{array}{l}\text { \$/ton } \\
\text { \$/ton } \\
\text { \$/ton } \\
\text { \$/1b } \\
\text { \$/lb } \\
\text { \$/ton } \\
\text { \$/ton }\end{array}$ & $\begin{array}{l}8.86 \\
0.00 \\
0.00 \\
0.00 \\
8.36 \\
0.50 \\
0.00 \\
0.00\end{array}$ & $\begin{array}{l}0.32 \\
0.00 \\
0.00 \\
0.00 \\
0.30 \\
0.02 \\
0.00 \\
0.00\end{array}$ \\
\hline $\mathrm{F}$. & $\begin{array}{l}\text { Subtotal Maintenance Materials } \\
\text { Mill Liners and Media } \\
\text { General Maintenance }\end{array}$ & $\begin{array}{r}3 \% 0 \\
\text { (excluding }\end{array}$ & $\begin{array}{l}\text { ital } \\
\text { ig equip.) }\end{array}$ & $\begin{array}{l}1.86 \\
0.35 \\
1.51\end{array}$ & $\begin{array}{l}0.07 \\
0.01 \\
0.05\end{array}$ \\
\hline G. & Freight to User Site & 0.00 & \$/ton fuel & 0.00 & 0.00 \\
\hline $\mathrm{H}$. & Middling Coal Credit & 0 & \$/ton & 0.00 & 2.00 \\
\hline 1. & $\begin{array}{l}\text { Total Direct Costs } \\
(A+B+C+D+E+F+G+H)\end{array}$ & & & 49.72 & 1.79 \\
\hline J. & $\begin{array}{l}\text { Subtotal Indirect Costs } \\
\text { Taxes, Insurance, Supplies } \\
\text { General Admin. \& Sales } \\
\text { Net Cash Flow }\end{array}$ & 0.000 & $\begin{array}{l}\% \text { of Capital } \\
\text { NCF Factor }\end{array}$ & $\begin{array}{l}0.00 \\
0.00 \\
0.00 \\
0.00\end{array}$ & $\begin{array}{l}0.00 \\
0.00 \\
0.00 \\
0.00\end{array}$ \\
\hline & Total Operating Cost $(1+J)$ & & & 49.72 & 1.79 \\
\hline
\end{tabular}


operating cost summary sheet

The operating cost summary sheet is shown in Table 2 . The itenized costs are described in further detail in this section.

Item A

Purchased coal cost is the cost of coal purchased from the mine identified in the header of the summary sheet. This is normally a quoted price based upon the tonnage required per year. The large amounts required for most of these plants results in some price reductions.

Item B

Freight to the slurry plant is the cost of moving the coal to the plant by rail or barge depending upon the location of the mine and the slurry plant. Freight costs were obtained from AMAX Coil Company or from FINAMAX Coal Company and were based on uni:- train loads of coal for the specific case scenarios. The train and the engine were assumed to be owned by the rail company.

\section{Item $C$}

The labor costs include the cost of wages for operators, foremen, mechanical and electrical support, laboratory technicians, safety and environmental, personnel, warehouse, purchasing, secretaries, engineers, and plant manager. Labor rates were taken from industry labor rates for 1988 . More specific costs could be identified by plant location, but an average rate was used for the model regardless of the location. Certain fringe benefits and payroll costs were not included in these costs. The number of personnel and the estimated costs are shown in Table 4 .

\section{Item D}

Utility costs were based upon the rates available from local utilities. Power and water costs were included in the utility costs. Industrial rates were quoted for power which are usually a function of the peak usage and a straight cost per $\mathrm{kW} / \mathrm{hr}$. Power consumption for the plant assumes $80 \%$ of the installed horse power is used during processing.

\section{Item $E$}

Reagent costs include reagents used in cleaning the coal and in formulating the final slurry. The costs and consumption rates are based upon actual operating experience at AMAX R\&D center. Certain reagents are not used in scenarios that have chemical cleaning excluded. 
Table 4. Labor Requlrements for the Base Case Scenario

$\begin{array}{ll}\text { Area } & \text { Job Category } \\ & \text { Operators: } \\ 100 & \text { Unloading \& storage } \\ 200 & \text { Crushing } \\ 300 & \text { Initial Grinding } \\ 400 & \text { Physical Cleaning } \\ 500 & \text { Caustic Leach \& Filter } \\ 600 & \text { Acid leach \& Filtration } \\ 700 & \text { Hot Water Wash \& Filter } \\ 800 & \text { Fine Grinding } \\ 900 & \text { Slunry Preparation } \\ 1000 & \text { Storage \& Load Out } \\ 1100 & \text { Caustic Regeneration } \\ 1200 & \text { Waste Treatment \& Disposal } \\ 1300 & \text { Utilities } \\ & \text { Shift Foreman } \\ & \text { Mechanical Foreman } \\ \text { Mechanics } & \text { Electricians } \\ \text { Laboratory Technicians } & \text { Plant Manager } \\ \text { Plant Engineer } & \text { Process Engineer } \\ \text { Personnel Administrator } \\ \text { Safety/Environmental Officer } \\ \text { Purchasing Clerk } \\ \text { Warehouseman } \\ \text { Secretaries } \\ \text { Total \$/yr } \\ \text { \$/Ton Dry Coal } \\ \text { \$/MMBtu (HHV) }\end{array}$

\begin{tabular}{|c|c|c|c|}
\hline Number & & Wage & 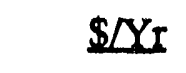 \\
\hline $\begin{array}{r}4 \\
2 \\
4 \\
4 \\
0 \\
0 \\
0 \\
0 \\
0 \\
4 \\
4 \\
4 \\
4 \\
4 \\
1 \\
20 \\
12 \\
5 \\
1 \\
1 \\
2 \\
1 \\
1 \\
1 \\
1 \\
2\end{array}$ & $\begin{array}{r}17 \\
17 \\
17 \\
17 \\
17 \\
17 \\
17 \\
17 \\
17 \\
17 \\
17 \\
17 \\
17 \\
20 \\
20 \\
17 \\
17 \\
15 \\
6,750 \\
5,625 \\
5,200 \\
5,062 \\
3,600 \\
2,947 \\
2,947 \\
2,947\end{array}$ & $\begin{array}{l}\$ / h r \\
\$ / h r \\
\$ / h r \\
\$ / h r \\
\$ / h r \\
\$ / h r \\
\$ / h r \\
\$ / h r \\
\$ / h r \\
\$ / h r \\
\$ / h r \\
\$ / h r \\
\$ / h r \\
\$ / h r \\
\$ / h r \\
\$ / h r \\
\$ / h r \\
\$ / h r \\
\$ / h r \\
\$ / m o \\
\$ / m o \\
\$ / m o \\
\$ / m o \\
\$ / m o \\
\$ / m o \\
\$ / m o\end{array}$ & $\begin{array}{r}141,440 \\
70,720 \\
141,440 \\
141,440 \\
0 \\
0 \\
0 \\
0 \\
0 \\
141,440 \\
141,440 \\
141,440 \\
141,440 \\
166,400 \\
41,600 \\
707,200 \\
424,320 \\
156,000 \\
81,000 \\
67,500 \\
124,800 \\
60,744 \\
43,200 \\
35,364 \\
35,364 \\
70,728\end{array}$ \\
\hline & & & $\begin{array}{r}3,075,020 \\
2.46 \\
0.08\end{array}$ \\
\hline
\end{tabular}




\section{Item $\mathrm{F}$}

Maintenance materials is broken into two parts because a fairly large portion of the maintenance cost is related directly to grinding. The grinding mill maintenance costs for liners and media have been broken out separately. The remaining costs are covered under general maintenance.

\section{Item $G$}

Freight to the user's site includes the cost of transporting the slurry to the user's site. This cost was not included in the cost scenarios at the request of Arthur D. Little. Inc.

\section{Item $\mathrm{H}$}

Middling coal credit is the credit for selling lower grade by product coal which is produced when heavy media separation is employed for physical cleaning. Heavy media separation was not used in any of the cost scenarios for Arthur D. Little, Inc.

\section{Item I}

Total Direct Costs are the sum of the itemized operating costs; Items A, B, C. D, E, and F.

\section{Item J}

Indirect costs include taxes, insurance, supplies, general administration, sales, and net cash flow. These costs were excluded at the request of Arthur D. Little. Inc., who included them separately.

\section{Item $\mathrm{K}$}

The total operating cost is the same as the Total Direct Costs since Indirect Costs have been excluded. 


\section{APPENDIX C}

SAMPLE CWS COST MODEL RUNS 


\section{Capltal Cost Summary for CWS Fuel Plant}

Plant Location: PITTSBURGH

Coal Type: Blue Gem

Caracity: 1.25 Million TN (Coal in Fuel)

Raw Coal Characteristics:

6 Percent Moisture

2 Percent Ash

0.7 Percent Sulfur

14,042 HHV (Btu/lb)
Slurry Fuel Specifications:

$\begin{aligned} 74 & \text { um Top Size } \\ 1 & \text { Perc nt Ash } \\ 1 & \text { Percent Sulfur } \\ \text { MED } & \text { Viscosity } \\ 55 \% & \text { Solids }\end{aligned}$

"No Finish Grinding of Chemical Cleaning Required

Item

Cost,

\$ Million

A. Subtotal Delivered Equipment Cost

13.971

Unloading \& Storage

1.333

Crushing

0.389

Initial Grinding

2.019

Physical Cleaning

1.325

Caustic Leach \& Filtration

0.000

Acid Leach \& Filtration

0.000

Hot Water Wash \& Filtration

0.000

Fine Grinding

0.000

Slurry Preparation

0.000

Storage \& Load Out

3.644

Caustic Regeneration

2.917

Waste Treatment \& Disposal

0.704

Utilities

1.641

B. Less Modularized Equipment Cost

$-3.518$

C. Bare Delivered Equipment Subtotal (A-B)

10.453

D. Installation $(24.8 \%$ of C)

E. Instrumentation $(25.5 \%$ of $\mathrm{C})$

2.592

2.665

F. Piping $(75.9 \%$ of $\mathrm{C})$

7.934

G. Electrical

3.502

H. Paint and Insulation ( $6.6 \%$ of $C$ )

0.690

I. Subtotal $(A+D+E+F+G+H)$

31.354

J. Buildings

10.443

K. Land and Site Development

1.451

L. Rail and Road Facilitios

1.710

M. Total Field Cost $(1+J+K+L)$

44.958

N. Engineering and Fees (13.8\% of $M$ )

O. Indirect Costs (18.3\% of $M$ )

8.227

P. Subtotal Construction Cost $(M+N+O)$

Q. Contingency $(20 \%$ of $P)$

R. Total Capital Cost $(P+Q)$

S. Working Capital ( $10 \%$ of R)

T. Final Total Capital Cost $(R+S)$ 


\section{Capltal Cost Summary for CWS Fuel Plant}

Plant Location: PITTSBURGH

Coal Type: Blue Gem

Capacity: 1.25 Million TN (Coal in Fuel)

Raw Coal Characteristics:

6 Percent Moisture

2 Percent Ash

0.7 Percent Sulfur

14,042 HHV (Btu/lb)

Slurry Fuel Specifications:

Mine to Slurry Plant: 0

Slurry Plant to User Site: 20

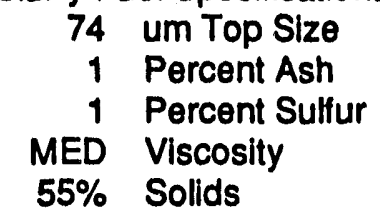

27.8 MM Btu/Ton

(Coal in Fuel)

"No Finish Grinding of Chemical Cleaning Required

Item

A. Purchased Coal

B. Freight to Slurry Plant

C. Subtotal Labor Operation \& Supervision Maintenance \& Supervision Analytical

Other Assignable Labor Cogeneration Plant Labor

D. Subtotal Utilities Electricity and Steam Process and Cooling Water

E. Subtotal Reagents

Caustic

Acid

Ammonia

Dispersant

Formaldehyde

Lime

Modifier
Unit Cost

$\begin{aligned} 30.00 & \$ / \text { Ton Raw } \\ 0.00 & \$ / \text { Ton Raw } \\ & \\ 17820 & \$ / H R \\ 17820 & \$ / H R \\ 15 & \$ / H R \\ 17820 & \$ / H R\end{aligned}$

$0.25 \$ / 1,000 \mathrm{gal}$

2.85 \$/ton

155 \$/ton

210 \$/ton

$0.557 \$ / / b$

$0.25 \$ / 1 \mathrm{~b}$

40 \$/ton

90 \$/ton
\$/Ton Dry Coal In Fuel

34.22

0.00

2.46

1.08

0.99

0.12

0.26

0.00

2.32

2.13

0.19

8.86

0.00

0.00

0.00

8.36

0.50

0.00

0.00

1.86

0.35

1.51

$3 \%$ of Capital (excluding grinding equip.)

G. Freight to User Site

\section{$0.00 \$$ \$ton fuel}

0.00

0.00

49.72

0.00

0.00

0.00 General Admin. \& Sales Net Cash Flow

0.000 NCF Factor

0.00

49.72

\$/MM Btu

HHV

1.23

0.00

0.09

0.04

0.04

0.00

0.01

0.00

0.08

0.08

0.01

0.32

0.00

0.00

0.00

0.30

0.02

0.00

0.00

0.07

0.01

0.05

0.00

0.00

1.79

0.00

0.00

0.00

0.00

1.79 
Capital Cost Summary for CWS Fuel Plant

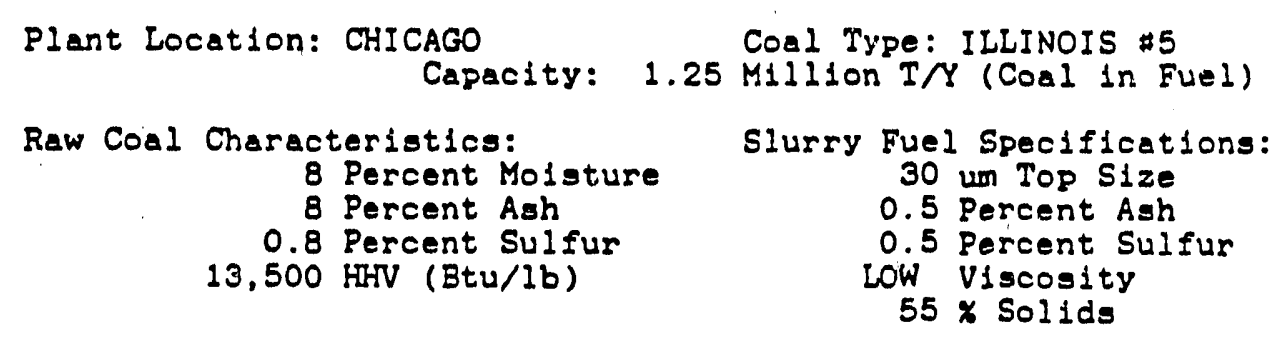

Item

A. Subtotal Delivered Equipment Cost
Unloading \& Storage
Crushing
Initial Grinding
Physical Cleaning
Caustic Leach \& F1ltration
Ac1d Leach \& F1ltration
Hot Water Wash \& Filtration
Fine Grinding
Slurry Preparation
Storage \& Load Out
Caustic Regeneration
Waste Treatment \& Disposal
Ut1litleg

B. Less Modularized Equ1pment Cost

C. Bare Delivered Equipment Subtotal (A-B)

D. Installation ( $24.8 \%$ of $C$ )

E. Instrumentation (25.5\% of C)

F. Plpine (75.9* of $C$ )

G. Electrical (33.5\% of $C$ )

H. Paint and Invulation ( $6.6 \%$ of $\mathrm{C}$ )

I. Subtotal $(A+D+E+F+G+H)$

J. Buildings

$R$. Land and Site Development

L. Rail and Road Faclidties

M. Total Field Cost $(I+J+K+L)$

N. Engineering and Fees ( $13.8 \%$ of $M$ )

0 . Indirect Costs (18.3\% of $M$ )

P. Subtotal Construction Cost $(\mathrm{M}+\mathrm{N}+0)$

Q. Contingency ( $20 \%$ of $F$ )

R. Total Capital Cost $(P+Q)$

S. Working Cap1tal ( $10 \%$ of $R$ )

T. Final Total Capltal Cost $(R+S)$
Cost, $\$$ milison

95.961

1.333

0.389

2.019

1.325

11.242

6.322

8.312

9.062

0.358

3.644

2.917

0.704

48.335

$-\quad 50.213$

45.748

11.346

11.666

34.723

15.326

3.019

172.040

10.443

1.451

1.710

185.644

25.619

33.973

245.236 49.047

294.283 29.428

323.711 
Operating Coet Summery for CWS Fuel Plent

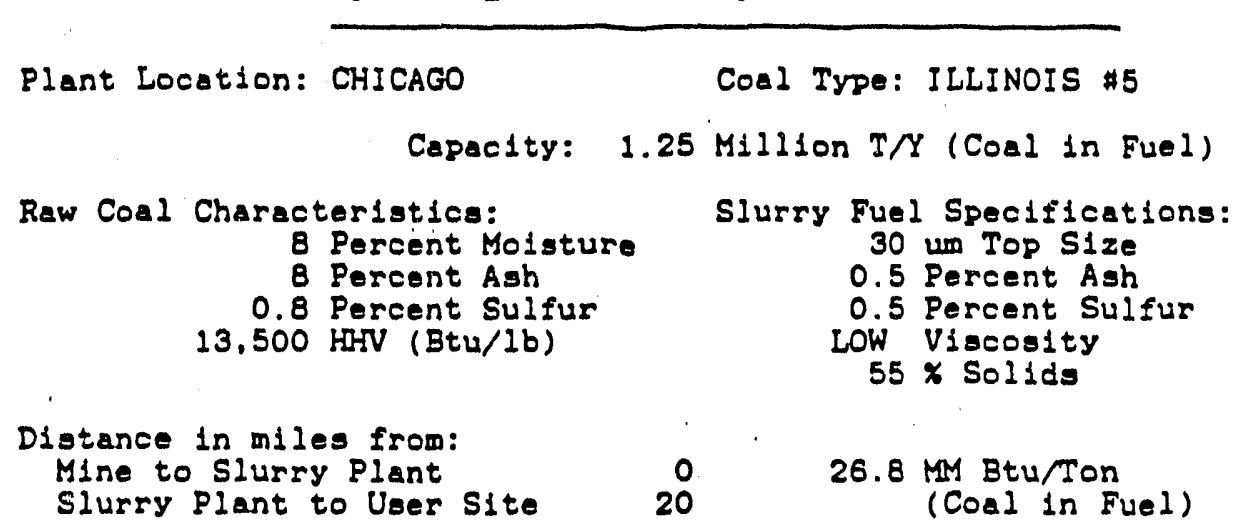

ITEM

A. Purchased Coal

B. Freleht to Slurry Plant

C. Subtotal Labor Operation \& Supervision Maintenance \&Supervision Anaiytical

Other Assi mable Labor Cogeneration Plant Labor
UNIT COST

$\begin{array}{cc}20.00 & \text { \$/TON RAW } \\ 0.00 & \text { \$/TON RAW }\end{array}$

$17 \& 20$

$17 \& 20$

15

15

\& 20

D. Subtotal Ut111t1es Electriclty and Steam Process and Cooling Water

0.25

E. Subtotal Reagenta Caustic

Ac1d

Ammonia

Dispersant

Formaldehyde

Ine

Modifier

$\$ /$ RR

$\$ / \mathrm{NR}$

$\$ /$ TRR

$\$ / \mathrm{TR}$

\section{5}

$\$ 11,000$

eal

\section{5}

210

0.557

0.25

40

90

s/ton
$\$ / t o n$
$\$ /$ ton
$\$ / 1 b$
$\$ / 1 b$
$\$ /$ ton
s/ton

\$TON IRY COAL IN FUEL
S.MM BTU HIIV

F. Subtotal Malntenance Materials M11I Linera and Media General Malntenance (excluding grindine equip.)
0.00

.87

4.18

1.87

0.99

0.12

0.26

0.93

0.00

0.16

0.07

0.04

0.00

0.01

0.03

1.93

1.74

0.07

0.06

0.01

0.19

1. 41

37.99

15.11

11.55

1.58

8. 36

0.50

0.62

0.28

0.56

0.43

0.06

0.31

0.02

0.02

0.01

8. 19

2.25

0.30

5.94

0.08

0.22

G. Freight to User Site

0.00 \$/TON FUEL

0.00

0.00

H. Middline Coal Credit

$0 \$$ TION

0.00

0.00

I. Total Direct Costs $(A+B+C+D+E+F+G+H)$

J. Subtotal Indirect Costs Taxes, Insurance, Supplies General Admin. \& Sales Net Cash Flow

0 * of Capital

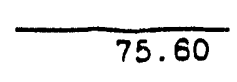

0.00

0.00

0.00

0.000 NCF Factor

0.00

K. Total Operating Cost $(I+J)$

2.81

0.00

0.00

0.00 0.00 
APPENDIX D

COAL FEEDSTOCK ANALYSES 


\section{COAL Fagdstock dATA}

COAL NAME - $\frac{\text { Hazard } \$ 4}{\text { Hazard } \$ 4}$
SEAM NAME -
MINE NAME - Cumberland Colleries
COAL RANK - High Volat ile Bituminous
CONTACT - Jim Lilly

\begin{tabular}{|c|c|c|c|c|}
\hline & & AS RCVD & 1.3 FLOT & CHEMICAL CLEAN \\
\hline Moisture & wts & 1.01 & 0.89 & \\
\hline Ash & wt: & 5.59 & 2.53 & \\
\hline Volatives & wt: & 35.06 & 37.43 & \\
\hline Fixed Carbon & wes & 59.41 & 60.04 & \\
\hline HHV & wtz & 14,203 & 14,724 & \\
\hline MAF HHV & wt & 15,044 & 15,106 & \\
\hline S.G. (dry basis) & wt8 & & 1.269 & \\
\hline Molsture & wto & 0.00 & 0.00 & \\
\hline Ash & wt & 0.00 & 0.00 & \\
\hline Carbon & wt8 & 83.90 & 84.01 & \\
\hline Hydrogen & wt8 & 5.52 & 5.59 & \\
\hline Nitrogen & wt8 & 1.59 & 1.68 & \\
\hline Chlorine & wto & NA & $\mathrm{NA}$ & \\
\hline sulfur & wt8 & 0.85 & 0.74 & \\
\hline Oxygen & wtz & 8.14 & 7.98 & \\
\hline Pyritic Sulfur & wt: & 0.101 & 0.005 & \\
\hline organic sulfur & wtz & 0.74 & 0.90 & \\
\hline Total & wt: & 0.84 & 0.91 & \\
\hline
\end{tabular}


$\mathrm{P}_{2} \mathrm{O}_{5}$

$\mathrm{SiO}_{2}$

$\mathrm{Fe}_{2} \mathrm{O}_{3}$

$\mathrm{Al}_{2} \mathrm{O}_{3}$

$\mathrm{TiO}_{2}$

CaO

MgO

$\mathrm{SO}_{3}$

$\mathrm{K}_{2} \mathrm{O}$

$\mathrm{Na}_{2} \mathrm{O}$

PbO

N1O

\begin{tabular}{|c|c|c|}
\hline wt? & 0.117 & 0.101 \\
\hline wt8 & 53.40 & 47.70 \\
\hline wto & 5.72 & 4.84 \\
\hline wt. & 31.80 & 36.80 \\
\hline wts & 1.91 & 1.97 \\
\hline wt. & 1.843 & 3.28 \\
\hline wt: & 0.610 & 0.715 \\
\hline wts & NA & $N A$ \\
\hline wt: & 1.27 & 0.89 \\
\hline wt & 0.48 & 0.81 \\
\hline$w t$ & 0.079 & 0.081 \\
\hline Wt: & 0.015 & 0.051 \\
\hline
\end{tabular}

Oxidizing Reducing Oxidizing Reducing

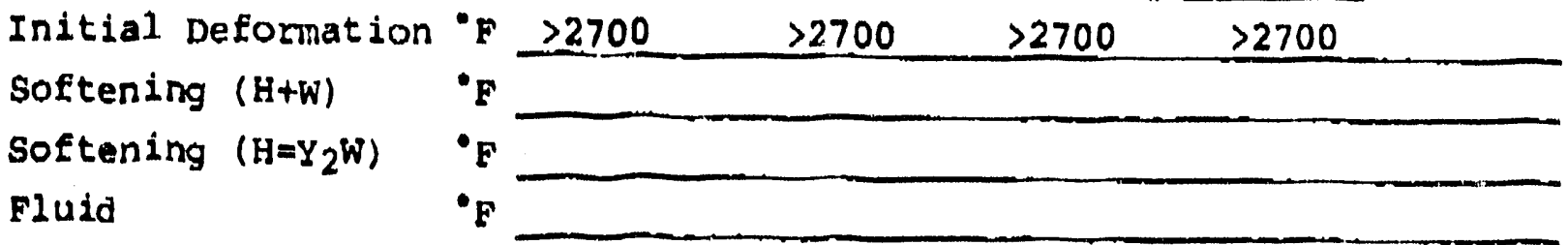

Hardgrove Ind

- Equil Moisture

F.S.I.

Btu Recovery, \&

Wt. Recovery, \&

visc 65 Coal, CP

visc 608 Coal, cP

vise $80^{\circ} \mathrm{C}, 67 \mathrm{coal}$

\subsection{2}

\begin{tabular}{ll}
100.00 & 45.31 \\
\hline 100.00 & 45.12 \\
\hline
\end{tabular}

Disp 658 Coal, wto

Disp 608 Coal, wt:

Stability w/o

stabilizer Rob

for 1 math,

wt?

wto 


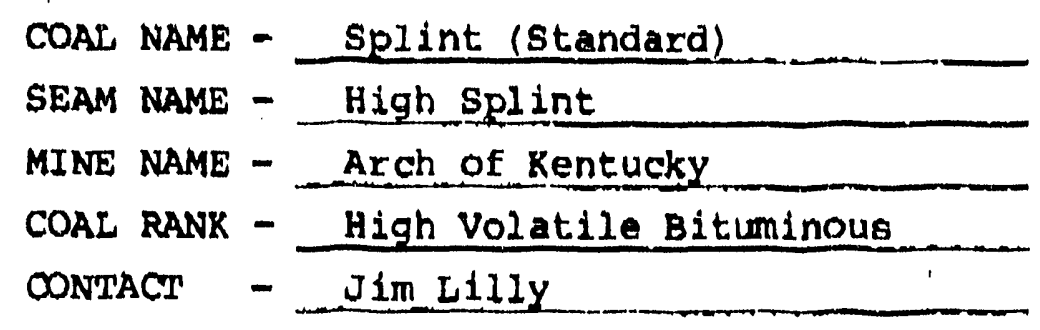

\begin{tabular}{|c|c|c|c|c|}
\hline & & AS RCVD & 1.3 FLOT & CHEMICAL CLEAN \\
\hline Moisture & wt & 3.68 & 1.41 & 1.80 \\
\hline Ash & wt: 8 & 18.80 & 2.67 & 0.15 \\
\hline volatives & wtE & 31.76 & 39.84 & \\
\hline$r^{\prime}+$ xed Carbon & wet & 49.44 & 57.49 & \\
\hline HHV & wt & 12,120 & 14,579 & \\
\hline MAF HHV & wt: & 14,937 & 14,979 & \\
\hline S.G. (dry basis) & wtz & & 1.264 & \\
\hline Moisture & wt: & 0.00 & 0.00 & 0.00 \\
\hline Ash & wts & 0.00 & 0.00 & 0.18 \\
\hline Carbon & $w t z$ & 84.19 & 84.38 & 83.66 \\
\hline Hydrogen & wt: & 5.71 & 5.72 & 5.47 \\
\hline Nitrogen & wto & 1.50 & 1.60 & 1.57 \\
\hline sulfur & wt: & 0.48 & 0.97 & 0.49 \\
\hline Oxygen & wet & 8.12 & 7.34 & 8.63 \\
\hline Pyritic Sulfur & wtz & 0.31 & 0.05 & 0.005 \\
\hline Organic Sulfur & wes & 0.07 & 0.51 & 0.469 \\
\hline Total & wt: & 0.38 & 0.52 & 0.479 \\
\hline
\end{tabular}


$\mathrm{P}_{2} \mathrm{O}_{5}$

$\mathrm{SHO}_{2}$

$\mathrm{Fe}_{2} \mathrm{O}_{3}$

$\mathrm{Al}_{2} \mathrm{O}_{3}$

$\mathrm{TiO}_{2}$

$\mathrm{CaO}$

$\mathrm{MgO}$

$\mathrm{SO}_{3}$

$\mathrm{K}_{2} \mathrm{O}$

$\mathrm{Na}_{2} \mathrm{O}$

Pbo

Nio

\begin{tabular}{|c|c|c|c|}
\hline wto & 0.150 & 0.189 & 0.355 \\
\hline wt: & 55.00 & 43.90 & 27.3 \\
\hline wts & 4.60 & 11.70 & 11.8 \\
\hline wes & 21.10 & 27.10 & 9.35 \\
\hline wto & 1.05 & 1.85 & 12.80 \\
\hline wt: & 2.46 & 8.26 & 4.25 \\
\hline$w t 8$ & 1.51 & 1.67 & 1.70 \\
\hline wto & NA & NA & - \\
\hline wt: & 3.33 & 0.76 & 0.90 \\
\hline wts & 0.20 & 0.31 & 11.0 \\
\hline wt & $<0.012$ & 0.097 & 0.323 \\
\hline wt: & 0.005 & 0.060 & 1.47 \\
\hline
\end{tabular}

Oxidizing Reducing Oxidizing Reducing

\begin{tabular}{|c|c|c|c|c|c|c|c|}
\hline Initial Deformation & "F & 2,480 & 2450 & 2443 & 2342 & 2246 & 1830 \\
\hline Softening $(H+W)$ & $\bullet$ & 2665 & 2555 & 2568 & 2442 & 2341 & 1885 \\
\hline Softening $\left(\mathrm{H}=\mathrm{Y}_{2} \mathrm{~W}\right)$ & & $>2700$ & 2660 & 2595 & 2480 & 2359 & 1920 \\
\hline Fluid & $\bullet$ & & $\geq 2700$ & 2615 & 2611 & 2389 & 1985 \\
\hline
\end{tabular}

Hardgrove Ind

- Equil Moisture 2.84

F.S.I.

Btu Recovery, \&

Wt. Recovery,

100.00 47.79

100.00 47.66

visc $65 \%$ Coal, op

Vise 60\% Coal, CP

visc $80^{\circ} \mathrm{C}, 678 \mathrm{Coal}$

Disp e 658 Coal, wt:

Disp 608 Coal, wto

Stability $w / 0$

Stabilizer,

stabilizer Rob

for 1 mnth,

wt:

wt: 


\section{COAL FEEDSTOCK DATA}

COAL NAME - $\frac{\text { Stenson }}{\text { SEAM NAME - Elkhorn } 2}$
MINE NAME - Stenson
COAL RANK - High VOlatile Bituminous
CONTACT - Jim Lilly

AS RCVD $\quad 1.3$ FLOY

CHEMICAL CLEAN

\begin{tabular}{|c|c|c|c|c|}
\hline Moisture & wt8 & 2.64 & 0.99 & 1.41 \\
\hline Ash & wto & 3.38 & 1.88 & 0.18 \\
\hline Volatives & wto & 37.02 & 38.07 & \\
\hline Fixed Carbon & wt 8 & 59.60 & 60.05 & \\
\hline HEV & $w t z$ & 14,695 & 14,908 & \\
\hline MAE HHV & wt? & 15,209 & 15,194 & \\
\hline S.G. (dry basis) & wto & & 1.301 & \\
\hline Moisture & $w t 8$ & 0.00 & 0.00 & 0.09 \\
\hline Ash & wt: & 0.00 & 0.00 & 0.20 \\
\hline Carbon & $w t q$ & 84.26 & 84.46 & 83.35 \\
\hline Hydrogen & $w+8$ & 5.71 & 5.90 & 5.67 \\
\hline Nitrogen & $w t q$ & 1.52 & 1.53 & 1.59 \\
\hline Chlorine & $w t 8$ & NA & $\mathrm{NA}$ & \\
\hline Sulfur & wto & 1.00 & 1.51 & 0.70 \\
\hline Oxygen & wt & 7.51 & 6.60 & 8.49 \\
\hline Pyritic Sulfur & $w t 8$ & 0.277 & 0.110 & 0.005 \\
\hline Organic Sulfur & wt & 0.69 & 0.71 & 0.690 \\
\hline Total & wts & 0.96 & 0.82 & 0.700 \\
\hline
\end{tabular}




\begin{tabular}{|c|c|c|c|c|}
\hline $\mathrm{P}_{2} \mathrm{O}_{5}$ & wt 8 & 0.066 & 0.113 & 0.293 \\
\hline $\mathrm{SiO}_{2}$ & wts & 34.80 & 30.10 & 15.9 \\
\hline $\mathrm{Fe}_{2} \mathrm{O}_{3}$ & $w+8$ & 21.30 & 15.80 & 18.3 \\
\hline $\mathrm{Al}_{2} \mathrm{O}_{3}$ & wt: & 27.20 & 30.10 & 9.03 \\
\hline $\mathrm{TiO}_{2}$ & wt: 8 & 1.16 & 1.34 & 5.50 \\
\hline $\mathrm{CaO}$ & wts & 5.60 & .7 .59 & 3.45 \\
\hline MgO & wt: & 1.23 & 1.63 & 0.97 \\
\hline $\mathrm{SO}_{3}$ & wt 8 & NA & $N A$ & - \\
\hline $\mathrm{K}_{2} \mathrm{O}$ & wt 8 & 1.79 & 0.90 & 1.16 \\
\hline $\mathrm{Na}_{2} \mathrm{O}$ & wtz & 0.86 & 1.21 & 15.1 \\
\hline $\mathrm{PbO}$ & wt 8 & 0.104 & 0.245 & 0.204 \\
\hline NiO & wt & 0.045 & 0.056 & 0.668 \\
\hline
\end{tabular}

Oxidizing Reducing Oxidizing Reducing

\begin{tabular}{lllllllll} 
Initial Deformation & ${ }^{*} \mathrm{~F}$ & 2459 & 2367 & 2375 & 2375 & 2361 & 1990 \\
Softening $(\mathrm{H}+\mathrm{W})$ & ${ }^{\mathrm{F}}$ & 2526 & 2442 & 2395 & 2395 & 2379 & 2081 \\
${ }\left(\mathrm{H}=\mathrm{Y}_{2} \mathrm{~W}\right) }$ & ${ }^{\mathrm{F}}$ & 2565 & 2480 & 2410 & 2410 & 2386 & 2105 \\
Fluid & ${ }^{\mathrm{F}}$ & 2593 & 2582 & 2505 & 2505 & 2387 & 2125 \\
\hline
\end{tabular}

Hardgrove Ind

\& Equil Moisture

$$
3.06
$$

F.S.I.

Btu Recovery,

Wt. Recovery, \&

\begin{tabular}{ll}
100.00 & 43.81 \\
\hline 100.00 & 43.85
\end{tabular}

visc 658 Coal, CP Visc 608 coal, $\mathrm{CP}$ visc $80^{\circ} \mathrm{C}, 67 \% \mathrm{Coal}$

Disp $658 \mathrm{Coal}$, wto

Disp 608 Coal, wt 
APPENDIX E

ALTERNATIVE DESIGNS FOR HIGHER EFFICIENCY 


\subsection{RANKINE BOTTOMING CYCLE ANALYSIS}

In this section a Rankine Bottoming Cycle (RBC) is considered in order to increase the power efficiency of the coal fueled diesel by recovering the heat rejected in the exhaust, water jacket cooling system, and the lube system. This analysis is intended to provide a first order estimate of the cycle efficiency benefits which could be obtained through the use of such a system. The result, as explained in Section 1.8, is that the use of $R B C$ could increase the power plant efficiency from $39 \%$ to over $46 \%$. Further analysis and optimization of the cycle would be required during the design of the system. The assumptions associated with each component in the system are presented at the appropriate point in the analysis.

Figure 1 presents a schematic representation of a simplified RBC. In this system, only heat from the diesel exhaust is recovered. The diesel exhaust is the heat source shown in Figure 1. For purposes of this analysis, steam was chosen as the working fluid of the cycle. Other working fluids could be used, such as toluene, to improve the cycle performance at the expense of toxicity and cost. The following section outlines the calculations performed on each component of the cycle.

\subsection{Heat Source - Diesel Engine}

The following performance data is based on 2 twenty cylinder turbo-charged Cooper Bessemer diesel engines.

Fuel Input:

Electrical Output:

Exhaust Gas Conditions after Turbocharger

Mass Flow:

Pressure:

Temperature:
$105.66 \times 10^{6} \mathrm{BTU} / \mathrm{hr}$.

$12 \mathrm{MW}$

In order to study the effect of higher exhaust temperatures on cycle efficiency, it was assumed that the exhaust gas temperature could be raised without changing the power output, which would require design modifications to the engine. In the analysis this was done by reducing the exhaust mass flow, so that the heat rejected in the exhaust gas remains constant. For simplicity in the analysis, it was assumed that the constant pressure specific heat of the exhaust gas is:

$$
C_{\text {gas }}=0.25 \frac{B T U}{10^{\circ} R}
$$




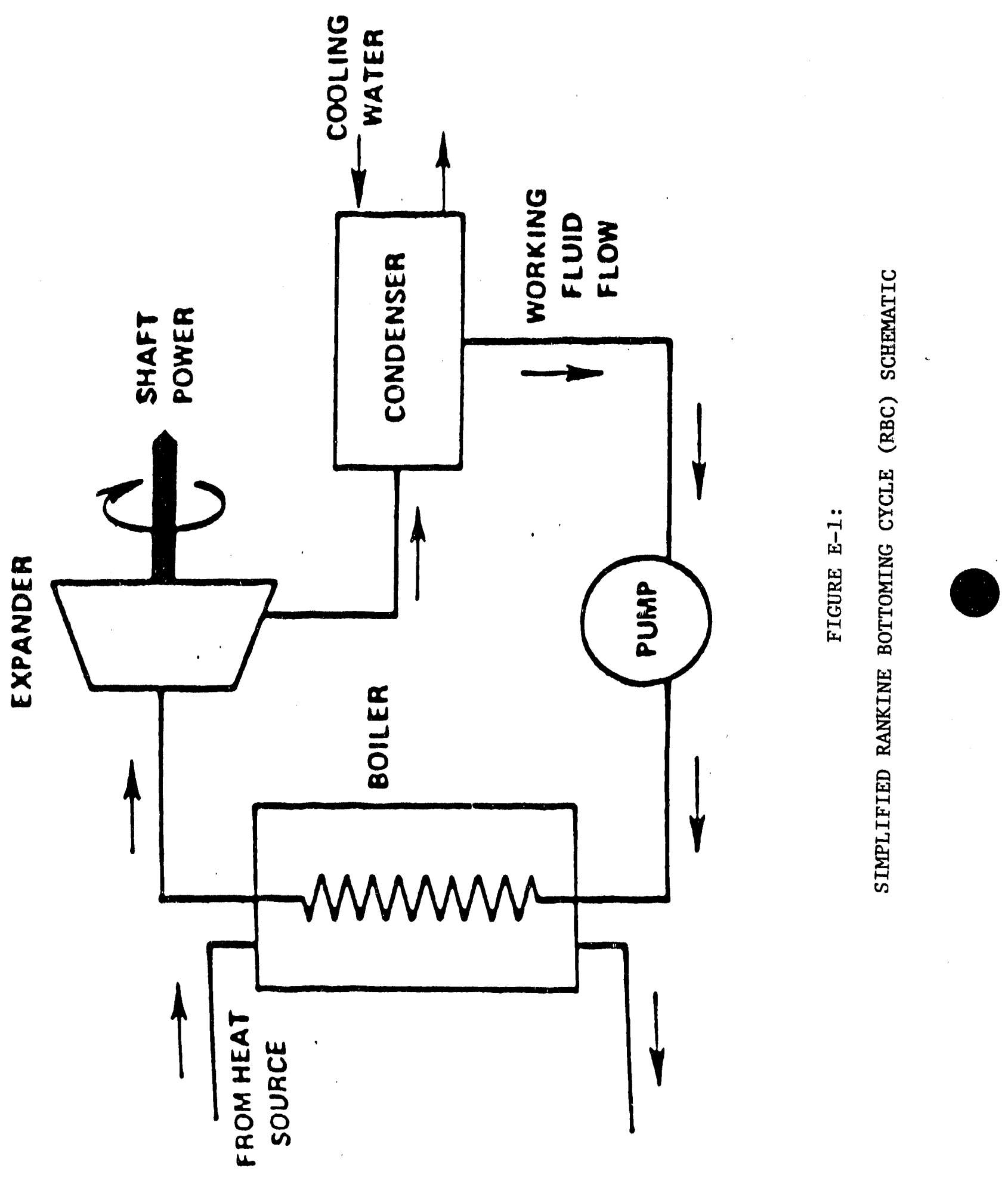


The heat contained in the exhaust gas can then be calculated as follows:

$$
Q_{\text {exh }}=m_{\text {gas }} C p_{\text {gas }}\left(T_{\text {gas }}-T_{\text {ambient }}\right)+Q_{\text {fg }}
$$

in which the latter term in the equation is the latent heat of vaporization of water in the exhaust gas. The exhaust gas conditions for the four exhaust gas temperature cases are calculated using these assumptions.

\begin{tabular}{|c|c|c|c|c|}
\hline Case & $\begin{array}{l}\mathbf{T}_{\text {gas }} \\
\left({ }^{\circ} \mathbf{F}\right)\end{array}$ & $\begin{array}{c}\mathbf{Q}_{\text {fg }} \\
\left(10^{6} \mathbf{B T U} / \mathbf{h r} .\right)\end{array}$ & $\begin{array}{c}\mathbf{Q}_{\text {Exh. }} \\
\left(10^{6} \mathbf{B T U} / \mathbf{h r} .\right)\end{array}$ & $\begin{array}{c}\dot{m}_{\text {gas }} \\
(\mathbf{l b .} / \mathbf{h r} .)\end{array}$ \\
\hline 1 & 660 & 8.5 & 37.34 & 206,000 \\
\hline 2 & 750 & 8.5 & 37.34 & 177,477 \\
\hline 3 & 850 & 8.5 & 37.34 & 153,813 \\
\hline 4 & 1,110 & 8.5 & 60.50 & 206,000 \\
\hline
\end{tabular}

Note that in Case 4 the assumption of constant exhaust heat is not maintained. This case is presented to simulate a burner in the diesel exhaust duct, which provides combustion of the unburned coal particles in the diesel exhaust for contral of emissions.

\subsection{Boiler Calculations}

Assumptions o Steam side boiler pressure of $250 \mathrm{psia}$

- Stack temperature of $330 \circ \mathrm{F}$ to minimize $\mathrm{H}_{2} \mathrm{SO}_{4}$ corrosion

- Feedwater temperature of $220 \mathrm{oF}$

- Superheated steam loaves the boiler at ( $\left.T_{\text {gas }}-100 \circ \mathrm{F}\right)$

- $11 / 2 \%$ heat loss due to radiation

The equations for calculating performance of the boiler are:

$$
\mathrm{Q}_{\text {recov. }}=0.985 \mathrm{~m}_{\text {gas }} \mathrm{Cp} \text { gas }\left(\mathrm{T}_{\text {gas }}-330^{\circ} \mathrm{F} \text {. }\right)
$$




$$
\dot{m}_{\mathrm{glm}}=\frac{Q_{\text {recov }}}{n_{\mathrm{slm}-n_{1 / w}}}
$$

where:

$Q_{\text {recov. }}=$ heat recoverable from exhaust gas

$r_{\mathrm{stm}}=$ mass flow of steam produced

$\mathrm{h}_{\mathrm{stm}}=$ enthalpy of steam leaving boiler

$h_{\mathrm{fw}}=$ enthalpy of feedwater entering boiler

\begin{tabular}{|c|c|c|c|c|c|c|c|}
\hline Case & $\begin{array}{c}T_{\text {gas }} \\
\left(\sigma_{F}\right)\end{array}$ & $\begin{array}{c}T_{\text {stm }} \\
(\mathrm{OF})\end{array}$ & $\mathrm{h}_{\text {stm }}$ & $\stackrel{m}{m^{\prime}} g_{h r}^{a s}$ & $\begin{array}{c}\text { Q recov } \\
\left(10^{6}\right. \\
\text { BTU/hr. })\end{array}$ & $\begin{array}{c}h_{f w} \\
(B T U / l b .)\end{array}$ & $\begin{array}{c}m_{\text {stm }} \\
(\mathrm{lb} . / \mathrm{hr} .)\end{array}$ \\
\hline 1 & 660 & 560 & $1,296.8$ & 206,000 & 16.74 & 189.05 & 15,121 \\
\hline 2 & 750 & 650 & $1,345.3$ & 177,477 & 18.36 & 189.06 & 15,879 \\
\hline 3 & 850 & 750 & $1,397.6$ & 153,813 & 19.70 & 189.05 & 16,302 \\
\hline 4 & 1,110 & 1,000 & $1,627.6$ & 206,000 & 39.57 & 189.05 & 29,562 \\
\hline
\end{tabular}

Steam enthalpy was obtained by using the 1967 ASME steam tables:

\subsection{Turbine Calculations}

Assumptions: 0 Turbine efficiency of $80 \%$ including the generator

o Turbine exhaust pressure of $3^{\prime \prime} \mathrm{HgA}$

The equations for calculating the performance of the turbine are:

$$
h_{2}=h_{1}-n_{l}\left(h_{1}-h_{2 i}\right)
$$

Turbine Power Output $=m_{\mathrm{stm}}\left(\mathrm{h}_{1}-\mathrm{h}_{2}\right)$ 
where:

$\eta_{t}=$ turbine efficiency

$h_{1}=$ enthalpy of steam at turbine inlet

$\mathrm{h}_{2 \mathrm{i}}=$ enthalpy at turbine exit assuming isentropic expansion from turbine inlet conditions to turbine exhaust pressure

\begin{tabular}{|c|c|r|c|c|c|}
\hline Case & $\begin{array}{c}m_{\mathbf{g t m}} \\
(\mathbf{l b . / h r})\end{array}$ & $\begin{array}{c}\mathbf{h}_{\mathbf{1}} \\
(\mathbf{B T U} / \mathbf{l b} .)\end{array}$ & $\begin{array}{c}\mathbf{h}_{2 \mathrm{i}} \\
(\mathbf{B T U} / \mathbf{l b} .)\end{array}$ & $\begin{array}{c}\mathbf{h}_{2} \\
(\mathbf{B T U} / \mathbf{l b} .)\end{array}$ & $\begin{array}{c}\text { Power } \\
(\mathbf{k W})\end{array}$ \\
\hline 1 & 15,121 & $1,296.8$ & 933 & 1,006 & 1,290 \\
\hline 2 & $.5,879$ & $1,345.3$ & 956 & 1,034 & 1,449 \\
\hline 3 & 16,302 & $1,397.5$ & 981 & 1,064 & 1,592 \\
\hline 4 & 29,562 & $1,527.6$ & 1,039 & 1,137 & 3,387 \\
\hline
\end{tabular}

\subsection{Condenser Calculations}

Assumptions: o Condenser Pressure, 3" $\mathrm{HgA}$

o Condenser Temperature, $116^{\circ} \mathrm{F}$

The heat given up by the steam leaving the turbine during the condensation process must be rejected by the condenser by utilizing a source of cooler water such as a river, or through the use of a cooling tower. The equation to calculate this heat rejection is:

$\mathrm{Q}_{\text {cond }}=\dot{m}_{\mathrm{stm}}\left(\mathrm{h}_{2}-\mathrm{h}_{3}\right)$ 
where:

$\mathrm{Q}_{\text {cond }}=$ heat rejected by the condenser

$\mathrm{h}_{2} \quad=$ enthalpy of steam entering the condenser

$h_{3}=$ enthalpy of water leaving the condenser

\begin{tabular}{|c|c|c|c|c|}
\hline Case & $\underset{\left(m_{\text {atm }}\right.}{\left(\mathbf{l b} . / h_{\text {r. }}\right)}$ & $\begin{array}{c}h_{2} \\
(B T U / l b .)\end{array}$ & $\begin{array}{c}\mathbf{h}_{\mathbf{3}} \\
(\mathrm{BTU} / \mathrm{lb} .)\end{array}$ & $\begin{array}{c}Q \text { cond } \\
\left(10^{6} \mathrm{BTU} / \mathrm{HR} .\right)\end{array}$ \\
\hline 1 & 15,121 & 1,006 & 81.9 & 13.97 \\
\hline 2 & 15,879 & 1,034 & 81.9 & 15.12 \\
\hline 3 & 16,302 & 1,064 & 81.9 & 16.01 \\
\hline 4 & 29,562 & 1,137 & 81.9 & 31.19 \\
\hline
\end{tabular}

\subsection{Pump Calculations}

Assumptions: o Pump exit pressure is $25 \%$ higher than boiler pressure, to overcome losses in pipes

o Pump isentropic efficiency is $70 \%$

- Pump drive efficiency is $95 \%$

The equations for calculating the pump performance are as follows:

$$
h_{4}=h_{3}-\frac{h_{3}-h_{41}}{\eta_{p}}
$$

Pump Power Input $=\dot{m}_{\mathrm{fw}} \frac{\left(h_{4}-h_{3}\right)}{\eta_{\alpha}}$

where:

$h_{3} \quad=$ pump inlet enthalpy

$h_{4} \quad=$ pump exit enthalpy 
$h_{41} \quad=$ pump exit enthalpy assuming isentropic pumping from inlet conditions to exit pressure

$\eta_{p} \quad=$ isentropic pump efficiency

$\eta_{d} \quad=$ pump drive efficiency

$m_{1 \omega}=$ feedwater mass flow rate

\begin{tabular}{|c|c|c|c|c|c|}
\hline Case & $\begin{array}{c}\mathbf{h}_{\mathbf{3}} \\
(\mathbf{B T U} / \mathbf{l b} .)\end{array}$ & $\begin{array}{c}\mathbf{h}_{\mathbf{4 i}} \\
(\mathrm{BTU} / \mathbf{l b} .)\end{array}$ & $\begin{array}{c}\mathbf{h}_{\mathbf{4}} \\
(\mathrm{BTU} / \mathbf{l b} .)\end{array}$ & $\begin{array}{c}\dot{m}_{\mathrm{fw}} \\
(\mathbf{l b} / \mathbf{h r})\end{array}$ & $\begin{array}{c}\text { Power } \\
\mathbf{k W}\end{array}$ \\
\hline 1 & 81.9 & 83.7 & 84.5 & 15,121 & 12.1 \\
\hline 2 & 81.9 & 83.7 & 84.5 & 15,879 & 12.7 \\
\hline 3 & 81.9 & 83.7 & 84.5 & 16,302 & 13.1 \\
\hline 4 & 81.9 & 83.7 & 84.5 & 29,562 & 23.7 \\
\hline
\end{tabular}

\subsection{Dil Cooler}

In the boiler calculation section it was assumed that the feedwater temperature entering the boiler was $220 \circ \mathrm{F}$. For this to be true, the feedwater must be heated by some means to this temperature. The assumption applied here is that the heat rejected by the oil cooler is sufficient to accomplish this heating. If it is assumed that $3 \%$ of the input heat to the diesel engine is rejected to the lube system, then there will be sufficient heat available for this feedwater heating, for all four cases. In a more rigorous analysis, all the heat available from the oil cooler would be used to heat the feedwater and a number of iterative cycle calculations would be performed, which when converged would yield a new feedwater temperature.

\subsection{Water Jacket Heat Recovery}

As can be se an from Figure 2, approximately 17\% of the input fuel energy is rejected to the water jacket of the diesel engine. In order to recover this low temperature energy, a low pressure loop in the RBC is required. Figure 3 shows the water jacket fluid supplying heat to an evaporator. A more efficient method is to use ebullient cooling, in which saturated steam, generated by the boiling of water in the water jacket is admitted directly to a low pressure stage of the turbine. Calculations of the power output which can be gained by utilizing this rejected heat are outlined below: 

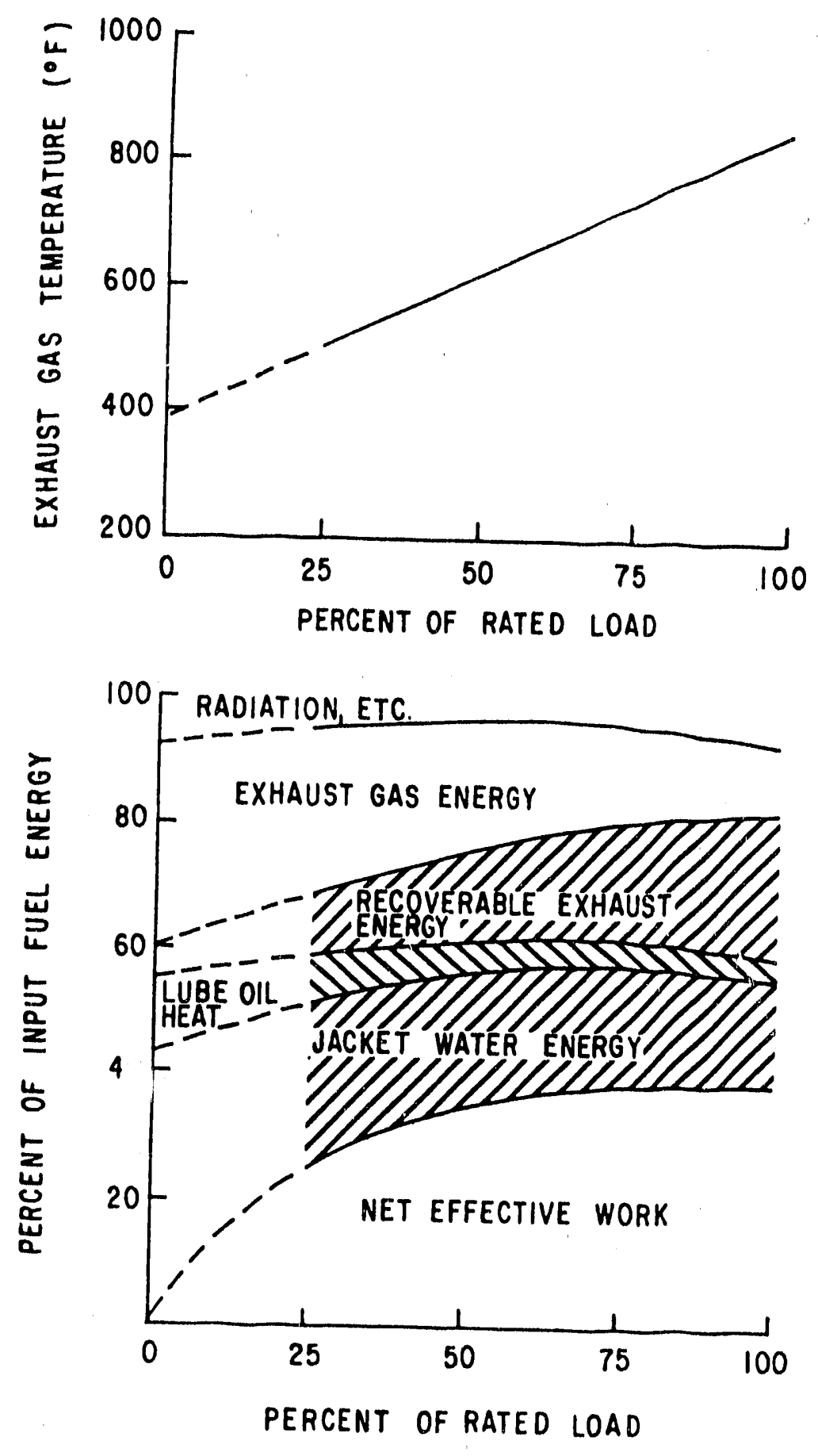

FIGURE E-2: ENERGY DISTRIBUTION OF TYPICAL TURBO-CHARGED DIESEI ENTEINE

SOURCE: "HEAT RECOVERY EQUIPMENT FOR ENGINES", C. L. SEGASER, ICES TECHNOLOGY EVALUATIONS

ANL/CES/TE 77-4

E-8 


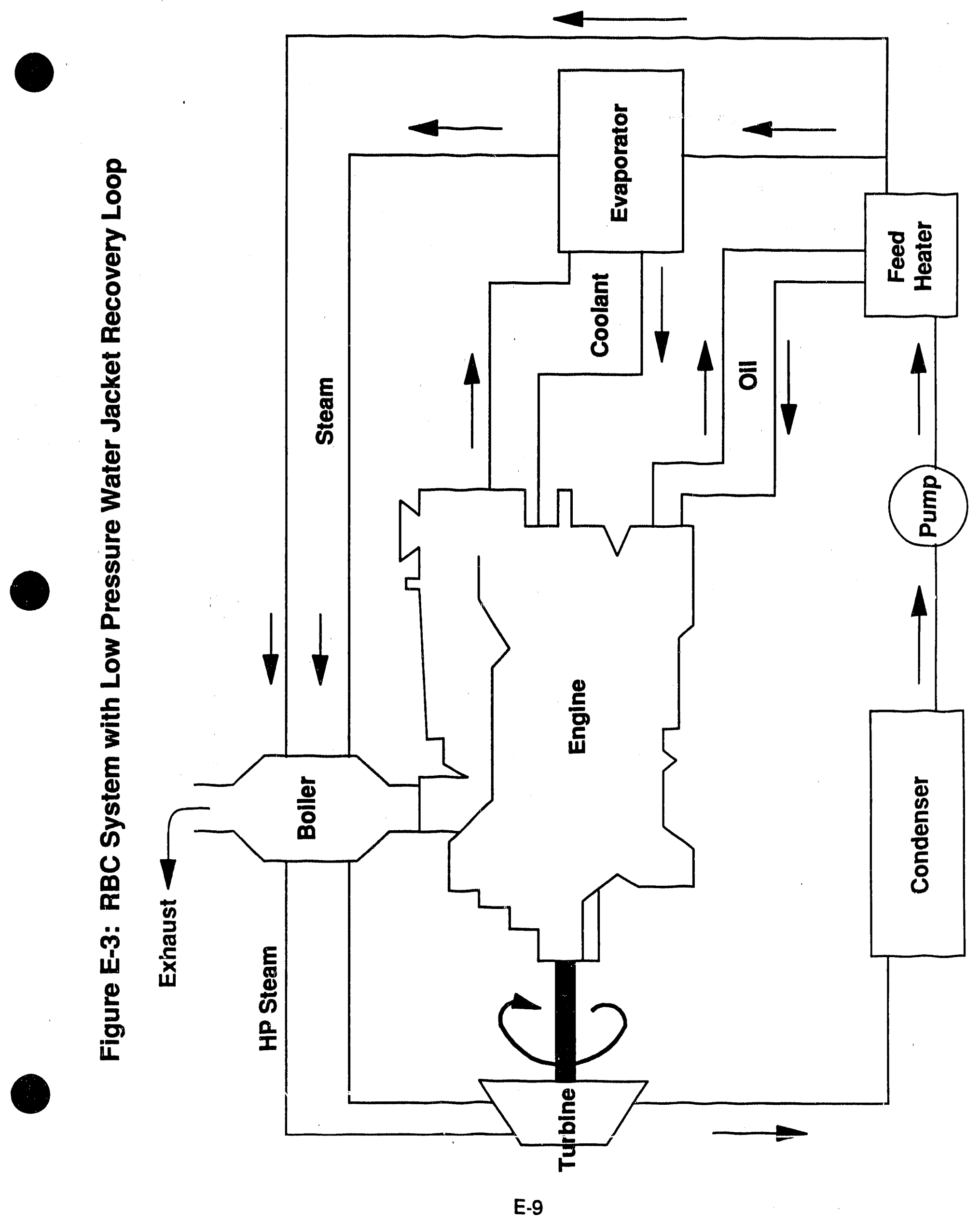


Assumptions: o Saturated steam conditions in water jacket

$$
\begin{aligned}
& P_{\text {stm }}=15 \mathrm{psig} . \\
& \mathrm{T}_{\text {stm }}=250 \circ \mathrm{F} . \\
& \mathrm{h}_{\text {stm }}=1,164 \mathrm{Btu} / \mathrm{lb} .
\end{aligned}
$$

- $17 \%$ of the diesel input energy is rejected to the water jacket.

- $80 \%$ efficient turbine.

The following analysis of the water jacket heat recovery system is based on Case 3.

The heat rejected to the water jacket is calculated as follows:

$$
\begin{aligned}
Q_{W J} & =Q_{\text {INPUT }}(0.17) \\
& =\left(105.66 \times 10^{\circ} \frac{\mathrm{Btu}}{\mathrm{hr}}\right)(0.17)=17.96 \times 10^{\circ} \frac{\mathrm{Btu}}{\mathrm{hr}}
\end{aligned}
$$

The turbine output is then calculated using the same procedure as outlined in Section 1.3.

$$
\begin{aligned}
h_{2} & =h_{1}-\eta_{T}\left(h_{1}-h_{21}\right) \\
& =1164-0.8(1164-989)-1024 \frac{B t u}{16}
\end{aligned}
$$

Turbine Power Output $=\dot{m}\left(h_{1}-h_{2}\right)$

$$
\begin{aligned}
& =\frac{18420 l b / h r(1164-1024) \frac{814}{16}}{3412.14 \frac{814}{\mathrm{kWh}}} \\
& =756 \mathrm{~kW}
\end{aligned}
$$

This additional power output is then added to that of Case 3.

$k W_{\text {turoine }}=1592+756=2348$ 


\subsection{Summary and Conclusions}

The following table summarizes the results of the earlier calculations.

\begin{tabular}{|c|c|c|c|c|c|c|c|c|}
\hline Case & $\begin{array}{c}\mathrm{T}_{\text {gas }} \\
\left({ }^{\circ} \mathrm{F}\right)\end{array}$ & $\begin{array}{c}\mathrm{Q}_{\text {gas }} \\
\left(10^{6}\right. \\
\mathrm{Btu} / \mathrm{hr})\end{array}$ & $\begin{array}{c}\mathrm{kW} \\
(\text { diesel })\end{array}$ & $\begin{array}{c}\mathrm{kW} \\
\text { (turbine) }\end{array}$ & $\begin{array}{c}\mathrm{kW} \\
(\mathrm{pump})\end{array}$ & $\begin{array}{c}\mathrm{kW} \\
(\text { total) }\end{array}$ & $\begin{array}{c}n \\
\text { Total } \\
\text { Cycle }\end{array}$ & $\begin{array}{c}\% \eta \\
\text { improve- } \\
\text { ment }\end{array}$ \\
\hline base & 660 & 37.34 & 12000 & - & - & 12000 & 0.388 & - \\
\hline 1 & 660 & 37.34 & 12000 & 1290 & -12 & 13278 & 0.429 & 10.6 \\
\hline 2 & 750 & 37.34 & 12000 & 1449 & -13 & 13436 & 0.434 & 11.9 \\
\hline $3 \mathrm{a}$ & 850 & 37.34 & 12000 & 1592 & -13 & 13579 & 0.439 & 13.1 \\
\hline $3 \mathrm{~b}$ & 850 & 37.34 & 12000 & 2348 & -19 & 14329 & 0.463 & 19.3 \\
\hline 4 & 1110 & 60.50 & 12000 & 3387 & -23 & 15364 & 0.407 & - \\
\hline
\end{tabular}

Case $3 \mathrm{~b}$ is identical to Case $3 \mathrm{a}$, with the addition of water jacket heat recovery.

Based on the above information, the following observations can be made:

- The simplified $\mathrm{RBC}$ results in a $10.6 \%$ improvement in overall cycle efficiency. ( $42.9 \%$ efficiency instead of $38.8 \%$ for the unmodified coal diesel engine).

- A $100^{\circ} \mathrm{F}$ increase in diesel exhaust temperature preheated air brings about an additional $1.2 \%$ increase in cycle efficiency (to $43.4 \%$ ).

$0 \quad$ The addition of water jacket heat recovery to the RBC would increase overall cycle efficiency by $6.2 \%$ (to $46.3 \%$ ).

The water jacket heat recovery provides an additional two-thirds of the heat recovery of the simplified $\mathrm{RBC}$ system, and is therefore a worthwhile addition to the cycle despite its additional complexity. The increases in exhaust temperature, also provide a significant cycle improvement, though not as dramatic. As stated earlier, this analysis is intended to provide a preliminary estimate of the magnitude of gains possible with RBC system. Optimization of boiler pressures, approach temperature differences, feedwater temperatures, etc. would allow fine tuning of the cycle. Overall cycle efficiencies beyond $46 \%$, perhaps as high as $50 \%$ may be possible.

In Case 4, which uses a burner in the exhaust duct for control of ernissions, the use of an RBC system becomes even more important. Additional fuel must be supplied to the burner, with no increase in power output. The RBC allows a substantia! portion o? this wasted heât tú té recuvered and converted to electrical output. 
APPENDIX F

EMISSION CONTROL TECHNOLOGIES 


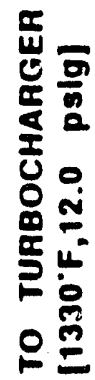

$\frac{\sigma}{0}$
$\frac{5}{0}$
$\dot{0}$
$<$
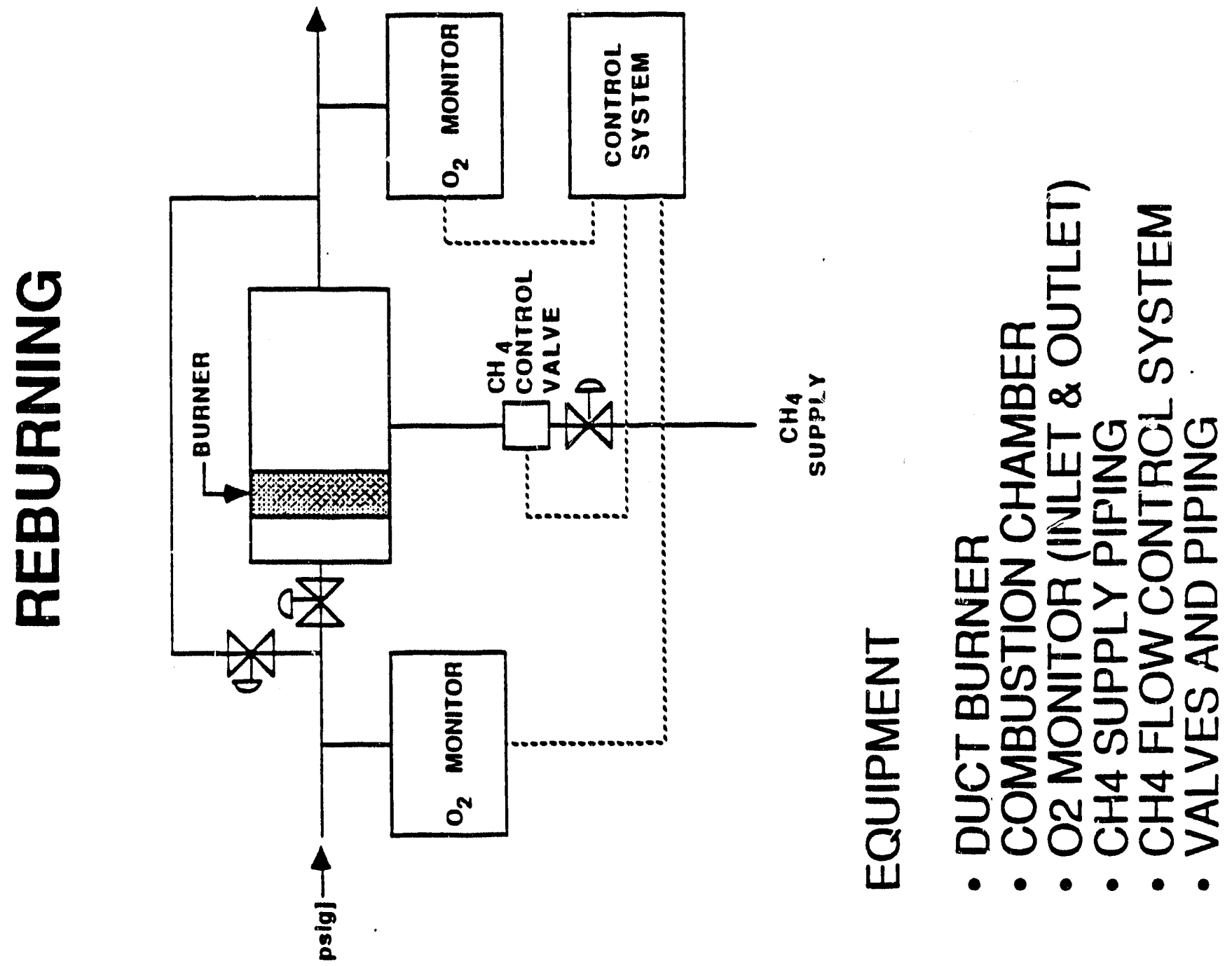

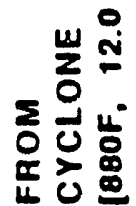




\section{$\mathrm{NH}_{3}$ INJECTION \\ IN BAGHOUSE}

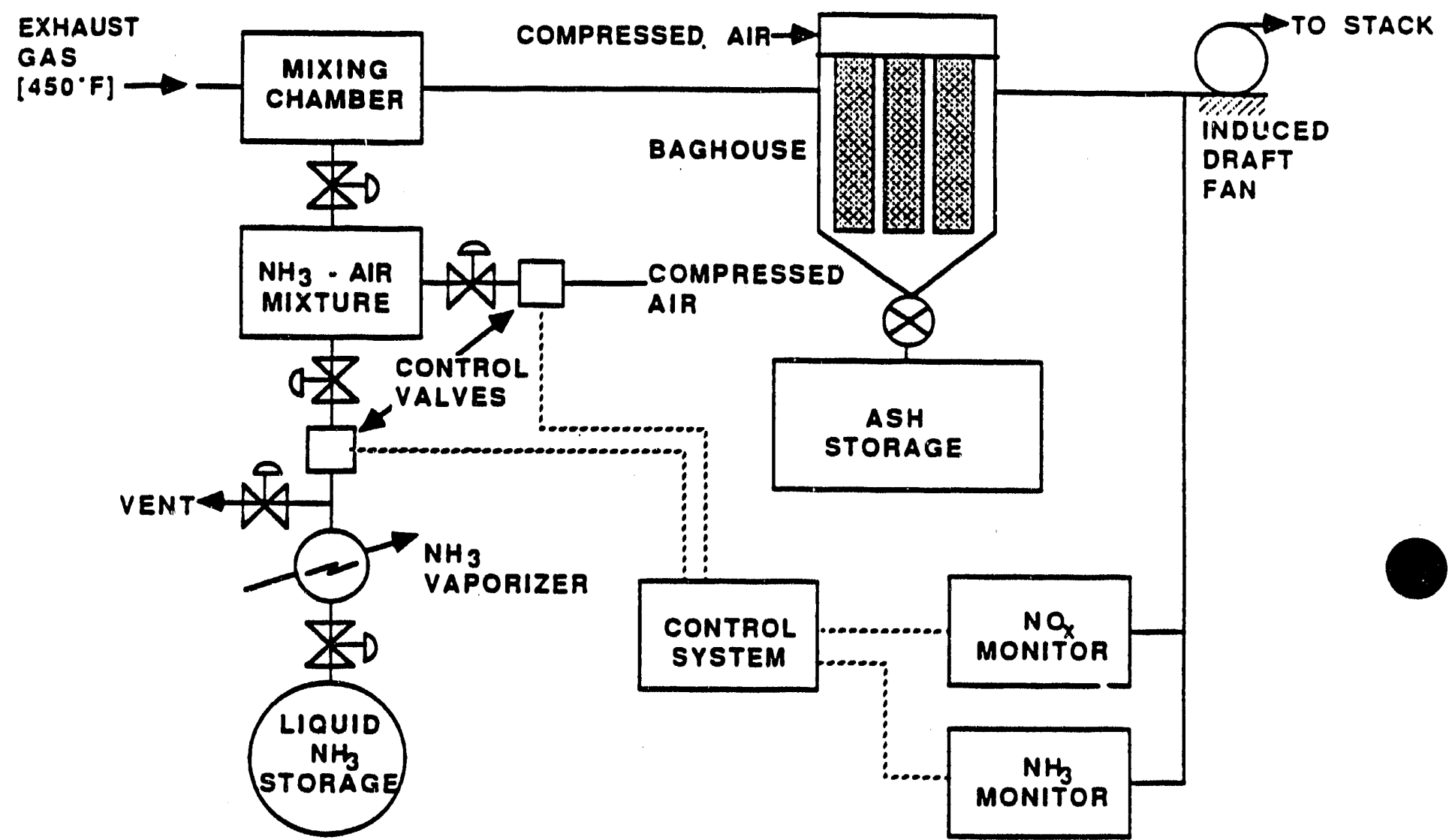

\section{EQUIPMENT}

- $\mathrm{NH}_{3}$ HANDLING SYSTEM:

- LIQUID STORAGE TANK

- VAPORIZER

- VALVES AND PIPING

- HOLDING TANK FOR $\mathrm{NH}_{3}$ /AIR MIXTURE

- $\mathrm{NH}_{3}$ INJECTORS AND MIXING CHAMBER CONTROL SYSTEM - CONTROL VALVES

- NO AND NH 3 MEASUREMENT EQUIPMENT

- CONTROLLER

- BAGHOUSE INCLUDIR!S ROTARY AIRLOCK AND ASH STORAGE (NOTE: THE BAGHOUSE MAY HAVE TO BE DESIGNED FOR TEMPERATURES $>400^{\circ} \mathrm{F}$ ) 

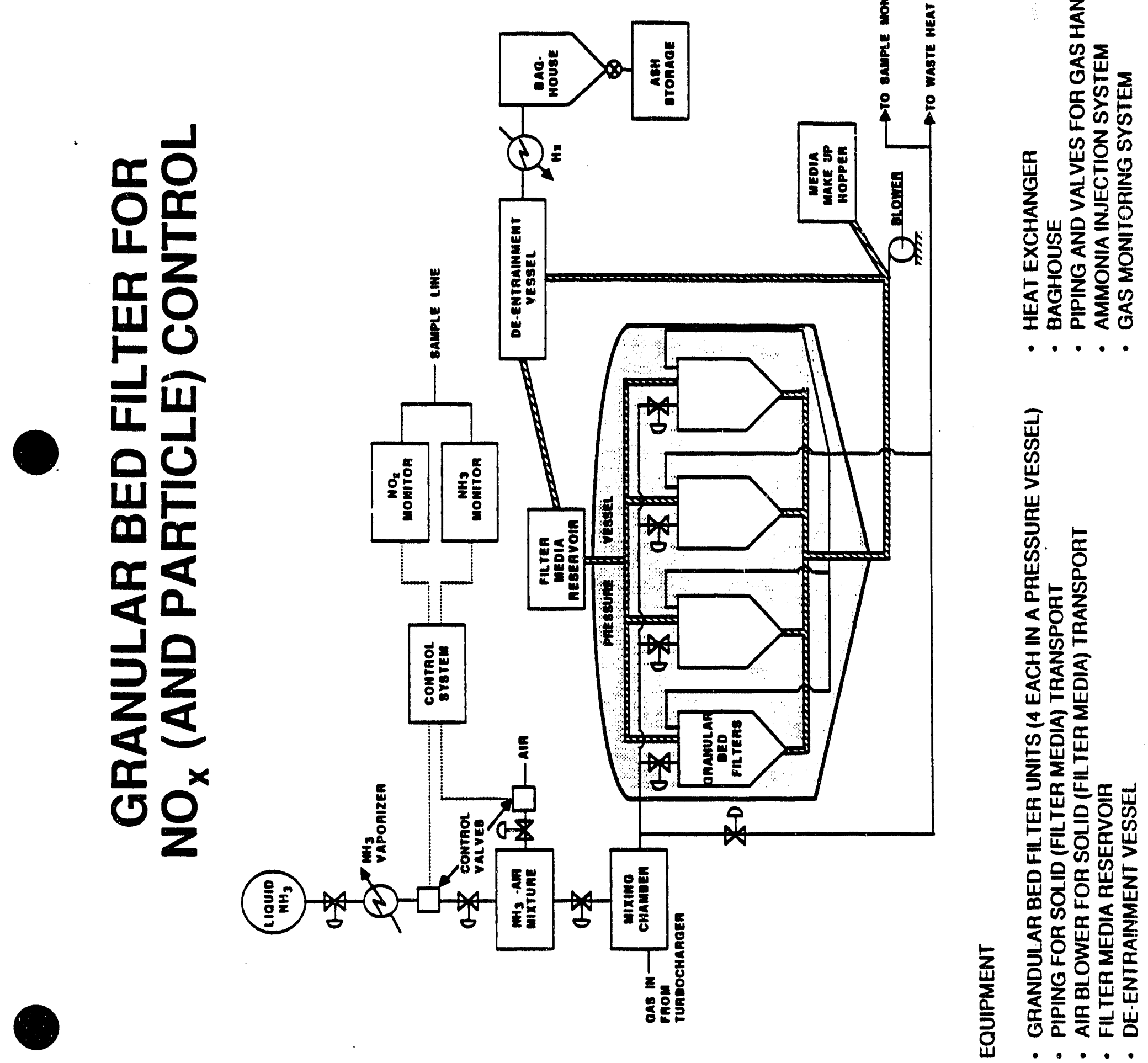

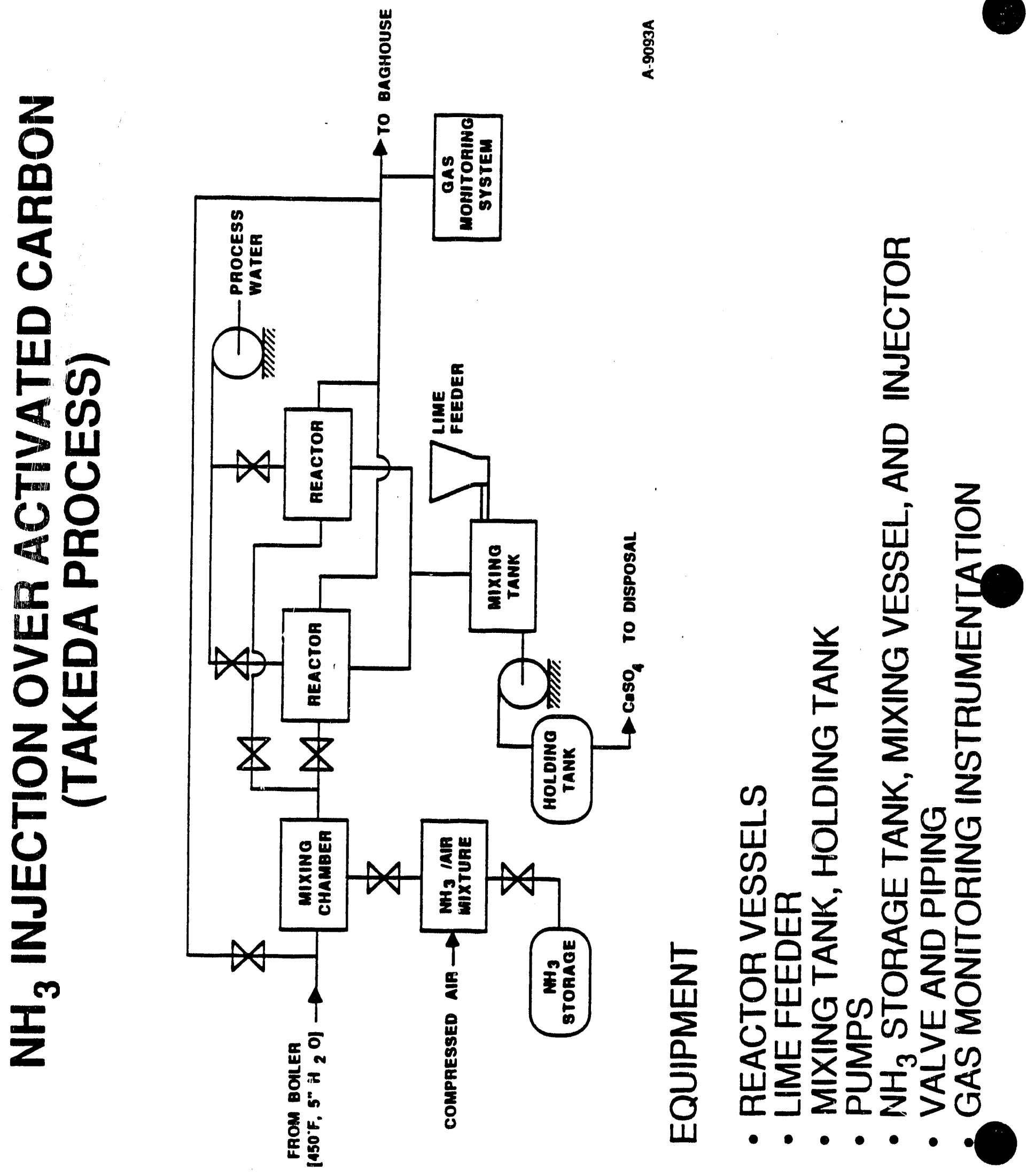


\section{SELECTIVE CATALYTIC \\ REDUCTION}

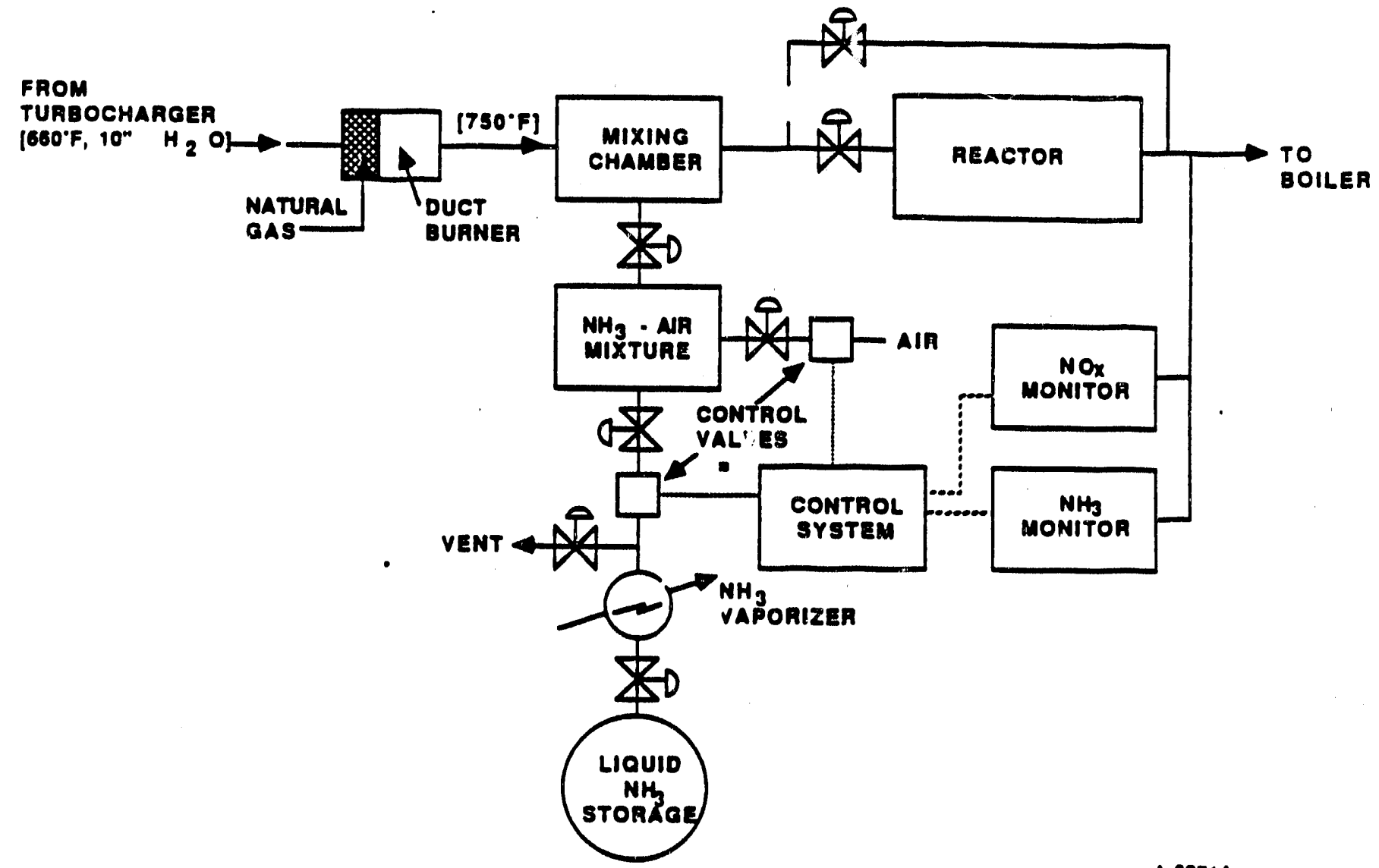

A-8951A

\section{EQUIPMENT}

- NH 3 HANDLING SYSTEM:

- LIQUID STORAGE TANK

- VAPORIZER

- VALVES AND PIPING

- HOLDING TANK FOR NH IAIR MIXTURE

- NH 3 INJECTORS AND MIXING CHAMBER CONTROL SYSTEM

- CONTROL VALVES

- NO $\times$ AND NHB MEASUREMENT EQUIPMENT

- CONTROLLER

- REACTION CHAMBER

- VALVES AND PIPING

$$
\text { F-5 }
$$




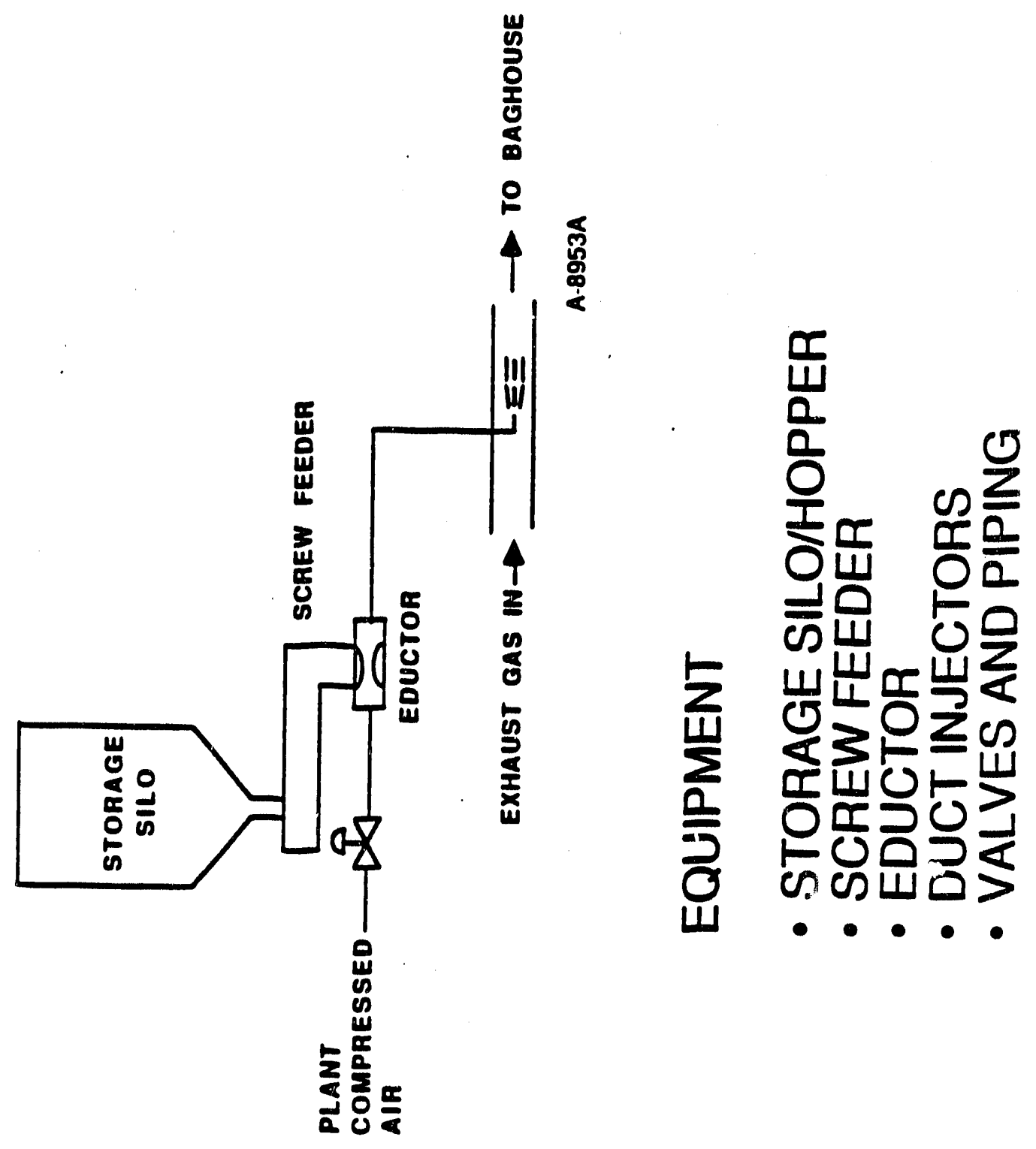



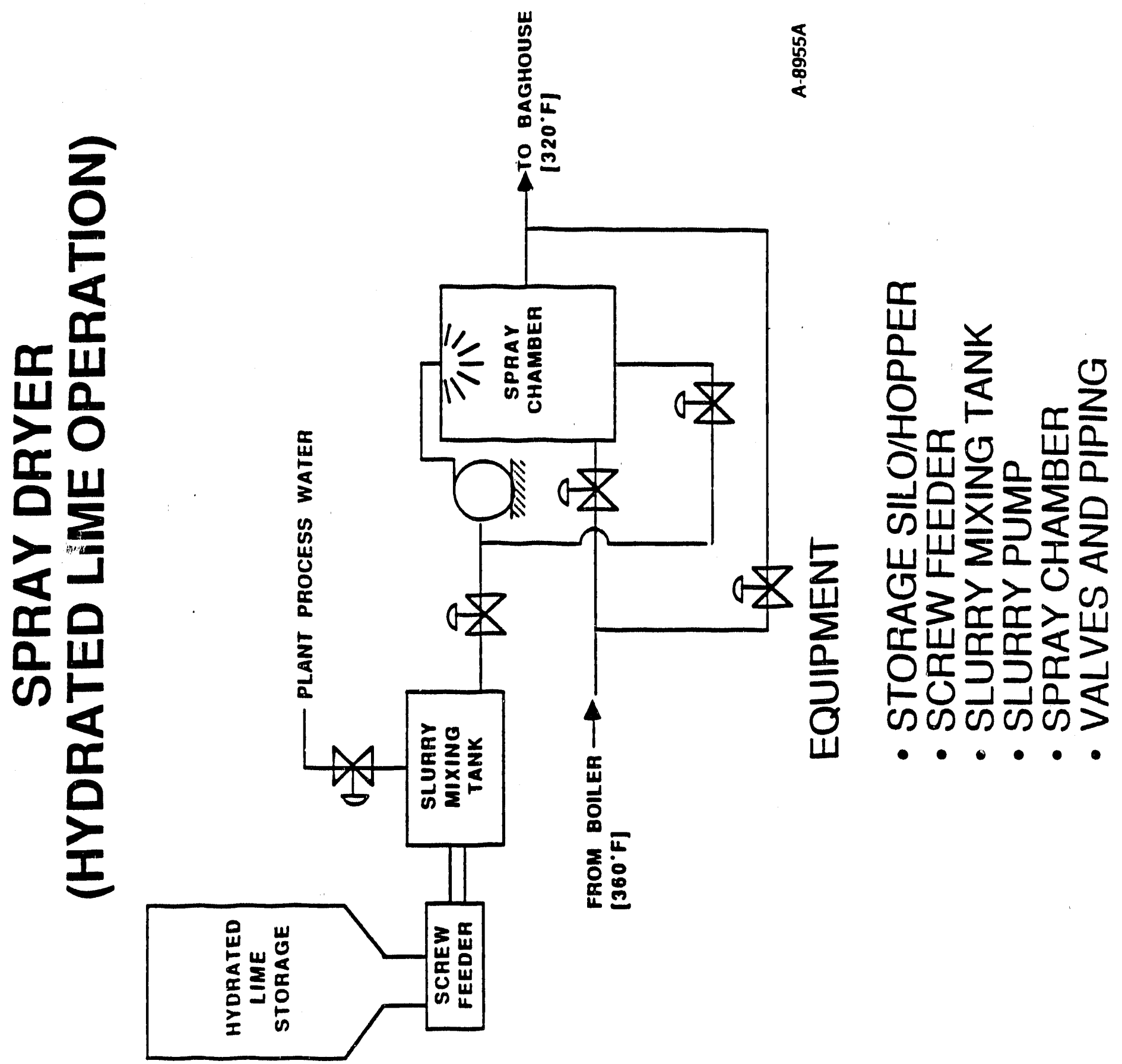


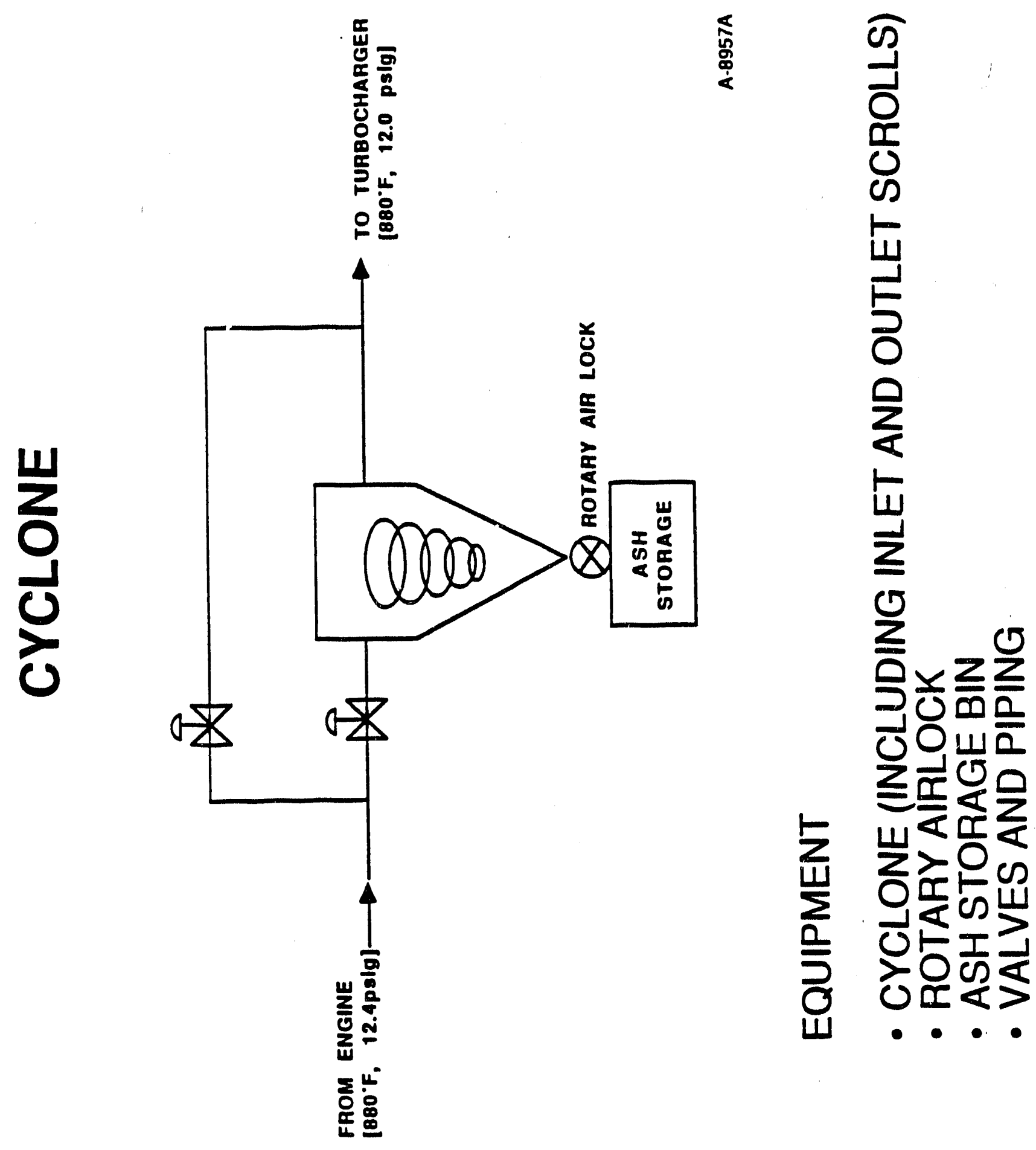




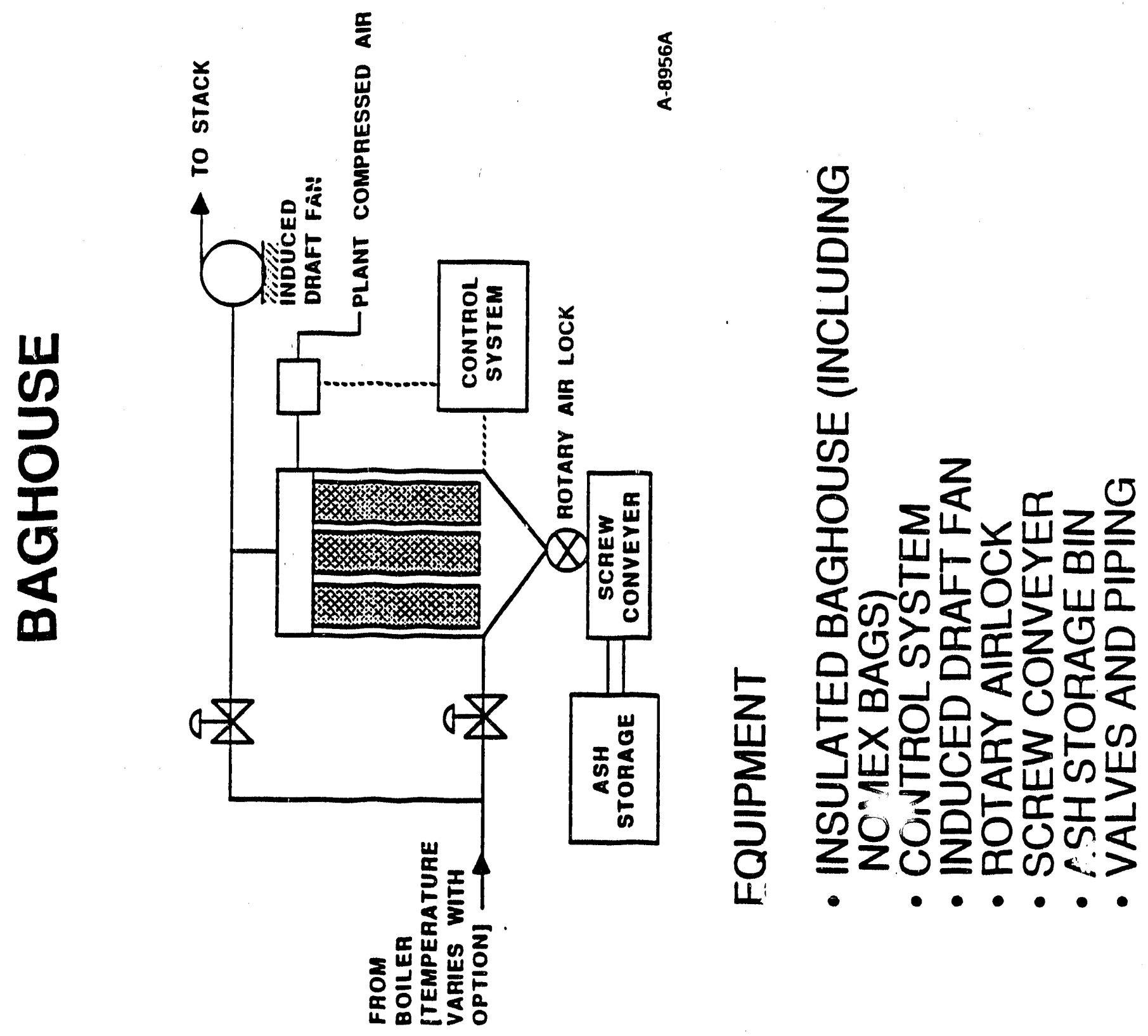




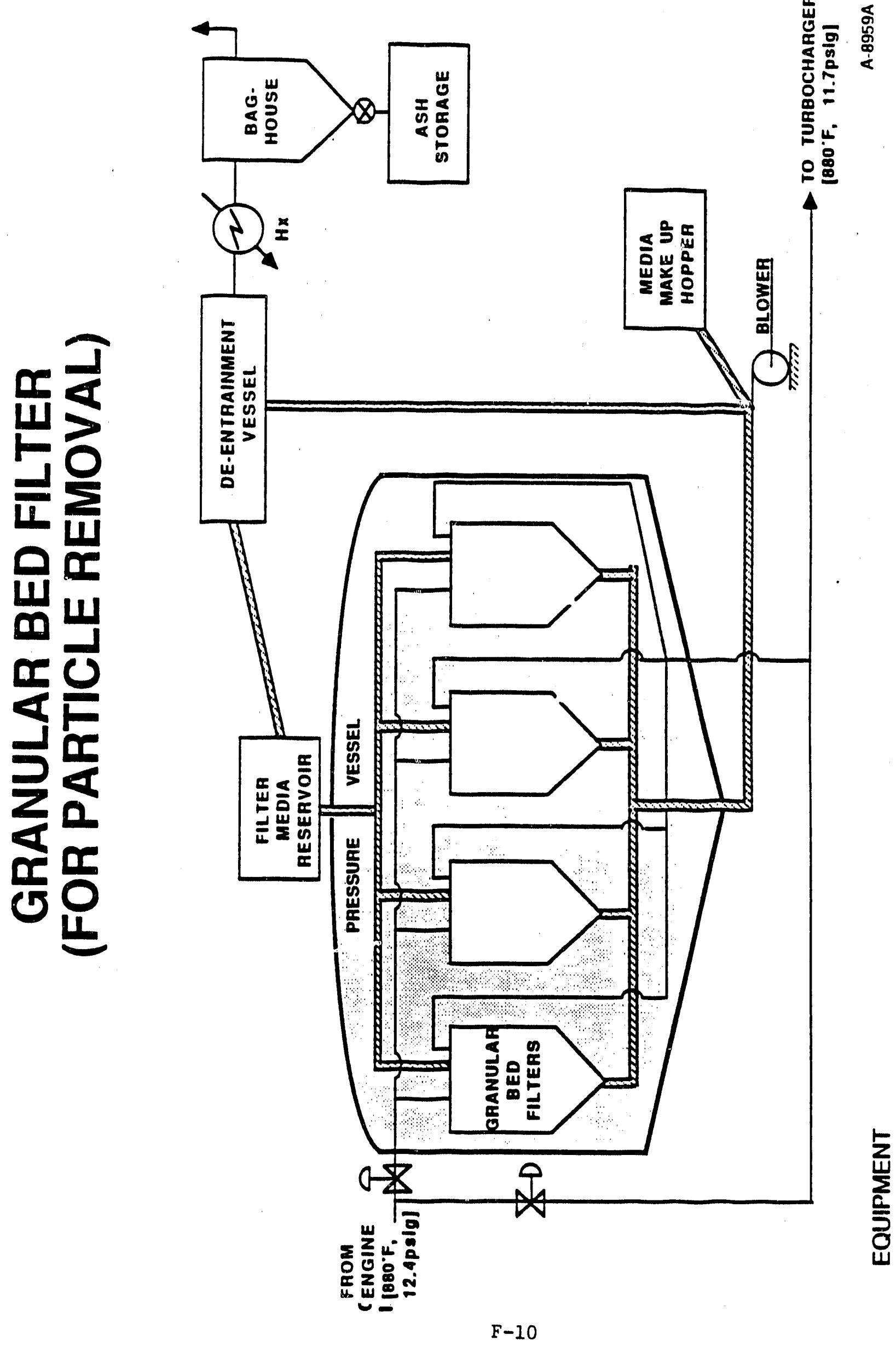

岕

당

$00<$

1 造

$\frac{1}{0} \frac{1}{\alpha}$

电听

山F出

조

ल $\frac{\pi}{0}$

탄

不

品里

때응 폴 풍 $\frac{\pi}{4}$ 요 픙뜸 舟 뚜음

上 $503 \frac{1}{2}$ 이음 $\geq 2$

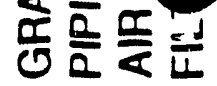




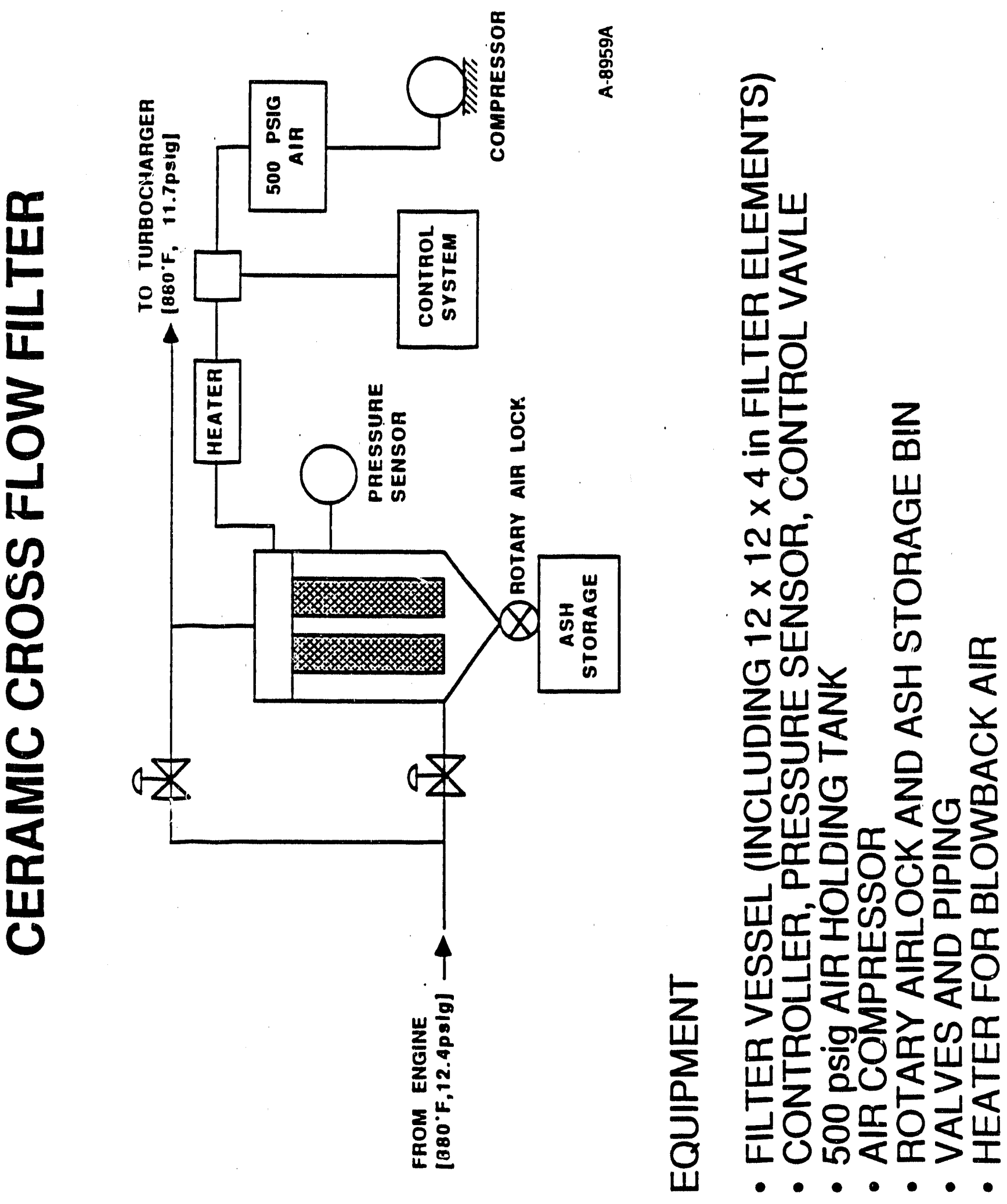


APPENDIX G

EMISSION CONTROL SYSTEM OPTIONS - PROCESS DIAGRAMS 


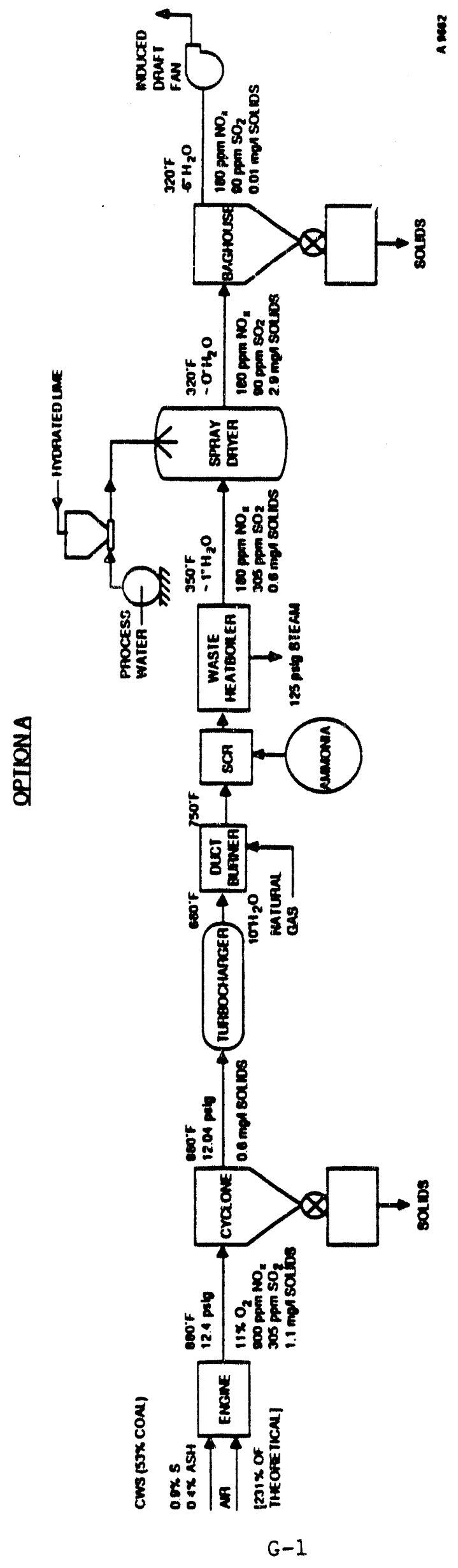




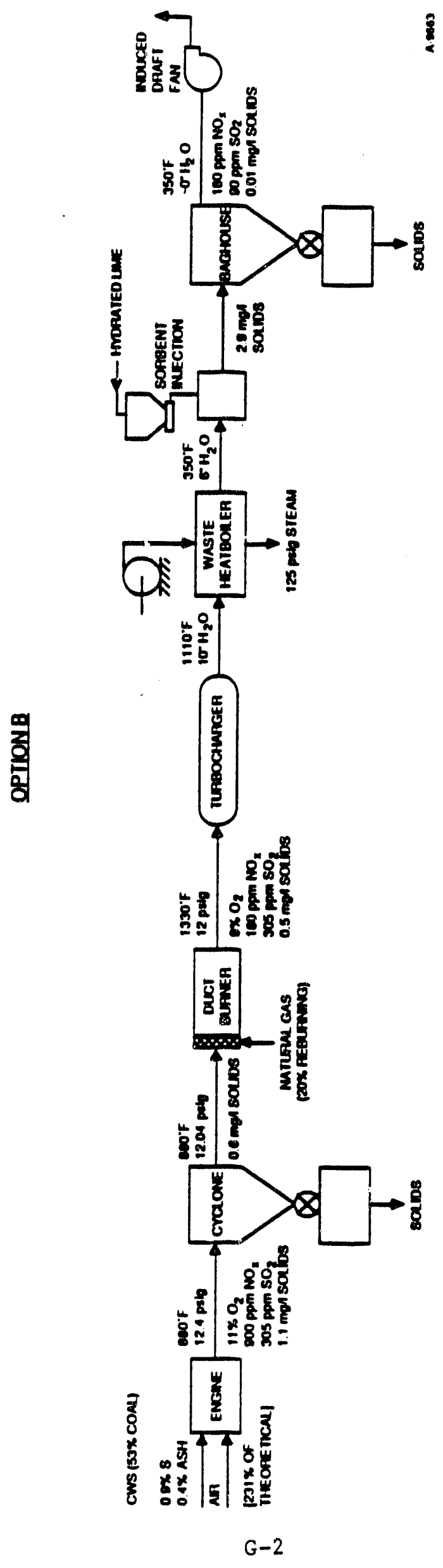




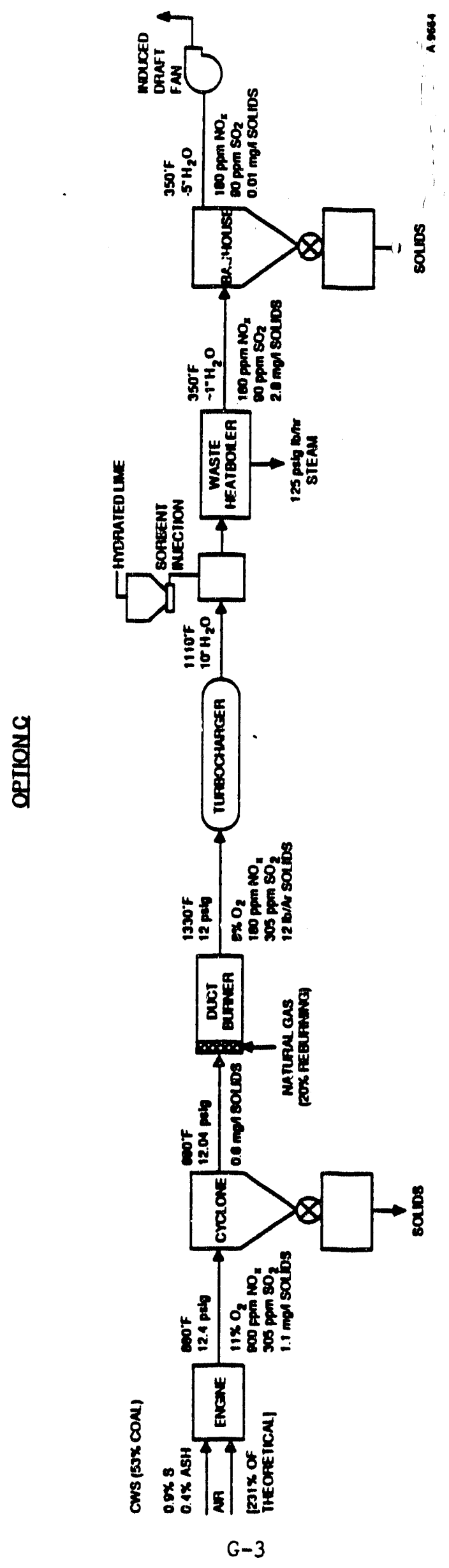




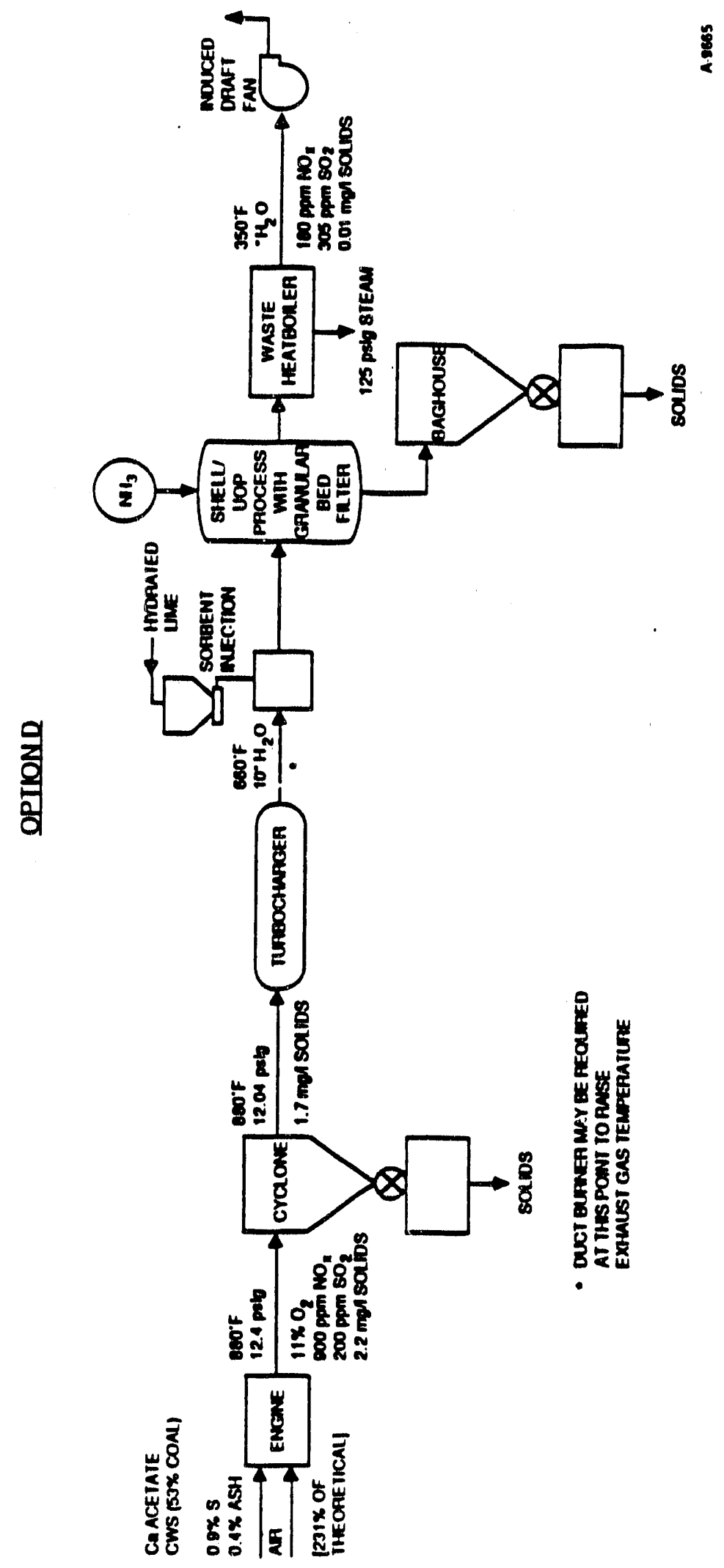

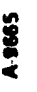




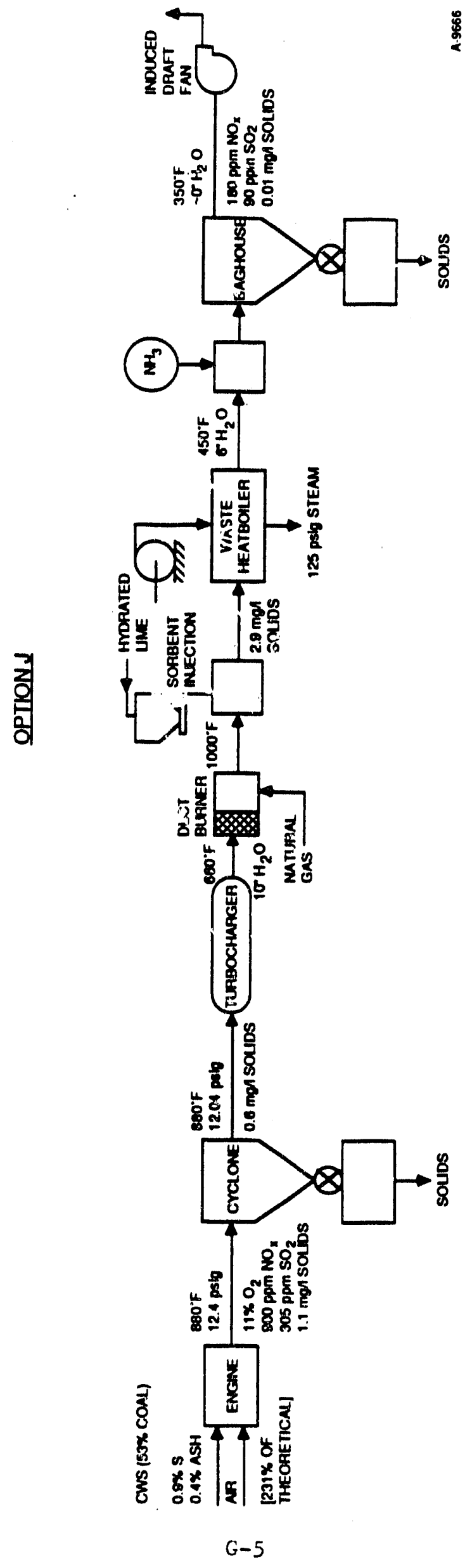




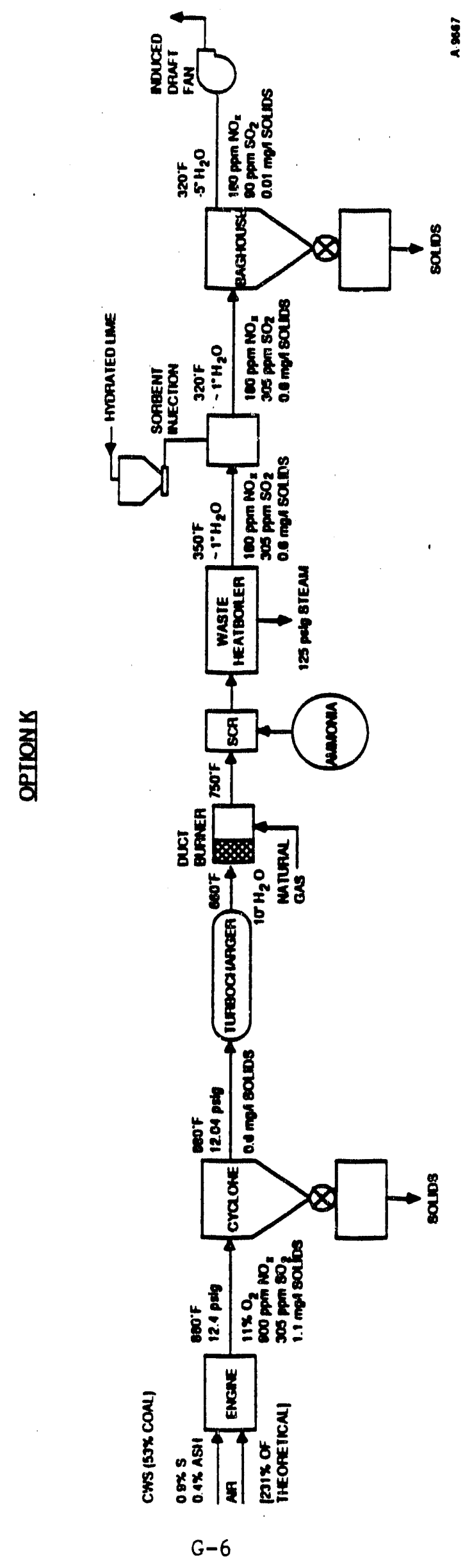




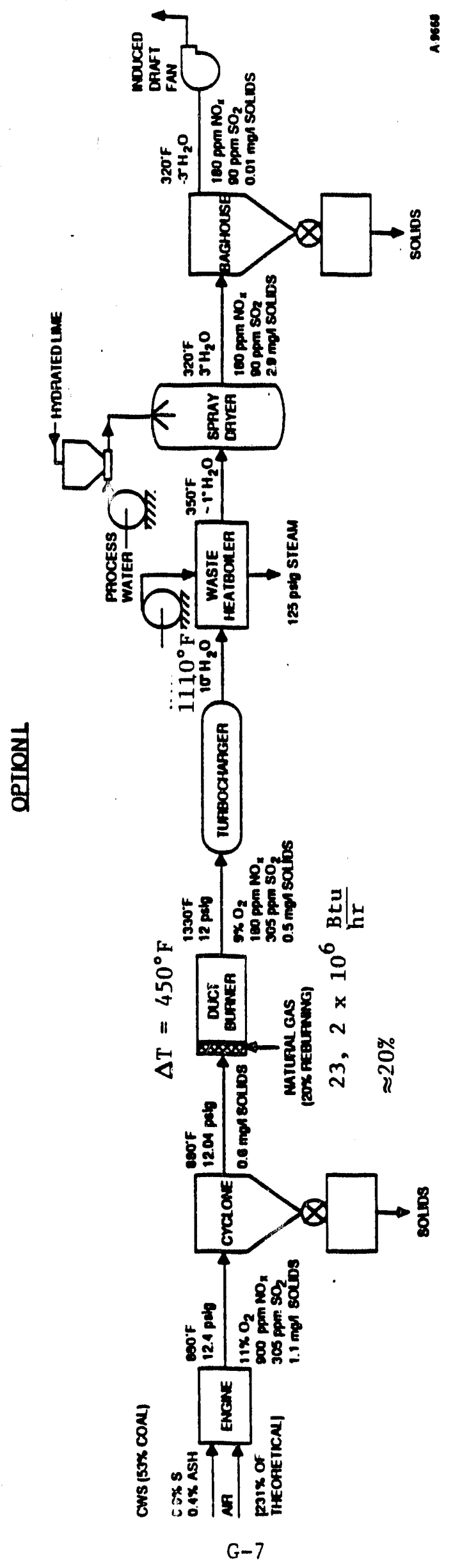




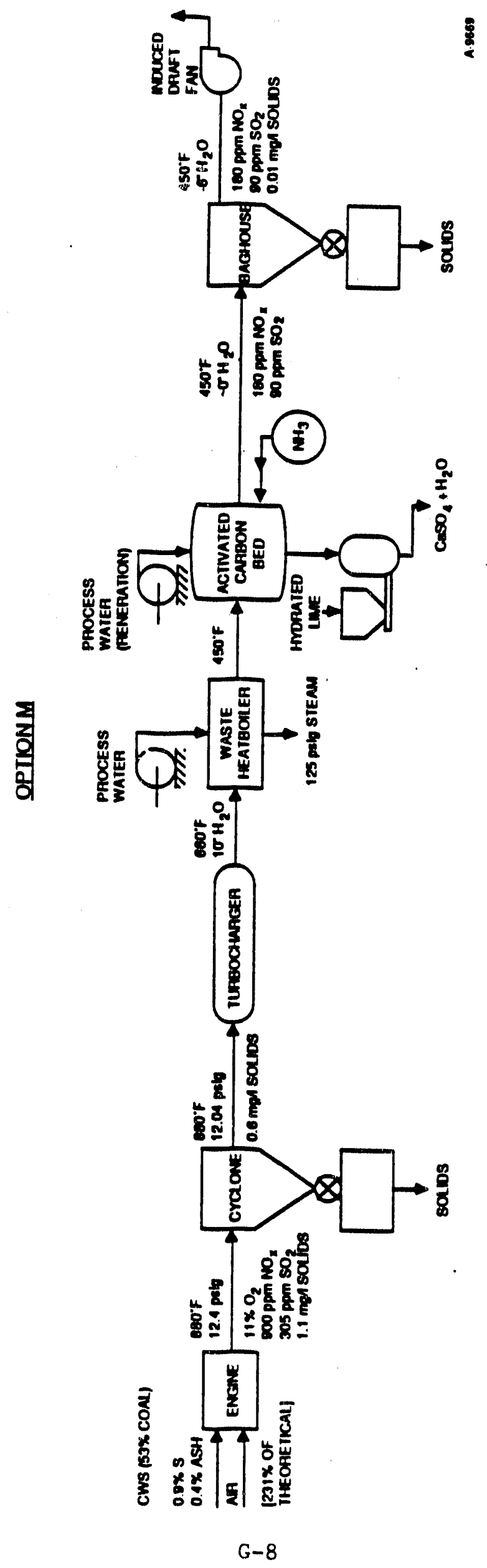




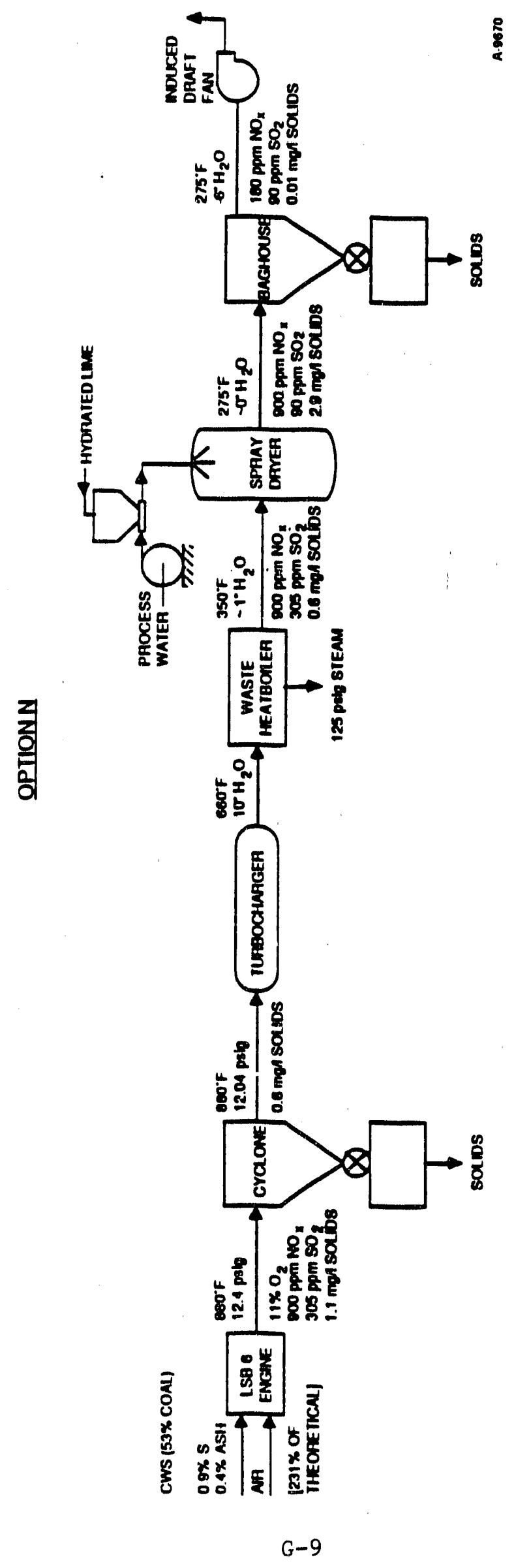


APPENDIX H

COST CALCULATIONS FOR EMISSION CONTROL SYSTEM OPTIONS 


\title{
Coalfueled Diesel Engine Emission Control Economics \\ Cost Strmary for ofTION A
}

\author{
Systam: 1 Engine (a 6 Cylinder) \\ 1.8 ine power output
}

CAPITAL

Equipment:

SCR Unit

Duct Burner

Spray Dryer

Cyclone

Baghouse

Induced Draft Fan

Differential Boiler Cost

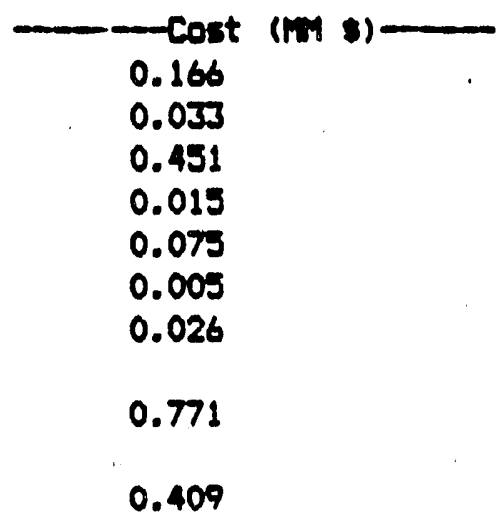

Installation Costs:

1.180

Total Installed Equipment cost

1.180

Engineering and Home Office Foes, General

Facilities, 20\% Contingency

0.425

Total Plant Cost

1.605

Royalties

0.001

Freprodui:tion Costs and Inventory Capital

Initial supplies and Materials

0.063

0.073

Total Capital Cost 
Operators/Sthjft: 0.5

$\begin{array}{ll}\text { Operat ing Labor (a } 21.55 \text { /hour) } & 0.094 \\ \text { Maintenance Factor: } 0.05 & \\ \text { Maintenance Labor Cost } & 0.023 \\ \text { Overhead Labor Cost } & 0.035 \\ \text { Total Labor Cost } & 0.152 \\ \text { Maintenance Supplies Cost } & 0.034 \\ \text { Total Operat ing and Maintmance Cost } & 0.186\end{array}$

Fixed Oplarating and Maintmance Cost ${ }^{\circ}$. 0.121

Variable Depariing and Maintmance Cost 0.065

Variable Operating Cost: s/hour

Natural bae a \$3.50/1000 curft. 2.90

Amonia $\quad 0.0 .25 / 16 \quad 4.13$

Sorbent $2870 /$ ton 2.10

Catalyst $\quad 2(2 \mathrm{yr}$ life) 6.41

Raw Water $0.0 .60 / 1000 \mathrm{gal} 0.02$

Stean $285.64 / 1000$ ib 1.51

Electricity $20.05 / k$ hn 1.92

Disposal $06.50 /$ ton 0.29

Bag a (1 yn $11 \mathrm{fe}$ ) 1.49

Total $\quad 20.76 \quad 0.118$

Total Variabie Operating costs (2 $65 \%$ utilization) 0.183

$\begin{array}{ll}\text { Cost of Capital (15\% per year) } & 0.261\end{array}$

$\begin{array}{ll}\text { Total Annua! Operating Cost } & 0.365\end{array}$ 


\section{Coalfueled Diesel Engine Emission Contral Economics \\ Cost Sumary for OPTION B}

\section{System: 1 Engine 106 Cylinder) \\ 1.8 power output}

CAPITAL

\section{Equipwent:}

Ruburning Unit

Low Teaperature Lieve Injection

Cyejone

Baghouse

Indueer Draft Fan

Differuntial Boiler Cost

Total Equipment

$0.003 \mathrm{t}(\mathrm{m})$
0.030
0.015
0.075
0.005
0.034
0.192
0.089

Total Instalied Equipient Cost

0.101

0.382

Preprodustion Costs and Inventory Capital

Initial supplies and materials

0.027

0.001

Total Capital Cost

0.411 
Dperators/5hift: 0.5

Operat ing Labor (9 $821.55 /$ hour) $\quad 0.094$

Maintenance Factor: 0.04

Maintenanee Labor Cost $\quad 0.004$

Overhead Labor Cost $\quad 0.030$

Total Labor Cost 0.128

Maintenance Supplies Cost $\quad 0.007$

Total Oporating and Maintenance Cost 0.135

Fixed Dpusating and Maintmance Cost $\quad$ U.098

Variable Operating and Maintenance Cost 0.047

Variable Operating Cost: \$/hour

Natural tias a \$3.50/1000 cu.ft. 13.71

Sorbent 2.10

Stean $0 \$ 5.64 / 1000$ ib (16.55)

Electricily $\$ 0.05 / k$ th 1.04

Disposal 0.29

Bag a (1 yr Iife) 1.49
Total
2.08
0.012

Total Variable Operating Costs (o $65 \%$ utilization)

0.059

Cost of Capjtal (15\% per year)

0.062

Total Annued Operating Cost

0.208 


\section{Cosiffueled Diesel Engine Emission Contral Economics}

Cost Sumary for option C

System: I Engine is a Cylindar)

1.8 powar" output

CAPITAL

Equipant:

Reburning Undi

High Teaperature Lian infection

Cyclone

Baghouse

Induced Draft Fan

Differential Boiler Cost

Total Equipment

Installation Costs:

Total In:italled Equipment cost

Engineering and Howe Office Fees, General Facilililes: 20\% Contingency

Total Plant cos?

Preproduction Costs and Inventory Capital

Initial supplies and Materials

Total Capital Cost

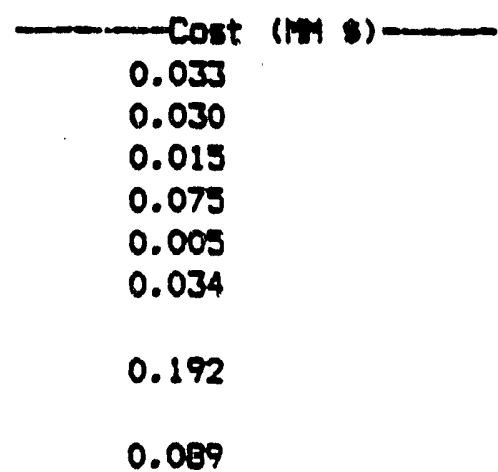

0.281

0.101

0.382

0.027

0.001 
OPERATING COSTS

$-\operatorname{Cost}(\operatorname{lin} \$ / y)\rangle-$

Operators/Shift: 0.5

Operating Labor (a $\$ 21.55$ /hour) 0.094

Maintenance factor: 0.04

Maintenance Labor Cosit $\quad 0.004$

Overhead Labor Cost $\quad 0.030$

Total Labor Cost $\quad 0.128$

Maintenance Supplies Cost $\quad 0.007$

Total Operating and Maintenance Cost 0.135

$\begin{array}{ll}\text { Fixed Operating and Maintenanes Cost } & 0.088\end{array}$

Variable Operating and Maintemance Cost 0.047

Variable Operating Cost: s/hour

Natural Gas $\$ \$ 3.50 / 1000$ cu.ft. 13.71

Sorbent 2.10

Stran $\$ \$ 5.64 / 1000$ lb (16.55)

Electricity 1.04

Disposal $6.50 /$ ton 0.29

Bag a (1 yr life) 1.49

$\begin{array}{lll}\text { Total } & 2.08 & 0.012\end{array}$

Total Varizble Operating Costs (0 657 utilization) 0.054

Cost of Capital (15\% per year) 0.062

$\begin{array}{ll}\text { Total Anriua: Operating Cost } & 0.208\end{array}$ 
Cost Stumary for OPTION D

System: 1 Engine (A 6 Cylinder)

1.8 power output

CAPITAL

Equipment:

Calcium Fuel Addtive (Ca/s = 1$)$

Cyclone

lifgh Temperature Lime Injection (Ca/s $=1)$

Shell/Lop Unit with Granular Bed

Indured Draft Fan

Differential Boiler Cost

Total Equipment

\begin{tabular}{|c|c|}
\hline $\begin{array}{l}- \text { Cost } \\
0.000 \\
0.015\end{array}$ & $(m / 1)$ \\
\hline $\begin{array}{l}0.030 \\
0.296 \\
0.005 \\
0.026\end{array}$ & \\
\hline 0.372 & \\
\hline 0.229 & \\
\hline & 0.601 \\
\hline
\end{tabular}

Total Installed Equipment Cost

0.216

Engineering and Howe Office Fecs, General

Facilities, $20 \%$ Contingency

Total Plant Cost

0.817

Royalties

0.003

Preproduction Costs and Inventery Capital

0.242

Inttial Jupplies and Materials

0.087

Total Capital .Cost

1.150 
Dparators/Shift: 0.5

Operat ing Labor (a \$21.55/hour) 0.094

Madntenance Fuctor: 0.09

Maintenanes Labor Cost

0.022

Overhead Labor Cost

0.035

Total Lahor Cost

0.150

Maintenance Supplies Cost

0.032

Total Operating and Maintenance cost

0.183

Fixed Operating and Maintenance Cost

0.119

Variable Operating and Maintenance Cost

0.064

Variable Operating Cost:

Ammonia $00.25 / 1 b$

$\$$ /hour

Fuel Additive $82.07 / 16$

4.13

Catalyst

a $(2 \mathrm{yr} 1 \mathrm{ife})$

Cooling Hater O $50.15 / 1000 \mathrm{gal}$

87.87

Stean

จ $85.64 / 100016$

3.12

0.20

Electricity

$280.05 / k$ in

1.51

Disposal

D $\$ 6.50 /$ ton

1.14

0.48

Total

98.45

0.561

Total Variable Operating Costs (2 65\% utilization)

0.623

Cost of Capital (15\% per year)

0.172

Total Annuad Operating Cost

0.916 
Cost Sumary for OPTION J

System: \& Engine (2 6 Cylinder)

1.8 me power output

CAPITAL

Equipment:

High Teaperature Lise Injection

Duct Burner

Amwonia Injection in Baghouse

(at $450 \mathrm{~F}$ )

Cyclone

Insulated Baghouse

Induced Draft Fan

Difterential Baller Cost

Total Equipment

Installation Costs:

Total Ins:tal jed Equipaent Cost

Engineeri:g and Home Dffice Fres, General Faciditius, $20 x$ Contingency

Total Plant Cost

Preproduition Costs and Inventory Cafital

Initial Sufplies and Materials

Total Capita? Cost

$-\operatorname{Cost}(m)-$
0.030
0.033
0.084
0.015
0.101
0.005
0.001
0.269
0.142

$0.4: 1$

0.148

0.559

0.054

0.001

0.614 
Operators/Shift: 0.5

$\begin{array}{ll}\text { Operat ing Labor (a } \$ 21.55 / \text { hour) } & 0.094 \\ \text { Maintenance Factor: } 0.04 & \\ \text { Maintenance Labor Cost } & 0.007 \\ \text { Overhead Labor Cost } & 0.030 \\ \text { Total Labor Cost } & 0.131 \\ \text { Maintenance Supplies Cost } & 0.010 \\ \text { Total Dparat ing and Maintenance Cost } & 0.142\end{array}$

Fixed Dparating and Maintenance Cost

Variable Operating and Maintanance Cost 0.049

Variable Dperating Cost: \$/hour

Natural Gas $\$ 3.50 / 1000 \mathrm{cu} .+1.11 .10$

Ammonia $\quad 0 \$ 0.25 / 16 \quad 4.13$

Sorbent 2.10

Stean $\$ 5.64 / 1000$ 1b $(6.34)$

Electricity 1.04

Disposal $\$ 6.50 /$ ton 0.29

Bag a (1 yr life) 1.49

$\begin{array}{lll}\text { Total } & 13.91 & 0.079\end{array}$

Total Varicale Operating Costs (a $65 \%$ utilidzation)

0.128

Cost of Capital (15\% por year)

0.092

Total Annua: Operating Cost

0.313 


\section{Coal-Fueled Diesel Fingine Emission Contral Economics \\ Cost Sunmary for OPTION $K$}

System: 1 Engine (a 6 Cylinder)

1.8 we power output

\section{CAPITAL}

Equipment:

SCR Unit

Duct Burner

Low Temperature Lime Injectian

lyctone

Baghouse

Induced Iraft Fan

Differential Boiler Cost

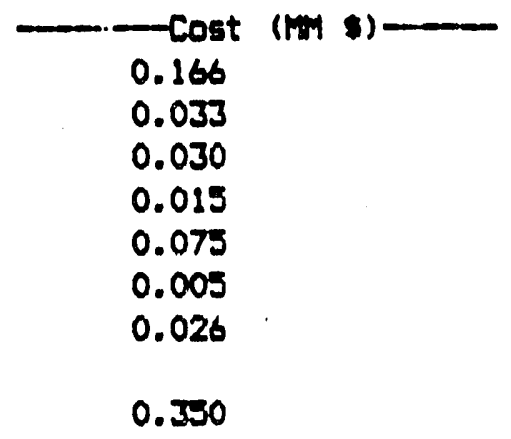

Installation Costs:

0.149

Total Initajled Equipment Cost

0.499

Engineering and Home Office Fees, General Facilitizs: 20\% Contingency

0.180

Total Plant Eost

0.679

Royaltie:s

0.001

Preproduition Costs and Inventory Capital

0.055

Initial Suppijes and Materials

0.073

Total Capital- Cost

0.808 


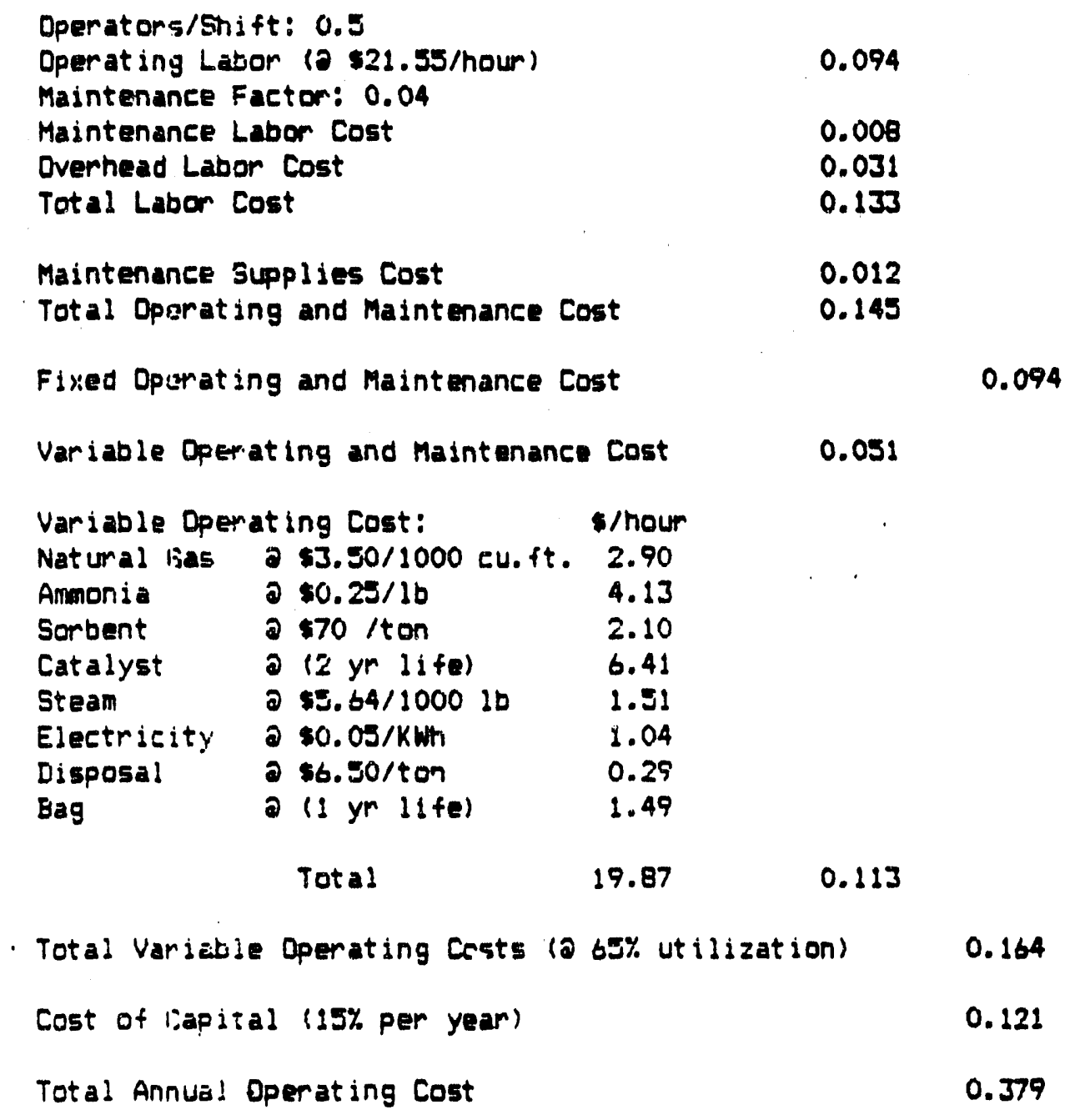




\section{. Coalfueled Diesel Fingine Enission Contral Economies \\ Cost SI umanary for OPTION L}

\section{System: 1 Engine (a 6 Cylinder) \\ 1.8 mive powar output}

CAPITAL

Equipwent:

Reburning Unit

Spray

Cyelu" .

Bag

Induked Draft Fan

Differential Boiler Cost

Total Equipment

Installation Costs:

Total Installed Equipment Cost

Engineering and Howe Office Fecs, Gerieral Facilities, $20 x$ Cont ingency

Total Plant Cost

Preproduction Costs and Inventciry Capital

Initial Sufplies and Materials

Total Capjital Cost

- Cost (m $)-$
0.033
0.451
0.015
0.075
0.005
0.034
0.613
0.349

0.962

0.346

1.308

0.051

0.001

1.360 


\begin{tabular}{|c|c|c|c|}
\hline \multicolumn{2}{|l|}{$\begin{array}{l}\text { Operators/Shift: } 0.5 \\
\text { Operat ing Labor } 10 \$ 21.55 \text { /hour) } \\
\text { Maintenance Factor: } 0.05 \\
\text { Maintenance Labor Cost } \\
\text { Overhead Labor Cost } \\
\text { Total Labor Cost }\end{array}$} & $\begin{array}{l}0.094 \\
0.019 \\
0.034 \\
0.147\end{array}$ & \\
\hline \multicolumn{2}{|c|}{$\begin{array}{l}\text { Maintenance Supplies Cost } \\
\text { Total Dporat ing and Maintenance Cost }\end{array}$} & $\begin{array}{l}0.029 \\
0.176\end{array}$ & \\
\hline \multicolumn{3}{|c|}{ Fixed Dperating and Maintenance Cost } & 0.114 \\
\hline \multicolumn{2}{|c|}{ Variable Operating and Maintenance Cost } & 0.062 & \\
\hline \multicolumn{3}{|c|}{ 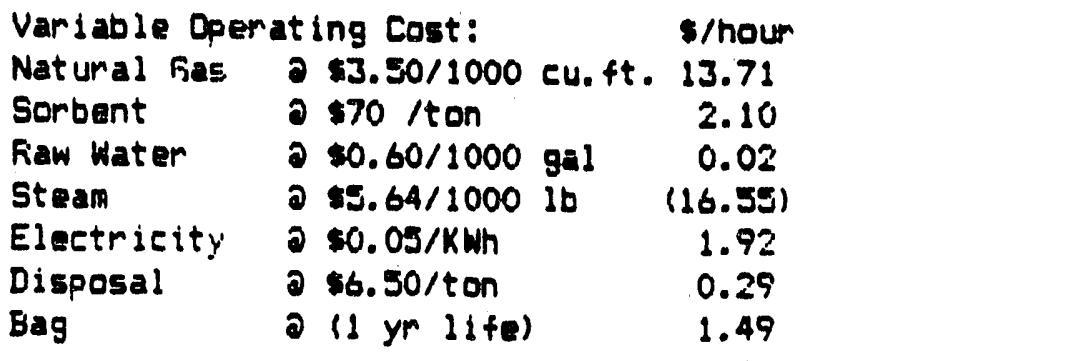 } & \\
\hline Total & 2.98 & 0.017 & \\
\hline \multicolumn{3}{|c|}{$\begin{array}{l}\text { Total Varizbje Operating Costs (0 65\% utilization) . } \\
\text { Cost of lapital ( } 15 \% \text { per year) }\end{array}$} & $\begin{array}{l}0.079 \\
0.204\end{array}$ \\
\hline
\end{tabular}




\section{Coal-fueled Diesel Engine Emission Control Economics \\ Cost Summary for OPTION M}

\section{System: 1 Engine 10 6 (ylindar) \\ 1.8 powe potput}

\section{CAPITAL}

Equipment:

Takeda Proceas Unit

Cyc lone

Baghouse

Incueed Iraft Fan

Differential Boiler Cost

Total Equipment

Installation Costs:

Total Instalded Equipment Cost

Engineering and Howe Office Fees, General

Facilities: $20 \%$ Contingency

Total Plant Cost

Royalties

Preprodui:tion Costs and Inventory Capiral

Initial Supplies and Materials

Total Capita? Cost
$(M N)$

0.405

0.015

0.075

0.005

(0.012)

0.488

0.452

0.940

0.338

1.278

0.005

0.084

0.042 
Operators/Shift: 0.5

$\begin{array}{ll}\text { Operat ing Labor (o } \$ 21.55 / \text { hour) } & 0.094 \\ \text { Maintenance Factor: } 0.08 & \\ \text { Maintenance Labor Cost } & 0.030 \\ \text { Overhead Labor Cost } & 0.037 \\ \text { Totcl Labor Cost } & 0.161 \\ \text { Maintenance Supplies Cost } & 0.045 \\ \text { Total Dprat ing and Maintenance Cost } & 0.206\end{array}$

Fixed Dp:anating and Maintenance Cost

Vardab de Openat ing and Maintenance Cost

0.072

Variable Dperating Cost:

Ammonia

Sorbent

Catalyst

Raw Water

Steam

Electrieity

Disposal

Bag a $\$ 0.25 / 1 b$

a $\$ 70 / \operatorname{ton}$

a (2 yn 1ife)

a $\$ 0.60 / 1000 \mathrm{gal}$

a $55.64 / 100010$

a $\$ 0.05 / k$ th

a $\$ 9.50 /$ ton

a (l yr life)

Total
\$ /nour

4.13

0.60

7.17

0.02

10.63

0.94

1.66

1.49

$26.60^{\circ}$

0.152

Total Variatile Dperating Costs (a 65\% utilization)

Cost of Capital (15\% per year)

Total Annual Dperating Cost 


\section{System: 1 Engine (a 6 Cylinder) \\ 1.8 power output}

CAPITAL

Equipwent:

Spray Dryer

Cyclone

Baghouse (27S F)

Indused Draft Fan

[lifterential Boiler Cost

Total Equipment

Installation Costs:

Cost (m) 1 -

0.451

0.015

0.075

0.005

0.023

0.569

Total Instal led Equipment Cosit

0.338

Engineering and Home Office Fecs, General

Facilities. 20z Contingency

Total Plant Cost

0.327

1.234

Preproduction Costs and Inventory Capital

Initial sueplies and Materials

0.055

0.001

Total Capital Cost

1.290 


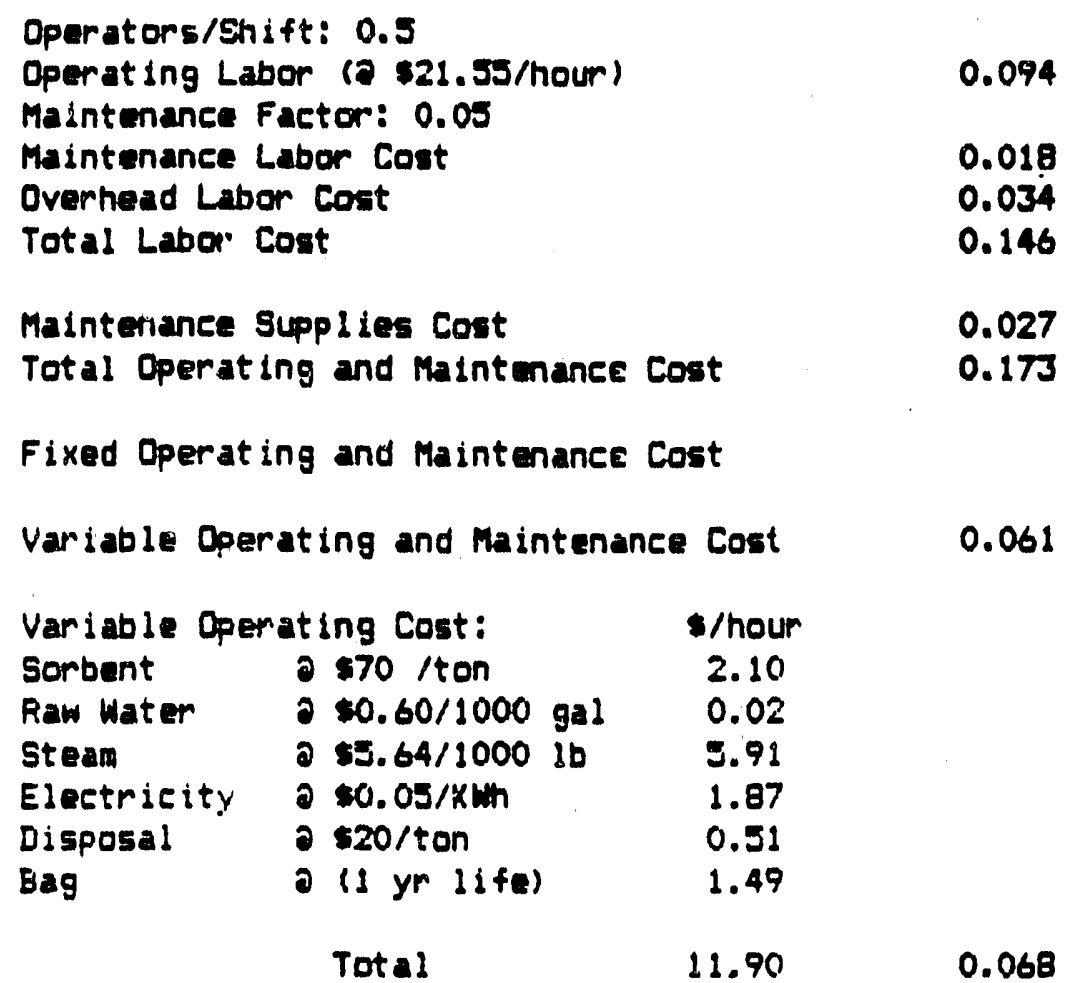

Total Variable Dperating Costs (a 65\% utilization) 0.128

$\begin{array}{ll}\text { Cost of Capital (15\% per year) } & 0.193\end{array}$

Total Annua! Operating Cost $\quad 0.434$ 


\section{Coal-Fueled Diesel Engine Emission Contral Economics \\ Cost Sumary for OPTION A}

System: 4 Engines (20 6 Cylinder)

7.2 Mule power output

CAPITAL

Equipment:

Str Unit

Duct Burner

Spray Dryer

Cyclone

Baghouse

Induced Draft Fan

Oi: zrential Boiler Cost

Total Equipment

Installation Costs:

Total Installed Equipment Cost

Engineering and Howe Office Feas, General Facilities: $20 \%$ Contingency

Total Flant Cout

Royalties

Freproduition Costs and Inventory Capital

Initial supp!ies and Materjals

Total Capital Cost

\begin{tabular}{|c|}
\hline $\begin{array}{l}0 . \operatorname{cost} t \\
0.433 \\
0.033 \\
0.797 \\
0.059 \\
0.132 \\
0.014 \\
0.060\end{array}$ \\
\hline 1.528 \\
\hline
\end{tabular}

2.314

0.833

3.147

0.003

0.201

0.298 


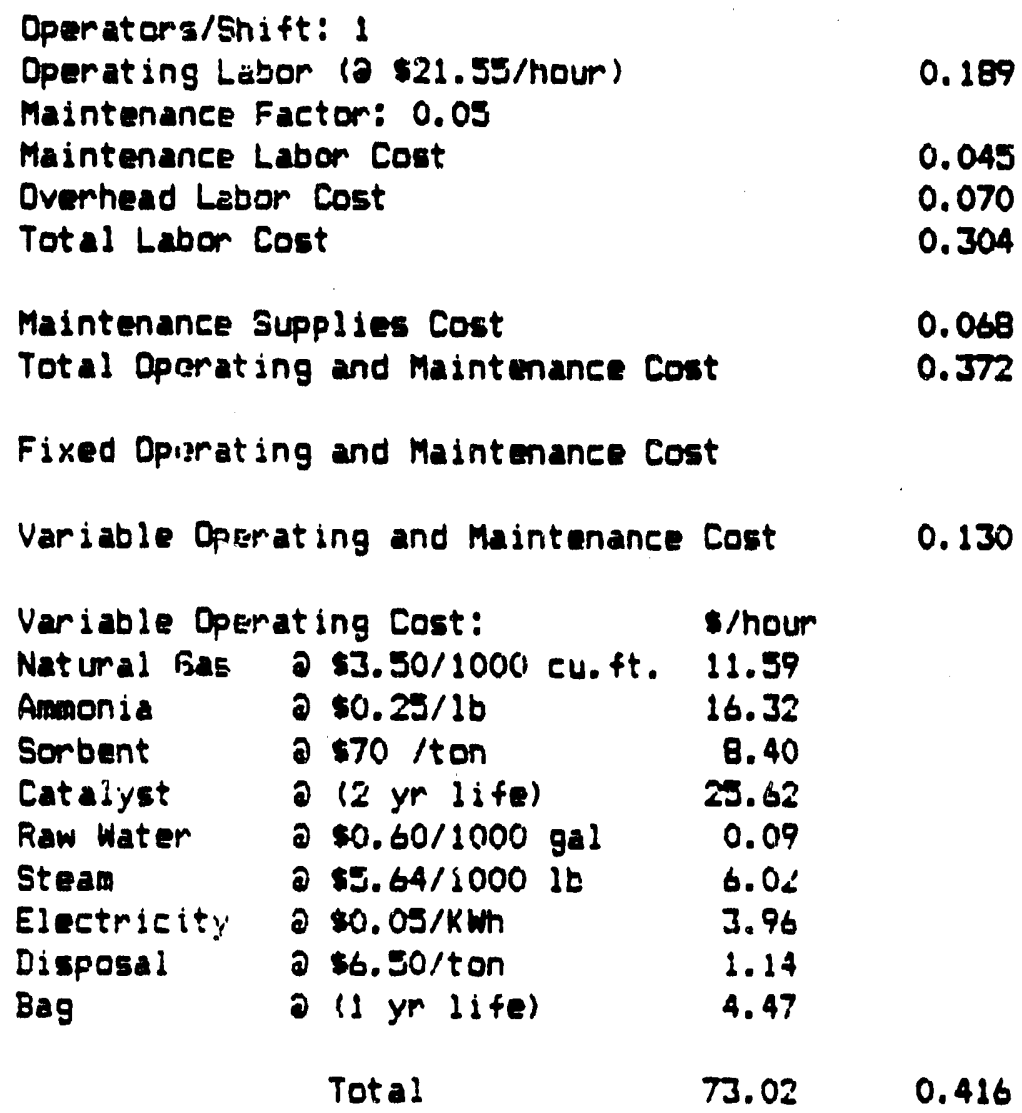

Total Variable Operating Costs (a 65\% utilization) 0.546

$\begin{array}{ll}\text { Cost of liapital (15\% per year) } & 0.347\end{array}$

Total Annus: Operating Cost 1.335 


\section{Coalfueled Diesel Engine Emission Control Economics \\ Cost Sunmary for OPTION B}

System: 4 Engines (a 6 Cylinder)

7.2 mwe power output

CAP ITAL

Equipment:

Reburning Unit

\begin{tabular}{c}
- Cost (my s) \\
\hline 0.134 \\
0.057 \\
0.059 \\
0.132 \\
0.014 \\
0.079
\end{tabular}

Total Equipment

0.475

Installatjon Costs:

0.198

Total Installed Equipment Cost

0.673

Engineering and Home Office Fecs, General

Facilities, 20\%, Contingency

0.242

Total Flant Cost

0.915

Preproduction Costs and Inventciry Capital

0.063

Initial Sueplies and Materials

0.009

Total Capitai Cost

0.987 
Operators/Shift: 1

Operating Lasor (a $\$ 21.55 /$ hour)

0.189

Maintenance Factor: 0.04

Maintenance Labor Cost

0.011

Overhead Labor Cost

0.060

Total Labor Cost

0.260

Maintenance Supplies Cost

0.016

Total Operating and Maintenance Cost

0.276

Fixed Opiarating and Maintenance Cost

0.179

Variable Operating and Maintenance Cost

0.097

Variable Operating Cost:

\$/hour

Natumal fas $0 \$ 3.50 / 1000$ cu.ft. 54.82

Sorbent

2 $\$ 70 /$ ton

8. 40

Stean

2 $\$ 5.64 / 1000$ 1b

(66.21)

Elactricity

2 $\$ 0.05 / \mathrm{kWh}$

3.83

Disposal

2.5.50/ton

1.14

Bag

a (l yr life)

4.47

Total

6.45

0.037

Total Variatle Operating Costs (a 65\% utildzation)

0.134

Cost of Capital (15\% per year)

0.248

Total Annual Operating Cost

0.461 


\section{Coal fueled Diesel Fngine Emission Control Economics \\ Cost SImmary for OPTION C}

System: 4 Engines (0 6 Cylinder)
7.2 power output

CAPITAL

Equipaent:

Reburning Unit

High Temperature Liwe Injection

Cyclone

Baghouse

Induied oraft Fan

Ilifferential Boiler Cost

Total Equipment

$\begin{array}{ll} & \text { Cost (m } 1)- \\ 0.134 & \\ 0.057 & \\ 0.059 & \\ 0.132 & \\ 0.014 & \\ 0.079 & \\ 0.475 & \\ 0.198 & \\ & \\ 0.242 & \\ 0.915 & \\ 0.063 & \\ 0.009 & \end{array}$

Initial Supplies and Materials

0.987

Total Capital Cost 
Operators/Shift: 1

$\begin{array}{ll}\text { Operating Labor (a } \$ 21.55 \text { /hour) } & 0.189 \\ \text { Maintenance Factor: } 0.04 & \\ \text { Maintenance Labor Cost } & 0.011 \\ \text { Overhead Labor Cost } & 0.060 \\ \text { Total Labor Cost } & 0.260 \\ & \\ \text { Maintenance Supplies Cost } & 0.016 \\ \text { Total Operating and Maintenance Cost } & 0.276\end{array}$

Fixed Operating and Maintenance Cost

Variable Operating and Maintenance Cost 0.097

Variable Operating Cost: $/$ hour.

Natural Gas a $\$ 3.50 / 1000$ cu.ft. $\mathbf{5 4 . 8 2}$

Sorbent 870 iton 8.40

Stean $\$ 5.64 / 100010 \quad(66.21)$

Electricity 3.83

Disposal a so.so/ton 1.14

Bag (1 yr life) 4.47
Total
6.45
0.037

Total Variable Operaing Costs (a 65\% utilization) 0.134

Cost of Capital (15\% per year) $\quad 0.148$

Total Annwe: Operating Eost . 0.461 


\section{Coal fueled Diesel Engine Enission Control Economics \\ Cost SImmary for OPTION D}

\section{System: 4 Engines (a la Cylinder) \\ 7.2 twe power output}

CAPITAL

Equipment:

Caleium Fuel Additive (Ca/s = 1)

Cyclone

High Tenperature Lime Injectiori (Ca.s = 1)

Shell/UOP Unit with Granular Bed Indwied Draft Fan

Differential Boiler Cost

- Cost $(\mathrm{mon})-$
0.000
0.059
0.057
0.795
0.014
0.060
0.985

Installation Costs:

0.616

Total Instailed Equipment Cost

Engineering and Home Office Fecs, General Facilities, $20 \%$ Cont ingency

0.576

Total Plant Cost

Royalties

0.009

Preproduction Costs and Inventery Capital

0.909

Initial Sufplies and Materials

0.330

Total Capital Cost 


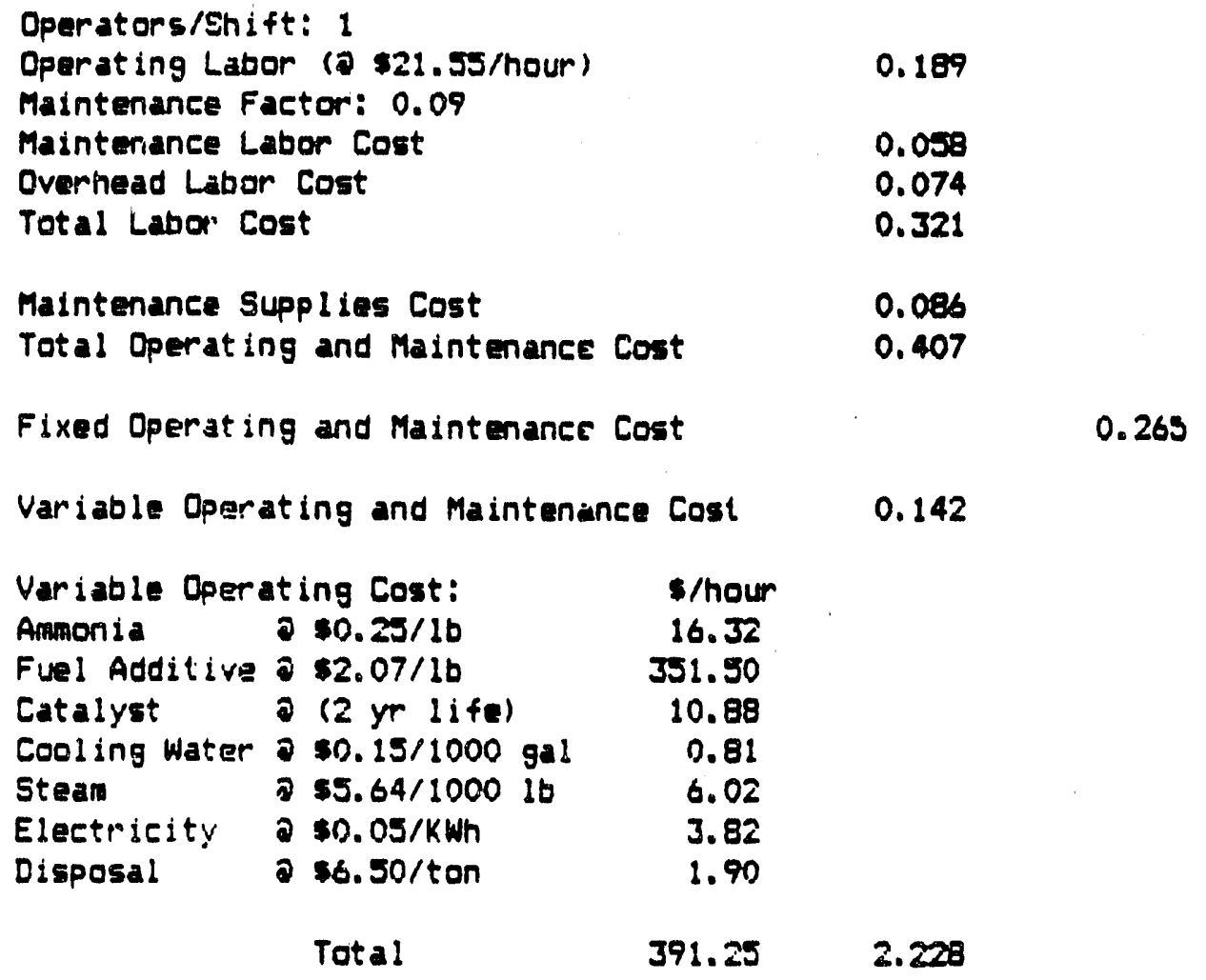




\section{Coal-Fuelod Diesel Engine Emission Contral Economics \\ Cost Summary for optiow J}

\section{System: 4 Engines (0 6 Cylinder) \\ 7.2 we power output}

\section{CAPITAL}

\section{Equipment:}

High Tenperature Line Injection Duct Burner

nomania Injection in Baghouse (at $450 \mathrm{~F}$ )

Cyclone

Insulated Baghouse

Induced Draft Fan

Difterential Boiler Cost

Total Equipment

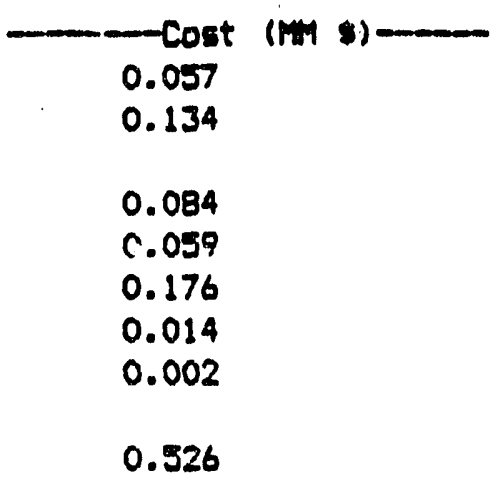

Installation Costs:

0.265
Total Instad Jed Equipment Cost

Engineering and Howe Dffice Feas, General Facilities: $20 \%$ Contingeney

Total Plant Cost

0.285

1.076

Preproduition Costs and Inventory Capital Initial supplies and Materiads

0.207

0.009

0.791

Total Capital Cost 
OPERATING COSTS

- Cost $($ m $\$(y))-$

Operators/Shift: 1

Dpera'ting Labor (a) $\$ 21.55 /$ hour) $\quad 0.189$

Maintenance Factor: 0.04

Maintenance Labom Cost $\quad 0.013$

Overhad Labor Cost $\quad 0.060$

Total Labor Cost $\quad 0.262$

Maintenance Supplias Cost $\quad 0.019$

Total Opamating and Maintmance cost $\quad 0.281$

Fixec Oprating and Maintenance Cost 0.183

Variable Openating and Maintenance Cost 0.098

Variable Deprating Cost: \$/hour

Natural fas a $\$ 3.50 / 1000 \mathrm{cu} . \mathrm{ft} .44 .40$

Amonia $\quad 250.25 / 1 b \quad 16.32$

Sorbent $870 /$ ton 8.40

Steam $\$ 5.64 / 1000$ ib (24.95)

Electricity $00.05 / k$ Wh 3.83

Disposal a $6.50 /$ ton 1.14

Bag a $11 \mathrm{yn} 11 \mathrm{fe}) \quad 4.47$

$\begin{array}{lll}\text { Total } & 53.61 & 0.305\end{array}$

Total Variatle Operating Costs (0 65\% utilization) 0.403

Cost of Capital (15\% per year) $\quad 0.194$

$\begin{array}{ll}\text { Total Annua! Operating Cost } & 0.780\end{array}$ 


\section{Coal-Fueled Diesel Engine Emission Contral Economics \\ Cost Sumary for OPTION $K$}

System: 4 Engines (a 6 Cylinder)

7.2 moe powen output

CAPITAL

Equipment:

SCR Unit

Duet Burner

I.ow Temperature Lime Injection $\quad 0.057$

Cyelone

Baghouse

Inciuced Draft Fan

Difterential Boiler Cost

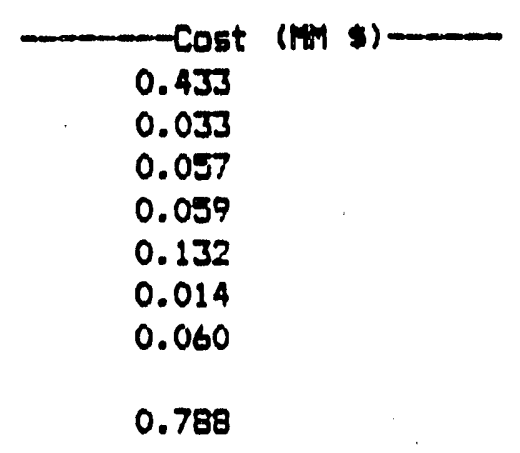

Installaticn Costs:

0.328

Total Instajled Equipment Cost

1.116

Engineering and tome Office Fees, Generad Facilities, 20\% contingency

0.402

Total Plant Cost

1.518

Royalties

0.003

Freprodurit:ar Costs and Inventory Capital

0.187

Initial Supplies and Materials

0.298

Total Capital Cost

1.957 
Operators/shift: I

Oparat ing Labor (a $\$ 21.55 /$ hour) $\quad 0.189$

Maintenance Factor: 0.04

Maintenance Labor Cost $\quad 0.017$

Overhead Labor cost $\quad 0.062$

Total Labor Cost $\quad 0.268$

Maintenance Supplies Cost $\quad 0.025$

Total Opisrating and Maintenance Cost 0.293

Fixed Opanating and Maintenance Cost 0.191

Variable Dperating and Maintenance Cost 0.102

Variable Operating Cost: \$/hour

Natural baE O $\$ 3.50 / 1000$ cu. ft. 11.59

Amonis $\quad 20.25 / 16 \quad 16.32$

Sorbent $\quad 8.40$ /ton

Catalyst a $12 \mathrm{yr}$ life) 25.62

Stean $\quad 05.64 / 1000$ ib 6.02

Electricity $O 0.05 / \mathrm{k}$ Wh 3.83

Dispazad 0 s.50/ton 1.14

Bag a (1 yr life) 4.47

$\begin{array}{ccc}\text { Total } & 77.39 & 0.441\end{array}$

Total Vo.'iable Dperating Costs (o 65\% ut1lization) 0.343

$\begin{array}{ll}\text { Cost of Capital (15\% per year) } & 0.301\end{array}$

Total Annuad Operating Cost $\quad 1.035$ 


\section{Conlfueled Diesel Fingine Enission Control Economics \\ Cost Sumary for DPTION L}

System: 4 Engines (2 6 Cylinder)

7.2 mower output

CAPITAL

Equipment:

Reburning Unit

Spray' Dryer

C.yelone

Baghouse

Induied Draft Fan

Differential Boiler Cost

Total Equipment

- Cost (m)

0.134

0.797

0.059

0.132

0.014

0.079

1.215

Installation Costs:

0.656

Total Installed Equipment Cost

1.871

Engineering and Howe Office Feas, General

Facillties. $20 x$ Contingency

0.674

Total Plant Cost

2.545

Preproduction Costs and Inventory Capital

Initial Gupplias and Materials

0.109

0.009

Total Capital Cost

2.662 


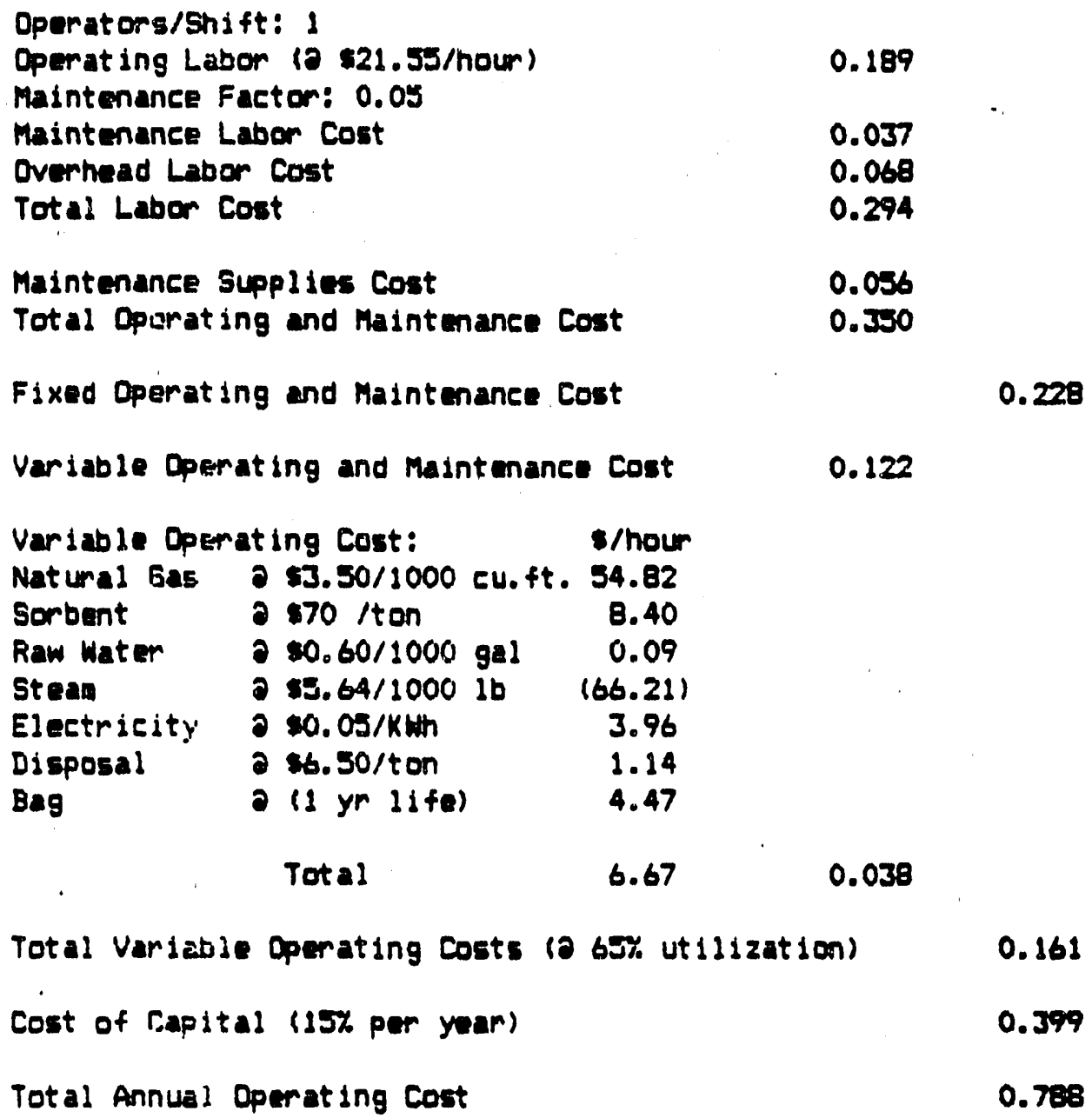




\title{
Coalfueled Diesel Fngine Emission Control Economies \\ Cost Simmary for DPTION M
}

\begin{abstract}
System: 4 Enginers (a 6 Cylinder)
7.2 mower output
\end{abstract}

\section{CAPITAL}

Equipment:

Takeda Process Unit

Cyclone

Baghouse

Induied Draft Fan

llifferential Boiler cost

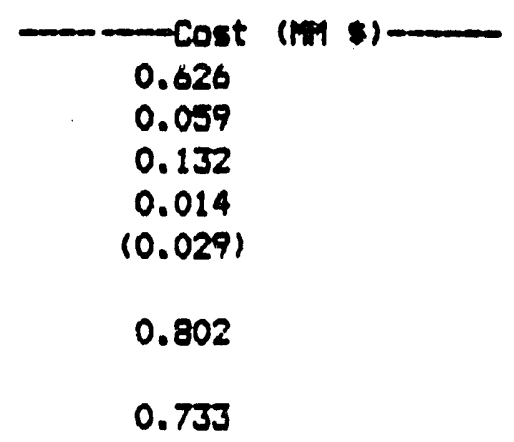

Installation Costs:

Total Equipment

1.535

Total Installed Equipment Cost

1.035

Engineer ing and Howe Office Fecs, General

Facilities. 20\% contingency

0.503

Total Plarit Cost

2.088

Royalties

0.008

Pieproduction Costs and Inventery Capital

0.230

Initial Guplies sid Materials

0.169

Total Capital Cost

2.494 


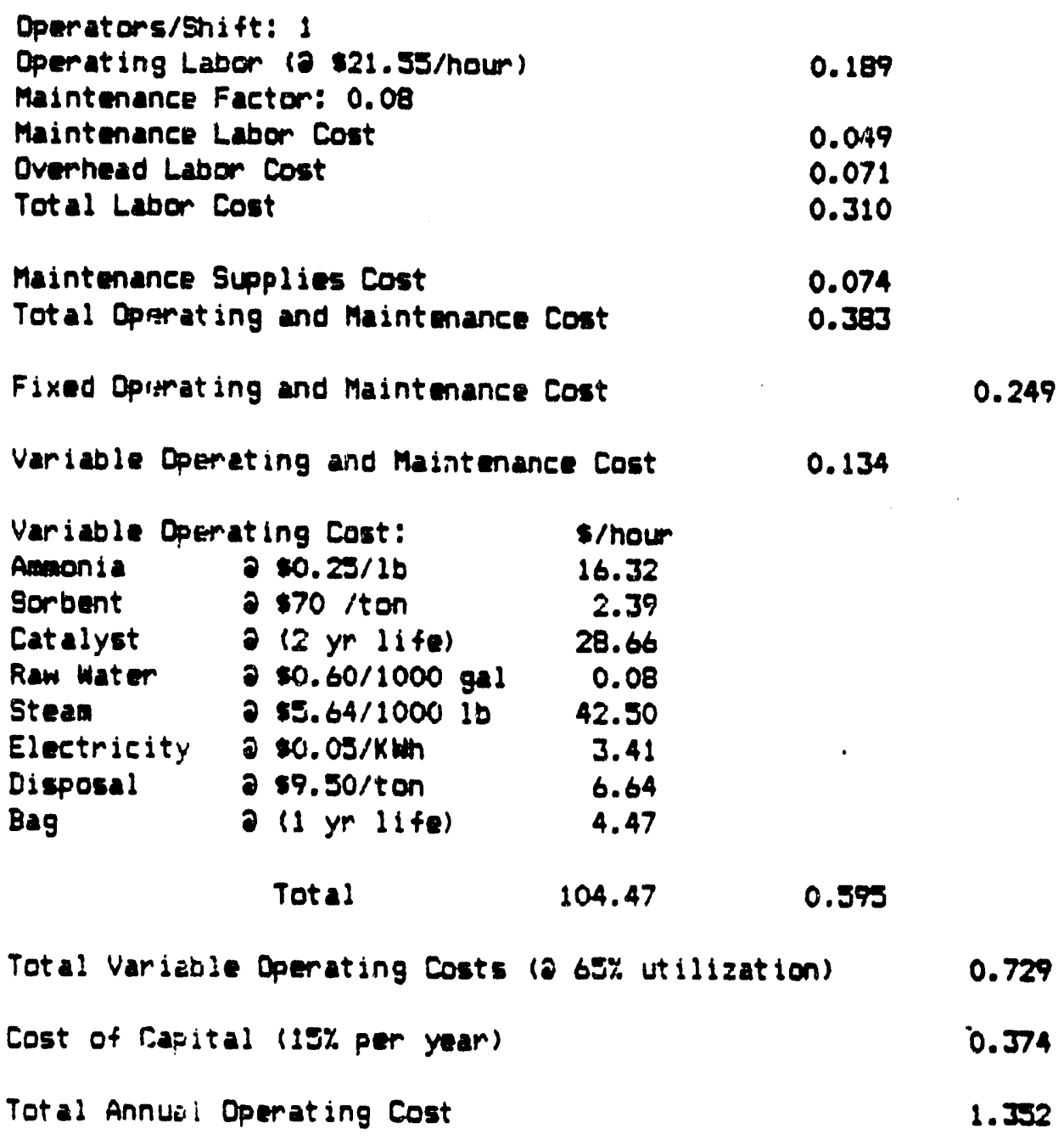




\section{Coal fueled Diesel Engine Enission Control Economics \\ Cost Simmary for OPTION N}

Systew: 4 Engines (a 6 Cylinder)

7.2 power output

\section{CAPITAL}

Equipaent:

Spray' Dryer

C.yelone

Baghouse (275 F)

Induied Draft Fan

lifierential Boiler Cost

Total Equipment

Instillation Costs:

Total Insta!led Equipment Cost

Engineering and Home Office Fecs, General

Facilities, $20 \%$ Continguncy

Total Plant cost

Preproduction Costs and Inventory Capital

Initial Jupplies and Materials

Total Capital Cost

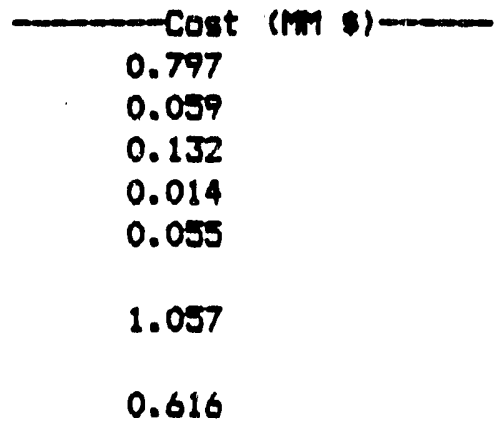

1.673

0.602

2.276

0.129

0.000 
Operators/Shift: 1

Operating Labor (a \$21.55/hour)

0.169

Maintenance Factor: 0.05

Maintenarice Labor Cost $\quad 0.033$

$\begin{array}{ll}\text { Overhasd Labar Cost } & 0.067\end{array}$

Total Labor Cost $\quad 0.289$

Maintenanee Supplies Cost $\quad 0.050$

Total Operating and Maintenance cost 0,339

$\begin{array}{ll}\text { Fixed Operating and Maintenance Cost } & 0.221\end{array}$

Variable Operating and Maintenance Cost 0.118

Variable Dperating Cost: s/hour

Sorbent $\quad 0 \$ 70 /$ ton $\quad 8.40$

Raw Water $0 \$ 0.60 / 1000 \mathrm{gal} 0.09$

Stear $25.64 / 1000$ ib 23.62

Electricity $20.05 / k 1$ th 3.91

Disposal a $50 /$ ton 2.00

Bag a (1 yr life) 4.47

$\begin{array}{lll}\text { Total } & 42.49 & 0.242\end{array}$

Tota! Variatle Operating Costs (0 65\% utilization) 0.361

Cosi of Capital (15\% por your) $\quad 0.361$

Total Annual Operating Cost $\quad 0.942$ 


\section{Coalfueled Diesel Fingine Emission Control Economics \\ Cost Sidmary for OPTION A}

System: 2 Engines (a 20 Cylindkr)

12 mive power output

CAPITAL

Equipient:

SCR Unit

Duct Burner

Spiay Dryer

Cyelone

Baghouse

Induied Draft Fan

Inifferential Boiler Cost

Total Equipment

Installation Costs:

Total Installed Equipment Cost

Engineering and How Office Faes, Beneral

Facilities: $20 z$ contingency

Total Plant Cost

Royalties

Preprodurition Costs and Inventopy Capital

Initial Supplies and Materials

Total Capital Cost

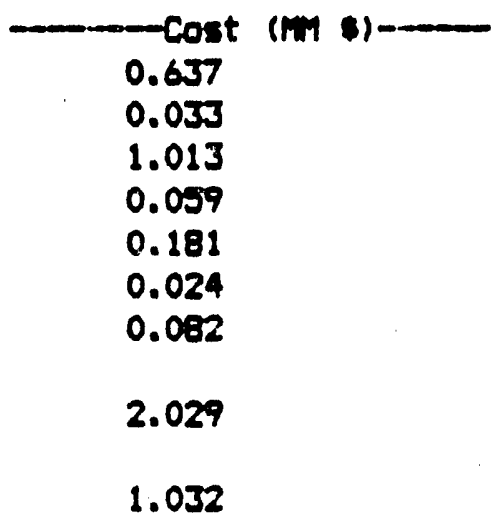

3.061

1.102

4.163

0.003

0.272

0.491

4.929 
Dperators/Shift: 1

Operating Labor (D $\$ 21.55 /$ hour)

0.189

Maintenance Factor: 0.05

Maintenance Labor Cost

0.060

Orerhead Labor Cost

0.075

Total Labor Cost

0.323

Maintenance Supplies Cost

0.091

Total Dpirating and Mainteriance Cost

0.414

Fixed Opizrating and Maintenance Cost

Variable Operating and Maintanance Cost

0.145

Variable Dperating Cost: s/hour

Naturad fas $283.50 / 1000 \mathrm{cu} . \mathrm{ft} .19 .32$

Amonia

a $10.25 / 16$

27.23

Sorbent

a $\$ 70 /$ ton

14.77

Catalyst

a (2 yr life)

D $\$ 0.60 / 1000 \mathrm{gal}$

42.71

Raw Water

D $\$ 5.64 / 1000$ it

0.14

Stean

a $10.05 / \mathrm{KWh}$

10.05

Electricity

- $6.50 /$ ton

3.71

Disposal

a (1 yr life)

2.23

Bag

Total

5.78

\section{Total}

105.84

0.603

Total Variable Operating Costs (2 65\% utidization)

Cost of rapital (15\% par year)

0.739

Total Annus! Operating Cost 


\section{Coal-Fuled Diesel Engine Emission Control Economics}

Cont Sumary for OPTION B

System: 2 Enginas (0 20 Cylinder)

12 power output

CAPITAL

Equipwent:

Robumning Unit

Low Temperat ure Lime injection

Cyclone

Baghouse

Induced Draft Fan

Difterential Boiler Cost

Total Equipment

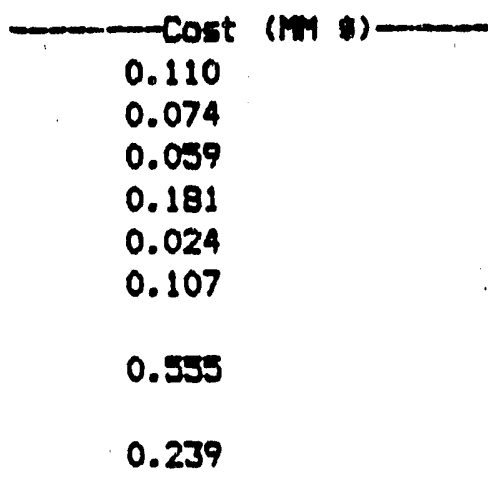

Installation Costs:

0.794

Total Installed Equipment Cost

Engineering and How Office Foss, Beneral

Facilities, $20 x$ Contingency

0.286

Total Plant cost

1.080

Preproduction: Costs and Inventory Capital

0.086

Initial Supplies and Materials

0.015

Total Capital Cost

1.180 
Operators/shift: 1

Operating Labor (0 $\$ 21.55$ /hour)

0.189

Maintenance Factor: 0.04

Maintenance Labor Cost

0.013

Overhead Lebor cost

0.061

Total Labor Cost

0.262

Maintemance Supplies Cost

0.019

Total Operating and Maintenance cost

0.281

Fixed Operating, and Maintenance Cost

0.183

Variable Operating and Maintenance Cost

0.098

Variable Operating Cost: shour

Natural Gas $\$ 3.50 / 1000$ cu.ft. 91.35

Sorbent $0 \$ 70 /$ ton 14.77

Stean $\$ 5.64 / 1000$ ib (110.36)

Electricity $0 \$ 0.05 / \mathrm{khH} \quad 5.58$

Disposal $06.50 /$ ton 2.23

Bag a (1 yr llfe) 5.78
Total
7.35
0.053

Total Varieble Operating Costs (0 $65 \%$ utiliza.ion)

0.152

Cost of Capital (15\% per year)

0.177

Total Annua: Operating Cost

0.512 


\section{Coal fualed Diesel Engine Emission Control Economies \\ Cost Simmary for DPTION C}

System: 2 Engines (a 20 Cylindre)

12 mive powar output

\section{CAPITAL}

Equipment:

Reburning Unit

liigli Temperature Lime injection C.yclone Baghouse

Induied Draft Fan

Iifferential Boiler Cost

Total Equipment

Installation Costs:

Total Installed Equipment Cost

Engineering and Howe Office Fecs, General

Facillties, 20z Contingency

Total Flant Cost

Preproduction Costs and Inventciry Capital

Initial Supplies and Materials

Total Capital Cost

- Cost (m $1-$
0.110
0.074
0.059
0.181
0.024
0.107
0.555
0.239

0.794

0.286

1.080

0.086

0.015 
Dperators/Shift: 1

Operat ing Labor (a $\$ 21.55$ /hour)

0.189

Maintenance Factor: 0.04

Maintenance Labor Cost

0.013

0.061

Overhead Labor Cost

0.262

Maintenance Supplies Cost

0.019

Total Opimat ing and Maintenance Cost

0.281

Fixed Oplarating and Maintenance Cost

0.183

Variable Operating and Maintenance Cost

0.098

Variable Derating Cost:

s/hour

Naturad fias a $\$ 3.50 / 1000$ cu.ft. 91.35

Sorbent

2 $\$ 70$ /ton

14.77

Stean

a $\$ 5.64 / 100016$

(110.36)

Electrieity

aso.05/kwh

3.58

2.5.50/ton

2.23

Bag

a (1 yr 1ite)

5.78

Total

9.35

0.053

Total Variable Operating Costs (a $65 \%$ utilization)

0.152

Cost of liapital (15\% per year)

0.177

Total Annuad Dperating Cost

0.512 


\section{Coalfueled Dimel Fingine Enission Control Economics \\ Cost Simmary for OPTION D}

System: 2 Engines (a 20 Cylindre)

12 The pown output

CAPITAL

Equipment:

Calciun Fuel Additive (Ca/s * 1$)$

Cyelone

liigh Temperature Lime Injection (Ca's $=1$ )

Sheil/UOP Unit with Oranular Bed Inviked Draft Fan

Differential Boiler Cost

Total Equipment

Installation Costs:

Total Installed Equipment Cost

Engineering and Howe Office Fecs, Generd: Facliltles, $20 \%$ Cont ingency

Total Flent Cost

Royalties.

Preproduction Costs and Inventcry Capital

Initial supplies and Matarials

Total Capital Cost

- Cost (m) 1$)-$
0.000
0.059
0.074
1.255
0.024
0.082
1.494
0.947

2.441

0.879

3.320

0.014

1.479

0.546

5.359 
Operators/Shift: 1

$\begin{array}{ll}\text { Operat ing Labor (o } \$ 21.55 \text { /hour) } & 0.189 \\ \text { Maintenance Factor: } 0.09 & \\ \text { Maintenance Labor Cost } & 0.089 \\ \text { Overhead Labor Cost } & 0.083 \\ \text { Total Labor Cost } & 0.360 \\ & \\ \text { Maintenance Supplies Cost } & 0.132 \\ \text { Total Opiarating and Maintenance Cost } & 0.492\end{array}$

Fixed Opreating and Maintenance Cost

0.320

Variable Operating and Maintenance Cost

0.172

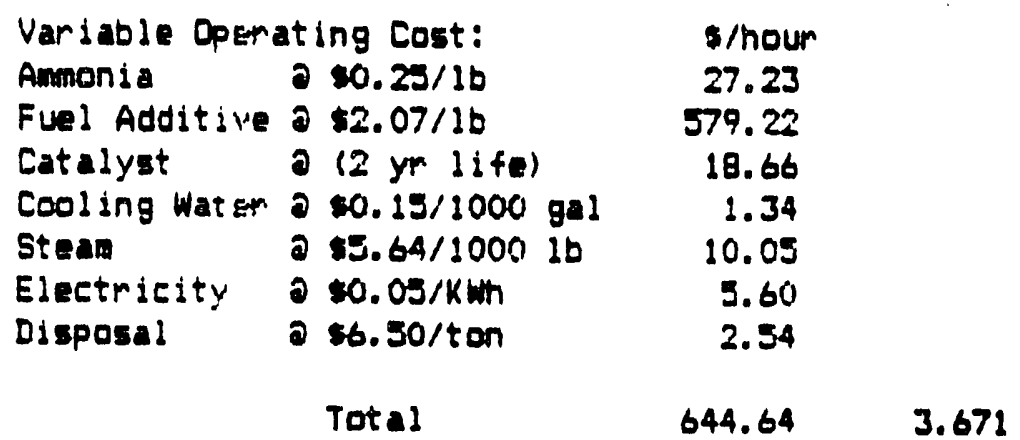

Total Variatle Operating Costs (0 65\% utilization)

Cost of lapital (15\% per year)

0.804

Total Annual Operating Cost

4.966 


\section{Coalfueled Diesel Engine Emission Control Economies}

Cost Summary for OPTION J

System: 2 Engines (a 20 Cylinder)

12 wive powar output

CAPITAL

Equipment:

High Tenperature Lime Injection

Duct Burner

Amonia Injection in Baghouse

(at $450 \mathrm{~F}$ )

Cyelone

Insulated Baghouse

Induced Draft Fan

Difterential Boiler" Cost

Total Equipaent

- Cost (m)
0.074
0.110
0.093
0.059
0.244
0.024
0.003
0.607

Installation Costs:

0.323

Total Installed Equipment Cost

0.730

Engineering and Howe Office Fees, General Facilities, $20 \%$ Contingancy

Total Plant Cost

ว. 335

1.265

Preproduction Costs and Inventory Capitad

0.266

Initial Stfplies and Materials

0.015

Total Capital Cost

1.546 
Dperators/shift: 1

Operat ing Labor (a $\$ 21.35 /$ hour) $\quad 0.189$

Maintenance Factor: 0.04

Maintenance Labor Cost

0.015

Overhead Labor Cost

0.061

Total Labor Cost

0.265

Maintenance Supplies Cost

0.022

Total Opiarating and Maintenance Cost

0.287

Fixed Oprarating and Maintenance Cost

0.187

Variable Operating and Maintanance Cost

0.100

Variable Operating Cost:

\$ /nour

Natural fias

a $\$ 3.50 / 1000 \mathrm{cu} . \mathrm{ft} .74 .10$

Ammonia

a $\$ 0.25 / 16$

27.23

Sorbent

a $\$ 70 /$ ton

14.77

Steara

a $\$ 5.64 / 1000$ 1b

(28.04)

Electrieity

a $\$ 0.03 / k$ th

5.58

Disposal

a $\$ 6.50 /$ ton

2.23

Bag

a (1 yr life)

5.78

Total

101.56

0.578

Total Variatie Operating Costs (0 65\% uti11zation)

0.678

Cost of rapital (15\% per year)

0.232

Totad Annuad Operating Cost

1.097 


\section{Coal fueled Diesel Fingine Enission Control Economics}

Cost Simmany for DPTION $K$

System: 2 Engines (a 20 Cylindre)

12 mise powar output

CAPITAL

Equiprent:

SCR unit

Duet Burner

Low Temperature Lime Injection

Cyclone

Baghouse

Iriduied Draft Fan

lifterential Bo iler Cost

Total Equipment

1.090

Installation Costr:

0.451

Total Installed Equipment Cost

1.541

Engineering and Howe Office Fecs, General Facilities, $20 \%$ Cont ingency

0.555

Total Plant Cost

2.096

Royalties

0.003

Preproduction Costs and Inventery Capital

0.276

Initial Jueplies and Materials

0.491

Total Capital Cost

2.866 


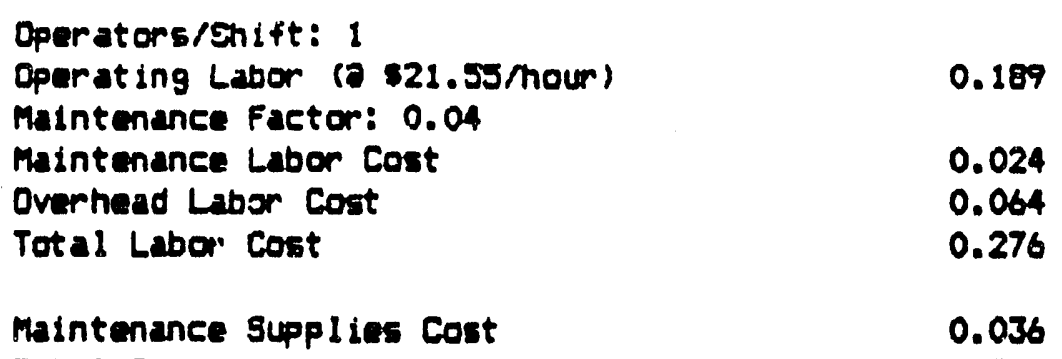




\section{Coal fuelad Diesel Engine Emission Control Economics}

Cost SImary for OPTION L

System: 2 Engines (2 20 Cylinder)

12 move power output

\section{CAPITAL}

Equipwent :

$$
\text { Reburning Unit }
$$

Spray Dryer

C.yelone

Baghouse

Induied Draft Fan

Differential Boiler cost

Total Equipment

$-\operatorname{Cost}(\mathrm{m})-$
0.110
1.013
0.059
0.181
0.025
0.107
1.494
0.820

Installation Costs:

Total Inst3! lod Equipment Cost

0.833

3.147

Preproduction Costs and Inventory Capital

0.137

Initial Supplies and Materials

0.015

Total Capital Cost 
Operators/sinjift: 1

Operating Labor (0 \$21.55/hour)

0.189

Maintenance Factor: 0.05

Maintenance Labor Cost

0.046

Overhead Labor Cost

0.071

Total Labor Cost

0.306

Madntenance Supplics Cost

0.069

Total Opereting and Maintenance Cost

0.375

Fixed Opreating and Maintmance Cost

0.244

Variable Depmating and Maintenanee Cost

0.131

Variable Demating Cost:

$\$$ /hour

Naturad fas

a \$3.50\%:.100 eu.ft. 91.35

Sorbent

- $\$ 70 /$ ton

14.77

Raw Water

a $10.60 / 1000$ gad

0.14

Stean

a \$5.64/1000 ib

(110.36)

Electricjty

a $\$ 0.05 / \mathrm{kwh}$

5.71

- $96.50 / t$ on

2.23

Bag

- (1 yp life)

5.78

Totel

9.62

0.055

Tota! Variable Operating Costs (a 65\% utilization)

0.186

Cost of rapital (15\% per year)

0.495

Total Annual Operating Cost

0.925 


\section{Cad-fueled Diesel Engine Enission Control Economies \\ Cost Sumary for OPTION M}

Systam: 2 Engines (a 20 Cylinder)

12 power output

CAPITAL

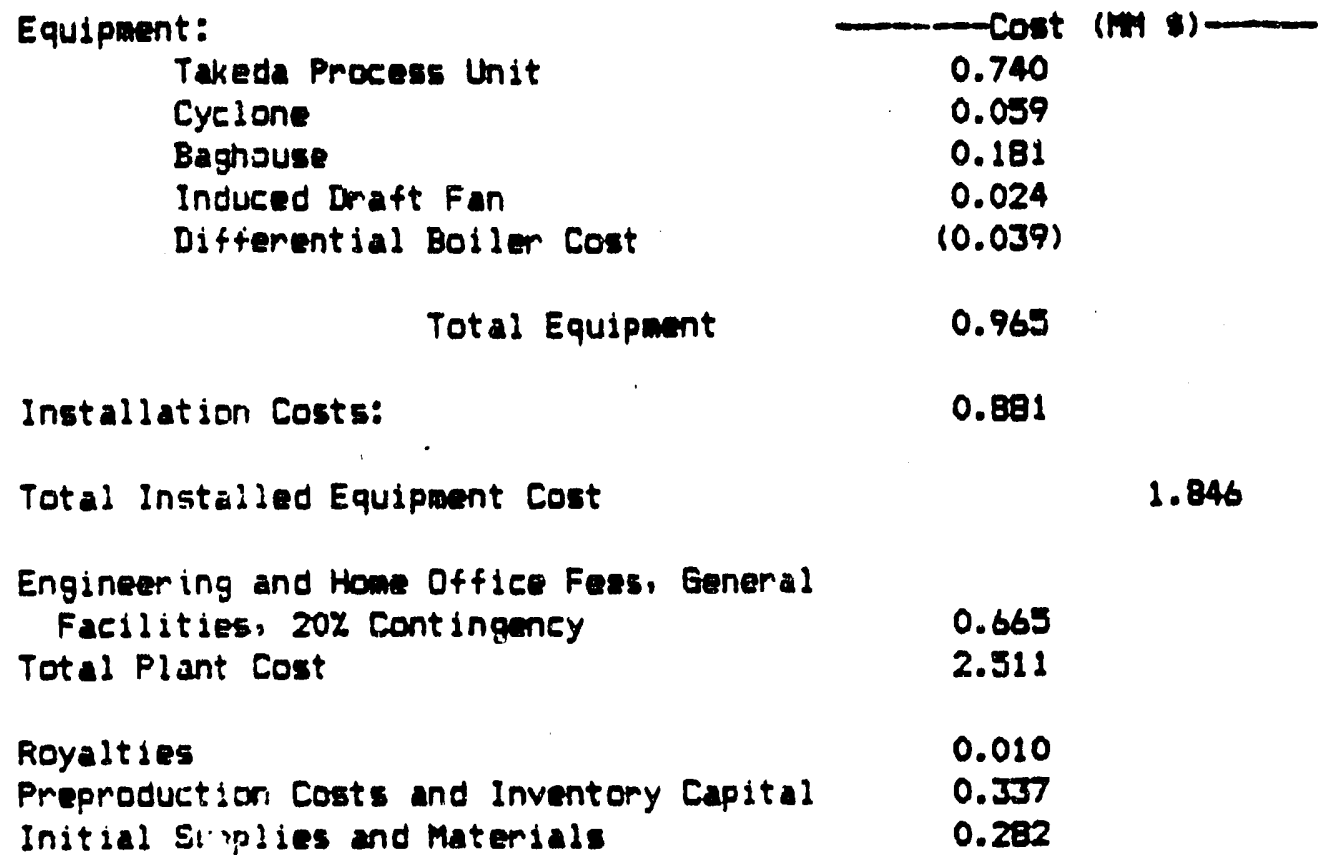

Total Capital Cost $\quad 3.140$ 
Operators/Shift: 1

Oparating Labor (0 $\$ 21.55$ /hour) $\quad 0.189$

Maintenance Factor: 0.08

Maintenance Labor Cost $\quad 0.059$

Overhead Labor Cost $\quad 0.074$

Total Labor Cost $\quad 0.322$

Maintenance Supplies Cost $\quad 0.089$

Total Operating and Maintenance Cost 0.411

$\begin{array}{ll}\text { Fixed Operating and Maintenance Cost } & 0.267\end{array}$

Variable Deperating and Maintenance Cost $\quad 0.144$

Variable Operating Cost: S/hour

Amsonia $280.23 / 16 \quad 273$

Sorbent $\quad 3 \$ 70 /$ ton 3.98

Catalyst a (2 yr life) 47.7

Raw Water $\$ \$ 0.60 / 1000 \mathrm{gal} 0.14$

Stean $\$ \$ 5.64 / 1000$ ib 70.88

Electricity $\$ 0.05 / \mathrm{kWh} \quad 5.43$

Disposal a s9.50/tor. 11.32

Bag $\quad(1 \mathrm{yr} 11 \mathrm{fe}) \quad 5.78$

$\begin{array}{lll}\text { Total } & 172.53 & 0.992\end{array}$

Total Variable Operating Cozts (0 65\% utilization) 1.126

$\begin{array}{ll}\text { Cost of Capital (15\% per year) } & 0.471\end{array}$

Total Annual Operating Cost 1.864 


\title{
Coalfueled Diesel Engine Emission Control Economics \\ Cost Sumary for OPTION $N$
}

\begin{abstract}
Systew: 2 Engines (O 20 Cylinder)
12 mive power output
\end{abstract}

CAPITAL

Equipment:

Spray Dryer

Cyelone

Baghouse (275 F)

Incueed Draft Fan

Difterential Boiler Cost

Total Equipment

Installation Costs:

Total Installed Equipment Cost

Engineering and Howe Office Fees, General

Fucilities, $20 z$ Contingency

Total Plasit Cost

Preproduct:ton Costs and Inventory Capital

Inttial Supplies and Materials

Total Capital Cost

- Cost (m) 1 (im 1.013
0.059
0.181
0.024
0.072
1.349
0.786

2.135

0.769

2.904

0.174

0.005

3.082 
Dperators/shift: 1

Operating Labor (0 $\$ 21.55$ /hour) 0.189

Maintenance Factor: 0.05

Maintenance Labor Cost

0.043

Overhead Labor cost

0.070

Total Labor Cost

0.301

Maintenance Supplies Cost

0.064

Total Dpizating and Maintenance cost

0.365

Fixed Oprating and Maintenance Cost

Varzaole operaring ang maineenance cost

0.220

Variable Dperating Cost:

\$ /hour

Sorbent

a $\$ 70 / \tan$

14.77

Raw Water

2 $\$ 0.60 / 1000 \mathrm{gal}$

0.14

Steam

จ $\$ 5.64 / 1000$ 10

39.40

Eleetrieity

a $\$ 0.05 / k$ wh

5.66

Disposal

2 $\$ 20 /$ ton

3.67

Bag

a (1 yr life)

5.78

Total

64.42

0.375

Total Variable Operating Costs (a c5\% utilization)

0.523

Cost of C.apital (15\% per year)

0.462

Total Annual Operating Cost 


\section{Coal-fueled Diesel Engine Emission Control Economics \\ Cost Summary for oPTION A}

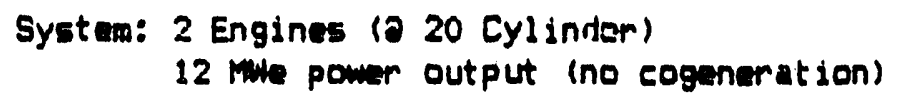

System: 2 Engines (a 20 Cylinder)

12 power output (no cogeneration)

\section{CAPITAL}

Equipaent:

SCR Unit

Duet Burner

Spray Dryer

Cycione

Baghouse

Indueed Draft Fan

Gas Cooler

Total Equipment

Instadlation Costs:

Total Installed Equipment Cost

Engineering and Home Office Fees, General

Facilities, $20 \%$ Contingericy

Total Plant Cost

Royalties

Preproduition Costs and Inventory Capitad

Initial Supplies and Materials

Total Capital Cost

- Cost (m) $\$-$
0.637
0.033
1.013
0.059
0.181
0.024
0.104
2.051

3.123

1.124

4.247

0.003

0.312

0.491

5.053 


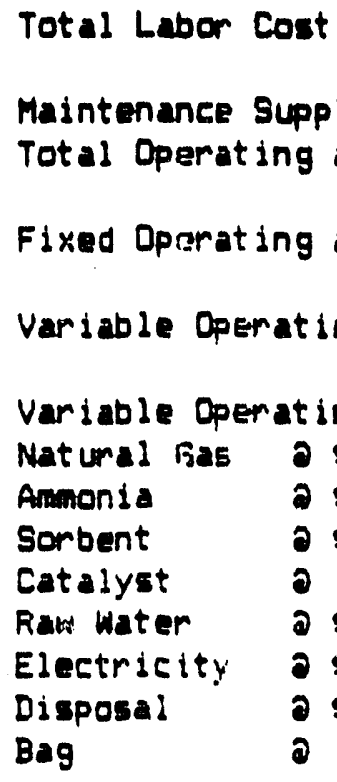

0.062

0.075

0.326

0.072

0.418

0.272

0.146 
Cost Summary for OPTION B

System: 2 Enginas (a 20 (y)inder)

12 power output (no cogeneration)

\section{CAPITAL}

Equipment:

Rebuming Unit

Low Temperat ure Lime Injection

Cyclone

Daghouse

Induced Draft Fan

fas Cooler

\section{Total Equipment}

Instadlation costs:

Total Installed Equipment Cost

Engineering and How Office Foes, General Facililies, 20x cont ingency

Total Plant Cost

Preproduition Costs and Inventory Capital

Initial siupplies and Materials

Total Capital Cost

$-\operatorname{cost}(\min )-$
0.110
0.074
0.059
0.181
0.024
0.115
0.563
0.283

0.846

0.305

1.151

0.170

0.015 
Operators/5hift: 1

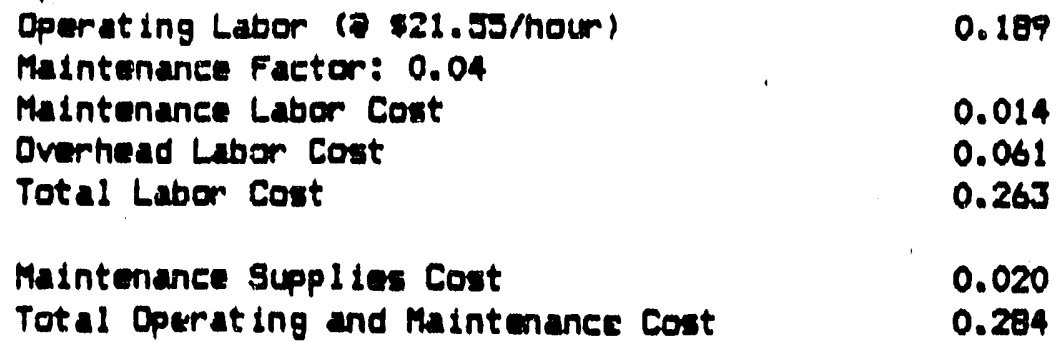

Fixed Operating and Maintenance Cost

0.184

Variable Dperating and Maintenance Cost 0.100

Variable oparating Cost: \$/hour

Natural Gas $\$ \$ 3.50 / 1000$ cu.ft. 91.35

Sombent $\$ 70 /$ ton 14.77

Raw Water $\quad 30.60 / 1000 \mathrm{gal} 3.46$

Electriejty $00.05 / k$ m 5.69

Disposal $26.50 /$ ton 2.23

$\begin{array}{lll}\text { Total } & 123.28 & 0.702\end{array}$

Total Variable Dperating Costs (a $65 \%$ utilization) 0.801

$\begin{array}{ll}\text { Cost of Capital (15\% per yar) } & 0.200\end{array}$

Total Annual Operating Cost $\quad 1.186$ 


\section{Coal funlad Diesel Fingine Enission Control Econnmics \\ COst Simanary for DPTION C}

System: 2 Engines (a 20 Cylinder)

12 mine power output (no cogenaration)

CAPITAL

Equipwent:

Reburning Untt High Temperature Lime Injection Cyelone Baghouse Indured Draft fan Gas Cooler

Total Equipwent

Installation Costs:

Total Installed Equipment Cost

Engineering and Howe Office Facs, General Facilities, $20 \%$ Cont ingency

Totad Plant Cost

Preproduction Costs and Inventory Capital Indtial supplies and Materials

Total Capital Cost

\begin{tabular}{l}
- Cost (m) \\
\hline 0.110 \\
0.074 \\
0.059 \\
0.181 \\
0.024 \\
0.115 \\
0.563 \\
0.283
\end{tabular}

0.846

0.305

1.251

0.170

0.015

1.335 
Operators/Shift: 1

Dperat ing Labor (a $\$ 21.55 /$ hour) $\quad 0.189$

Maintenance Facton: 0.04

itaintenance Labor Cost

0.014

Overhead Labor Cost

0.061

Total Labor Cost

0.263

Maintenance Supplies Cost

0.020

Total Dporating and Maintenance Cost

0.284

Fixed Opgrating and Maintenance Cost

0.184

Variable Opemating and Mainitanance Cost

0.100

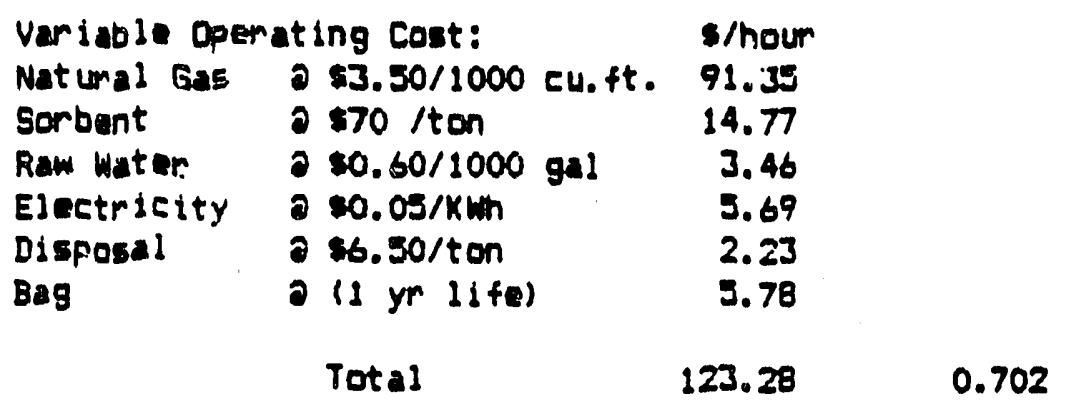

Total Variatile Operating Costs (a 65\% ut 111zation) 0.001

Cost of lapital (15\% per yar) $\quad 0.200$

Totad Annua! Operating Cost $\quad 1.186$ 


\section{Coalfueled Diesel Engine Emission Control Economies}

Cost Stmary for OPTION D

Syst can: 2 Engines (a 20 Cylinclar)

12 power output (no cogmerstion)

CAPITAL

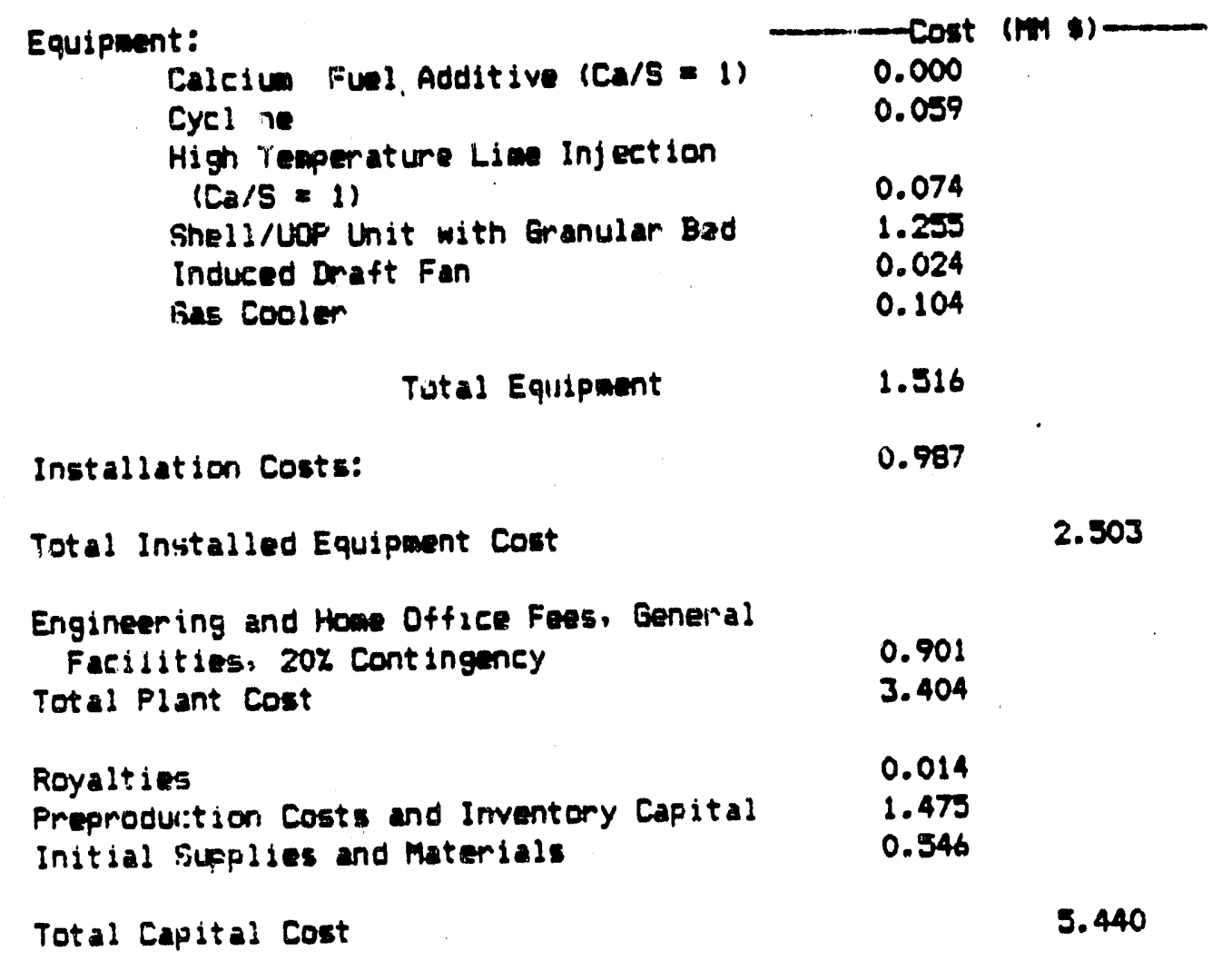


Operators/Shift: 1

Operating Labor (o $\$ 21.55 /$ hour)

0.189

Maintenance Factor: 0.09

Maintenance Labor Cost

0.090

Overhead Labor Cost

0.084

Total Labor Cost

0.363

Maintenance Supplies Cost

0.135

Total Opizrating and Maintenance Cost

0.498

Fixed Operating and Maintmance Cost

0.324

Variable Dperating and Maintenance Cost

0.174

Variable Dperating Cost:

Ammonia O $\$ 0.25 / 16$

s/hour

Fuel Additive O \$2.07/10

27.23

Catalyst

a $(2 \mathrm{ym}$ life)

Raw Water

a $\$ 0.60 / 1000 \mathrm{gal}$

Cooling water a $\$ 0.15 / 1000$ gal

Electricity

a $80.05 / \mathrm{kith}$

Disposal

$28.50 /$ ton

579.22

18.66

1.76

1.34

3.71

2.54

Tot al

636.46

3.624

Total Variable operating costs (a $55 \%$ utilization)

3.798

Cost of Capital (15\% per year)

0.816

Totad Annual Dperating Cost

4.938 
Coal-Fusled Diesei Engine Emission Control Economics

Cost Sumary for ofTIon J

System: 2 Engines (O 20 Cylindar)

12 mis power output (no cogeneration)

CAPITAL

Equipment:

High Temperature Lime Injection

Duct Burnem

Amponia Injection in Baghouse

(at $450 \mathrm{~F}$ )

Cyclone

Insulated Baghouse

induced Draft Fon

fias Cooler

- Cost $(1)=$
0.074
0.110
0.093
0.059
0.244
0.024
0.112
0.716
0.366

Installation Costs:

Total Equipmant

1.082

Total In:italing Equipment Cost

Engineering and Howe Office Fees, General

Facilities, $20 \%$ Contingency

Total Plant cost

0.390

1.472

Preproduction Costs and Inventory Capital

0.283

Initial Stap!ies and Materials

0.015

Total bapta: Cost

1.772 
OPERATING COSTS

Operators/stift: 1

$\begin{array}{ll}\text { Operating Labor 10 } 121.55 \text { /hour) } & 0.189 \\ \text { Maintenance Factor: } 0.04 & \\ \text { Maintenance Labor Cost } & 0.017 \\ \text { Overhead Labor Cost } & 0.062 \\ \text { Total Labor Cost } & 0.268 \\ \text { Maintenance Supplies Cost } & 0.026 \\ \text { Total Opisat ing and Maintenance Cost } & 0.294\end{array}$

Fixed Operating and Maintenance cost

0.191

Variable Operating and Maintenance Cost

0.103

Variable Operating Cost: s/hour

Natural bas O \$3.50/1000 cu.ft. 74.10

Anionia $20.25 / 10 \quad 27.23$

Sorbent 0 \$70 /ton 14.77

Raw Water $0.60 / 1000 \mathrm{gal} 2.45$

Electricity O $0.03 / \mathrm{Km} \quad 3.69$

Disposal a $3.50 /$ ton 2.23

Bag o ld yr lifel 5.78

$\begin{array}{lll}\text { Total } \quad 132.25 & 0.753\end{array}$

Total Variatile Operating Costs (0 65\% ut1lization) $\quad 0.656$

Cost of Capital (15\% per year) 0.266

Total Annuad Operating Cost $\quad 1.313$ 


\section{Cad-Fueled Diesel Engine Enission Control Economies \\ Cost Summary for OPTION $K$}

System: 2 Engines (a 20 Cylinder)

12 we powar output (no cogenaration)

CAPITAL

Equipment:

SCR Unit

Duct Burnar

L.ow Temperature Lime Injection

Cycjone

Eaghouse

Induced Draft Fan

bas Cooler

Total Equipment

Installation Costs:

Total Installed Equipment Cost

Engineering and Howe Offlce Fors, General Facidities, 20\% Continguncy

Total Flant Cost

Royalt i R:

Preproduition Costs and Inventory Capital Initial supplies and Materials

Total Capital Cost

\begin{tabular}{l}
- Cost (m) \\
\hline 0.637 \\
0.033 \\
0.074 \\
0.059 \\
0.181 \\
0.024 \\
0.104 \\
1.112 \\
0.491
\end{tabular}

1.603

0.577

2.180

0.003

0.273

0.491 
Operators/sndft: 1

Dperat ing Labor 10821 . S5 Molitin?

0.189

Maintenanee Factor: 0.4

Midintenance Labor Cove

Ovarhead Labor Cost

0.025

0.064

Total Labor Cost

0.278

Maintenance Supplies Cost

0.037

Total Opresating and Maintenance Cost

0.315

Fixed Oprarating and Maintenance Cost

0.205

Variable Openating and Maintmanea Cost

0.110

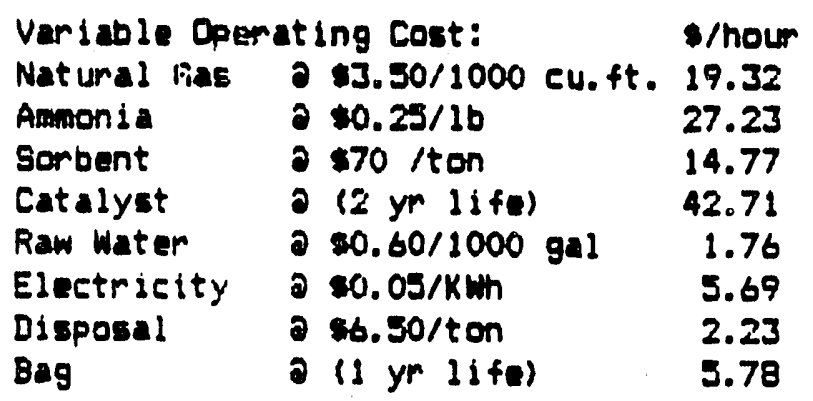
Total
119.49
0.680

Total Varizule Operating Cests (a 65\% utilization)

0.790

Cost of Capital (15\% per year)

0.442

Total Annuad Operating Cost

1.437 


\section{Coal-Fueled Diesel Engine Emission Control Economics \\ Cost Summary for OPTION L}

System: 2 Engines (a 20 Cylinidsr)
12 me power output (no cogeneration)

CAPITAL

Equipment:

Reburning Unit

Spray Dryer

Cyclone

Baghouse

Indueed Draft Fan

Fas Cooler

- Cost (m s)

0.110

1.013

0.059

0.181

0.025

0.115

Total Equipaent

1.502

Installation Costs:

0.864

Tutal Initialled Equipment cost

2.366

Engineering and Howe Office Fess, General Facilities, $20 \%$ Contingency 0.852

Total Plant cost

3.218

Preproduction Costs and Inventory Capital

Initial Sufplies and Materials

0.221

0.015

Tota! Capital Cost

3.453 


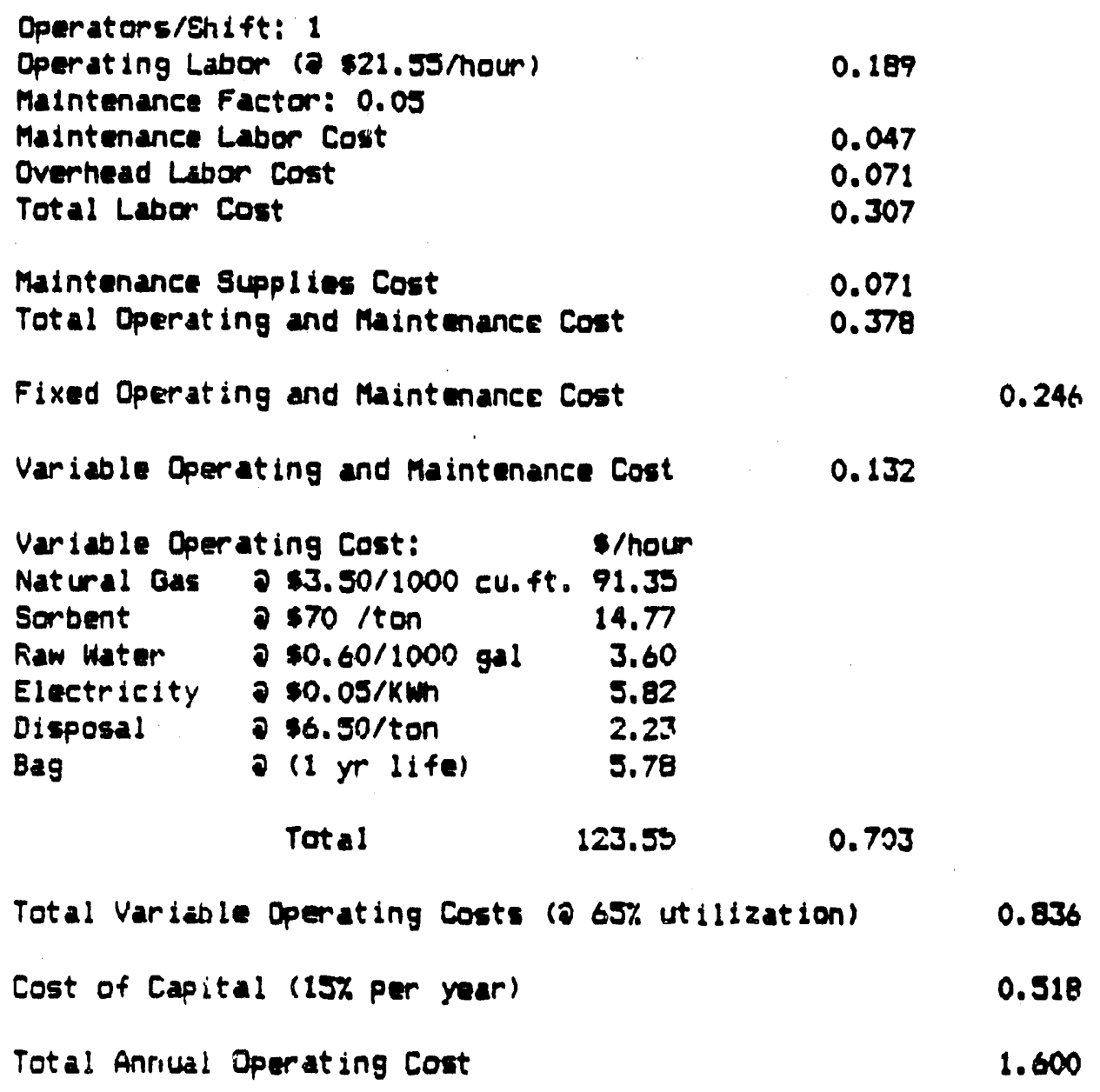




\section{Coal fueled Dirsel F.ngine Emission Control Economics \\ Cost Simmary for DPTION $m$}

System: 2 Engines (a 20 Cylindk $r$ )

12 Whe power output (nu cogeneration)

\section{CAPITAL}

Equipment:

Talieda Process Unit

Cyelone

Baghouse

Induced Draft Fan

Cias Cooler

- Cost (14)
0.740
0.059
0.181
0.024
0.102
1.106
0.920


0.729
2.755
0.010
0.293
0.282

Total Capital Cost 
Operators/5nift: 1

$\begin{array}{ll}\text { Operat ing Labor (o } \$ 21.55 \text { /hour) } & 0.189 \\ \text { Malntenance Factor: } 0.08 & \\ \text { Maintenance Labor Cost } & 0.065 \\ \text { Overhead Labor Cost } & 0.076 \\ \text { Total Labor Cost } & 0.330 \\ \text { Maintenance Supplies Cost } & 0.097 \\ \text { Total Opurat ing and Maintenance Cost } & 0.427\end{array}$

Fixed Opsating and Maintenance Cost

0.278

Variable Operating and Maintenance cost

0.149

Variable Oper
Ammonia
Sorbant
Catalyst
Raw Water
Electrieity
Disposal
Bag

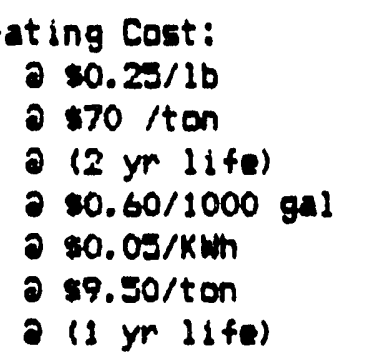

Total
$\$$ /hour

27.23

3.98

47.77

1.04

5.54

11.32

5.78

0.427

$$
102.66 \quad 0.585
$$

Total Variable Operating Costs (a 65\% utjlization)

0.734

Cost of liapital (15\% per year)

0.501

Total Annuad Operating Cost

1.513 


\section{Coal fueled Diesel Fingine Emission Control Economics}

Cost Simmary for OPTION $N$

System: 2 Engines (a 20 Cylindkr)

12 me power output (no cogeneration)

\section{CAPITAL}

Equipment:

Sppray Dryer

Cyelone

Eaghouse $(275 \mathrm{~F})$

Induied Draft Fan

Gas Cooler

- Cost (nr 1$)$
1.013
0.059
0.181
0.024
0.102
1.379
0.825

Installation costs:

2.204

Total Installed Equipment Cost

0.793

2.997

Facillties, 20
rotal Plant \&o.

0.149

Preproduction Costs and Inventory Capital

0.005

Initial supplies and Materials

3.151

Total Capital Cost 
Operators/shift: 1

Operating Labor (a $\$ 21.55 /$ houm) $\quad 0.189$

Maintenance Factor: 0.05

Maintenance Labon Cost $\quad 0.044$

Overhead Labor Cost $\quad 0.070$

Total Labor Cost $\quad 0.303$

Maintenance Supplies Cost $\quad 0.066$

Total Oparating and Maintenance Cost $\quad 0.369$

Fixed Dpiarating and Maintenance Cost $\quad 0.240$

Variable Dperating and Maintenance Cost $\quad 0.129$

Variable Operating Cost: s/nour

Sorbent $280 /$ ton 14.77

Raw Water a $80.60 / 1000 \mathrm{gal} 1.08$

Electrielty $0.05 / \mathrm{kWh} \quad \mathbf{5 . 7 7}$

Disposal a s20/ton 3.67

Bag a (1 yr life) 5.78

$\begin{array}{lll}\text { Total } & 31.07 & 0.177\end{array}$

Total Variable Operating Costs (0 65\% utilization) 0.306

Cost of Capital (15\% per year) $\quad 0.473$

$\begin{array}{ll}\text { Total Annuad Operating Cost } & 1.019\end{array}$ 


\section{Coal-funled Diesel Engine Emission Control Economies}

Cost Sumary for OPTION A

Syst em: 4 Engines (a 20 Cylinder)

24 poump output

\section{CAPITAL}

Equipiant:

SCR Unit

Duct Burnar

Spray Dryer

Cyclone

Baghouse

Incueed Draft Fan

Differential Boiler Cost

\section{Totad Equipwent}

3.161

Installation Costs:

1.608

Total Installed Equipment cost

4.769

Engineering and Home Office Fees, General Facilities, 20\% Contingeney

Total Plant Cost

6.486

Royalties

0.007

Preproduition Costs and Inventory Capital

0.576

Initiad Sufplies and Materials

0.983

Totad Capital Cost

8.052 
Dperators/Stift: 1

Operating Labor (O $\$ 21.55 /$ hour) $\quad 0.189$

Maintenance Factor: 0.03

Maintenance Labom Cost $\quad 0.094$

Overhand Labor Cost $\quad 0.085$

Total Labor Cost $\quad 0.368$

Maintenance Supplies Cost $\quad 0.141$

Total Operating and Milintenanee Cost $\quad 0.509$

Fixed Operating and Maintenance Cost 0.331

Variable Opemating and Maintenance Cost $\quad 0.178$

Variable Operating Cost: s/hour

Natural bas $\$ 3.50 / 1000$ cu.ft. 38.64

Amonia $00.23 / 16 \quad 54.45$

Sorbent $2870 /$ ton 29.38

Catalyst $\quad 2(2 \mathrm{ym} 11 \mathrm{fe}) \quad 85.41$

Raw Water $\partial 0.60 / 1000 \mathrm{gal} 0.29$

Stean 20.10

Electrietty $20.05 / \mathrm{K}$ (10.24

Disposal a $8.30 /$ ton 4.47

Bag a (1 yr $11+a) \quad 11.56$

Total $254.74 \quad 1.450$

Total Variable Operating Costs (0 65\% utilization) 1.620

$\begin{array}{ll}\text { Cost of Capital (15\% per year) } & 1.208\end{array}$

$\begin{array}{ll}\text { Total Annued Operating Cost } & \mathbf{3 . 1 6 7}\end{array}$ 


\section{Coalfusled Diesel Engine Enission Control Economics}

Cost Simany for DPTION B

System: 4 Engines (a 20 Cylindtr)

24 pomer output

CAPITAL

Equipment:

Reourning Unit

Low Temperature Lime Inijection

Cyelone

Baghause

Indwied Draft Fan

lifferential Boiler Cost

Total Equipmenit

- Cost $(\mathrm{m})-$
0.220
0.107
0.119
0.363
0.043
0.162
1.014
0.461

Installation Costs:

1.475

Total Inelalled Equipment Cost

0.531

2.006

Preproduction Costs and Inventery Capital

0.140

Initial sufplies and Materials

0.030

Total Capital Cost

2.176 
Dperators/Shift: 1

Operating Labor (a $\$ 21.55$ /hour) $\quad 0.189$

Maintenance Factor: 0.04

Maintmence Labor Cost $\quad 0.024$

Overhead Labor Cost $\quad 0.064$

Total Labor Cost $\quad 0.277$

Maintenance Supplies Cost 0.035

Total Dperating and Maintmance Cost $\quad 0.312$

$\begin{array}{ll}\text { Fixed Opurating and Maintenance Cost } & 0.203\end{array}$

Variable Operating and Maintenance Cost 0.109

Variable Operating Cost: S/mour

Natumal fas $2 \$ 3.50 / 1000$ cu.ft. 182.70

Sorbent $2970 /$ ton 29.58

Steam a $\$ 5.64 / 1000$ ib (220.73)

Electricity $050.05 / \mathrm{k}$ th 11.11

Disposal a se.50/ton 4.47

Bag a (1 ym life). 11.56

$\begin{array}{lll}\text { Total } & 18.69 & 0.106\end{array}$

Total Variande Opera.ing Costs (0 65\% utilization) 0.215

Cost of Capital (15\% per year) 0.326

Total Annus: Operating Cost $\quad 0.744$ 
Coal-fueled Diesel Engine Enission Control Economies

Cost Summary for OPTION C

System: 4 Engines (a 20 Cylinntar)

24 me power output

Equiprent:

Robuming Unit

High Temperature Lime Injection

Cyclone

Baghouse

Indueed Draft Fan

Difterential Boiler Cost

Total Equipment

Installation Costs:

Total Installed Equipwent Cost

Engineering and Home Office Feas, General Facilities, $20 \%$ Contingency

Tolad Plant Cost

Preprodurtion Costs and Inventory Capital Initial Supplies and Materials

Total Capital Cost

- Cost $(m)-$
0.220
0.107
0.119
0.363
0.043
0.162
1.014
0.461



0.531
2.006
0.140
0.030

2.176 
Oparators/Shift: 1

Oparating Libor (5 $\$ 21.55$ /hour) $\quad 0.189$

Maintenance Factor: 0.04

Maintenance Labor Cost $\quad 0.024$

Overhead Labor Cost $\quad 0.064$

Total Labor Cost $\quad 0.277$

Maintenance Supplies Cost 0.035

Total Operating and Maintenance Cost 0.312

Fixed Operating and Maintenance Cost 0.203

Variable Operating and Maintenence Cost 0.109

Variable Operating Cost: \$/hour

Natural Gas a \$3.50/1000 eu.ft. 182.70

Sorbent 29.58

Stean $\$ \$ 5.64 / 1000$ ib (220.73)

Electricity $0 \$ 0.05 / k$ ht 11.11

Disposal $\$ 6.50 /$ ton 4.47

Bag a (1 yr life) 11.56

$\begin{array}{lll}\text { Total } & 18.69 & 0.106\end{array}$

Total Variable Operating Cocts (a 65\% utilization) 0.215

$\begin{array}{ll}\text { Cost of liapital (15\% por year) } & 0.326\end{array}$

Total Annua: Operating Cost $\quad 0.744$ 


\section{Coalfueled Diesel Engine Enission Control Economics}

Cost Stmmary for OPTION D

System: 4 Engines (o 20 Cylindar)

24 mive power output

CAPITAL

Equipient:

Calcium Flal Additive (Ca/S = 1)

$-\frac{\operatorname{cost}(\min )}{0.000}$

Syclone

0.119

High Temperature Liwe Injection $(\mathrm{Ca} / \mathrm{S}=1)$

0.107

She 1: /UOP Unit with Eranular Bed

2.447

Induced Draft Fan

0.043

Differential Boiler Cost

0.123

Totad Equipment

2.841

Installation Costs:

1.836

Total Instad led Equipment Cost

4.677

Engineering and Howe Office Fees, General Facilities, $20 \%$ Contingency

1.684

Total Plant Cost

6.361

Royalties

0.023

Preproduction Costs and Inventory Capital

2.821

Initial supplies and Materials

1.091

Total Capital Cost

10.301 
Operators/Stift: 1

Operating Labor (a $\$ 21.55 /$ houm ) $\quad 0.189$

Maintanance Factom: 0.09

Maintenance Labor Cost

0.089

Overhead Labor Cost

0.083

Total Labor Cost

0.361

Maintenance Supplies Cost

0.134

Total Dperating and Maintenance Cost

0.495

Fixed Dpisating and Maintenance Cost

0.322

Variable Dperating and Maintenance Cost

0.173

Variable Dperating Cost:

$\$$ /hour

Ammonia

a $\$ 0.25 / 10$

34.45

Fuel Additive \$2.07/10

1159.44

Catalyst

a $(2$ yr $1 i f e)$

37.32

Cooling Water a \$0.15/1000 gal

Steam

2\$5.64/1000 ib

2.69

Electrieity

a $\$ 0.05 / k$ Wh

20.10

Disposal

a \$6.50/ton

11.20

5.09

Total

1290.29

7.347

Total Varjable Operating Costs (O 65\% utilization)

7.52 .0

Cost of Capital (15\% por year)

1.545

Total Annua: Operating Cost 


\section{Coal-fusled Diesel Engine Emission Contral Economics \\ Cost Simmary for OPTION J}

\section{System: 4 Engines (D 20 Cylindar)}

24 mive power output

CAPITAL

Equipenent:

High Teaperature Lisae Injection

Duct Burner

Ammonia Injection in Baghouse

(at $450 \mathrm{~F}$ )

Cyejone

Insulated Baghouse

Incueed Draft Fan

Differential Boiler Cost

Total Equipment

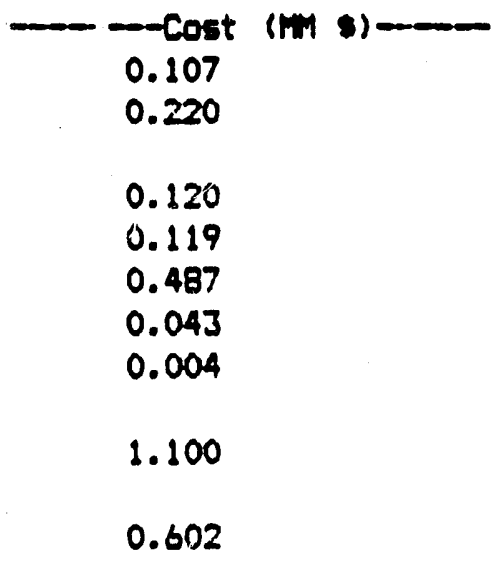

1.702

0.613

2.315

0.508

0.030

Initial supplies and Materials

2.853 


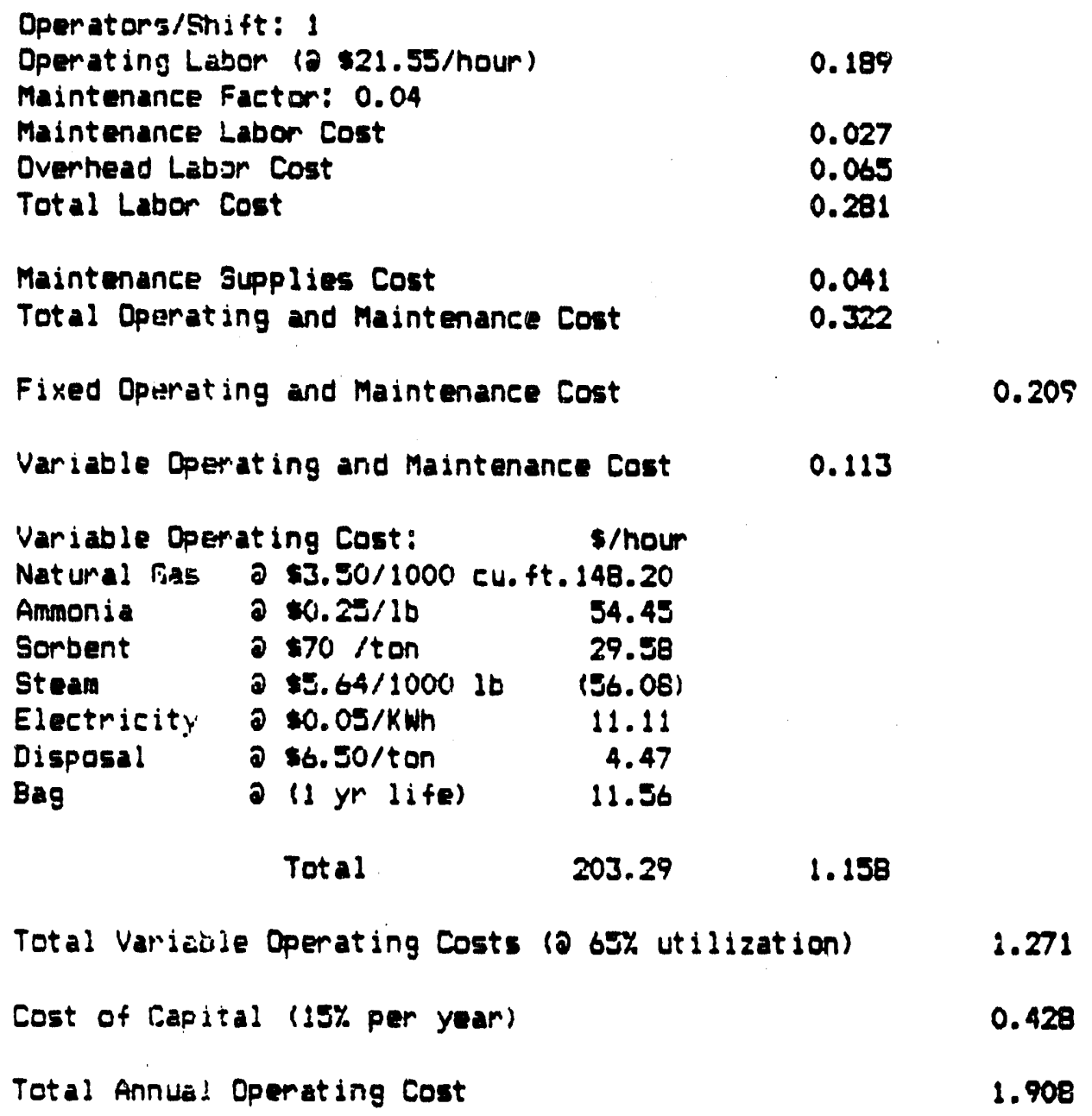




\section{Coal Fueled Diesel Engine Enission Control Economies \\ Cost Sumary for OPTION $k$}

System: 4 Engines (a 20 Cylindar)

24 mive powar output

\section{CAPITAL}

Equiprent:

SCR Unit

Duet Burner

I.ow Temperature Lime Injection

liyclone

Eaghouse

Induced Draft Fan

Differential Boiler Cost

Total Equipment

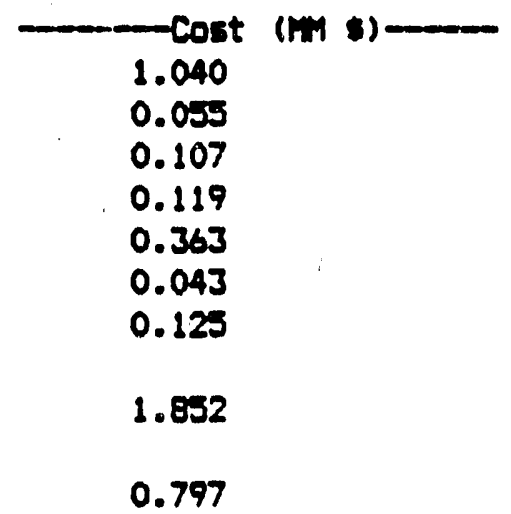

Instaldation Costs:

2.649

Total In:itilled Equipment Cost

Engineering and Howe Office Fees, General

Facilities: $20 z$ Continganey

0.954

Total Plant Cost

3.603

Royalties

0.007

Preprodurtion Costs and Inventory Capital

0.321

Initial Supplies and Materials

0.993

Total [apita] Cost

5.114 
Dperators/shift: 1

$\begin{array}{ll}\text { Operat ing Labor (a } \$ 21.55 / \text { hour) } & 0.189 \\ \text { Maintenance Factom: } 0.04 & \\ \text { Maintenance Labor Cost } & 0.041 \\ \text { Overhead Labor Cost } & 0.069 \\ \text { Total Labor Cost } & 0.299 \\ & \\ \text { Maintenance Suppiles Cost } & 0.062 \\ \text { Total Operat ing and Maintenance Cost } & 0.361\end{array}$

Fixed Opurating and Maintenance Cost

Variable Operating and Maintenance Cost 0.126

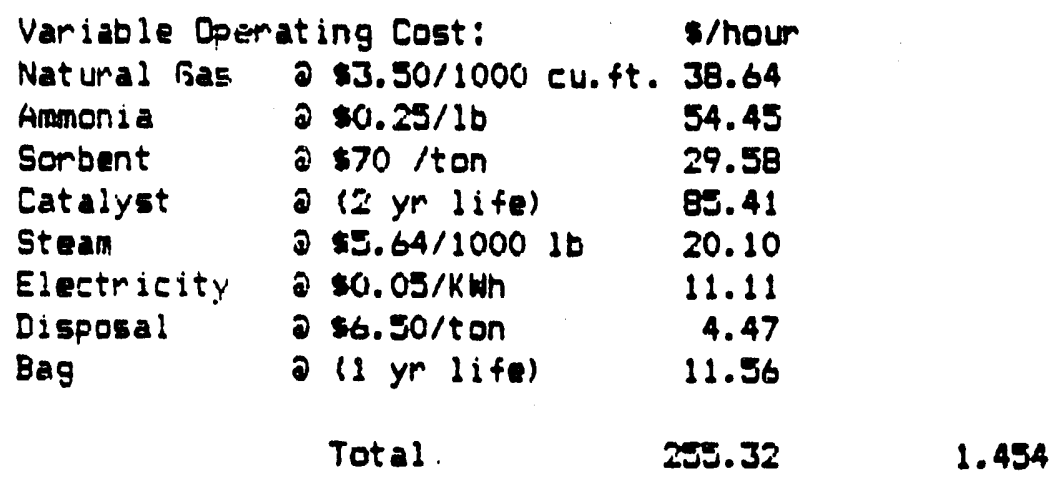

Total Variabie Operating Costs (0 65\% utilization)

Cost of liapital (:5\% per year)

0.767

Total Annued Operatirig Cost

2.582 


\section{Coalfuelad Diesel Fingine Emission Control Economics}

\section{Cost SImmary for OPTION L}

5ystem: 4 Engines (2 20 Cylindtr)

24 wate power output

\section{CAPITAL}

Equipment :

Reburning Unit

Sppay Dryer

Cyelone:

raghouse

Induied Draft Fan

Diffarential Boiler Cost

Total Equipment

Installation Costs:

Total Insta: led Equipment Cost

Engineering and Home Office Fees, General

Facilitios, $20 z$ Contingency

Total Plaiflt Cost

Preproduction Costs and Inventory Capital

Initial sufplies and Materials

Total Capital Cost

\begin{tabular}{l}
- Cost (m \\
\hline 0.220 \\
1.416 \\
0.119 \\
0.363 \\
0.043 \\
0.162 \\
2.323 \\
1.272
\end{tabular}

3.595

1.294

4.889

0.214

0.030

5.133 
Operators/shift: 1

Operating Labor (a $\$ 21.53 /$ hour) $\quad 0.189$

Maintenance Factor: 0.05

Maintenance Labor Cost

0.072

Overnead Labor Cost

0.078

Total Labor Cost

0.339

Maintenance Supplies Cost $\quad 0.108$

Total Dpereting and Maintmance Cost . 0.447

Fixed Opimating and Maintmanee Cost 0.291

Variable Operating and.Maintenance Cost 0.156

Variable Dperating Cost: \$/hour

Natural tias a $\$ 3.30 / 1000 \mathrm{cu} . \mathrm{ft} .182 .70$

Sorbent 29.58

Raw Water $0 \$ 0.60 / 1000$ gal 0.19

Stean $05.64 / 1000$ ib (220.73)

Electricity $20.05 / k$ hh 10.24

Disposal a $8.50 /$ ton 4.47

Bag o (1 yr life) 11.56
Totad
18.11
0.103

Total Variabse Dperating Costs (0 6J\% utilization) $\quad 0.259$

Cost of lapital (15\% por year) $\quad 0.770$

Total Annua! Dperating Cost $\quad 1.320$ 


\section{Coal-fuled Diesel Engine Emission Control Economiss \\ Cost sumary far option M}

\section{System: A Engines (2 20 Cylinuter) \\ 24 vove power output}

\section{CAPITAL}

Equipment:

Takeda Process Unit

Cyclone

Eaghouse

induced Draft Fan

Differential Boider Lost

Total Equipment

Instaldalion Costs:

Total Instalded Equipment Cost

Engineering and Home Office Fees, General Facidities: $20 \%$ Contingency

Total Plant Cost

Royalties

Preproduition Costs and Inventory Capjtal

Iridtal supplies and Materiads

Totad Capita! Cost

1.001
0.119
0.363
0.043
$(0.060)$
1.466
1.307

2.773

0.998

3.771

0.013

0.616

0.364

4.965 
DPERATING COETS

Operators/Shift: 1

Operating Labor (a $\$ 21.55$ /hour)

0.189

Maintenance Factor: 0.08

Maintenarice Labor Cost

0.089

Overnead Labor Cost

0.083

Total Labor Cost

0.361

Maintenance Supplies Cost

0.133

Total Operating and Maintenance Eost

0.494

Fixed Operating and Maintenance Cost

0.321

Variable Operating and Maintenence Cost

0.173

Variabie Ope
Ammonia
Sorbent
Cataiyst
Raw Water
Steam
Electrieity
Disposal
Bag ating Cost:

a $\$ 0.25 / 10$

a $\$ 70 /$ ton

a (2i yr $1 i+e)$

a $50.60 / 1000 \mathrm{gal}$

a $\$ 5.64 / 1000$ ib

a $10.05 / \mathrm{km}$

- $\$ 9.50 /$ ton

- (1 yr life)

Total \$/hour

54.45

7.97

95.54

0.28

141.77

10.71

22.63

11.56

344.91

1.964

Total Variatie Dperating Costs (0 65\% utilization)

2.137

Cest of Capital 115\% per year)

0.745

Total Annua: Operating Cost

3.203 


\section{Coal Fueled Diesel Fngine Enission Control Economics \\ Cost Simmary for OPTION $N$}

System: A Enģines (a 20 Cylinder $r$ )

24 Tile power output

\section{CAPITAL}

Equipment:

Splas' Dryer

S.yelone

Baghouse (275 F)

Induled Draft Fan

llifferential Boiler Cost

Total Equipment

Installation Costs:

Cost $(\min$

1.416

0.119

0.363

0.043

0.110

2.051

1.206

Total Insta:led Equipment Cost

$3.2 \% 7$

Engineering and Hane Office Fecs, General

Facilities, $20 \%$ Cont ingency

Total Flant Cost

1.173

4.430

Preprodurtion Costs and Inventory Capital

0.289

Initial supplies and Materials

0.010

Total Capital Cost

4.729 


\begin{tabular}{|c|c|c|c|}
\hline \multicolumn{3}{|c|}{$\begin{array}{l}\text { Operators/Stift: } 1 \\
\text { Operating Labor (a } \$ 21.5 \mathrm{E} \text { /hour) } \\
\text { Maintenance Factor: } 0.05 \\
\text { Maintenance Labor Cost } \\
\text { Overhead Labor Cost } \\
\text { Total Labor Cost }\end{array}$} & $\begin{array}{l}0.189 \\
0.065 \\
0.076 \\
0.330\end{array}$ \\
\hline \multicolumn{3}{|c|}{$\begin{array}{l}\text { Maint sance Supplies Cost } \\
\text { Total Oparating and Maintenance Cost }\end{array}$} & $\begin{array}{l}0.098 \\
0.428\end{array}$ \\
\hline \multicolumn{4}{|c|}{ Fixed Opparating and Maintenance Cost } \\
\hline \multicolumn{3}{|c|}{ Varjable Operating ano Maintenance Cost } & 0.150 \\
\hline \multirow{2}{*}{\multicolumn{2}{|c|}{ 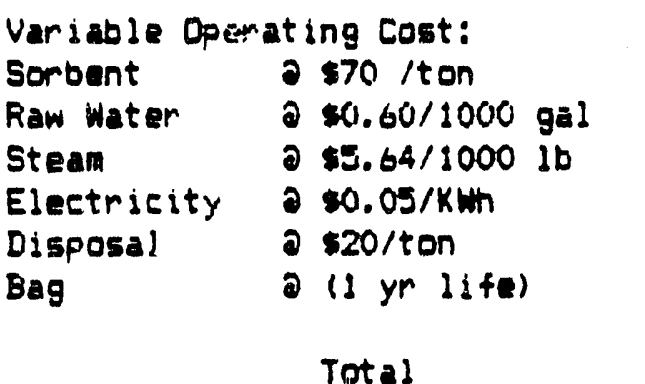 }} & $\begin{array}{r}\$ / \text { hour } \\
29.58 \\
0.29 \\
78.80 \\
10.19 \\
7.35 \\
11.56\end{array}$ & \\
\hline & & .77 & \\
\hline
\end{tabular}

Total Variatie Operating Costs (a 65\% utilization)

0.934

Cost of Lapital (15\% por year)

0.709

Total Annue: Operating Cost 
APIENDIX I

COMPUTER MODEL OF COAL-FUELED DIESEL SYSTEMS 
DESCRIPIION

PG 1

IP 2-3

PE $4-6$

PP 7

PG 8

PG 9

PG 10

PG 10

PG 11

PG 11

PG 11

PG 12

PG 13

PG 14

PG 14

PG 14

PG 15

Ps 15

PG 16

PG 17

PG 17

PG 18

PG 19

PG 19

PG 20

PG 21

PG 22

PG 23

PG 24

PG 25

PG 26

PG 26

PG 27
COVER

MACROS USED TO MANIPULATE MODEL

DIRECTORY OF RANGE NAMES USED IN MODEL

KEY VALUES

TREND INDICES

COAL PROPERTIES BY SOURCE

CHARACTERISTICS OF SELECTED FUELS BY REGION

TRANSPORTATION COST INPUTS BY REGION

SELECTED COAL CHARACTERISTICS

FIXED AND VARIABLE TRANSPORTATION COST COMPONENTS

COST OF TRANSPORTING COAL TO SLURRY RLANT

COAL SLURRY PLANT CAPITAL COST

COST OF COAL DELIVERED TO SLURRY PLANT

SLURRY CHARACTERISTICS \& PROCESS COSTS

SLURRY COST SUMMARY

COST OF TRANSPORTING SLURRY TO UTILITY PLANT

COAL-FIRED DIESEL ENGINE CAPITAL COST (PER $6 \mathrm{MW}$ ENGINE)

FOOTNOTE TO PAGE ABOVE

COAL-FIRED DIESEI ENGINE MAINTENANCE COSTS

COAL-FIRED DIESFL ENGINE EFFICIENCY/CONVERSION VALUES

COST PER KWh ATTRIBUTABLE TO FUEL FOR COAL-FIRED ENGINE

EERFORMANCE STATISTICS

ZOAL-FIRED DIESEL ENGINE EMISSIONS CONTROL COSTS

COAL-FIRED DIESEL ENGINE CAPITAL \& OPERATING COSTS

COAL-FIRED DIESEL ENGINE FUEL TRANSPORT STATISTICS

COST COMPARISON

COAL PREMIUM (DISC'T) OVER GAS/OIL

COSTS BASED ON ASSUMED FUEL OIL PRICES

OIL-FIRED DIESEL UNGINE PLANT CAPITAL COST (PER $6 \mathrm{MW}$ ENGINE)

OIL-FIRED DIESEL ENGINE MAINTENANCE COSTS

OIL-FIRED DIESEL ENGINE EFFICIENCY/CONVERSION VALUES

COST PER KWh FOR FUEL USED BY OIL-FIRED ENGINE

GAS/OIL-FIRED DIESEL ENGINE CAPITAL \& OPERATING COSTS 


\begin{tabular}{|c|c|}
\hline WORKSHEET: & MAIN \\
\hline FILE NAME: & TR10 \\
\hline DISK NAME: & TOB-8701 \\
\hline DEVELOPER: & TODD BURGER AND BOB RANCATORE \\
\hline SUBCASE & $61366-03$ \\
\hline TODAY IS: & 23-May-89 04:39:06 PM \\
\hline \multicolumn{2}{|c|}{ 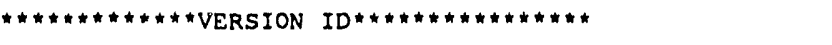 } \\
\hline DATE: & 29-Mar-86 \\
\hline TIME : & $06: 00: 00 \mathrm{PM}$ \\
\hline DESCRIPTN: & Transfer to $1-2-3$ Plus addns \\
\hline \multicolumn{2}{|c|}{ 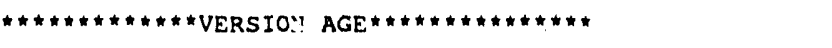 } \\
\hline DAYS: & 26 \\
\hline MONTHS : & 1 \\
\hline YEARS : & 3 \\
\hline LOCATION OF MACROS: & A24 \\
\hline RANGE NAME DIRECTORY: & A200 \\
\hline
\end{tabular}




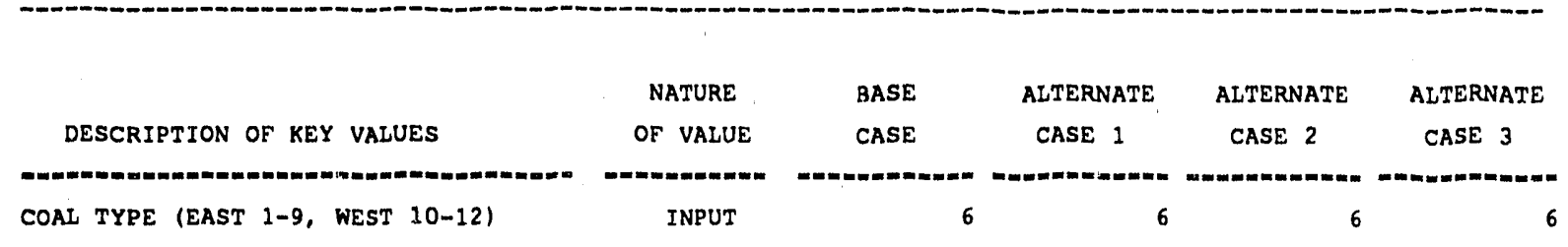

COAL TYPE BASED ON TYPE

SLURRY PLANT TYPE

LOAD FACTOR
BLUE GEM

BLUE GEM

BLUE GEM

BLUE GEM
INPUT

INPUT
AMAX

AMAX

AMAX

AMAX

80.008

80.008

80.008

80.008

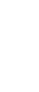

\section{.}


COAL, PROPERTIES BY SOURCE

\begin{tabular}{|c|c|c|c|c|c|c|c|c|c|c|c|}
\hline CODE & STATE & TYPE/FIELD & MOISTURE & $\begin{array}{l}\text { VOLATILE } \\
\text { MATTER }\end{array}$ & $\begin{array}{l}\text { CARBON } \\
\text { (FIXED) }\end{array}$ & ASH & $\begin{array}{l}\text { TOTAL } \\
\text { SULFUR }\end{array}$ & $\begin{array}{l}\text { ORGANIC } \\
\text { SULFUR }\end{array}$ & $\begin{array}{l}\text { PYRITIC } \\
\text { SULPHUR }\end{array}$ & $\mathrm{BTU} / \mathrm{LB}$ & $\begin{array}{l}\text { COST/TON } \\
\text { DRY COAL }\end{array}$ \\
\hline$-\infty$ & 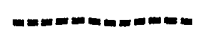 & 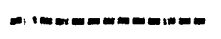 & 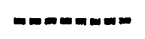 & $-=-m-m m m$ & $=-m-m-n$ & $m-m-m=$ & 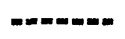 & מח & $-m-m-n=k$ & $-m+\infty=-\infty$ & $-m=-m-$ \\
\hline 1 & ALABAMA & S. APPALACHIA & 2.808 & 28.00 & 58.008 & $10.00 t$ & 0.758 & 0.348 & 0.41 & 12,500 & $\$ 36.50$ \\
\hline 2 & ILLINOIS & QL IUITY CIR. & 8.004 & 35.008 & 47.008 & 8.508 & 2.508 & 1.13 t & 1.388 & 11,700 & $\$ 29.50$ \\
\hline 3 & ILLINOIS & ILLINOIS 15 & $10.00 *$ & 36.008 & 42.008 & 12.008 & 4.508 & 0.708 & 0.388 & 11,900 & $\$ 20.00$ \\
\hline 4 & ILLINOIS & ILLINOI: 16 & 14.004 & $38.00 t$ & 37.008 & 13.008 & 3.508 & 1.588 & 1.938 & 10,500 & $\$ 20.50$ \\
\hline 5 & KENTUCKY & SPLINT & 4.008 & 31.008 & 47.008 & 18.004 & $2.00 t$ & 0.808 & 1.208 & 14,100 & $\$ 27.50$ \\
\hline 6 & KENTUCKY & BLUE GEM & 6.008 & 38.00 & 54.00 & $2.00 t$ & 0.708 & 0.308 & 0.408 & 14,000 & $\$ 34.50$ \\
\hline 7 & PENNSYLVANIA & ELHHORN & 2.004 & 37.008 & 58.008 & 3.008 & 3.008 & $1.20 \%$ & 1.808 & 24,100 & $\$ 27.50$ \\
\hline 8 & KENTUCKY & HAR:ARD 14 & 2.00 & $35.00 t$ & 59.004 & 6.008 & 0.858 & 0.748 & 0.108 & 14,200 & $\$ 27.50$ \\
\hline 9 & W. VIRGINIA & PIITSBURGH & 6.008 & 37.004 & 53.008 & 8.008 & 1.008 & 0.454 & 0.554 & 13,000 & $\$ 27.00$ \\
\hline 10 & COLORADO & GREEN RIVER & $8.00 \%$ & 37.008 & 46.008 & 9.008 & 0.508 & 0.228 & 0.288 & 11,600 & $\$ 22.25$ \\
\hline 11 & UTAH & CAS TLEGATE & $7.00 t$ & 0.00 & 0.008 & 5.008 & 0.508 & 0.208 & 0.301 & 13,500 & $\$ 23.00$ \\
\hline 12 & UTAH & KAIPAROWITZ & 10.001 & 38.008 & 41.008 & $9.00 t$ & 0.608 & $0.27 t$ & 0.338 & 11,500 & $\$ 26.00$ \\
\hline
\end{tabular}

NOTE: Molsture, volatlle matter, "C" and organle sulfur values are based on ADL prof 1 le data.

Ash, total sulfur, BTU/Ib and price are based on "COAL WEEK" May 9, 1988.

Coal price is avelage of term price quotes, FOB mine. 


\begin{tabular}{|c|c|c|c|c|c|}
\hline & UNIT OF & BASE & ALTERNATE & ALTERNATE & ALTERNATE \\
\hline DESCRIPTION & MEASURE & CASE & CASE 1 & CASE 2 & CASE 3 \\
\hline 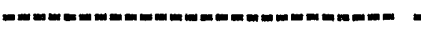 & - & 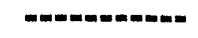 & 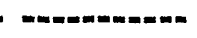 & 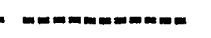 & 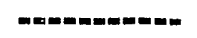 \\
\hline COAL REGION (EAST/WEST)? & REGION & EAST & EAST & EAST & EAST \\
\hline COAL TYPE IN REGION & LOCATION & BLUE GEM & BLUE GEM & BLUE GEM & BLUE GEM \\
\hline \multicolumn{6}{|l|}{ COAL SOURCE CHARACTERISTICS } \\
\hline VOLUME & LBS/CU.FT. & 59 & 59 & 59 & 59 \\
\hline ENERGY/WEIGHT & BTU/LB & 14,000 & 14,000 & 14,000 & 14,000 \\
\hline ENERGY/VOLUME & BTU/CU.FT. & 823,529 & 823,529 & 823,529 & 823,529 \\
\hline MOISTURE CONTENT & \& BY WT & 6.008 & 6.008 & 6.008 & 6.008 \\
\hline ASH CONTENT & \& BY WT & 2.008 & 2.008 & 2.008 & 2.008 \\
\hline ORGANIC SULFUR CONTENT & \& BY WT & 0.308 & 0.308 & 0.308 & 0.308 \\
\hline NITROGEN CONTENT & \& BY WT & & & & \\
\hline COST AT MINEMOUTH & SHORT TON & $\$ 34.50$ & $\$ 34.50$ & $\$ 34.50$ & $\$ 34.50$ \\
\hline COST AT MINEMOUTH & $\$ \$ \$ / M M$ BTU & $\$ 1.23$ & $\$ 1.23$ & $\$ 1.23$ & $\$ 1.23$ \\
\hline & \multicolumn{5}{|c|}{ FIXED AND VARIABLE TRANSPORTATION COST COMPONENTS } \\
\hline & UNIT OF & BASE & ALTERNATE & ALTERNATE & ALTERNATE \\
\hline DESCRIPTION & MEASURE & CASE & CASE 1 & CASE 2 & CASE 3 \\
\hline 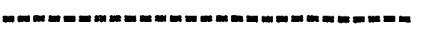 & 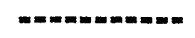 & 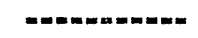 & 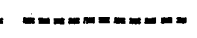 & $-m-n=n=m-m=0$ & $-m-m-m=-m=n$ \\
\hline \multicolumn{6}{|l|}{ U.S. RAILROAD RATES } \\
\hline FIXED HAUL COMPONENT & \$\$\$ & $\$ 3.2192$ & $\$ 3.2192$ & $\$ 3.2192$ & $\$ 3.2192$ \\
\hline VARIABLE HAUL COMPONENT & \$\$\$/1000 MI & $\$ 21.8200$ & $\$ 21.8200$ & $\$ 21.8200$ & $\$ 21.8200$ \\
\hline \multicolumn{6}{|l|}{ U.S. TRUCK RATES } \\
\hline FIXED HAUL COMPC'JENT & \$\$\$ & $\$ 0.9276$ & $\$ 0.9276$ & $\$ 0.9276$ & $\$ 0.9276$ \\
\hline VARIABLE HAUL COMPUNENT & $\$ \$ \$ / 1000 \mathrm{MI}$ & $\$ 82.6534$ & $\$ 82.6534$ & $\$ 82.6534$ & $\$ 82.6534$ \\
\hline \multicolumn{6}{|l|}{ RAIL PREFERRED OVER TRUCK } \\
\hline \multirow[t]{2}{*}{ AT WHAT DISTANCE: } & MILES & 38 & 38 & 38 & 38 \\
\hline & \multicolumn{4}{|c|}{ COST OF TRANSPORTING COAL TO SLURRY PLANT } & \\
\hline & UNIT OF & BASE & ALTERNATE & ALTERNATE & ALTERNATE \\
\hline DESCRIPTION & MEASURE & CASE & CASE 1 & CASE 2 & CASE 3 \\
\hline 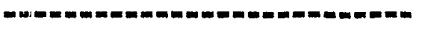 & $m-m m=n m m=n$ & 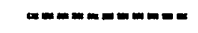 & 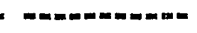 & $m=n m m=m=m$ & 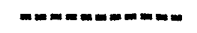 \\
\hline COAL REGION TO SLURRY PLANT & MIJES & 590 & 590 & 590 & 590 \\
\hline \multicolumn{6}{|l|}{ U.S. RAILROAD RATES } \\
\hline DEIIVERY PRICE & \$\$\$/TON & $\$ 16.0930$ & $\$ 16.0930$ & $\$ 16.0930$ & $\$ 16.0930$ \\
\hline COST/DISTANCE & \$S\$/TON MI & $\$ 0.0273$ & $\$ 0.0273$ & $\$ 0.0273$ & $\$ 0.0273$ \\
\hline COST/ENERGY & $\$ \$ \$ / M M$ BTU & \$0.5748 & $\$ 0.5748$ & $\$ 0.5748$ & $\$ 0.5748$ \\
\hline \multicolumn{6}{|l|}{ U.S. TRUCK RATES } \\
\hline DELIVERY PRICE & \$\$\$/TON & $\$ 49.6931$ & $\$ 49.6931$ & $\$ 49.6931$ & $\$ 49.6931$ \\
\hline COST/DISTANCE & \$\$S/TON MI & $\$ 0.0842$ & $\$ 0.0842$ & $\$ 0.0842$ & $\$ 0.0842$ \\
\hline COST/ENERGY & $\$ \$ \$ / M M$ BTU & $\$ 1.7748$ & $\$ 1.7748$ & $\$ 1.7748$ & $\$ 1.7748$ \\
\hline \multicolumn{6}{|l|}{ MINIMUM COS'T TRANSPORTATION } \\
\hline IS VIA TRUCK/RAIL & MODE & RAIL & RAII & RAIL & RAIL \\
\hline \multicolumn{6}{|l|}{ MINIMUM TRANSPORTATION RATE } \\
\hline DELIVERY PRICE & \$\$S/TON & $\$ 16.0930$ & $\$ 16.0930$ & $\$ 16.0930$ & $\$ 16.0930$ \\
\hline COST/DISTANCE & \$\$\$TTON MI & so. 0273 & $\$ 0.0273$ & $\$ 0.0273$ & $\$ 0.0273$ \\
\hline COST/ENERGY & \$\$S/MM BTU & $\$ 0.5748$ & $\$ 0.5748$ & $\$ 0.5748$ & so. 5748 \\
\hline
\end{tabular}


COAL SLURRY PLANT CAPITAL COST

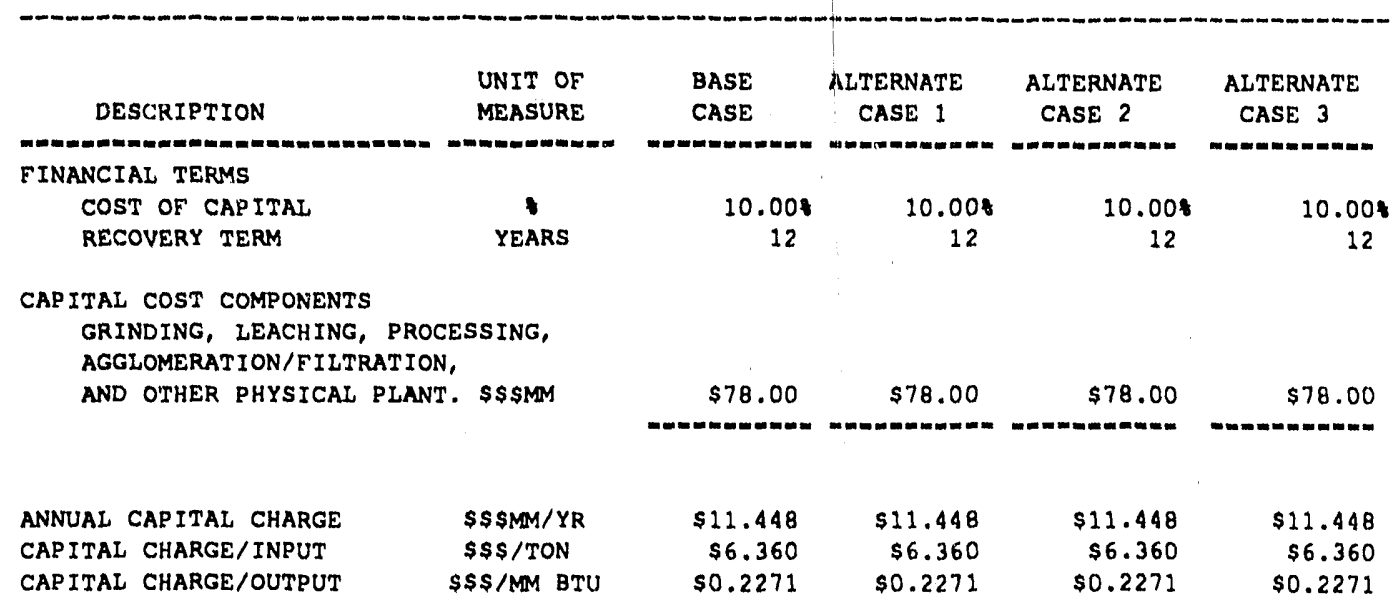

COST OF COAL DELIVERED TO SLURRY PLANT

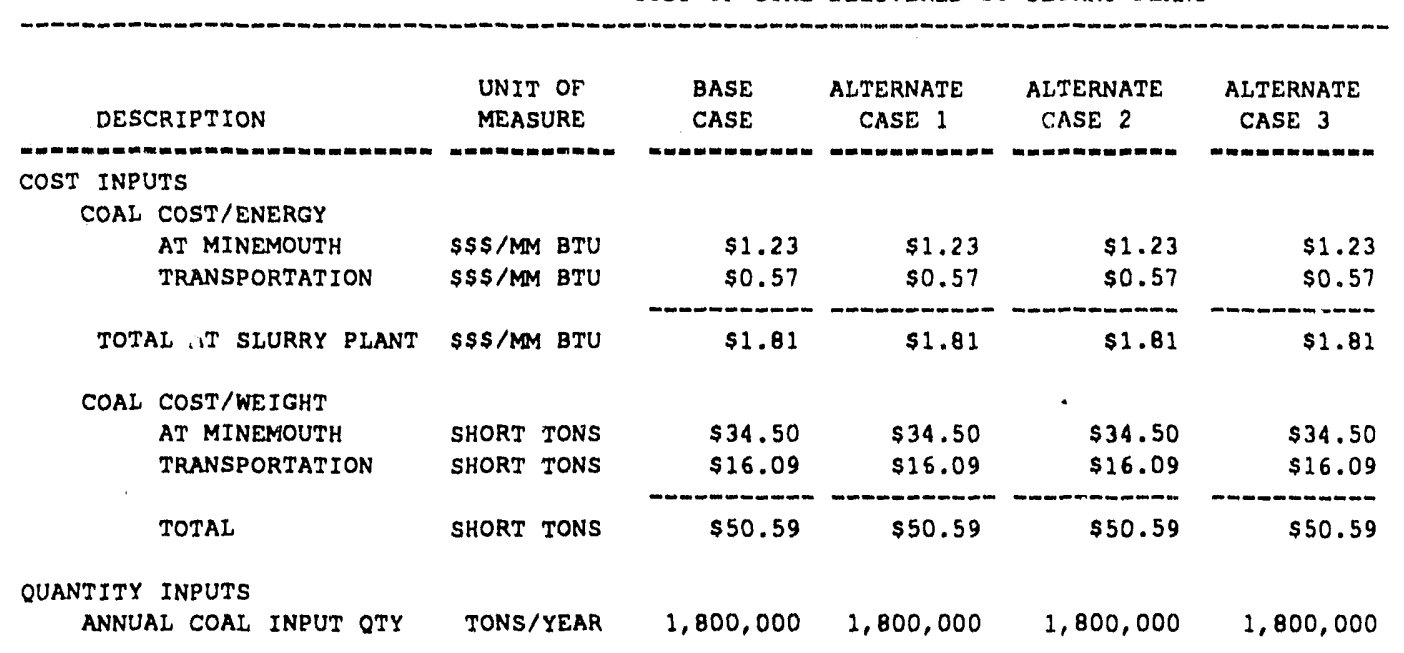

TONS OF SLURRY OUTPUT SHORT TONS $\quad 1,714,286 \quad 1,714,286 \quad 1,714,286 \quad 1,714,286$




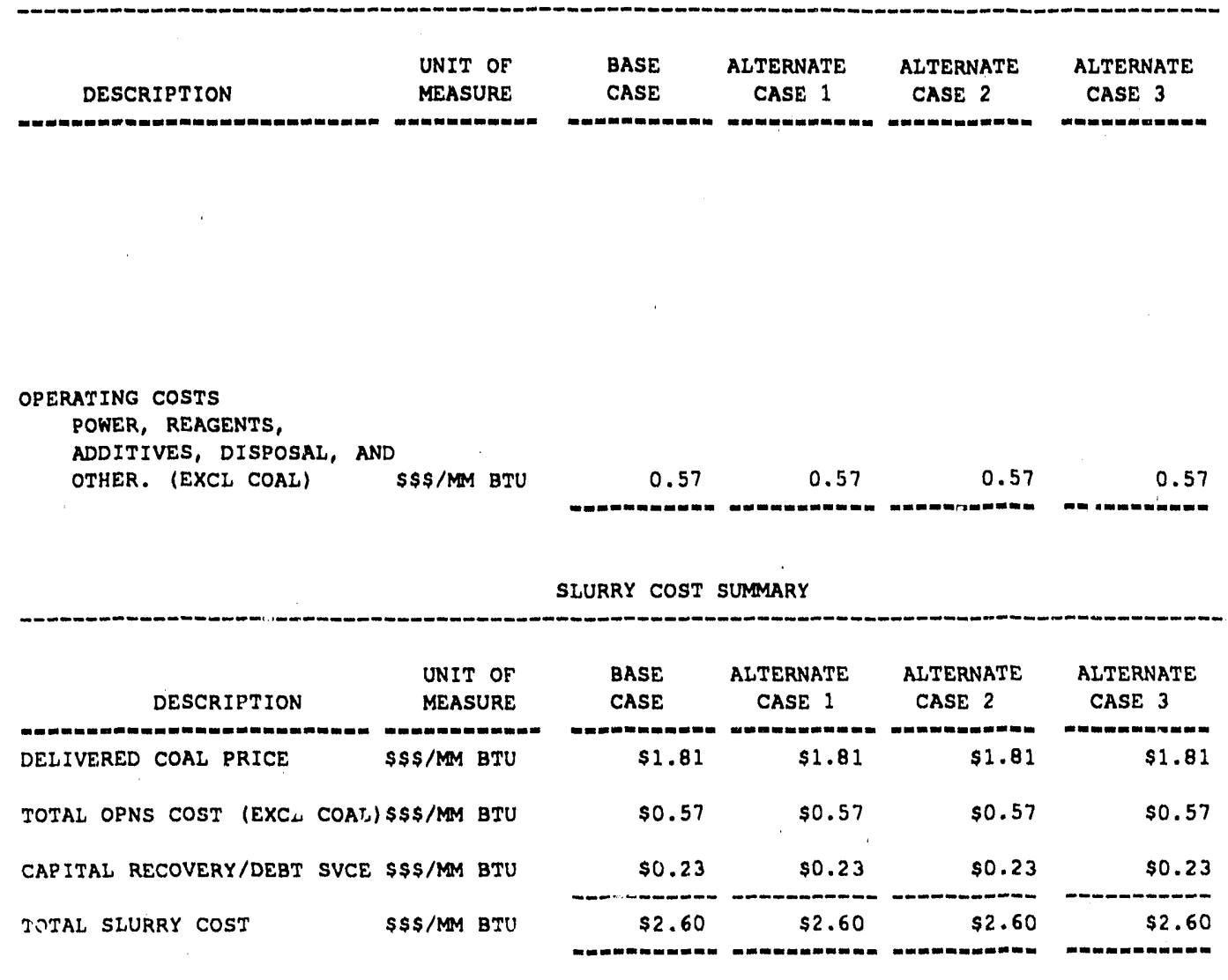

COST OF TRANSPORTING SLURRY TO UTILITY PLANT

\begin{tabular}{|c|c|c|c|c|c|}
\hline DESCRIPTION & $\begin{array}{l}\text { UNIT OF } \\
\text { MEASURE }\end{array}$ & $\begin{array}{l}\text { BASE } \\
\text { CASE }\end{array}$ & $\begin{array}{c}\text { ALTERNATE } \\
\text { CASE } 1\end{array}$ & $\begin{array}{l}\text { ALTERNATE } \\
\text { CASE } 2\end{array}$ & $\begin{array}{l}\text { ALTERNATE } \\
\text { CASE } 3\end{array}$ \\
\hline 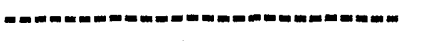 & (n) & $m m=m m m-m=m$ & $-m-m=m-m=-n$ & 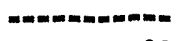 & 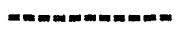 \\
\hline SLURRY TO UTILITY PLANT & MILES & 20 & 20 & 20 & 20 \\
\hline \multicolumn{6}{|l|}{ U.S. RAILROAD RATES } \\
\hline DELIVERED PRICE & $\$ \$ \$ / T O N$ & $\$ 3.8166$ & $\$ 3.8166$ & $\$ 3.8166$ & $\$ 3.8166$ \\
\hline COST/DISTANCE & \$\$/TON MI & $\$ 0.1908$ & $\$ 0.1908$ & $\$ 0.1908$ & $\$ 0.1908$ \\
\hline COST/ENERGY & $\$ \$ \$ / M M$ BTU & $\$ 0.2870$ & $\$ 0.2870$ & \$0.2870 & $\$ 0.2870$ \\
\hline \multicolumn{6}{|l|}{ U.S. TRUCK RATES } \\
\hline DELIVERED PRICE & \$\$\$TON & $\$ 2.6270$ & $\$ 2.6270$ & $\$ 2.62 .70$ & $\$ 2.6270$ \\
\hline COST/DISTANCE & SSS/TON MI & $\$ 0.1314$ & $\$ 0.1314$ & \$0.1314 & s0.1314 \\
\hline COST/ENERGY & 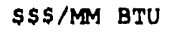 & $\$ 0.1975$ & $\$ 0.1975$ & \$0.1975 & \$0.1975 \\
\hline \multicolumn{6}{|l|}{ MINIMUM COST TRANSPORTATION } \\
\hline IS VIA TRUCK/RAIL & MODE & TRUCK & TRUCK & TRUCK & TRUCK \\
\hline \multicolumn{6}{|l|}{ MINIMUM TRANSPORTATION RATE } \\
\hline DELIVERED PRICE & \$\$\$/TON & $\$ 3.8166$ & $\$ 3.8166$ & $\$ 3.8166$ & $\$ 3.8166$ \\
\hline COST/DISTANCE & $\$ \$ \$ / T O N ~ M I$ & $\$ 0.1908$ & $\$ 0.1908$ & $\$ 0.1908$ & $\$ 0.1908$ \\
\hline COST/ENERGY & $\$ \$ \$ / M M$ BTU & $\$ 0.2870$ & $\$ 0.2870$ & $\$ 0.2870$ & $\$ 0.2870$ \\
\hline
\end{tabular}


COAL-FIRED DIESEL ENGINE CAPITAL COST (PER 6 MW ENGINE)

\begin{tabular}{|c|c|c|c|c|c|}
\hline DESCRIPTION & $\begin{array}{l}\text { UNIT OF } \\
\text { MEASURE }\end{array}$ & $\begin{array}{l}\text { BASE } \\
\text { CASE }\end{array}$ & $\begin{array}{l}\text { ALTERNATE } \\
\text { CASE } 1\end{array}$ & $\begin{array}{l}\text { ALTERNATE } \\
\text { CASE } 2\end{array}$ & $\begin{array}{l}\text { ALTERNATE } \\
\text { CASE } 3\end{array}$ \\
\hline 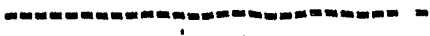 & 促 & $\ln =m-m=$ & $=-m=$ & $m \infty-\infty$ & \\
\hline \multicolumn{6}{|l|}{ FINANCIAL STATISTICS } \\
\hline COST OF CAPITAL & 3 & 10.008 & $10.00 t$ & 10.008 & 10.008 \\
\hline RECOVERY TERM & YEARS & 12 & 12 & 12 & 12 \\
\hline \multicolumn{6}{|l|}{ OPERATING STATISTICS } \\
\hline POWER RATING & MEGAWATTS & 6 & 6 & 6 & 6 \\
\hline ANALYSIS PERIOD & YEARS & 20 & 20 & 20 & 20 \\
\hline AVAILABILITY & 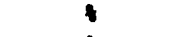 & 90.008 & 90.008 & $90.00 \%$ & 90.008 \\
\hline IOAD FACTOR & 3 & 80.008 & 80.004 & 80.004 & $80.00 *$ \\
\hline OPERATING PERIOD & ARS PER YEAR & 6307 & 6307 & 6307 & 6307 \\
\hline POWER GENERATED & MWH & 760,000 & 760,000 & 760,000 & 760,000 \\
\hline \multicolumn{6}{|l|}{ CAPITAL COST COMPONENTS } \\
\hline LUBE SYSTEM & \$\$\$ & $\$ 65,000$ & $\$ 65,000$ & $\$ 65,000$ & $\$ 65,000$ \\
\hline PISTONS \&ISTON RINGS & \$\$\$ & $\$ 70,000$ & $\$ 70,000$ & $\$ 70,000$ & $\$ 70,000$ \\
\hline CYLINDER LINERS & \$\$\$ & $\$ 200,000$ & $\$ 200,000$ & $\$ 200,000$ & $\$ 200,000$ \\
\hline CYLINDER HEAD & \$\$ & $\$ 300,000$ & $\$ 300,000$ & $\$ 300,000$ & $\$ 300,000$ \\
\hline VALVES & \$\$ & $\$ 40,000$ & $\$ 40,000$ & $\$ 40,000$ & $\$ 40,000$ \\
\hline FUEL PUMP C INJECTOR & \$\$\$ & $\$ 300,000$ & $\$ 300,000$ & $\$ 300,000$ & $\$ 300,000$ \\
\hline INSTRUMENTS & \$\$\$ & $\$ 200,000$ & $\$ 200,000$ & $\$ 200,000$ & $\$ 200,000$ \\
\hline TURBOCHARGER & $\mathbf{\$ \$ \$}$ & $\$ 600,000$ & $\$ 600,000$ & $\$ 600,000$ & $\$ 600,000$ \\
\hline CAM SHAFT \& BEARINGS & $\mathbf{\$ \$ \$}$ & $\$ 100,000$ & $\$ 100,000$ & $\$ 100,000$ & $\$ 100,000$ \\
\hline \multirow[t]{2}{*}{ MISCELLANY } & $\mathbf{\$ \$} \$$ & $\$ 250,000$ & $\$ 250,000$ & $\$ 250,000$ & $\$ 250,000$ \\
\hline & & - & 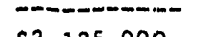 & $-2-2-2-2$ & $-\infty$ \\
\hline SUBTOTAL CRITICAL PARTS & $\mathbf{\$ \$ \$}$ & $\$ 2,125,000$ & $\$ 2,125,000$ & $\$ 2,125,000$ & $\$ 2,125,000$ \\
\hline \multirow[t]{2}{*}{ NON-CRITICAL PAR'IS } & \$\$\$ & $\$ 1,350,000$ & $\$ 1,350,000$ & $\$ 1,350,000$ & $\$ 1,350,000$ \\
\hline & \$\$\$ & $\$ 3,475,000$ & $\$ 3,475,000$ & $\$ 3,475,000$ & $\$ 3,475,000$ \\
\hline \multirow[t]{2}{*}{ INSTALLATION COSTS } & \$\$\$ & $\$ 1,737,500$ & $\$ 1,737,500$ & $\$ 1,737,500$ & $\$ 1,737,500$ \\
\hline & & 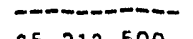 & $50-21050$ & $-m-2 m-200$ & $-x-50-10$ \\
\hline INSTALLED ENGINE COST & \$\$\$ & $\$ 5,212,500$ & $\$ 5,212,500$ & $\$ 5,212,500$ & $\$ 5,212,500$ \\
\hline \multirow[t]{2}{*}{ EMISSIONS EQUIPMENT } & $\mathbf{\$ \$}$ & $\$ 2,526,500$ & $\$ 2,464,500$ & $\$ 2,013,000$ & $\$ 590,000$ \\
\hline & & 57.739 .000 & $\$ 7.677,000$ & $57,225,500$ & $\$ 5,802,500$ \\
\hline TOTAL CAPITAL OUI:AAY & 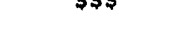 & $\begin{array}{l}\$ 1,139,000 \\
-2=m-m=n-m=m\end{array}$ & 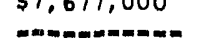 & 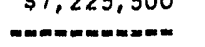 & 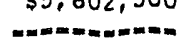 \\
\hline ANNUAL CAPITAL CHARGE & \$\$\$/YEAR & $\$ 1,1.35,801$ & $\$ 1,126,702$ & $\$ 1,060,438$ & $\$ 851,594$ \\
\hline \multicolumn{6}{|l|}{ CAPITAL CHARGE/OUTPUT } \\
\hline PRINCIPAL COMPONENT & \$\$\$/kWh & $\$ 0.0102$ & \$0.0101 & $\$ 0.0095$ & $\$ 0.0076$ \\
\hline \multirow{2}{*}{ COST OF CAPITAL } & \$\$\$/kWh & $\$ 0.0078$ & $\$ 0.0077$ & $\$ 0.0072$ & so.0058 \\
\hline & $\$ \$ \$ / k W h$ & \$0.0179 & $\$ 0.0178$ & $\$ 0.0167$ & so.0134 \\
\hline \multicolumn{6}{|c|}{ PRINCIPAL \& COST OF CAPITAL/OUTPUT } \\
\hline ENGINE & $\$ \$ \$ / k W h$ & $\$ 0.0121$ & s0.0121 & \$0.0121 & $\$ 0.0121$ \\
\hline EMISSIONS & $\$ \$ \$ / k W h$ & \$0.0059 & $\$ 0.0057$ & $\$ 0.0047$ & $\$ 0.0014$ \\
\hline \multicolumn{6}{|l|}{ NOTE AMOUNT (OVER) UNDER } \\
\hline \multicolumn{6}{|l|}{ STANDARD ENGINE COST: } \\
\hline \multirow{2}{*}{\multicolumn{2}{|c|}{$\begin{array}{l}\text { PRODUCTION OF' } \$ 2.35 \mathrm{M} \\
\text { INSTALLATION OF } \$ 1.15 \mathrm{M}\end{array}$}} & $(\$ 1,125,000)$ & $(\$ 1,125,000)$ & $(\$ 1,125,000)$ & $(\$ 1,125,000)$ \\
\hline & & $(\$ 587,500)$ & $(\$ 587,500)$ & $(\$ 587,500)$ & $(\$ 587,500)$ \\
\hline \multicolumn{2}{|l|}{ EMISSIONS PREMIUM ( $\$ .9 M$} & $(\$ 1,626,500)$ & $(\$ 1,564,500)$ & $(\$ 1,113,000)$ & $\$ 310,000$ \\
\hline TOTAL PREMIUM & & $(\$ 3,339,000)$ & $(\$ 3,277,000)$ & $(\$ 2,825,500)$ & $(\$ 1,402,500)$ \\
\hline
\end{tabular}


COAL-FIRED DIESEL ENGINE MAINTENANCE COSTS

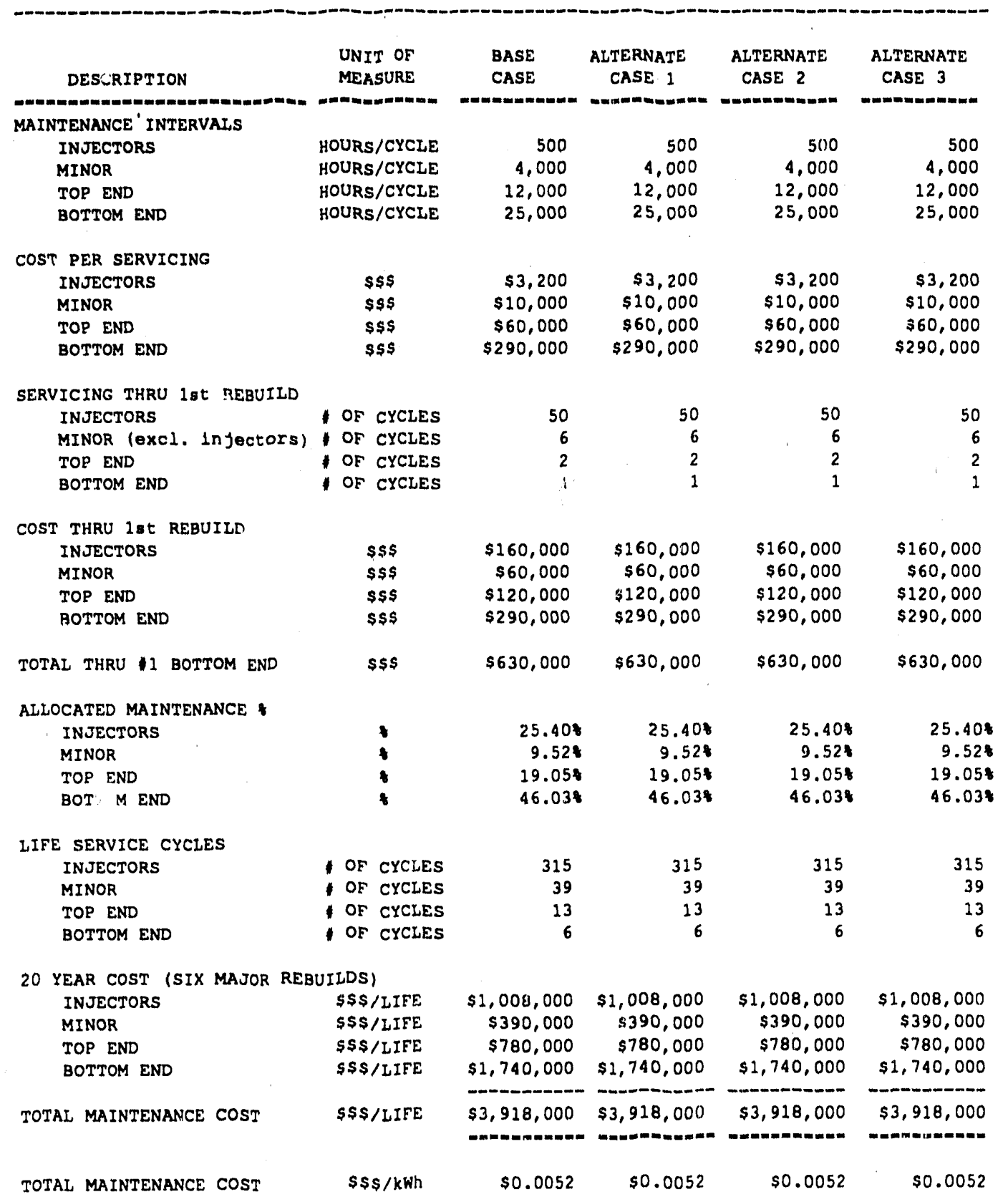




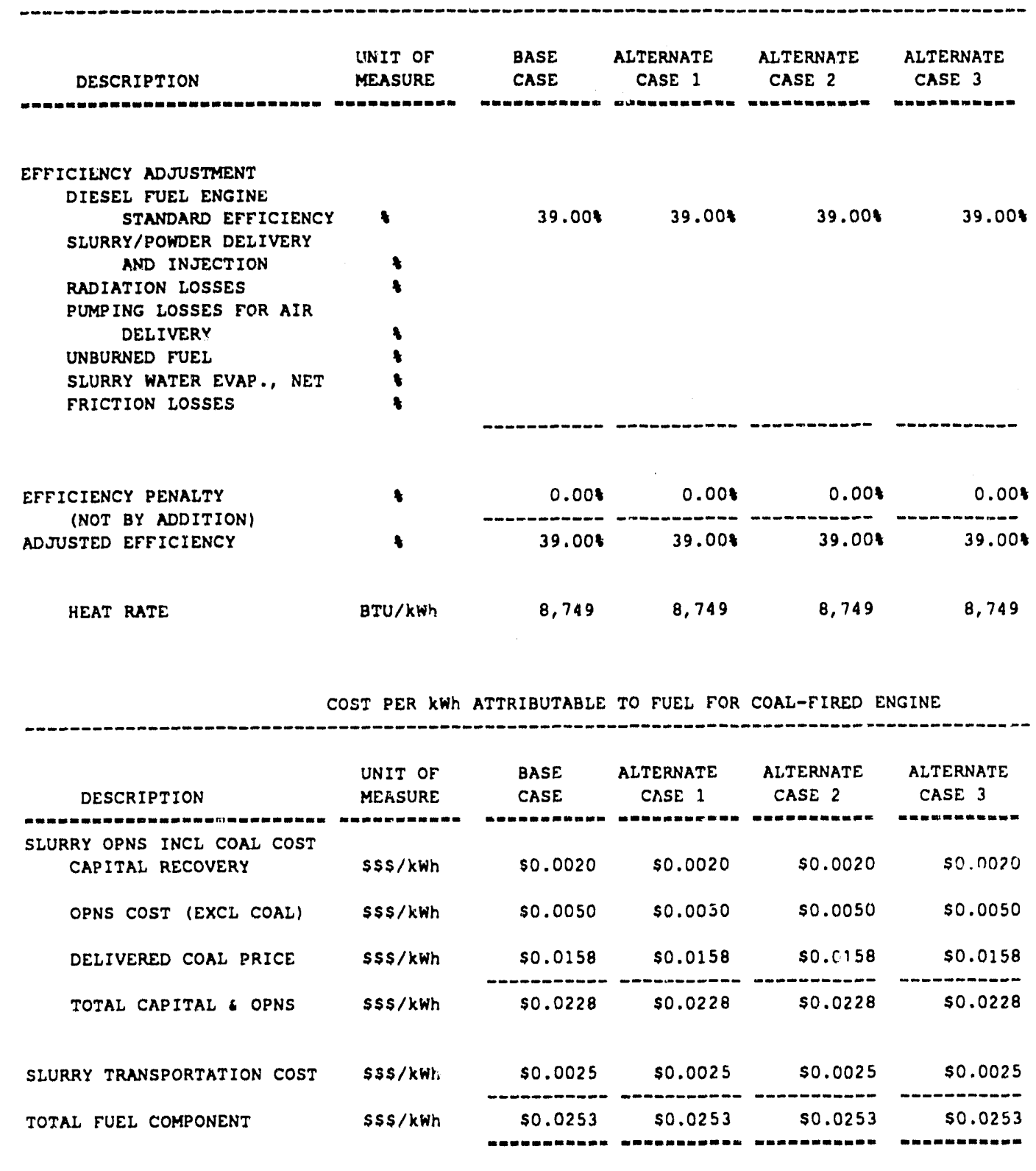




\begin{tabular}{|c|c|c|c|c|c|}
\hline DESCRIPTION & $\begin{array}{l}\text { UNTT OF } \\
\text { MEASURE }\end{array}$ & $\begin{array}{l}\text { BASE } \\
\text { CASE }\end{array}$ & $\begin{array}{l}\text { ALTERNATE } \\
\text { CASE } 1\end{array}$ & $\begin{array}{l}\text { ALTERNATE } \\
\text { CASE } 2\end{array}$ & $\begin{array}{c}\text { ALTERNATE } \\
\text { CASE } 3\end{array}$ \\
\hline 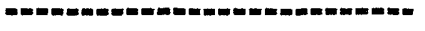 & 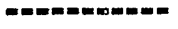 & 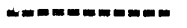 & 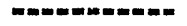 & 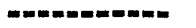 & $m- \pm=m-\infty$ \\
\hline \multicolumn{6}{|l|}{ SLURRY TRANSPORT } \\
\hline POWER GENERATED/ENGINE & MWH/YEAR & 38,000 & 38,000 & 38,000 & 38,000 \\
\hline NUMBER OF ENGINES & 4 & 6 & 6 & 6 & 6 \\
\hline POWER GENERATED/CIUSTER & MWH/YEAR & 228,000 & 228,000 & 228,000 & 228,000 \\
\hline HEAT RATE & BTU/kWh & 8,749 & 8,749 & 8,749 & 8,749 \\
\hline ENERGY REQUIRED/YEAR & MMBTU & $1,994,708$ & $1,994,708$ & $1,994,708$ & $1,994,708$ \\
\hline SLURRY ENERGY CONTENT & BTU/CUFT & 245,066 & 245,066 & 245,066 & 245,066 \\
\hline SLURRY REQ'D FOR YEAR & CUFT & $8,139,467$ & $8,139,467$ & $8,139,467$ & $8,139,467$ \\
\hline TANKCAR LOADS/YEAR (1) & 1 & 2,035 & 2,035 & 2,035 & 2,035 \\
\hline TANKCAR LOADS/WEEK (1) & 4 & 39 & 39 & 39 & 39 \\
\hline \multicolumn{6}{|l|}{ COAL TRANSPORT FROM MINEMOUTH } \\
\hline ENERGY REQUIRED/YEAR & MMTU & $1,994,708$ & $1,994,708$ & $1,994,708$ & $1,994,708$ \\
\hline COAL ENERGY/VOLUME & BTU/CUFT & 823,529 & 823,529 & 823,529 & 823,529 \\
\hline SLURRY/BYPRODUCT RATIO & $t$ & $50.00 \%$ & 50.008 & $50.00 t$ & 50.004 \\
\hline COAL REQ'D FOR YEAR & CUFT & $4,844,290$ & $4,8.44,290$ & $4,844,290$ & $4,844,290$ \\
\hline TRAIN CARLOADS/YEAR (2) & 4 & 1,425 & 1,425 & 1,275 & 1,275 \\
\hline TRAIN CARLOADS/WEEK (2) & 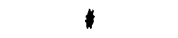 & 27 & 27 & 25 & 25 \\
\hline
\end{tabular}

NOTE (1): ASSUMES 30,000 GALLON TANKCARS 
COAL-FIRED DIESEL ENGINE EMISSIONS CONTROL COSTS

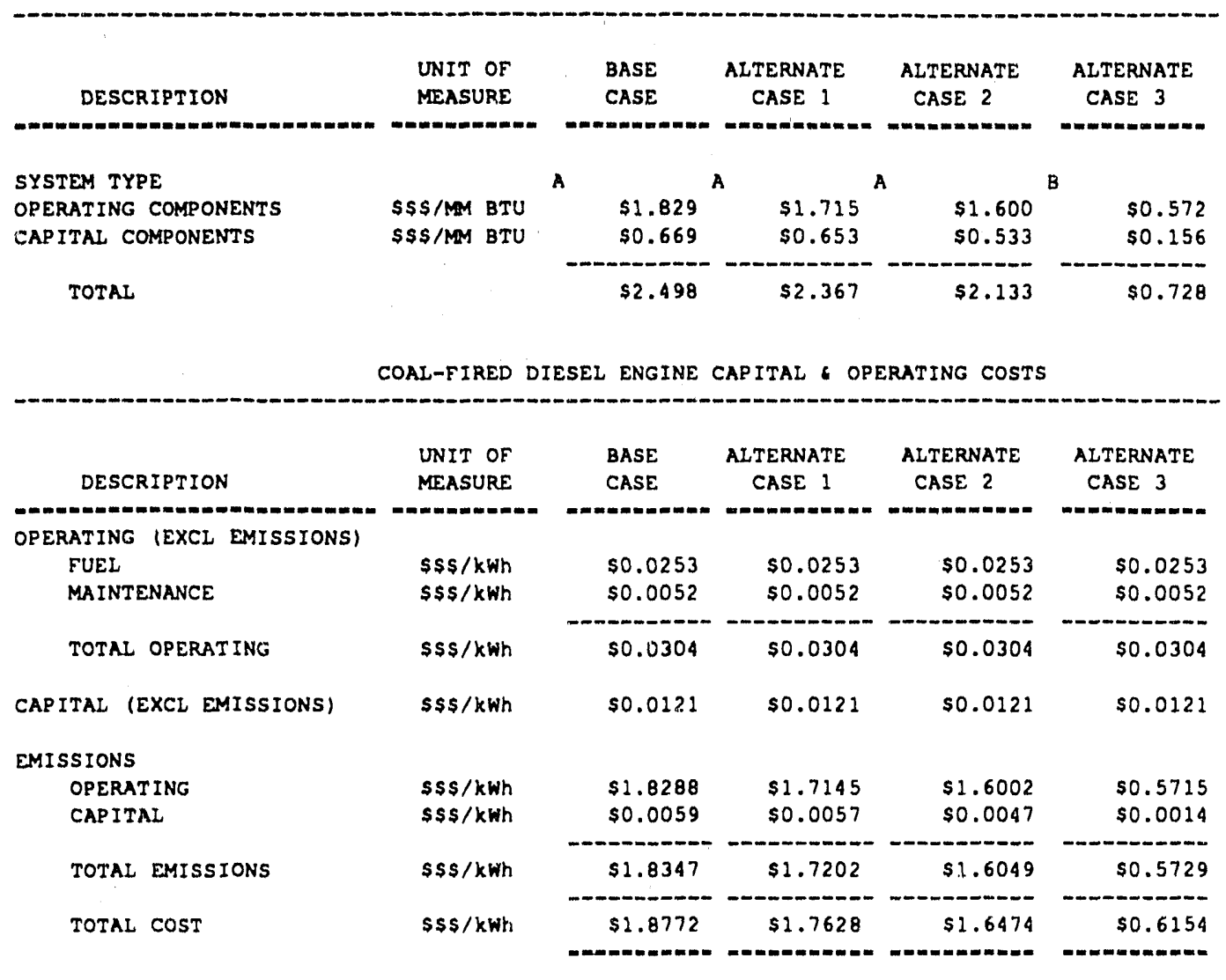


COST COMPARISON

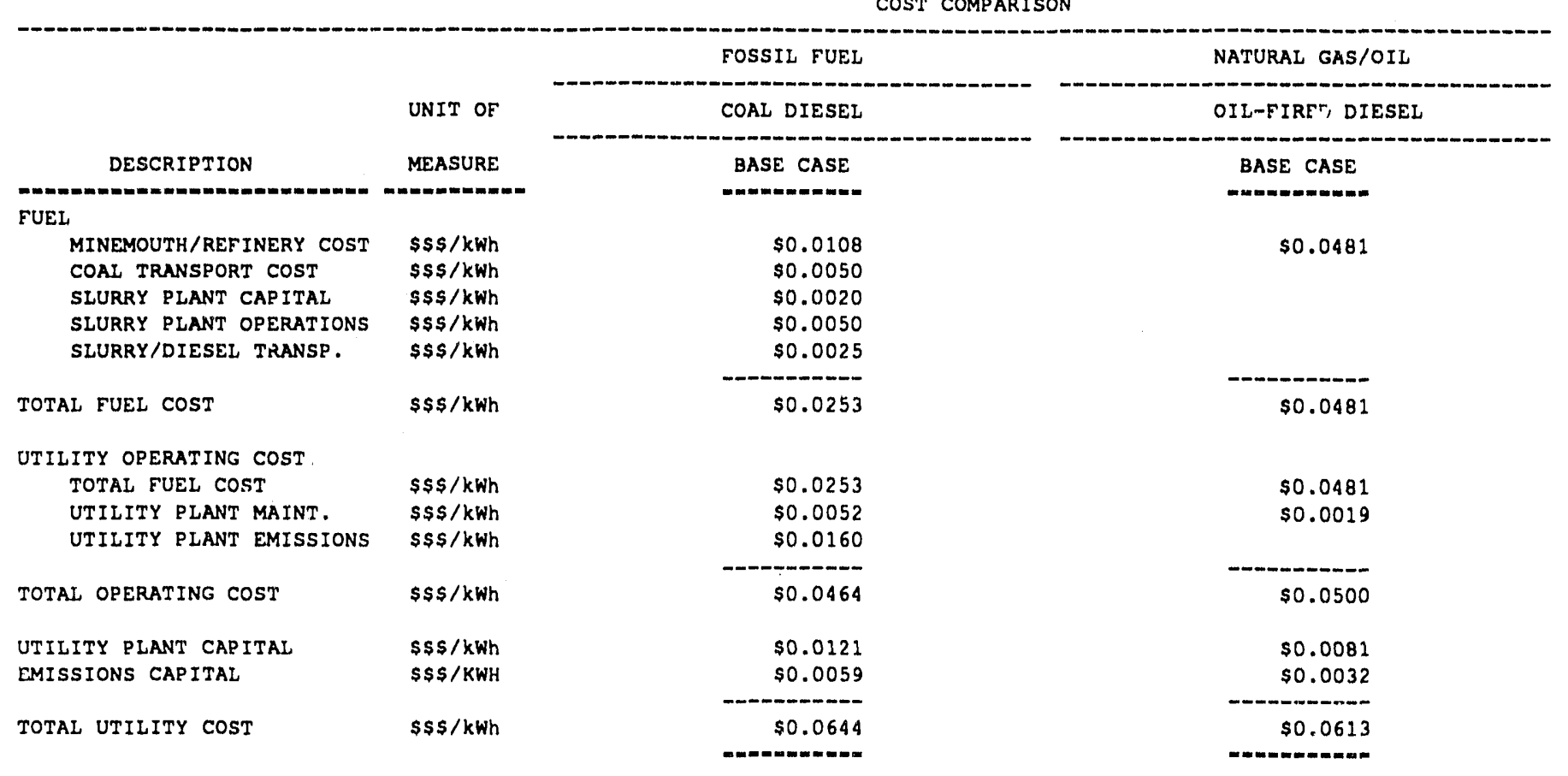




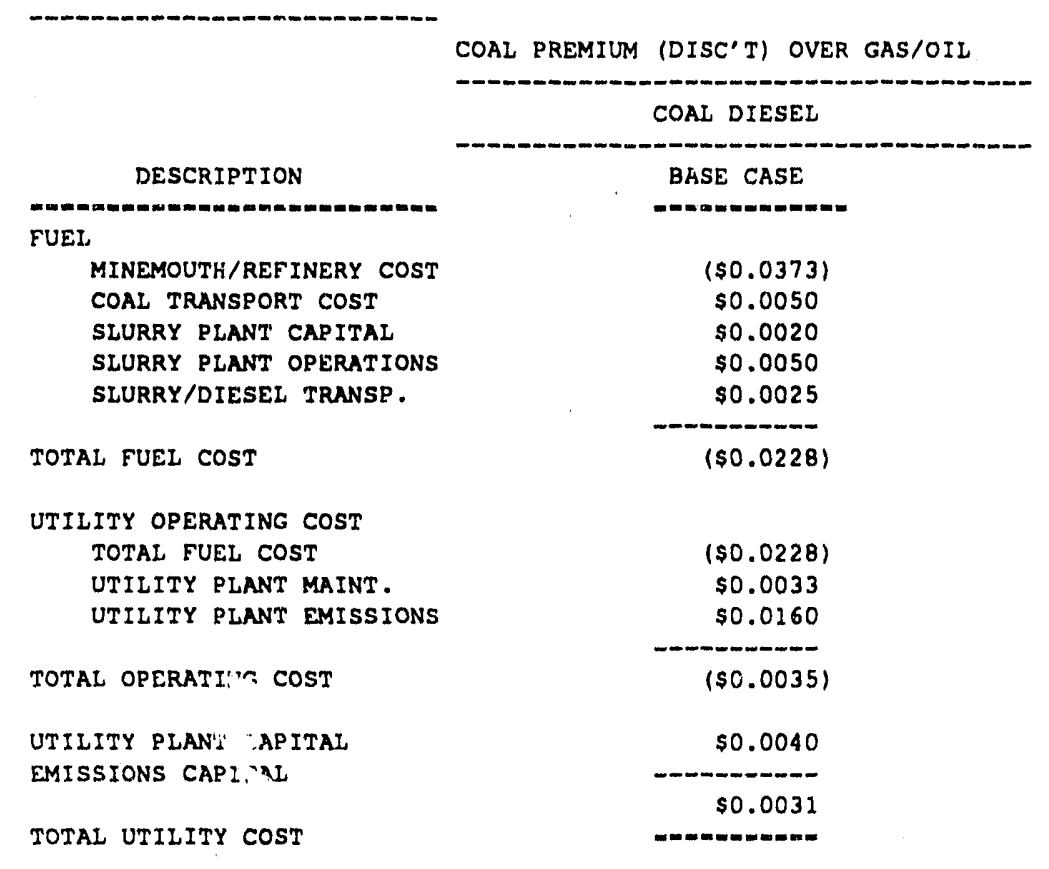


OIL-FIRED DIESEL ENGINE PLANT CAPITAL COST (PER 6 MW ENGINE)

\begin{tabular}{|c|c|c|}
\hline DESCRIPTION & $\begin{array}{l}\text { UNIT OF } \\
\text { MEASURE }\end{array}$ & $\begin{array}{l}\text { BASE } \\
\text { CASE }\end{array}$ \\
\hline 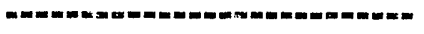 & $m m=m m=n=m=m$ & $m m=0-20 m m=$ \\
\hline \multicolumn{3}{|l|}{ FINANCIAI STATISTICS } \\
\hline COST OF CAPITAL & 8 & 10.008 \\
\hline RECOVERY TERM & YEARS & 12 \\
\hline \\
\hline $\begin{array}{l}\text { OPERATING STATISTICS } \\
\text { POWER RATING }\end{array}$ & MEGANATTS & 6 \\
\hline \multirow{2}{*}{$\begin{array}{l}\text { LIFE } \\
\text { AVAILABILITY }\end{array}$} & YEARS & 20 \\
\hline & 8 & 90.004 \\
\hline LOAD FACTOK & t & 80.00 \\
\hline POWER GENERATED & MW HOURS & 750,000 \\
\hline \multicolumn{3}{|l|}{ CAPITAL COST COMPONENTS } \\
\hline STANDARD ENGINE COST & s\$s & $\$ 2,350,000$ \\
\hline COST OF CRITICAL PARTS & 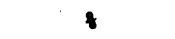 & 44.004 \\
\hline VALUE OF CRITICAL PARTS & \$\$\$ & $\$ 1,034,000$ \\
\hline \multirow{2}{*}{ ADJ FOR CRITICAL PARTS } & + & 100.008 \\
\hline & ss & s1 034.000 \\
\hline ADI COST-CRITICAL PARTS & & - \\
\hline PRODUCTION ENGINE COST & \$\$\$ & $\$ 2,350,000$ \\
\hline \multirow[t]{2}{*}{ INSTALLATION COSTS } & \$\$\$ & $\$ 1,150,000$ \\
\hline & & $--m-n-m$ \\
\hline \multirow[t]{2}{*}{ TOTAL CAPITAL OUTLAY } & \$\$\$ & $\$ 3,500,000$ \\
\hline & & 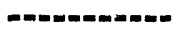 \\
\hline ANNUAL CAPITAL CHARGE & \$\$\$/YEAR & $\$ 513,672$ \\
\hline \multicolumn{3}{|l|}{ CAPITAL CHARGE/OUTPUT } \\
\hline PRINCIPAL COMPONENT & $\$ \$ \$ / M M ~ k W h$ & $\$ 0.0046$ \\
\hline \multirow{2}{*}{ COST OF CAPITAL } & \$\$\$/MM kWh & $\$ 0.0035$ \\
\hline & & 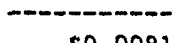 \\
\hline TOTAL CHARGE/OUTPUT & $\$ \$ \$ / M M \quad k W h$ & $\$ 0.0081$ \\
\hline
\end{tabular}


OIL-FIRED DIESEL ENGINE MAINTENANCE COSTS

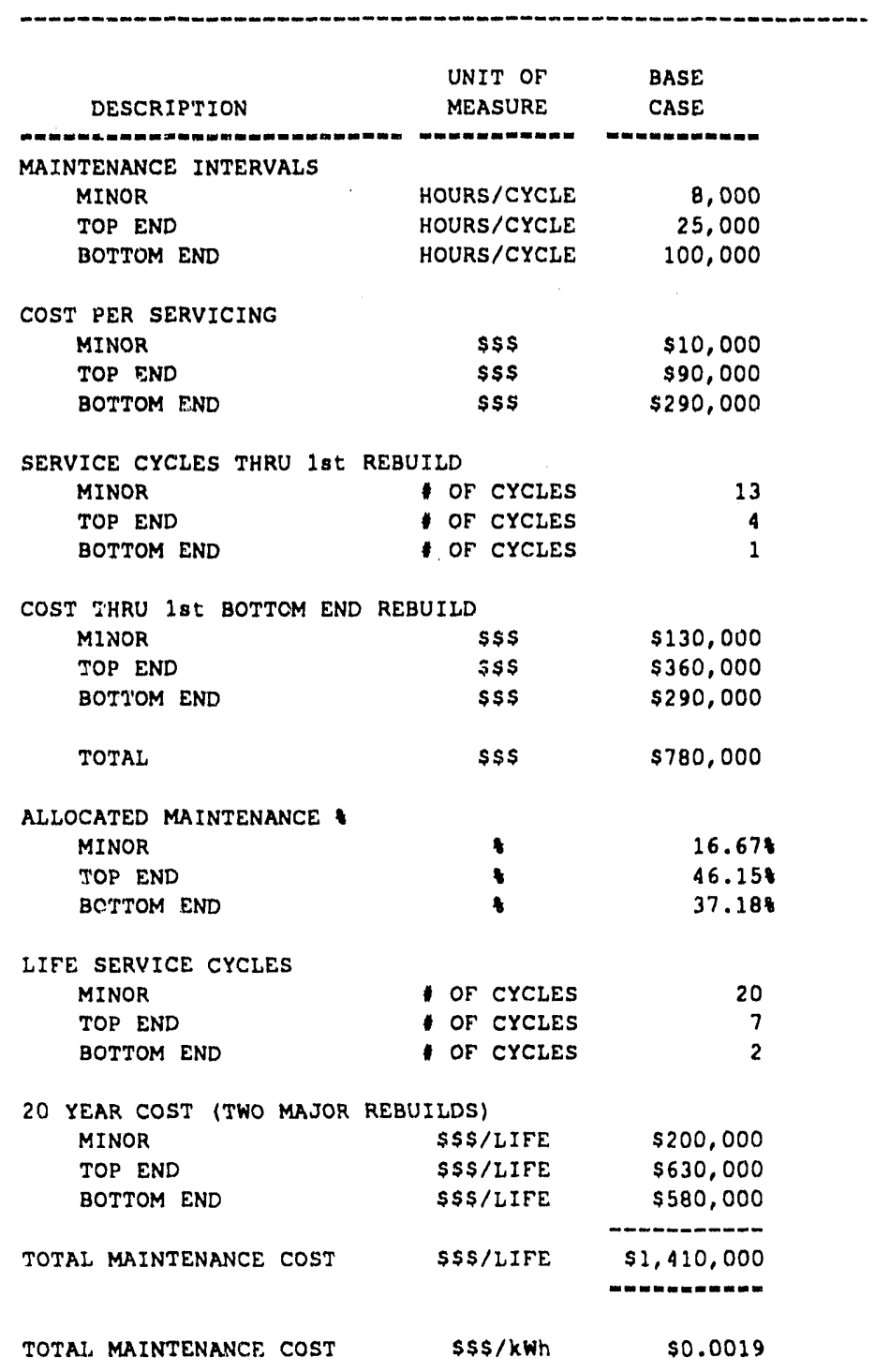


GAS/OIL-FIRED DIESEI ENGINE CAPITAI \& OPERATING COST

\begin{tabular}{|c|c|c|}
\hline DESCRIPTION & $\begin{array}{l}\text { UNIT OF } \\
\text { MERSURE }\end{array}$ & $\begin{array}{l}\text { BASE } \\
\text { CASE }\end{array}$ \\
\hline romen & - & - \\
\hline ENGINE PLANT CAPITAL & \$\$\$/kwh & \$0.0081 \\
\hline EMISSIONS CAPITAI & \$\$\$ / kwh & $\$ 0.0032$ \\
\hline ENGINE PLANT MAINTENANCE & s\$s/kwh & $\$ 0.0019$ \\
\hline FUEL & \$\$\$/kWh & $\$ 0.0481$ \\
\hline TOTAL COST & $\$ \$ \$ / k W h$ & so.0613 \\
\hline
\end{tabular}

EMISSIONS CONTROI SUBSYSTEM COSTS

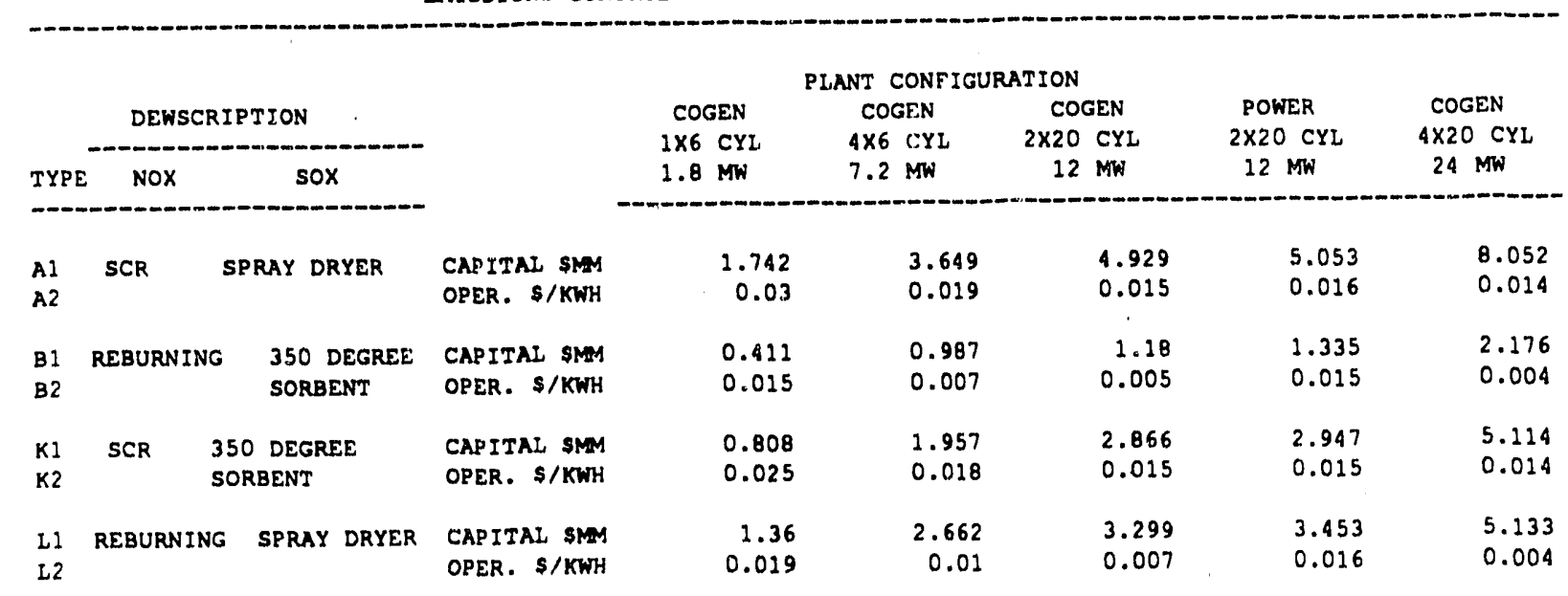



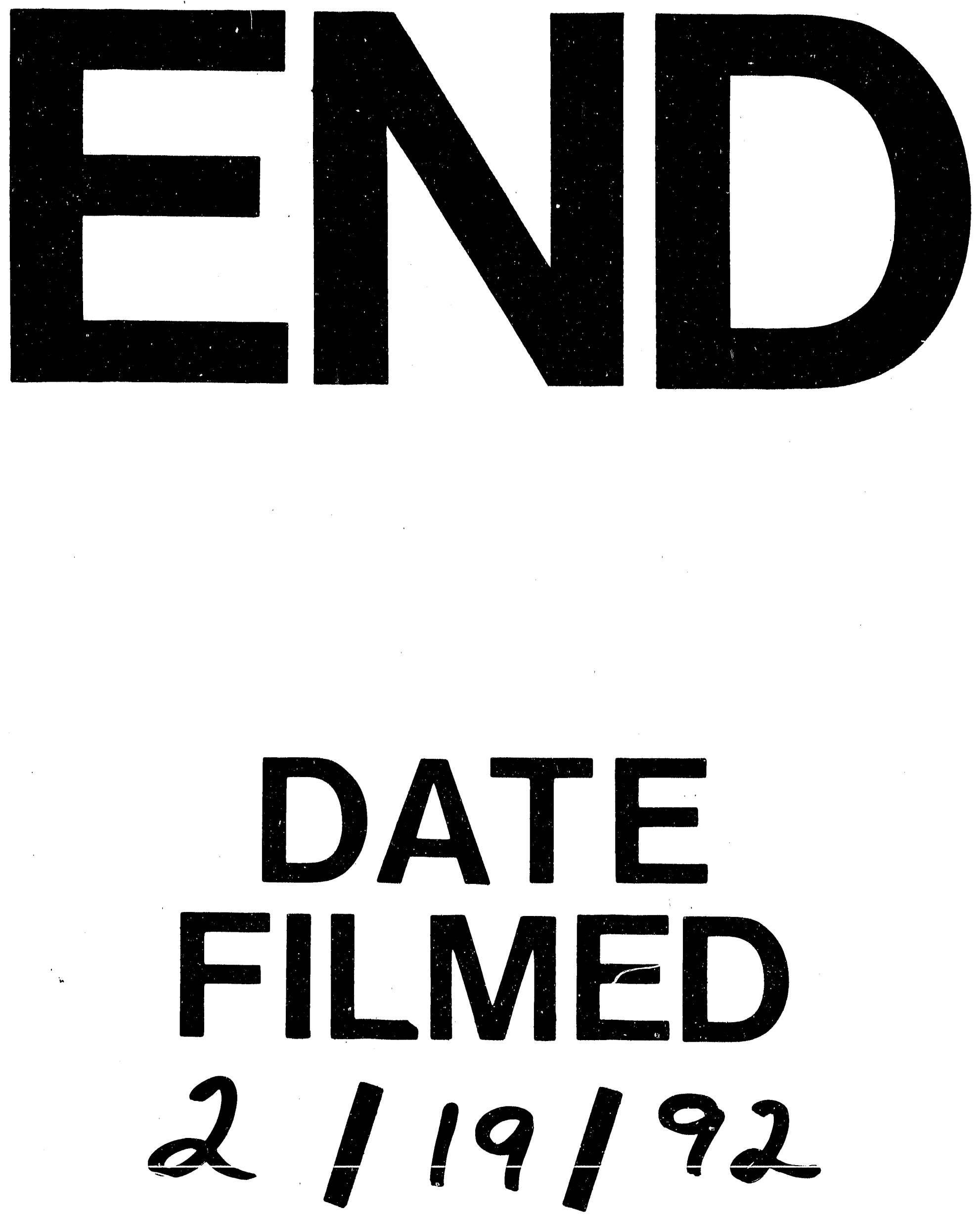
